\title{
THE COMPLETE FOXIUNTER
}

CHARLES RTCHARDSON 


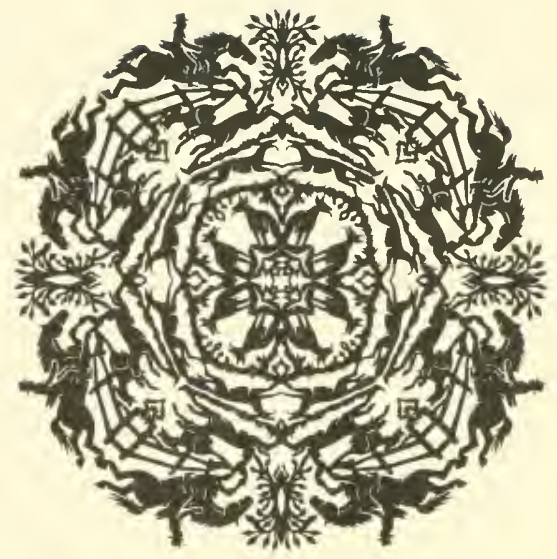

JOHN A.SEAVERNS 
TUFTS UNIVERSITY LIBRARIES

39090014533380

Webster Family Library of Veterinary Medicine Cummings School of Veterinary Medicine at Tufts University

200 Westboro Road

North Grafton, MA 01536 

THE COMPLETE FOXHUNTER 




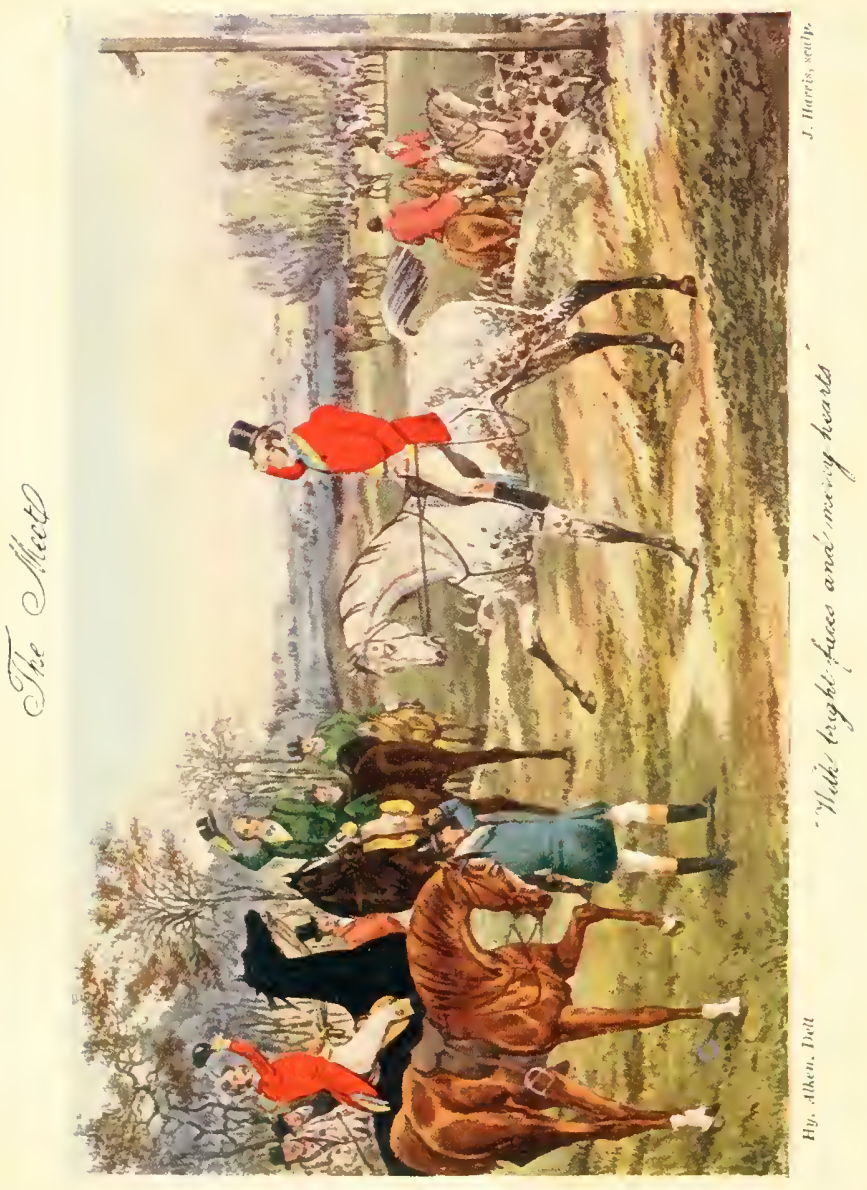




\section{THE COMPLETE FOXHUNTER}

BY

\section{CHARLES RICHARDSON}

HUNTING EDITOR OF "THE FIELD"

AUTHOR OF "THE ENGLish TURF," "PRACTICAL HintS

TO HUNTING NOVICES," ETC.

WITII FORTY-SIX ILLUSTRATIONS

OF WHICH FOUR ARE IN COLOUR

METHUEN \& CO.

36 ESSEX STREET W.C.

LONDON 
$2 \hat{C}^{2}$

$\mathrm{R}^{5}$

1902

First Published in 1908 
TO

THE DUKE OF BEAUFORT

WHO HAS UPHELD THE WORTHIEST TRADITIONS

OF THE CHASE

BY HUNTING A HUGE TRACT OF COUNTRY

ON SIX DAYS OF THE WEEK

FOR MANY SEASONS PAST

AND WHO HAS THROUGHOUT HIS LIFE

DEVOTED HIMSELF WHOLEHEARTEDLY TO THE SCIENCE OF FOXHUNTING

THIS VOLUME IS RESPECTFULLY DEDICATED 



\section{CONTENTS}

CHAPTER I

AN HISTORICAL SKETCH

CHAPTER II

THE DATES OF THE PRINCIPAL HUNTS • . . 12

CHAPTER III

MODERN CONDITIONS OF HUNTING. . . . . 25

CHAPTER IV

THE MASTER OF HOUNDS . . . . . . $\quad 5^{8}$

CHAPTER V

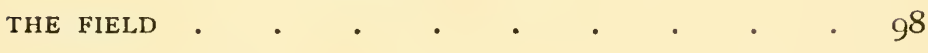

CHAPTER VI

HUNTING LOCALITIES .

CHAPTER VII

FOXHOUNDS . . . . . . . . . 201

CHAPTER VIII

THE VALUE OF FOXHOUNDS • . . . . . 220 
viii THE COMPLETE FOXHUNTER

\section{CHAPTER IX}

HORSES AND STABLES . . . . . . . 242

CHAPTER $\mathrm{X}$

HARRIERS AND BEAGLES . . . . . . 267 


\section{LIST OF ILLUSTRATIONS}

\section{IN COLOUR}

The MeET

"With bright faces and merry hearts." From The Analysis of the Hunting Ficld.

GetTing Away

"Let's take the lead." From The Analysis of the Hunting Field.

Foxhunting-Swishing at a RAsper.

From The National Sports of Great Britain.

Foxhunting. - Death.-Who Whoop !. . . . . . 288

From The National Sports of Great Britain.

\section{IN MONOTONE}

The Quorn Field on Gartree Hill • • . . . . 8

The Belvoir at Croxton Park . . • . • • . I2

The Quorn Kennels • • • • • • • • • • • 14

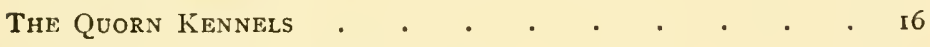

The Fitzwilliam (Milton) Kennels • . • • • • 20

FOR'ARD AWAY FROM TOYTOP (LORD ZETLAND'S) • • • • 22

Milton Hall (Mr. G. W. Fitzwilliam's) • • • • • 25

The Huntsman's House at Badminton . . . . . 30

Some "Pytchley" Noses . . . . . . . . . . 36

Lord Har rington's, Crossing the Smite • • • • . 44

Chas. Isaac, late Huntsman Mr. Fernie's Hounds • • 54

The Comte de Madie's Movable Hunting Box • • . 66

At the Pytchley Kennels . . . . . . . 72 .

The Terrier Man (The Belvoir) . . . . . . 80

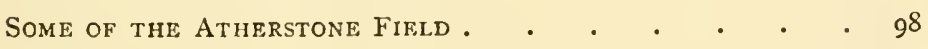

A Litter of Puppies, The Quorn . . . . . . . 110 
THE "QUORN" VIKING • . . . . . . . . . . 122

The Belvolr . . . . . . . . . . . . . . 152

Mr. Fernie and Chas. IsaAC . . . . . . 156

Mr. Fernie's Kennels . . . . . . . . . I6o

Gone to Ground (Mr. Fernie's) . • • • • • . I62

The "Warivicksinre" Wizard, Peterborough Champion igo6 i66

The Duke of Beaufort . . . . . . . . 169

With the Puckeridge . . . . . . . . . . I72

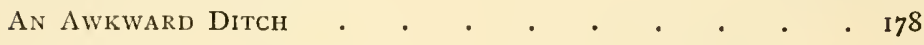

The Cattistock Country . . . . . . . . . $\quad$. 185

Repose (The Belvolk) . . . . . . . . . . . 188

Lord Zetland and his Secretary • • • . . . 192

The "Belvoir" HANdel . . . . . . . . 201

The "Atherstone" Cracker and Cornet . . . . 204

Head of the "Oakley" Syntax . . . . . . 208

The "Belvoir" Valesman . . . . . . . . 212

Mr. G. W. Fitzwilliam's Harper . • • • • . 216

The Duke of Beaufort's Druid and Rabsplan • • 222

The "Oakley" Democrat, Syntax, Bedford and Denton • 226

The "Atherstone" Careful and T. Whitemore . . . 230

The "Milton" Sanguine, and Huntsman . . . . 234

The "OAkley" Syntax. . . . . . . . . 238

Lord Annaly and Lord Spencer (The Pytchley) • • . 246

In the Home Counties . . . . . . . . 252

Lord Harrington's Hounds Crossing the Smite • • . 256

A Kill with the "Bicester" . . . . . . . 262

These illustrations are from photographs by Bowden Bros. 


\section{INTRODUCTION}

\section{WHICH CONTAINS THE PREFACE}

HAT hunting was never so popular as it is just now is a fact which admits of no dispute.

L Practically every inch of the country where riding is possible is hunted by one or more packs of hounds, and where the riding is bad, and there are no coverts for foxes-or too much population, as in Lancashire-there are harrier packs; while where there are neither foxhounds nor harriers, foot-beagles will surely be found. Otter-hound packs, too, travel all over the country during the summer months; and the crowds which are present at the August meets of the Devon and Somerset staghounds must be seen to be appreciated.

On all sides, indeed, evidence to the effect that hunting is the most important of all English field sports is afforded. The print shops, not only in London but in every town in the kingdom, have their windows full of hunting pictures; and many of the ordinary commercial advertisers of the day have brought similar scenes into requisition for the purpose of advertising their wares. At the Peterborough and Reigate hound shows no stranger could help being astonished at the crowd of men and women who come to worship at the 
shrine of the hound; and when any pack of hounds of great reputation is for sale, either privately or by auction, there is not only much excitement in the hunting world, but probably the sale is on so great a scale that it will be talked about for years to come. Just as this book goes to press a sale of thirty hounds for a sum of $£ 2000$ has been announced, and the price of over $£ 66$ per hound, though a high one, is not a record.

It is the case, moreover, that there is a steady increase in the number of hunting people, in spite of the fact that it costs more to hunt than it did a generation or two ago. But probably the increase is greater with regard to beagles and other hounds than in fields composed of men and women who ride. Not so long ago hunting on foot was little indulged in, except in the mountainous districts of Cumberland and Westmorland, and with a few packs of otter hounds. Now, however, there are whole communities of people who hunt on foot, scattered all over the country, and probably about a third of each field of foot hunters is composed of ladies. During the winter, too, very full reports are given each week of the doings of many of the principal packs of hounds, and there is every reason to believe that the supply of hunting news is by no means equal to the demand.

In the following pages some attempt is made to treat of foxhunting as it is carried on at the present day, and to show the great changes which have come into existence-not in the actual sport itself, but in the conditions which surround it. Every one who followed 
hounds about a generation ago must know that pursuit of the fox was a simpler affair than it is now-firstly, because the country was in a more natural state, and secondly, because very large "fields" were unusual except with certain Midland packs. Increase of population and the building which in recent years has been so much in evidence all over the country, to say nothing of many new railways, have all had an effect upon the sport, and now hunting is practically impossible in many suburban neighbourhoods where it flourished not so long ago.

It may be asked, "Who wants to hunt in the suburbs of any large town?", and of course there can be only one answer to such a question; but none the less it is a fact that many once good hunting countries have been curtailed owing to the extension of suburban districts. The result of this extension has been that all sorts of people have migrated from the inner to the extreme outer circles of London and of all large provincial towns, and have in their new abodes found themselves within reasonable touch of hunting. Many of these migrants, of course, are in no wise concerned when they happen to see hounds or hunting folk on the road; but others have been attracted, at first probably by the panoply of the chase, and afterwards by the sport itself.

It is not every one in these days who has had generations of hunting ancestors, and has therefore been practically born a foxhunter. Nor is it every one who is reared in an atmosphere of hunting; but there is, nevertheless, an extraordinary fascination about the sport which extends to all ranks of society, from the 
highest to the lowest, and is frequently to be found in the most unlikely persons. It is also the case that whereas foxhunters of fifty years ago were chiefly squires, farmers, parsons, and small country residents, with a sprinkling of townsmen, the fields of the present day are for the most part composed of business men and their families, or if not of the actual business men themselves, of men and women whose hunting has been assured by the success of commercial enterprise.

The squires have sold out and departed-at least, many of them have; parsons have almost ceased to hunt, which is a matter of extreme regret; and the hunting townsmen are no longer townsmen, but have migrated to the country, and hunt more than they did. The farmer still follows hounds in many countries, but he is not seen in such numbers as he once was-not because he is disinclined for the sport, but because present-day life hardly allows of the leisure which was possible a generation ago amongst some classes of society. Doubtless in nearly every hunting field there is a nucleus composed of the descendants of the original hunting men of the district, but in many cases this nucleus is remarkably small. On the other hand, there has been a great increase in the size of fields everywhere, and this increase it is which has been mostly drawn from the ranks of business people.

As regards the science of hunting we shall be almost silent, being of opinion that the question is best treated of by men who have not only held long periods of office as masters of hounds, but who have carried the horn 
themselves. The fact is that the observant huntsman has chances of noting the niceties and subtleties of hound work in a way which is impossible to the ordinary hunting man. The huntsman has pride of place, and can be always with his hounds; whereas the ordinary hunting man-if he conducts himself properly-is not always in a position to observe everything which takes place. Then, again, the huntsman is amongst his hounds in covert, and can actually (at times) see them find a fox; whereas ordinary followers, except when there are big woodlands, seldom go into covert, and when they follow hounds through a big woodland they are necessarily some distance behind.

As it happens, we have had opportunities for seeing hounds do every part of their work; but there are men and women who have hunted for years, and never actually seen a fox found by hounds. They have, of course, seen scores of foxes break covert, and have seen many depart from little places before hounds had a chance of finding them; but the actual discovery of a fox in his kennel by a hound which has winded him is a thing which is seldom witnessed by any one but a huntsman or whipper-in.

Then, again, there are standard works on the subject which were written by masters of hounds, and which hold their own to the present day. Of the older ones, Beckford's Thoughts on Hunting, published in I 78I, was the first real authority on foxhunting. The less-known but extremely valuable Observations on Fox Hunting, etc., by Colonel Cook, was published in I826; but whereas "Beckford" is a household word 
amongst hunting men, Colonel Cook is only appreciated by a few enthusiasts. Extracts from the Diary of a Huntsman, by Thos. Smith (1838), at one time master of the Craven - and actually master of the Pytchley when his book was published-has also much useful information on hounds and their work; and this was followed, only a year later, by The Noble Science, by F. P. Delmé Radcliffe, who for several seasons was master of the Hertfordshire. Then, after a lapse of eight years, came Notitia Venatica, by R. T. Vyner, the founder of the North Warwickshire country, and this work almost at once became a classic. It deals largely with hounds, and contained what is now the first volume of the Fox Hound Kennel Stud Book. Within the last few years new editions of all the above-with the exception of Colonel Cook's workhave been published, and a careful perusal of the lot should attune the mind of any aspiring foxhunter to a sense of the great importance of the sport. In more recent times two famous masters wrote on the science of hunting, viz. the late Colonel Anstruther Thomson and the late Lord Willoughby de Broke. The firstnamed began with a tiny pamphlet, which contained a lot of useful hints, but towards the close of his life he wrote his own biography, and therein is contained much useful information on hunting. Lord Willoughby de Broke's Advice on Fox Hunting is almost entirely concerned with the science of the sport, and contains the best and most condensed practical advice that has ever been given to huntsmen and whippers-in. The papers were first published in the Badminton Magazine, but three of them were recently issued in book-form by 
Messrs. Bumpus, of Oxford Street, and no master or hunt servant should be without them.

Having explained how hunting has been treated of from the point of view of the hound and its work, we may add that there are literally hundreds of books which deal with the sport in one fashion or another, but the above are the classics from the scientific point of view. As regards foxhunting fiction Surtees stands alone, although it is more than forty years since his last book was published. It need hardly be stated here that Surtees at times caricatured the sport, but he also wrote descriptive matter in connection with it which has never been excelled, and a careful reader can learn more about hunting from Surtees' novels than he can from the works of any other writer of novels. Whyte Melville wrote graphic descriptions of runs in the Shires, but these were fiction. The modern writer par excellence of accounts of real hunting is Captain Pennell Elmhirst, known all over the world as "Brooksby," and whose letters have held a foremost place in the pages of the Field for more than a generation.

But matters have become greatly changed since Surtees wrote, and there are people of either sex who are constantly inquiring as to what line of conduct they should pursue with a view to becoming foxhunters. "I wish very much to go out with hounds. Can you tell me how and where I can learn to hunt?" was the beginning of one letter which came into our hands. Another inquirer (quite recently) asked us for the following particulars: "Will you enumerate all the subscription packs in the kingdom, stating amount of 
each subscription? Will you also give locality of each pack, and say where horses can be hired, and at what price? And will you give some particulars as to the society in some of the hunting places, stating especially at which places golf can be obtained as well?" But perhaps the most extraordinary amount of ignorance is contained in the following letter :-

"I have lately bought half a dozen horses at the sale of a bankrupt mineral-water maker, and friends tell me there is a good opening if I take a hunting stable. Will you please give me information as to where would be the best place to go to, but it must be where I could rent a stable cheap. I think the horses look like hunting. Two of them are handsome, or will be when the collar marks have worn off. Those I would call special hunters, and charge more for. The others I would let to ladies or old gentlemen. Please say what I should be paid per day per horse, and mind you tell me of a place where $I$ would be able to let my horses most days. I thought 25s. for the special horses and $£ \mathrm{I}$ for the others would do, for then each horse might earn $£ 5$ or $£ 6$ a week if trade was good. I shall be much obliged if you will answer my questions, and also tell me anything which may occur to you that would help me."

Such a letter, of course, looked like a practical joke, but, as it happened, opportunity of testing the genuineness of the document was forthcoming, and it was ascertained beyond doubt that the man had written in perfectly good faith, having, on the advice of a friend -whose hunting knowledge was about equal to his own-bought the horses for a trifling sum, having 
been to some extent caught by the auctioneer's flowery descriptions of the nags, which, according to the man who disposed of them, could do 'unting, 'acking, or 'arness, and carry a cavalry hofficer as well.

But the most frequent inquiries are made with regard to hunting localities and subscriptions, to say nothing of such minor matters as dress and equipment; and the number of people who appear to be in doubt as to who should and who should not go out in scarlet is very great too; and many of the would-be foxhunters are almost as vague as the man who bought the mineral-water nags with regard to the number of days on which horses may hunt. In point of fact, there is always a section of the community which is anxious to begin hunting, but which hardly knows how to set about it. It is, to a great extent, for these people that the following pages have been written, for an attempt has been made at pointing out under what conditions hunting is carried on at the present day, and how and where the beginner can try his luck in the field. Something has also been said about his clothes, his saddlery, his horses and stables, and a certain amount of advice has been proffered to the novice; but the author has no wish to pose as an infallible authority, and he would merely remark that what he has written is the outcome of personal observation exercised over a great number of years in a great number of countries. 




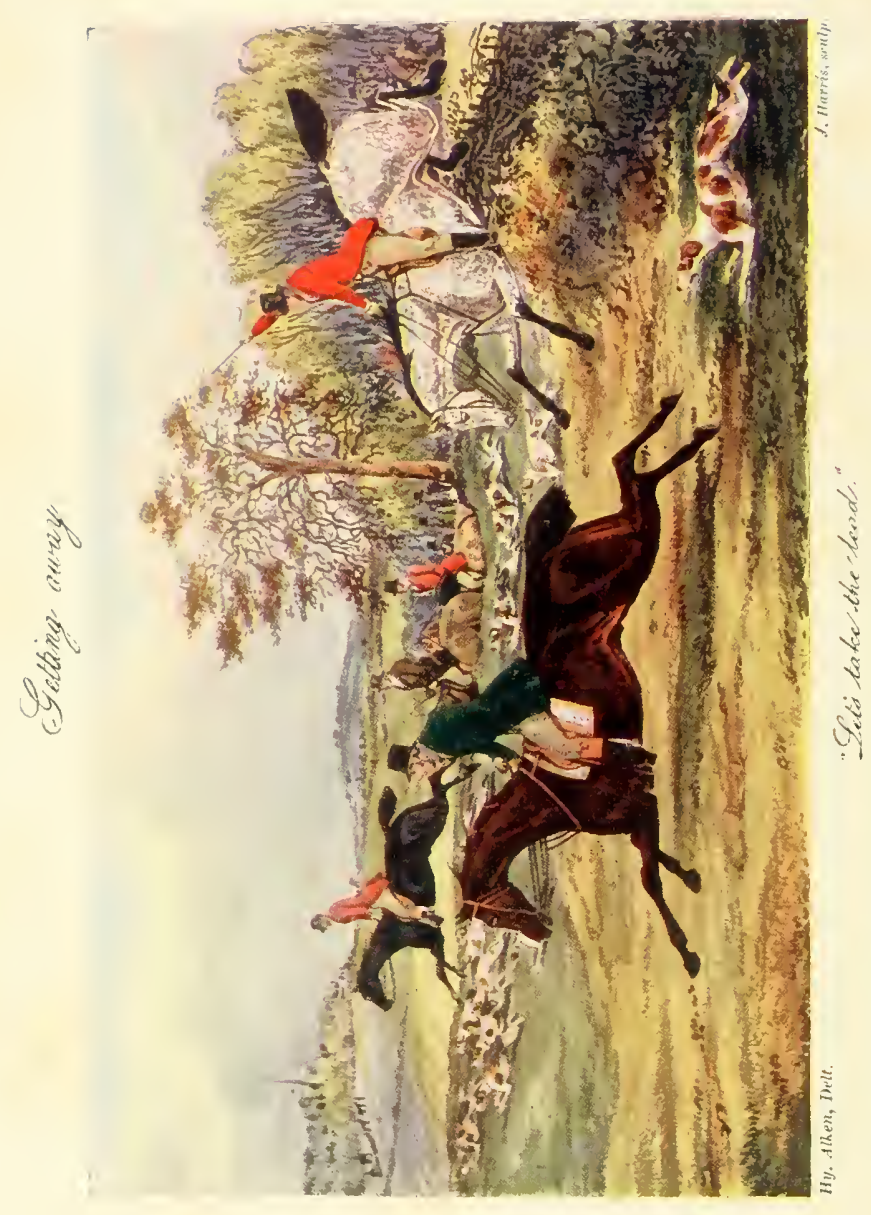




\section{THE COMPLETE FOXHUNTER}

\section{CHAPTER I \\ AN HISTORICAL SKETCH}

I

$T$ is an interesting, but none the less curious, fact that no accurate date can be fixed in connection which is forthcoming on the point being scanty, at times contradictory, and very often speculative. Facts indeed are wanting, and thus at the moment it is claimed for nearly half a dozen packs of hounds that they are the oldest in the kingdom, and hitherto no seeker after information has been able to prove a clear case for any one of them. What is quite certain is that previous to the commencement of the eighteenth century the stag, the buck, and the hare were the most important beasts of the chase, and that the fox was generally regarded as vermin, and most certainly had hardly begun to acquire the initial stages of the great reputation he was to enjoy a generation or two later.

Hunting had, however, been the chief sport of the English people from the earliest times, and so far back as during the period between $\mathrm{I}_{307}$ and 1327 one Guillaume Twici had written a manuscript on the subject, which is generally supposed to be the oldest English writing on hunting. To Xenophon, Arrian, and others who wrote on hunting thousands of years 
ago there is no need to refer, because no mention was made of the fox, and for the matter of that Twici's work, and all those which followed during the next three or four hundred years, treated of stag and hare, of hawking and fishing, and of other diversions, but were unanimously silent as regards what was so shortly to become the foremost beast of venery.

And as a matter of extreme probability, if not of actual fact, the reasons for the tardy appearance of the fox in hunting history are very simple ones. During what are known as the Middle Ages, and down to a much later period, the country was only half cultivated, and was in many districts covered with forests, several of which extended over thousands of acres. These were preserved for the chase of the stag or buck, and in like manner the open country was utilised for hawking, coursing, and, to a very limited extent, for hunting the hare by scent. Foxes were then classed with martens, wild cats, badgers, polecats, and others, and were not regarded with any great affection by the sportsmen of the day. But during the later Stuart period there was an extraordinary and very rapid improvement in the breed of horses. Arabs, barbs, and other Eastern sires were imported in great numbers, and in a few short years their influence had been so marked that the native breed showed marvellous improvement, and doubtless the sportsmen of the period found that they could be carried at a higher rate of speed than they had been accustomed to. Coeval with this improvement in horseflesh came the gradual disappearance of the stag and buck, owing to the extended cultivation of the land, and the clearing away of hundreds of thousands of acres of forest. Men who were keen on hunting found the country more open, 
and more rideable than their fathers and grandfathers had done, and about the same time they would doubtless discover that hounds ran faster in the open than they did in the huge woodlands, where the buck was the invariable quarry.

As a matter of fact, at the beginning of the seventeenth century the physical conditions of the land were changing very rapidly, and the time had arrived for quicker progression in a more open country, both for horses and hounds. Exactly when riding across country came into fashion is, however, just as much a matter of conjecture as the actual date of the first pack of foxhounds, but no doubt the lighter horses began to be scattered about the country during the period referred to, and then it was gradually discovered that in open country the fox was a nobler beast of chase than either the hare or the buck; but who actually made this discovery has never been satisfactorily proved, and though the library of the British Museum has been overhauled by many who have been anxious to solve the question, so far nothing decisive has been discovered. What is known is that packs of hounds have been in existence since the reign of Edward III, and probably during an earlier period. Indeed, in Baily's Hunting Directory it is claimed that the Penistone Harriers "were established in 1260 , in which year Sir Elias de Midhope was master. The Wilsons of Broomhead Hall furnished the pack with masters in the fourteenth, seventeenth, and eighteenth centuries... but the roll is incomplete until the last century." It was not until a hundred years later $(1362)$ that there is absolutely definite information about the now defunct Royal Buckhounds, but in the reign of Edward III there were a minimum number of fifteen couples in the 
pack, and various taxes were imposed in connection with the hunt in the counties of Surrey, Sussex, and Northamptonshire. The packs named were not foxhounds, however, and it is probably the case that during the eighteenth century many of the harriers, and even some of the staghound packs then in existence, changed from hare or stag to fox, the former because the fox had been found to be a more enduring animal, and the latter because the stags or bucks had disappeared.

"The Druid," in Silk and Scarlet, states that prior to I $75^{\circ}$ it was sound orthodoxy to hunt what first came to hand, and that it was not until some twenty years later that the line of demarcation between hare and fox began to grow sharp and clear. No doubt the two quarries were hunted indiscriminately by a majority of the packs which were in existence in the eighteenth century; some hunted hare in the autumn and fox in the spring; others had special days for either sport, and others again just hunted what came to hand, running a hare in the morning and a fox in the afternoon, or vice versa. Between 1750 and $\mathrm{I} 800$ all the more important establishments then existing gradually changed from stag, buck or hare to fox, but it was not until the latter of the two dates that foxhunting had taken the first place, and during the first twenty years of the eighteenth century the change was still in course of progress, though by this time it was the ultraprovincial packs which were following the example of the more important hunts.

And as regards the claims of seniority which have been made on behalf of certain packs of hounds. These may be briefly mentioned, but as a matter of fact the point is really of little consequence, for the broad 
fact remains that in every case there is no conclusive evidence as to the quarry which was at first pursued. About the antiquity of several packs there is, however, no dispute, and perhaps the oldest of all are the lately defunct Goodwood (formerly the Charlton), the Quorn, the Sinnington, the Bilsdale, and the predecessors of the South Dorset, Lord Portman's, Blackmore Vale and Cattistock, originally known as the Cranborne Chase Hunt. In the matter of continuity perhaps no very direct line has been handed down, and it is quite certain that in every case the limits of the original country have been greatly curtailed, but the evidence, such as it is, may be given, and dealing with the Charlton Hunt first, it may be gathered from the fifteenth volume of the Sussex Archaological Collections that a Kentish gentleman, named Roper, managed a pack of hounds for the Duke of Monmouth and Earl Grey in 1689, the year in which William III ascended the throne. This Charlton pack, it has always been understood, was kept to hunt fox alone, but records as to its earliest hunting are vague as to details, and the evidence seems to be more traditional than anything else. In Vyner's Notitia Venatica it is broadly stated that foxhunting first became an amusement in England at the end of the seventeenth century. As the earlier writers on hunting were apparently unable to solve the questions of dates and priority, it is hardly likely that such matters will ever be decided. The Charlton was, however, a prosperous hunt during the eighteenth century, and its legitimate successor was the Goodwood Hunt which came to an end about a dozen years ago. The present Duke of Richmond, then Lord March, was the last master of the Goodwood, and he gave up owing to want of support in the field. He had, as a matter of fact, main- 
tained a country of large area for a considerable number of years, hunting often four days a week, and had a first-rate pack of hounds, but when the fields dwindled to a mere nothing it was felt that there was little use in carrying on the hunt, and now much of the original Goodwood, or Charlton, country is hunted by Lord Leconfield, a little by the Hambledon, and some of the country near Arundel by the Crawley and Horsham pack. It may be mentioned, too, that the hunt which is known as Lord Leconfield's had hunted the Goodwood country for a period, during the early part of the nineteenth century, when Colonel George Wyndham, afterwards the first Lord Leconfield, was master.

From the above it will be seen that the continuity of the original Charlton Hunt has not been strictly preserved, and if it has a legitimate successor in these days to Lord Leconfield's Hunt the position must certainly be awarded. But it is no easy matter to say with exactitude when and how certain hunts began their existence, and thus, according to Baily's Hunting Directory, Lord Leconfield's country was first hunted by Lord Egremont about the year I773, and the same authority states that when Lord Egremont resigned he gave the pack to the then Duke of Richmond. But it is further recorded that at a later date Colonel Wyndham moved the kennels to Drove House, near Goodwood, from whence he hunted the Goodwood country, while at the same time his brother, Sir Henry Wyndham, hunted Lord Leconfield's present country under the name of the West Sussex, having kennels at Sladeland, and also at Findon. (The Findon kennels are still in existence, and are used at certain periods of the year by the Crawley and Horsham pack.) The result of every investigation goes to prove that the 
Charlton Hunt dates from before the accession of William III, that its operations were carried on in West Sussex, and probably in parts of Hants, and that after its collapse there were hounds at Goodwood and at Petworth-very often at both places-and that the Goodwood Hunt having come to an end, Lord Leconfield's hunt is the natural successor to that part of the country which must have been the centre of the hunt in its earliest days. Charlton, it may be stated, is a little village, lying in a hollow of the hills, not two miles from Goodwood racecourse, and close to the road which leads from Midhurst to Chichester.

The claims of the Quorn Hunt to be the oldest foxhound pack in the kingdom rest on the evidence of the famous Mr. Boothby's hunting-horn, of which an engraving was published in the Field some five-andtwenty years ago. This horn bears the following inscription :-

“'Thos. Boothby, Esq., Tooley Park, Leicester. With this horn he hunted the first pack of foxhounds then in England 55 years. Born 1677 , died 1752."

The year 1698 is given by some authorities as the commencement of Mr. Boothby's mastership, so that as far as the actual date is concerned the Charlton, which as we have shown existed in I689 and probably before that date, takes precedence, but whereas no reliable evidence is forthcoming that the Charlton hunted fox and fox alone before the close of the seventeenth century, the evidence of the horn strongly favours the supposition that Mr. Boothby's hounds were always a foxhound pack. This Mr. Boothby hunted a large portion of Leicestershire, and was, in fact, the first squire who is known to have hunted regularly in that locality, but the Quorn Hunt does not exactly claim him 
as its actual first master, and doubtless his pack was quite a private one. At the same time, seeing that much of his hunting took place in what has since been known as the Quorn country, and that Mr. Hugo Meynell established his hounds in the year following $\mathrm{Mr}$. Boothby's death, the claim of the country, if not of the individual Quorn Hunt, must be recognised, and if it is allowed on the evidence of the horn that Mr. Boothby confined his operations solely to foxhunting the claim is perhaps the strongest of the lot.

The Sinnington and the Bilsdale claim to go back to " 1680 or thereabouts," when the Duke of Buckingham established a pack, and it is pretty certain that hounds have been maintained in the neighbourhood ever since. But that they began as buckhounds, or harriers, is more than likely, and the present writer has been unable to fix any date when fox became the permanent quarry. It is, however, the case that the Sinnington country was at one time much larger than it now is, and notably it included what is now known as Sir William Cooke's country, while it has also been asserted that the Bilsdale country was originally part of it. And here it may be mentioned that there are several packs in Northeast Yorkshire, each claiming to be older than the other. Thus the Bilsdale makes a claim to be the legitimate successor of the Duke of Buckingham's Hunt; "the Goathland Hunt goes back to a remote period; it is mentioned in the records dating back to about I650, which are preserved at Pickering"; and lastly the Stainton Dale is popularly supposed to have been created by royal charter in the days of King Stephen. As to the Bilsdale and Sinnington it is almost certain that both countries were within the district where the Duke of Buckingham hunted, but 


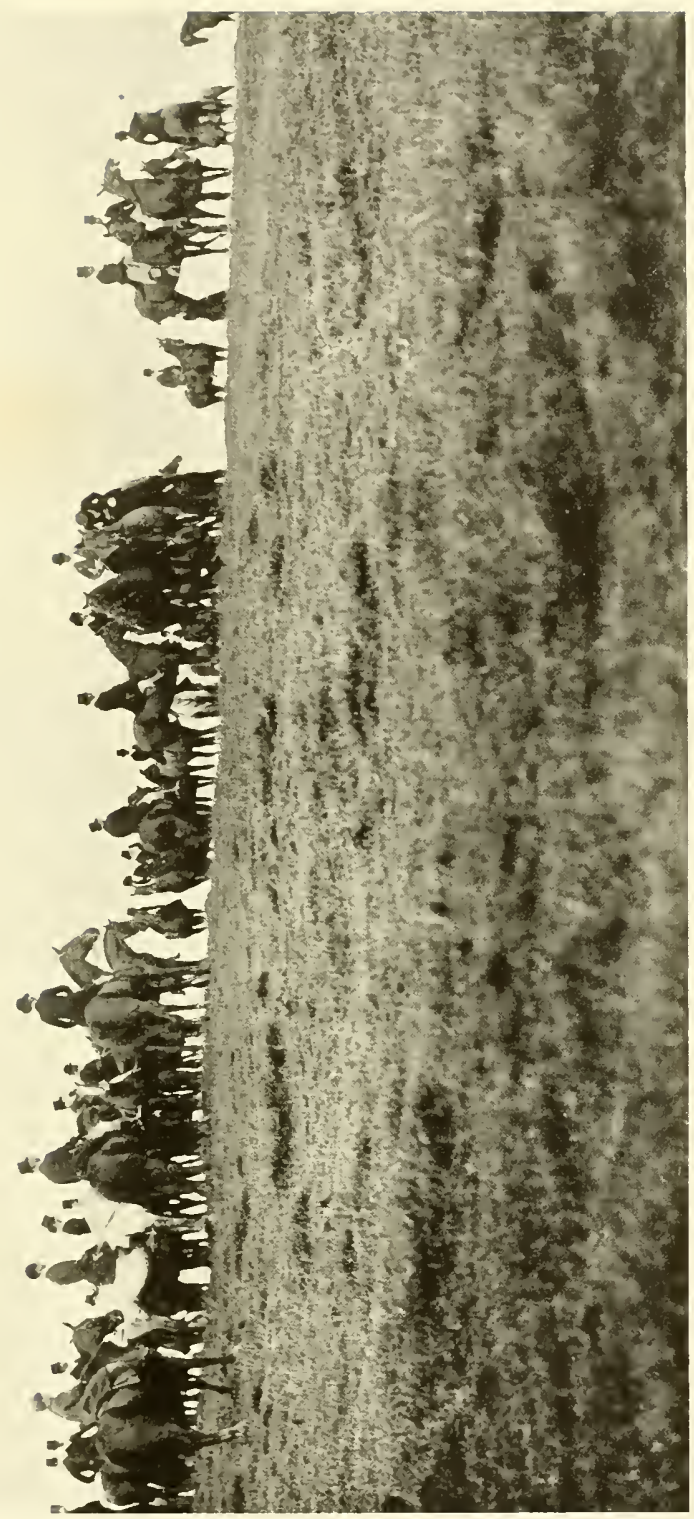

ב 

the forest of Pickering was generally supposed to be the Duke's favourite ground, and it is probable that his hunting operations were carried on in the countries where the Sinnington and Sir William Cooke's hounds are now located, and that he also hunted Bilsdale regularly. There is in Bilsdale a spot known as Buckingham Stone, where a horse of the Duke's is supposed to have died after a great run, and there is a local tradition to the effect that stag and fox were in those days hunted alternately, but Pickering Forest was disafforested in the reign of Charles I on account of the scarcity of deer, and as a matter of fact there is no definite evidence as to what quarry was most hunted in North-east Yorkshire until a hundred years later.

The Goathland claim to antiquity is also exceedingly vague, but it is pretty certain that hunting was carried on in what is now the Goathland country more than two hundred years ago, but that there was any properly constituted hunt is open to great doubt, and most certainly there is no authority as to the fox having been the animal hunted. Nor can the Goathland show a list of masters prior to Mr. Peirson, who held office in the early part of the last century; and the case with regard to the Stainton Dale is very similar, no records of the hunt having been kept.

Yet it is a firmly established tradition in this hunt that a royal charter was granted to it some time in the Middle Ages, and the present writer remembers being told (when a boy) that the charter granted them the exclusive right to hunt the coast from Whitby to Filey. In after years the Record Office yielded no evidence on the subject, and Mr. W. Scarth Dixon has suggested in the Foxhounds of Great Britain and Ireland that the charter was probably a permission to 
hunt from some one in authority, something like a right of free warren. This is a very probable solution of the matter, but there is something more to be said concerning the Stainton Dale, and that is that in all probability they have hunted nothing but foxes-at all events since the days of Charles I, when the adjoining royal Pickering Forest was disafforested. The operations of this hunt are now confined to a narrow strip of country, which is never more than five miles wide, and often less, and a great part of the hunting has always taken place on the cliffs, some of which (Hayburn Wyke, to wit) are densely wooded. These cliffs have always swarmed with foxes, and according to local tradition there have been no stags on the cliffs for more than two hundred years. It is probable then, though the evidence is only presumptive, that foxes were hunted in this locality at a very remote period, and though it has kept no records it is quite possible that the Stainton Dale is one of the very oldest, if not actually the oldest hunt in the kingdom, while it also may be said to have claims to have hunted foxes long before the fox was the general quarry.

The claims of the Cranborne Chase Hunt-of which the Blackmore Vale is the present-day representativeare somewhat vague. Miss Serrell, in With Hound and Terrier in the Field, boldly states that "the Cranborne Chase Hunt had the distinction of being the first country in which hounds were kept to hunt fox to the exclusion of other quarry." She then goes on to say that Mr. Thomas Fownes, who purchased certain rights in the chase in the middle of the seventeenth century, hunted his hounds from Stapleton, and built up a pack which was said to be the best in England. In the Encyclopadia of Sport it is stated that one of the earliest 
packs of foxhounds was established by Mr. Thomas Fownes, of Stapleton, about the year 1730. It will thus be seen that there is a big margin between the two dates, and it may be pointed out that mere assertion is not actual proof. 


\section{CHAPTER II \\ THE DATES OF THE PRINCIPAL HUNTS}

$\mathrm{S}$ has been explained, it can be of little real
consequence which of several hunts is the
oldest, because even if the matter was finally decided no special object would be gained. The real originators of foxhunting were the old family packs which became established during the latter part of the eighteenth century. Such packs, gradually turning their attention from the pursuit of hare or buck to fox alone, made the last-mentioned style of sport so generally popular that "countries" began to be formed where there was no family pack in possession, and thus at the end of the eighteenth and the beginning of the nineteenth centuries a whole host of hunts came into existence which are at the present day most flourishing affairs.

Of the great family packs the Belvoir, the Brocklesby, and the Badminton (the Duke of Beaufort's) claim precedence. Of these the Brocklesby has the longest history, for it claims to date from 1700 or a little earlier, while the Hound Lists go back to I746. It is also understood that the country, as at present constituted, has existed since I7 I4, when Messrs. Vyner, Tyrwhitt, and Pelham hunted it conjointly. After a while the two first-named masters retired, and since that time the hounds and country have been entirely in the hands 


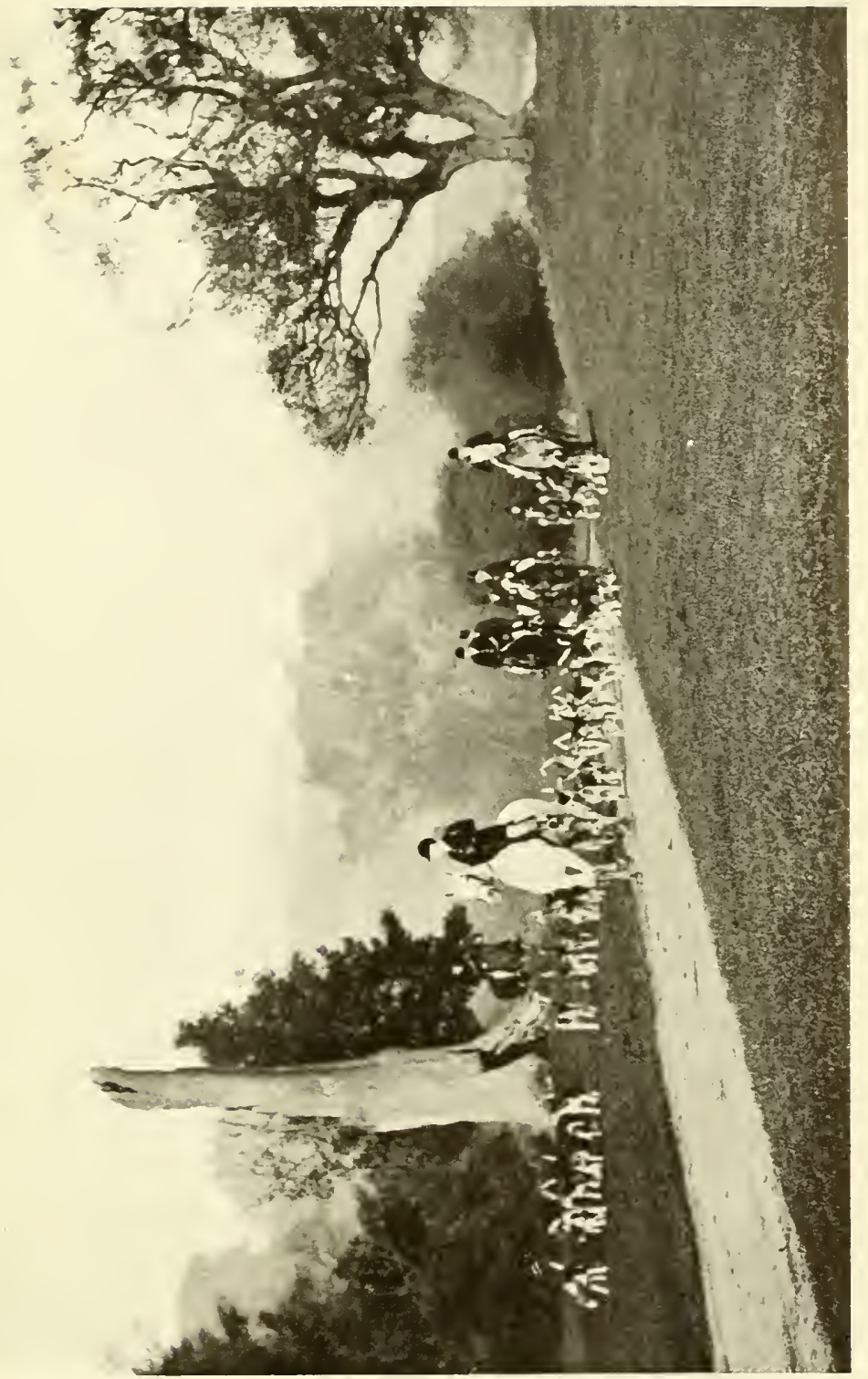



of the Pelham (Lord Yarborough's) family. The Brocklesby Hound Lists probably take the pedigree foxhound further back than any other lists which are in existence, and it. is hardly necessary to mention that the blood always has been, and still is, of extraordinary value.

The Belvoir Hunt dates from I750, and is supposed to have become a foxhound pack (exclusively) in 1762 . The hounds have always been owned by the reigning Duke of Rutland, and the mastership has been held in the family, except for two periods, viz. between 1830 and 1857 , when Lord Forester held office, and since I S96, when Sir Gilbert Greenall (the present master) took command, hounds and kennels being lent to him by the Duke of Rutland. That Belvoir blood has been for the last fifty years, and still is, the best in the world is a fact which hardly admits of dispute, but it came originally, in a great degree, from the Brocklesby, which in earlier days was almost the adjoining hunt, the Burton-of which the present Blankney is a partbeing the only intervener.

At what remote date hounds were first kept at Badminton there is no record to show, nor is it known when the pack changed from stag to fox. But the fifth Duke of Beaufort had foxhounds in the year 1786 , and since that date the pack has been regularly maintained by four Dukes of Beaufort in succession. In many ways the Badminton establishment is unique, more especially in the amount of sport which is afforded. For many seasons past hounds have hunted on every possible day, and at times two packs are out on the same day in different parts of the country, while on occasions an early morning hunt with one pack has been followed by another hunt with another pack later in the day. The 
country hunted is a huge one, almost the biggest in England, though the Warwickshire claims a larger acreage. The variation of country is very great; there is grass in fair quantities, light plough, heavy plough, vale land of mixed arable and grass, and much hilly country. Indeed, it is probable that the Badminton and the Belvoir stand alone in the matter of variety, for in the last-named hunt it is all grass on the Leicestershire side of the country, while in Lincolnshire almost every description of country is to be found. In the Badminton country the hills are much steeper than those of the Belvoir and the woodlands are bigger, but the great charm of the whole district is the wonderful fox supply, which never gives out. How this is managed one must be in the country to understand, but a most important factor in the great result is the extraordinary personality of the present Duke, who has made foxhunting the chief business of his life, and whose influence is so widespread that his example extends to the furthest confines of his hunt.

It has been shown that the three greatest family packs became foxhounds about the middle or towards the end of the eighteenth century, and now one may very briefly glance at some of the big subscription countries, merely with a view to showing how long they have been in existence. The Quorn has been mentioned; Mr. Fernie's Hunt is an offshoot of the Quorn, hunting part of the original Quorn country, and only dates from 1856 . The Cottesmore, on the other hand, is one of the very old countries, which was originally hunted by a family pack, but has been for long enough a subscription pack. The country was, in fact, first hunted by the Noel family, and the first record of the pack occurs in Thomas Noel's Book of Hounds, dated I732. Until i788 the Noel 


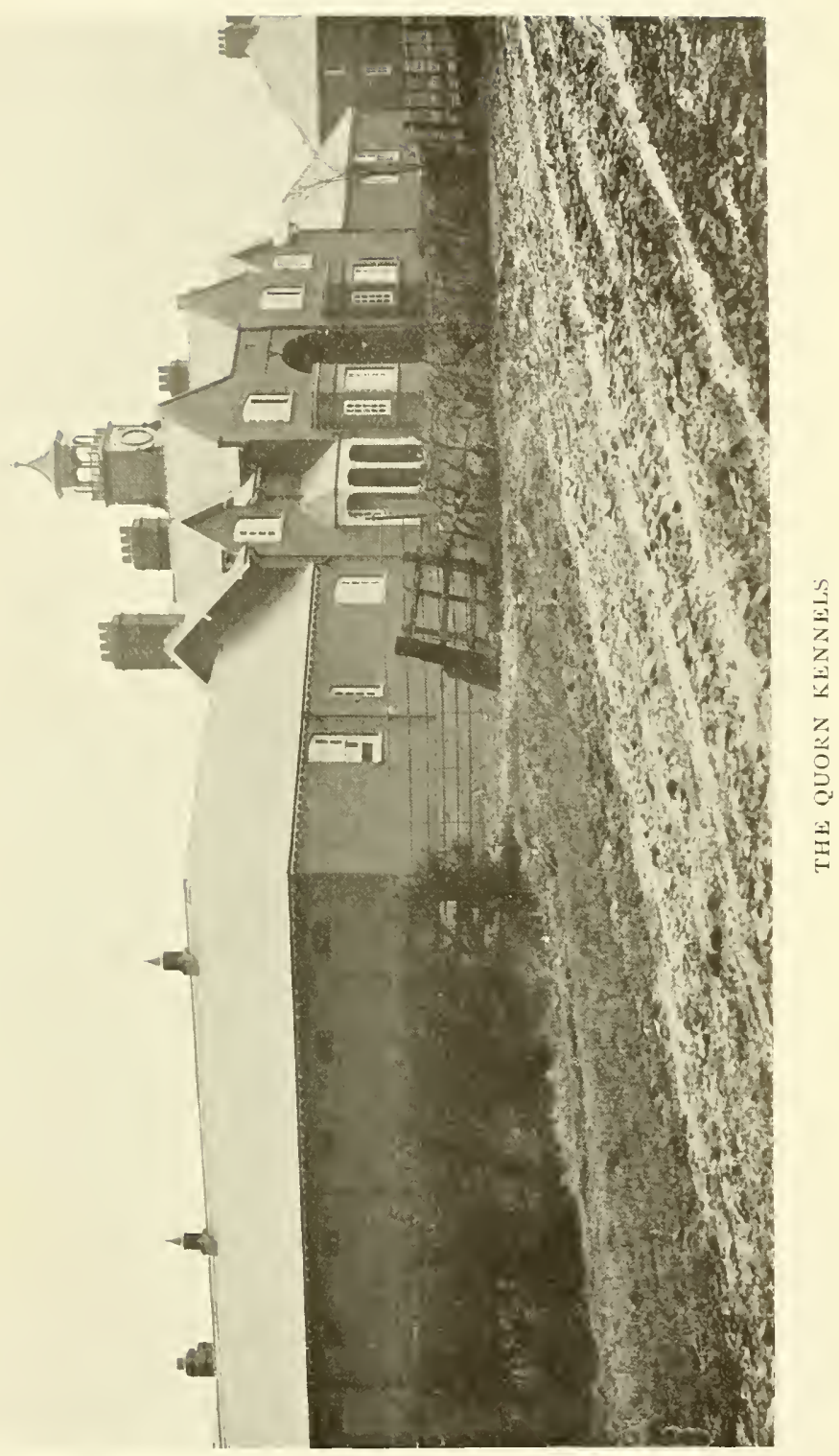



family maintained the hounds, but in that year they were sold to Sir William Lowther (afterwards Lord Lonsdale), and since that date there have been many masters, including several members of the Lowther family. The present Lord Lonsdale took office in 1907, having previously been master of the Quorn, the Woodland Pytchley, and the Blankney, and he signalised his accession to office by the purchase of the bitch pack of the South Cheshire, which came into the market owing to that country being reunited under one master. Lord Lonsdale bought these hounds at Rugby, and gave some £izoo odd for a short but beautiful pack.

The Pytchley is another of the old hunts, dating from I750 (or thereabouts), when Lord Spencer formed a club at the Old Hall in the little village of Pytchley (near the Midland main line on the eastern side of the country), but it was never exactly a family pack, in spite of the fact that the Spencer family have afforded no fewer than four masters. In 1782 the club had a membership of twenty-eight, exactly half of whom were titled, and the hunt has a list of masters which takes a lot of beating, though as a rule Pytchley masterships have been of short duration, there having been over thirty masters and joint masters in a period of ${ }_{15} 8$ years. Amongst the most celebrated were Mr. John Warde, Sir Bellingham Graham, Mr. Musters, Mr. George Osbaldeston, Mr. "Tom" Smith, Colonel Anstruther Thomson, Mr. W. M. Wroughton-a great houndman-and the present master, Lord Annaly. It is indeed a moot point amongst hunting people as to whether it is the greatest honour to be master of the Pytchley, the Quorn, or the Cottesmore; all three are positions of the highest importance in the hunting 
world, but amongst those who are conversant with all the ins and outs of hunting precedence perhaps mastership of the Quorn is most highly estimated. Amongst those who hunt in the Shires it is, probably, a question of individual opinion, however, and whilst the Northamptonshire folk consider the Pytchley to be the premier pack with the best country, Leicestershire people will, naturally enough, incline to Quorn or Cottesmore.

The Warwickshire dates from the commencement of Mr. Corbet's mastership in I79I, and the North Warwickshire from the advent of Mr. Robert Vyner (author of Notitia Venatica) in I838. The Atherstone, which lies to the west of the Quorn, was commenced in I804, and has always been a subscription pack, and the Meynell was established in I8I6 by Mr. Hugo Charles Meynell, and was in the hands of the founder and his son until I872, since when there have been half a dozen masters. Much of the Bicester was originally a part of the Warwickshire in Mr. Warde's time, but in I829 Mr. Drake formed the present country, and the Drake family have been much connected not only with this country but with the Old Berkeley, while the present head of the family, Mr. W. Tyrwhitt Drake, is master of the Old Berkshire. The adjoining Whaddon Chase is a family hunt, the mastership of which has been held by various members of the Selby-Lowndes family since before 1800 , but the country was originally a part of the Grafton, another of the old family packs, which was a private affair owned by the Dukes of Grafton for some generations prior to 1842 , but which has since been a subscription pack.

The Heythrop country was originally hunted by the Dukes of Beaufort, who owned Heythrop House, and spent part of the season there. In 1835 there was a 


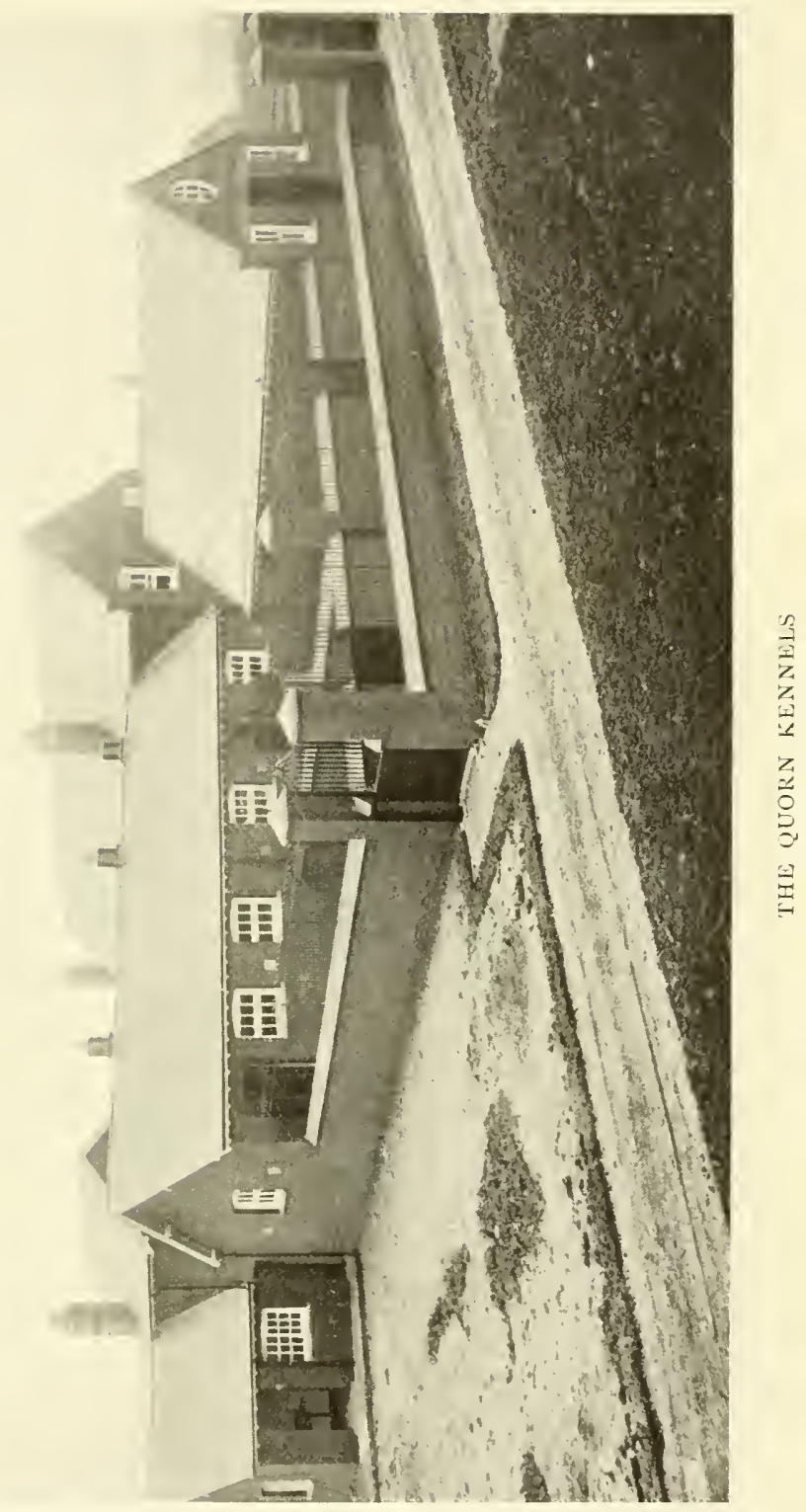



separation, and Lord Redesdale and Messrs. Langston and Webb formed a triumvirate of masters. The South Oxfordshire country dates from 1845 , and before that was part of a huge country which included the Old Berkshire and the Vale of White Horse, and which goes back to 1760 . The V.W.H. was taken from the Old Berkshire in 1831 , and was divided into the two divisions, of Cirencester and Cricklade, in 1886.

The Berkeley (Lord Fitzhardinge's) is a part of what remains of the once largest country in the kingdom, and which has for its two ends the present Berkeley country in Gloucestershire, and the present old Berkeley countries-east and west-in Herts, Bucks, and Middlesex. At what exact period the whole intervening country was in one hand is very doubtful, and the probable truth is that the Berkeley family in remote times hunted bits of it occasionally, and had establishments at either end of the district. In Baily's Hunting Directory it is boldly asserted that the Berkeley Hunt dates from 1613 , and that in 1807 Colonel Berkeley (afterwards Lord Segrave and after that again Lord Fitzhardinge) started the present pack. Then again we learn from the same authority that the Old Berkeley Hunt dates from the eighteenth century, which is a vague statement, to say the least of it.

What is practically certain is that the Berkeley hunting establishment was in its day one of the largest and most important the world has ever known, and some idea of its magnificence can be gleaned from Grantley Berkeley's Reminiscences of a Huntsman, published in I854. The author of this work-who was master of the Oakley from 1829 to 1834 -writes of his father, the fifth Earl of Berkeley, that he retained the orange, or yellow, or tawny plush for his hunt, and that Mr. 
Combe called his hounds the Old Berkeley, in remembrance of the name, and retained the livery. He then goes on to say: "To show the increase in packs of hounds in the last eighty or hundred years, my father used to hunt all the country from Kensington Gardens to Berkeley Castle and Bristol. Scratch Wood, a cover close to Wormwood Scrubs, was the nearest cover to London; but I have heard old Tom Oldaker say that, while with my father, he found a fox in Scratch Wood, and lost him in the rough ground and cover in Kensington Gardens. There was a kennel at Cranford, I believe a kennel at Gerard's Cross in my father's time, and I know there was one at Nettlebed." The last-named village lies between Henley-on-Thames and Oxford on the north side of the Thames, and is now on the boundary of the South Oxfordshire country. The above quotation speaks for itself, but if one took a direct line from Cranford to Berkeley Castle, the old Berks, V.W.H., and Duke of Beaufort's countries would be bisected, and it is extremely improbable that the Berkeley hounds hunted regularly in these districts. Indeed, the most likely solution of the story is that the Earls of Berkeley took hounds with them when they travelled between their Gloucestershire and Middlesex seats, and that they had their regular kennels at either place, while Nettlebed would be an occasional kennel for hunting a country which, after all, is only about five-and-twenty miles distant from Cranford.

The Craven country dates to the time of the fourth Lord Craven, in 1739 , but has been a subscription pack for more than a hundred years, and its neighbour, the Vine, is said to have been started in 1770 , and has a list of masters which goes back to I 790 . The H.H., or Hampshire Hunt, dates from about 1745 , but the 
pack were originally staghounds, and were only changed into foxhounds in 1793 . The list of masters of the Hambledon Hunt goes back to I79I, and the Hursley was originally part of the H.H., and dates as a separate establishment from 1837 . The Garth, again, has existed in its present state since 1850 , but the country was hunted long before, and Sir John Cope was master from I8I 7 to I850, while Mr. Garth, from whom the hunt takes its name, was in office from $185^{2}$ to 1902, and only died two years ago. The Old Surrey and the Surrey Union can each claim a life of a hundred years, but the Burstow were a harrier pack little more than forty years ago, and most of their country was originally a part of the Old Surrey. The list of masters of the East Kent begins with Sir H. Oxenden in I8I4, but the West Kent is of considerable antiquity, being one of several hunting establishments which were founded by Mr. John Warde, who hunted the Westerham country (from Squerries) in 1776 . The Tickham country was hunted a hundred years ago by Sir Edward Knatchbull, and afterwards by Lord Sondes, but the present hunt dates from 1832 . The Eridge was taken from the West Kent in 1879 , the East Sussex as at present constituted dates from 1853 , the Eastbourne from I89I, and the Southdown from 1843. But at some former period the East Sussex was a very important hunt, as the Southdown was part of it, and the Eastbourne was formed by dividing the Southdown.

The Essex Hunt can show a list of masters which dates back to 1785 , the East Essex dates from 1820 , the Essex and Suffolk is of rather uncertain origin, but has existed in its present state since ${ }_{1} S_{17}$, while the Essex Union dates from I822. The Puckeridge and Hertfordshire were originally one and the same 
country, and the Salisbury family had much to do with them towards the close of the eighteenth century, though hounds had been kept at Cheshunt before the Hatfield pack came into existence. The country was divided in 1799, when the Puckeridge Hunt was formed under the mastership of Mr. Sampson Hanbury, and meantime the Marchioness of Salisbury was in office with the parent pack on the western side of the country. The Cambridgeshire list of masters goes back to 1827 , but the hunt is said to be older, while the Suffolk list begins in the same year, but it is well known that the country was hunted long before.

The Fitzwilliam hound pedigree book goes back to 1760, but it is known that there was an earlier book, which was destroyed in a fire. The pack is a family one, and the blood, which is some of the very best in the kingdom, is generally spoken of as "Milton blood," the kennels being located at Milton Park. There are, too, other Fitzwilliam packs, known as Lord Fitzwilliam's, and which cover the two countries formerly known as Lord Fitzwilliam's and Lord Galway's, or the Grove. The first named of these two establishments, at Wentworth Woodhouse in South Yorkshire, was founded in I860, but the Grove Hunt, of which Lord Galway was master from 1876 to 1907 , dates to I827, and had hitherto been entirely in the hands of the Lumley, Foljambe, and Lord Galway's families. At the moment, however, Lord Fitzwilliam is master of two countries, and has two separate establishments, one at Wentworth and the other at Serlby.

Of the Lincolnshire packs the Belvoir, Brocklesby, and Blankney have been mentioned; the Burton have a list of masters which goes back to the third Lord Monson, 1774, and the Southwold began in 1823 , but a 


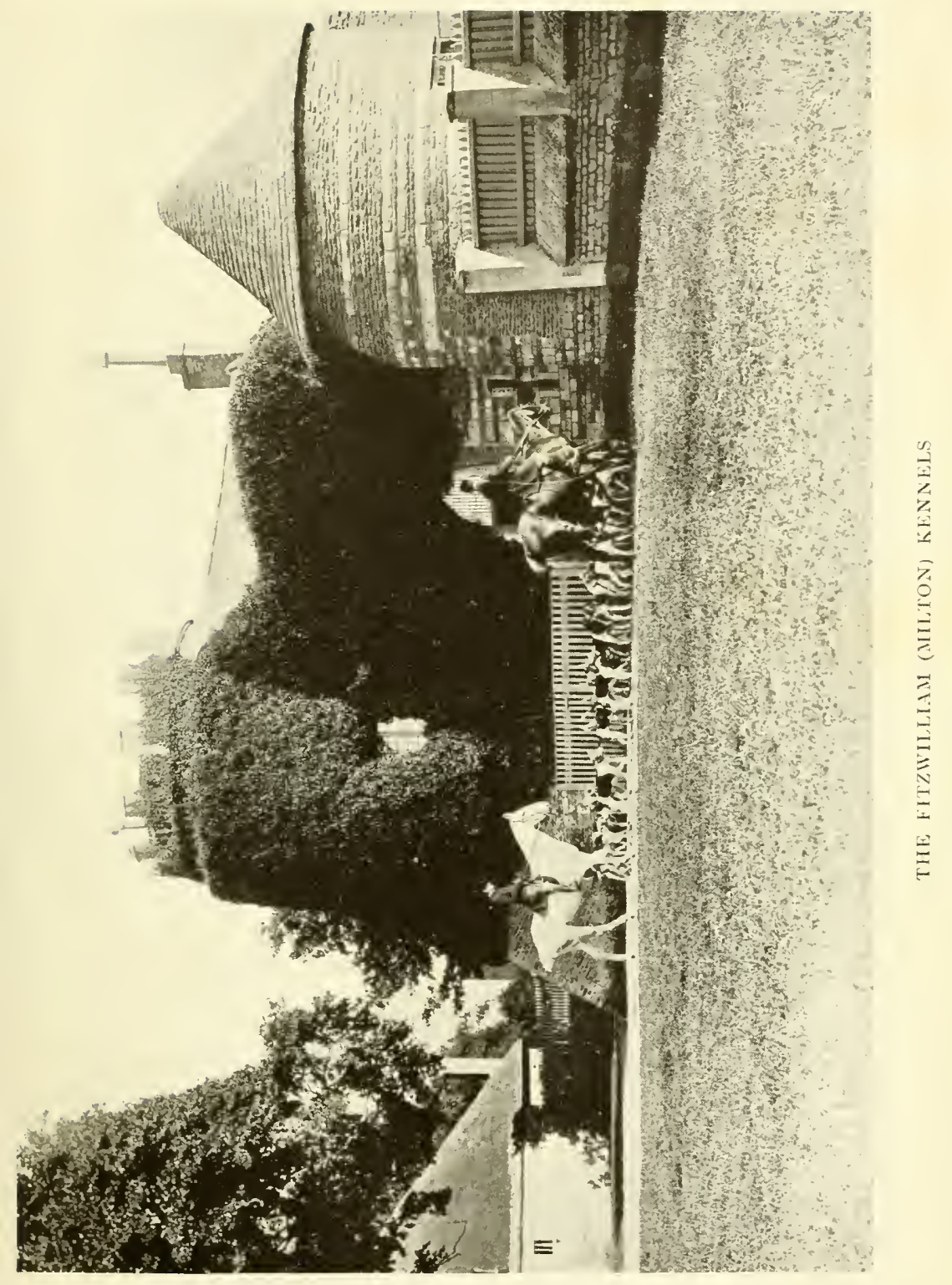



pack named the Gillingham had hunted the country for a couple of seasons before that date, and before that, again, the country was occasionally hunted by the Brocklesby.

Many of the Yorkshire packs are of considerable antiquity, and taking the country from the southern boundaries, and working northwards, the Badsworth Hunt was founded in I 730 by Mr. Bright, of Badsworth, whose hounds-according to tradition-used to meet at $5 \mathrm{a.m}$. in the regular season, whenever there was enough light, and at other times at daybreak. Another of the very old hunts is the Holderness, which dates from $I 726$, but what is more remarkable is that there is a complete list of masters from Mr. William Draper, I 726, down to the present day, and that since 1765 , when Mr. William Bethel of Low Hall took the mastership, there has been no change in the constitution of the country.

Lord Middleton's Hunt came into existence in 1764 , and has had many members of the Willoughby and Sykes families for its masters, and the Bramham Moor hounds have been in the possession of the Lane Fox family for at least one hundred and sixty years, during which time the country has existed in its present form. The York and Ainsty country, which in 1906 was divided into northern and southern divisions-each having its own master while the hunt is still maintained as one-has a list of masters which begins in I 821 , and the Sinnington, Bilsdale, Sir William Cooke's are all of great antiquity, as has been explained.

The Bedale country was originally part of the vast country hunted by Lord Darlington, whose hunt was called the Raby, and which included, at one time, all the country between Boroughbridge on the border of 
the present Bedale and York and Ainsty countries, and Sunderland Bridge, which is only four miles from Durham, and half that distance from the North Durham kennels. Lord Darlington gave up the Bedale country in 1832 , and since then a subscription pack has been maintained, but the adjoining country to the north, which has been known as Lord Zetland's since 1876 , is also part of Lord Darlington's Hunt, which dates from the latter end of the eighteenth century. The Cleveland Hunt, formerly the Roxby and Cleveland, was in existence more than a hundred years ago, and has a complete list of masters since $18 \mathrm{I} 7$, and earliest records of the Hurworth occur in 1803 . The two Durham packs are the successors of Mr. Ralph Lambton, who hunted the whole country from I 804 to 1838 . From that date until 1872 the pack was known as the Durham Country, but in that year a division of the country was made, under the titles of North and South Durham.

The Braes of Derwent country was hunted by Mr. Humble, of Eltringham, from the middle of the eighteenth century, and the pack was known about a hundred years ago as the Prudhoe. It then for a short period was called the Prudhoe and Derwent, but in I854 it became the Braes of Derwent. Its neighbour, the Haydon, was a very old harrier pack, but fox has been the quarry since the days of $\mathrm{Mr}$. Nicholas Maughan senior, who was the first master of the Tynedale, previous to i854. The country now known as the Tynedale had previously been a part of Sir Matthew White Ridley's country, the other part being the Morpeth country, which, like the Tynedale, has existed in its present state since 1854 . The Percy country was originally known as Lord Wemyss', and the master just named hunted the whole 


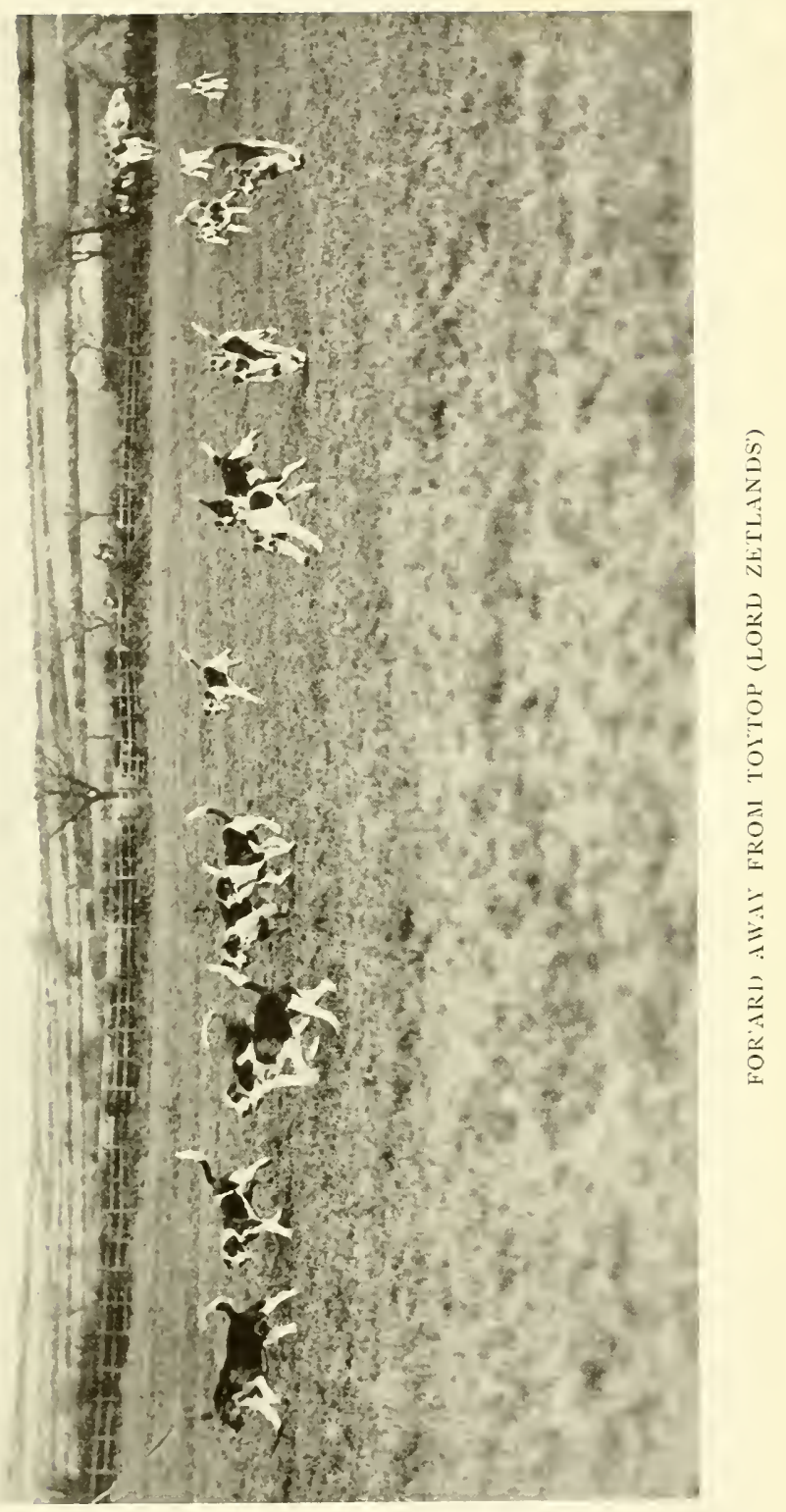



of North Northumberland, though he seldom went as far west as those districts where the Border and Coquetdale hunts are. The Border hounds have been in the family of the Robsons, of Byrness, for about a hundred years, but the Coquetdale is a comparatively new pack, and the Glendale merely a part of what was Lord Wemyss' country. The Cumberland Hunt was founded in 1770 .

There is no need to go into particulars concerning the antiquity of the many foot packs which hunt the Lake district, and Lancashire only supports staghounds and harriers, but the Cheshire Hunt dates from i 763 , while Sir Watkin Wynn's is a family pack which was established in 1788 . The North Staffordshire began in 1825 , and the South Staffordshire in 1805 , but the Shropshire goes back to 1775 , the Albrighton to a period previous to 1792 , the Wheatland to 1811 , and the Ludlow to 1780 , though there was a period between 1780 and 1814 when this country was unhunted. Major Bland, who resigned in $\mathrm{I}_{13} 3$, was the first master of the Worcestershire; the Ledbury came into existence in 1810 , and the Herefordshire, which was divided into North and South Herefordshire in 1869 , in 1826 , while the Monmouthshire Hunt Club was founded in 1835 , though hounds had been kept in the country previous to that date. The Cotswold is an offshoot of the Berkeley (Lord Fitzhardinge's) and dates from 1858 , and the North Cotswold country was only formed in 1868 by making a division of the big tract Lord Fitzhardinge had given up. The Croome is also a new hunt, as it was founded by Lord Coventry in 1867 , the country having previously been included in the Worcestershire Hunt.

The Cattistock dates from i8o6, and the Blackmore Vale from 1826 , but, as has been explained, the Cran- 
borne Chase and Mr. Thomas Fownes hunted most of Dorsetshire long before these dates. The South Dorset and Lord Portman's countries were both part of Mr. Farquharson's Hunt, which existed from 1806 until 1858 , and of which the Cattistock is the chief successor. The Tedworth country was founded by Mr. AsshetonSmith in 1826 , the South and West Wilts was formed by the joining of two packs, the South Wilts and the West Wilts, in I868, and the Wilton was established by Lord Radnor about the same date-the country being formed of bits lent by neighbouring hunts. The New Forest foxhounds go back to I 780 , and the New Forest Hunt Club was established ten years later.

Devonshire has a dozen packs of foxhounds and Cornwall four. Some of them are of considerable age, but they are more local in character than most of the packs further up the country, and there have been so many divisions, subdivisions, and rearrangements of some of the countries that it is no easy matter to mention correctly the dates of their actual commencement. Moreover, in the northern part of Devon foxhunting has a powerful rival in the shape of staghunting, and from Tiverton, northwards to the coast of the Bristol Channel, the staghunter is in a majority amongst local hunting folk. Lower down, that is to say further south, foxhunting is extremely popular, and such hunts as the Mid-Devon and South Devon have a long and honourable history. 



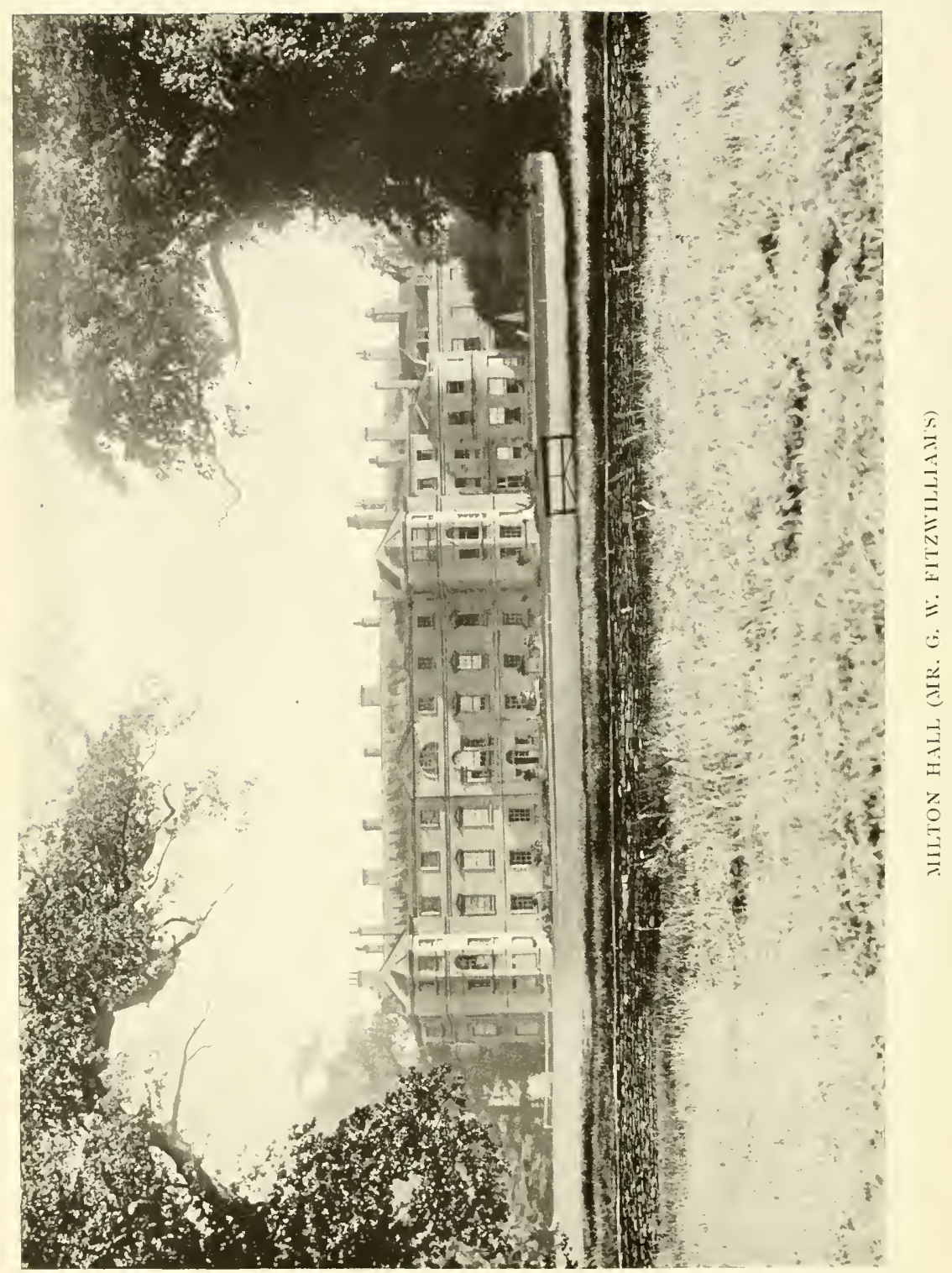




\section{CHAPTER III}

\section{MODERN CONDITIONS OF HUNTING}

M

ANY and great are the changes which have taken place in hunting during the last thirty or forty years. Not indeed in the actual manner of hunting, but rather in the conditions which surround it. As far as the style of pursuit of either fox, hare, or stag is concerned there is practically nothing new. Present-day masters and huntsmen bring out a pack of similar size to what was used a hundred years ago, and at a cursory glance little difference would be noticed-except perhaps in the matter of colour-between the hounds of our great-grandfathers and those used to-day. The expert would not be long in discovering where variations existed, but to the ordinary eye a pack of hounds is a pack of hounds all the world over. The method of drawing coverts, the subsequent run and general system of pursuing a fox, of casting hounds when they can no longer own the line, and of breaking the fox up when killed are probably much the same as they were in the earliest days of the sport. It is more than probable that fewer hunted foxes are dug out than was formerly the case, and doubtless there has been some alteration in the hours, but in all its chief essentials foxhunting is still conducted as it always was, the conditions only having changed.

And of the many changes which have taken place, or 
rather of new conditions which have come about, excessive game preservation and the general use of barbed wire are the most important, because they have in a very great degree altered hunting all over the kingdom. And first game preservation must be considered, and it will not be going wide of the mark to say that the extraordinary increase in the preservation of pheasants and partridges has practically ruined the hunting in many countries, while it has had a bad effect almost everywhere, a few favoured districts, such as the Shires and one or two other localities, alone excepted. Time was when game preservation and fox preservation went hand in hand; when the landowner, whether he was hunting man, or shooting man, or both, preserved foxes and game alike. He set just as much store on his coverts as does the biggest pheasant rearer of today; he preserved as strictly as the law allowed him, and to have his coverts drawn blank when hounds came was the biggest misfortune that could befall him -even if he did not hunt. But of the hand-reared pheasant he was entirely ignorant, while he had probably never heard of the foreign partridge. Such game as he had was well looked after, and so too were the foxes. But in those days men thought and felt differently about sport, and the ridiculous spirit of emulation, which tempts men to vie with each other in the matter of big bags, had not arisen in the country. Gradually, however, the tame or hand-reared pheasant was introduced to every corner of the kingdom where there was sufficient covert to shelter a brood, and at the moment the breeding of pheasants is nothing more or less than a craze, the chief victims of which are the hunting men and women of certain localities.

Not for a moment are we going to suggest that the 
owner has not the right to do as he likes with his land, or the tenant of shooting the right to rear as many half-tame pheasants as he can. We are merely going to state facts, and it is a bare, unvarnished truth that in many districts where this excessive game preservation is carried on foxes have disappeared in wholesale fashion, and the hunting has become little more than a farce. And in many places there is no open, honest hostility to the hunt, but an attempt to hoodwink the master and his field by the substitution of foxes which have been confined, or of real bagmen, for the genuine article. If a covert owner, or a shooting tenant, gives notice that he does not intend to preserve foxes, and that he would rather not have hounds near his coverts, then the master and his following know what to expect, and will probably give the place a wide berth, if only because of the danger of hounds picking up poison. But it is a fact that many covert owners and some tenants of shooting pretend to favour the hunt, and yet are in secret its worst enemies. Some of these men actually invite hounds to meet at their places and draw their coverts (generally in the spring of the year), and when this happens the coverts are never blank, but the foxes which are found, and which are generally killed, are, as a rule, miserable, mangy devils, which have been shut up in a barn or outhouse for weeks, or ever since they were cubs, or have been sent from Leadenhall Market overnight.

It is an unfortunate thing that what is known as a bagman was ever hunted, but it is the case that in quite an early period in the history of foxhunting it was common enough to hunt bagged foxes. As a matter of fact the custom arose through the scarcity of the genuine wild fox during the earlier days of the sport. It need hardly 
be stated again that until foxhunting came into fashion the fox had been regarded as vermin, and slain accordingly. This was in the days when men hunted stag or hare, and when the fox was practically unknown as a quarry for hounds. It happened, however, that when the great merits of the fox were discovered foxhound packs were established all over the country, and in many districts there were very few foxes to hunt. Thus it was a general practice in some localities to secure the wild foxes from unhunted districts, and turn them out before hounds. They were nearly always really wild foxes, which had not been long in captivity, that were hunted, and many of them afforded capital sport; but the system was a vicious one, which appealed to few genuine sportsmen, and it was carried to extremes in certain Tom-and-Jerry hunts, where they were not particular where the foxes came from. Then the dealers in wild animals took a hand in the game, and the term "Leadenhaller" was applied to a bag-fox more than sixty years ago. Gradually hunting of this character was discontinued, for foxes had increased everywhere, and there was no real demand for bagmen. But still there was always a certain amount of illicit traffic in foxes, and many covert owners, if at all doubtful as to the chances of a find, would have a bagman or two ready to turn down. Thus the half-and-half fox preserver has always known where to go to for the raw material, and of late he has depended almost entirely on the market when he wanted to save the reproach of having his coverts drawn blank.

Probably all hunting men whose lot is cast in a country where game is preserved to excess know all about the bag-fox, and what sort of a creature he is to hunt, but fields are in these days of such enormous 
size, and so many of the men and women who go out hunting care so little for the sport as sport, that when a fiasco occurs with a bagman they are often none the wiser. A fox is seldom seen by many of the field, and if he is found, hunted, and killed in covert, it is good odds that no one sees him except the hunt servants, and possibly the master. Thus there is always excitement when a fox is found, and if he is quickly brought to hand there are always some of a big field to rejoice at the mere fact of a kill, while those who suspect the real truth will often keep the suspicions to themselves.

In one good country, which for obvious reasons we shall not particularise, we were trotting on to a meet in company with the master, and never having been in the exact locality before, we interrogated him as to the likelihood of sport. He was not sanguine as to the morning draw, and candidly told us that hounds would probably find quickly, but that he doubted the capabilities of any foxes in those coverts he was likely to draw first. He had realised the situation exactly; hounds found a fox which ran three hundred yards, and when the huntsman picked him up he shook a shower of chaff out of his coat. A second fox ran from one little spinney to another a quarter of a mile away. He had a broken bit of rope round his neck, and hounds would not break him up. At a lawn meet in quite a different country we saw a quick find in some laurels, and what appeared to be a genuine, goodlooking fox broke away in view of a big field. He crossed a small park, and slipped under a gateway into a stubble field, securing a capital start, but he was quite dazed, and ran twice round the little enclosure he found himself in, never making any attempt to leave. 
He had not only an old, rusty collar round his neck, but part of a label attached. When such incidents as the above occur-and they are all too frequent in many localities-the master and the members of his hunt are being distinctly defrauded, and such friends to foxhunting as the men who invite hounds to their places and provide bagmen, knowing they do not allow wild foxes within their domains, had far better declare themselves, or even warn the hunt off the ground.

But the very simple, and what the Americans might call the very thin, device of providing bag-foxes is by no means the worst evil where the game craze is made a fetish of. The tampering with wild foxes by the gamekeepers of people who are friendly to the hunt, and indeed are very often hunting men themselves, is greatly carried on, and in many cases the owner of the coverts has no suspicion of what is taking place. The last-named is possibly a foxhunter, and under any circumstances a game preserver, but he wishes to find a good head of game on his land as well as foxes, and he instructs his keeper accordingly, but, in many cases, does not actually see for himself that his instructions are strictly carried out.

It need hardly be written here that in these days there are many varieties of game preserver, whereas a generation or two ago practically nearly all the ordinary shootings, and especially the small ones, were in the hands of their owners. But the small country squire has almost ceased to exist, and where he still owns the acres he is often obliged to let the shooting. Many estates, both large and small, have changed hands, and the shooting tenant, particularly the non-resident shooting tenant, has multiplied a hundredfold. The old squires used to have the game and the foxes in their 


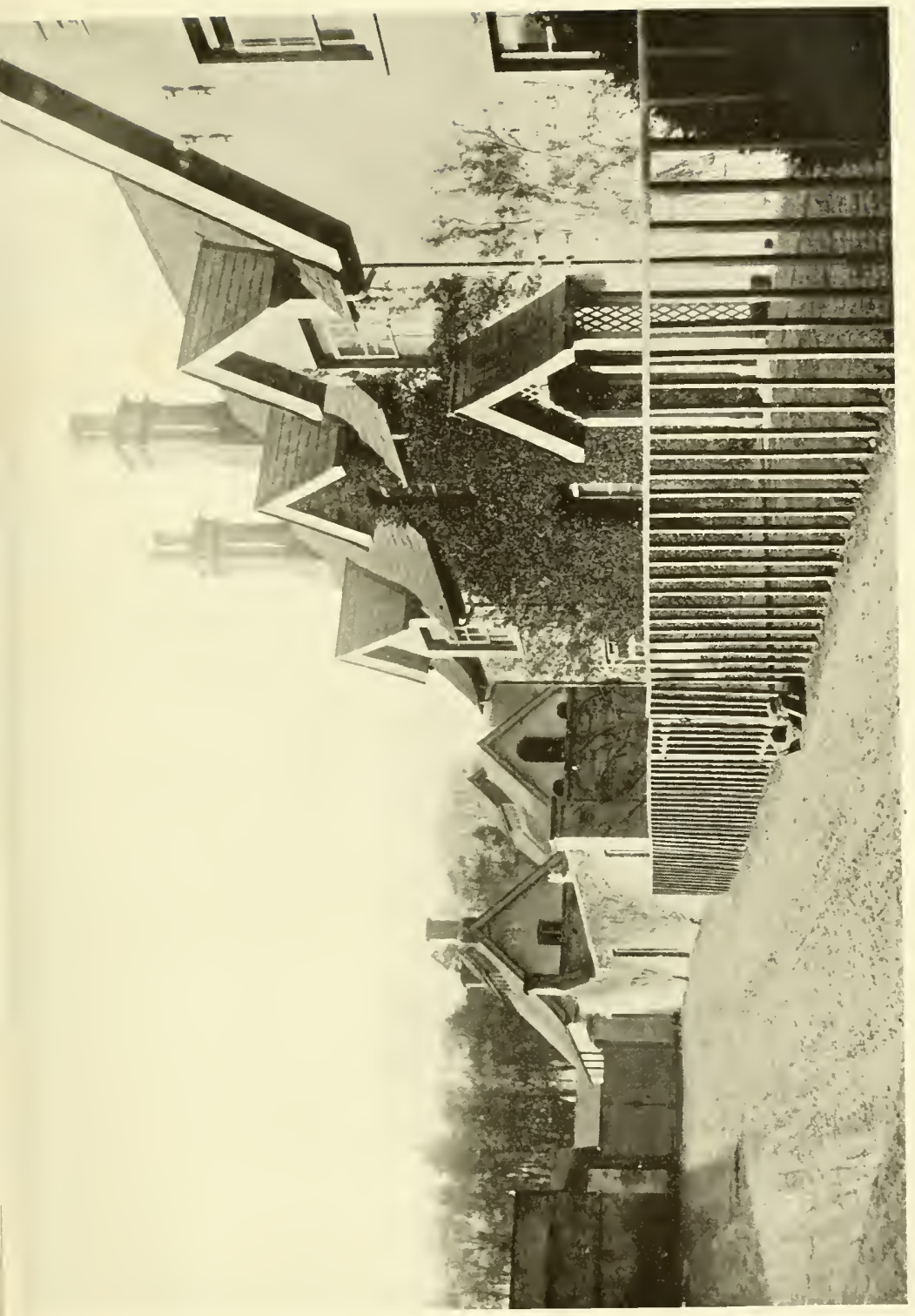



own hands, and their keepers acted rather as their masters' lieutenants than as individuals with extreme power in their hands. The average squire was often both a hunting man and a shooter, but if he did not actually hunt he knew all the hunting folk, and preserved foxes for them. At times he was practically his own gamekeeper, and when that was the case he carefully watched the foxes, and saw that they were not disturbed at breeding times; he was under any circumstances a friend to the hunt, and the hunt thoroughly appreciated his efforts ; indeed, we know of a twentystone man, who was never on a horse in his life, who was presented with a silver cup by the members of a local hunt because a certain covert of his had been drawn five-and-twenty times successfully. It was only six acres in extent, but its ponderous owner watched it night and day, and gained his reward when hounds invariably found a fox in it.

There is, however, little use in denying that times have changed, and we have got to face the situation as it is, and to make it better if possible. It must be understood, then, that what we are going to write about the failure of the fox supply only applies to certain countries, and not to all. In the Shires and, happily, in many other countries there are no grounds for complaint ; foxes are found in sufficient numbers, and a fair standard of sport is maintained; indeed, we are inclined to think that in a majority of countries there is little to complain of, and the fact is that where the hunting element dominates a district not much is heard of shortage of foxes, or of the very unfavourable specimens of the vulpine tribe which are sometimes found. But, unfortunately, there are other countries where matters are very bad indeed, and these cannot be 
ignored. Masters of hounds and hunting people generally are crying out for redress, and to put it briefly some of these countries will probably cease to exist unless there is an improvement. In some quarters a most pernicious doctrine has been put forward, to the effect that people have no business to hunt in a game country. This rank heresy has actually been approved by a journal avowedly written in the interests of sport, and the very fact of such an idea having found its way -not as a letter from one of the public, but as the opinion of the newspaper in question-into print, is evidence as to how the situation is strained in some countries.

Perhaps it is hardly worth our while to go into this part of the question, nor is it necessary for us to state how much a district is benefited by a pack of hounds and the money spent thereon. It need only be said that in the wonderful idea to which we have referred it was suggested that hunting people who lived in a game country should emigrate to the Shires or elsewhere, where game was not of so much consequence. That was the gist of the argument, but if the matter is looked at for a moment it will be seen that what was proposed was the abolition of hunting everywhere, except in some few particular districts. That residents in any country where there was a good deal of game should wish to hunt from home was quite ignored, and in effect the article suggested that where the land was suitable for a big head of game there should be no hunting. How the crowd driven to the places where hunting was still to be carried on were to be accommodated was not shown, nor was it demonstrated how the thousands and thousands of men and women who can afford to hunt a little from their own homes were to find the 
means for an annual pilgrimage to the Midlands. Possibly a more selfish idea was never thought of, let alone published, and no reference would have been made to it had it not been, as we have just stated, a strong piece of evidence as to the real feelings of some who encourage excessive game preservation.

And in place of the old squires, and their very satisfactory show of game as well as of foxes, we have in the countries referred to the big manor bought by, or let to, men who vie with each other in the size of their bags, and whose chief idea seems to be for each man to go one better than his neighbour. We are fond of pheasant shooting, and fonder still of shooting at driven partridges, but no one will ever make us believe that it is sportsmanlike to shoot until two, and sometimes three, guns are red hot, and until one is half deaf even with the small amount of noise which is produced by the modern cartridge. The battue in a rational way is right enough, because driven birds afford more sporting and more difficult shots than birds which are walked up, but when it is reflected that each particular battue gives pleasure to some six or eight people, and that a run with hounds causes as great an amount of pleasure to from ten to twenty times the number, it is shown how very selfish the battue is which involves the continual destruction of all foxes which may stray into its particular neighbourhood. It is all very well for the promoters of these big shoots to pretend to be friendly to the hunt, but as a matter of fact they often totally ignore the hunting interests of any district, and this is continually being done, especially when the proprietor of the shooting is non-resident.

Unfortunately, too, there are, in many countries, nonresident landlords, as well as non-resident tenants of 
shooting. By the former we mean men who own two or three estates, and keep one of them apparently for its shooting alone. When this happens such owners may come for the shooting two or three times during the season, bringing their party with them, and only staying a week or so at a time. Though owning a big property they do not spend more than two or three weeks of the year on it, and they are naturally outside the local life of the district, and-one must think-care little about what their neighbours may wish with regard to sport.

And if we look into the matter, a big estate where foxes are not preserved, in the midst of a hunting country, is a terrible thing. That it is not uncommon we have more than suggested, but if the hunting country is large in area it is quite possible that few beyond the master and his immediate entourage will ever know of the trouble and annoyance caused by such places. If it is an open secret that foxes are not preserved on such and such a manor hounds are probably not taken there, and of course they seldom run there, because the foxes which are hunted as a rule try to reach the coverts they were bred in, and have lived in ever since. Thus many of an average field hardly realise that a certain portion of the country in which they hunt is taboo; those who live near the ostracised coverts, who pass them on their way to meets, and on their homeward road, will, of course, understand why they are not drawn, but we have heard of men spending two or three seasons in a country where some big estates were to all intents and purposes closed to the hunt, and were yet unaware that hounds were not taken there as they were to any other covert in the hunt. They thought-when they came to consider the matter 
-that these coverts were drawn on the days when they were not out, and in one instance when the master complained to a comparatively new subscriber that he never went there because there were no foxes, the man naturally asked who the covert belonged to, and who rented the shooting.

This he was told, and though he said nothing at the time, he was, as it happened, a friend of both parties. The landlord, it should be said, was non-resident, and the tenant only came down at intervals, and could not be called a resident of the district. Well, the matter passed out of the master's thought, but a few weeks later he received a letter from the tenant of the shooting -a total stranger to him-stating that he (the tenant) had just heard that hounds never drew the coverts in question because there were no foxes in them, also that he was quite unaware of the state of affairs, and that as a matter of fact he was under the impression that the coverts were drawn in due course, and that he had always given orders that foxes should not be interfered with. The master's feelings when he received this letter can be well imagined. He was delighted to find that he had been under a misapprehension about the coverts, but was also terribly annoyed with himself for not having made personal application to the shooting tenant. It appears that a previous tenant had practically warned the hunt off, and when the shooting had changed hands it had been reported about the country that the new tenant was a friend of the former tenant, and an even greater enemy to hunting than his predecessor.

This story suggests two things, first that it is absolutely necessary for a master of hounds to approach every new-comer, who has land in his hand, and if 
possible to get into communication with every shooting tenant in his hunt. It also goes far towards proving that many keepers will hoodwink not only the hunt, but their own master, in their attempts to keep hounds out of their coverts. And scores of shooting tenants are entirely in the hands of their keepers, believing every word the keeper says, and acting on his advice as if it was the best in the world. Many worthy men who take shootings have little or no knowledge of country life, or even of the sport they are taking up. They must, at first at all events, depend upon their gamekeepers for information on a whole host of subjects, and when a keeper gives a false or highly coloured description of the enormities of the fox, and goes on to state that no one in the district really preserves, that the hunt takes care that foxes are turned down wherever hounds go, and that there is absolutely no need to have a fox on the ground, they often believe him because they know no better.

There are, of course, thousands of shooting tenants who are true sportsmen in every sense of the word, and in their hands a hunt will always be quite safe, but there are, at the same time, shooting muffs as there are hunting muffs, and the former are often the most gullible of individuals.

Coming to London by a South-Western train one November evening two years ago, after a day's hunting, we were joined at Guildford by a man carrying a gun and two or three brace of pheasants. He at once opened conversation, told us where he had been shooting (he had changed from a branch train and the place was not very near Guildford), and described his sport at length. He then began to question us about our hunting, and remarked that he had luckily got a 


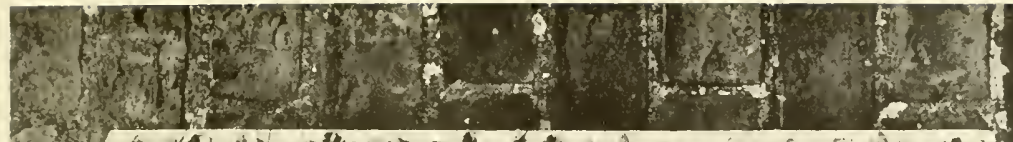
- MVYMYMYM hondANAMAda 3.

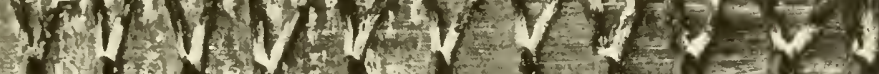
3. 1.20 .

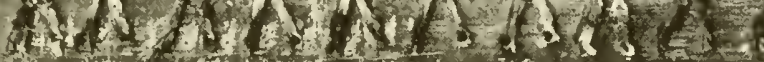
W WVM W M mAMANAMAN

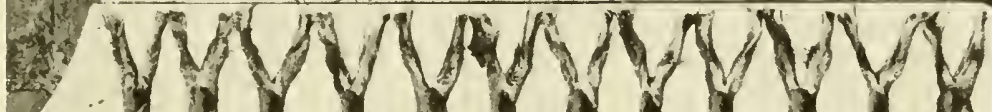

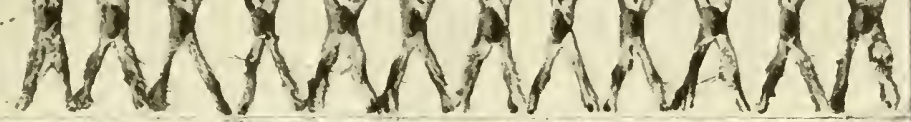

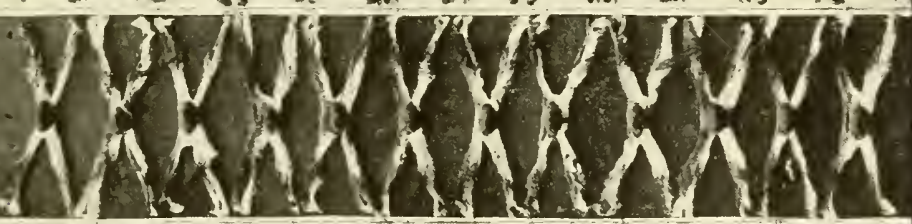

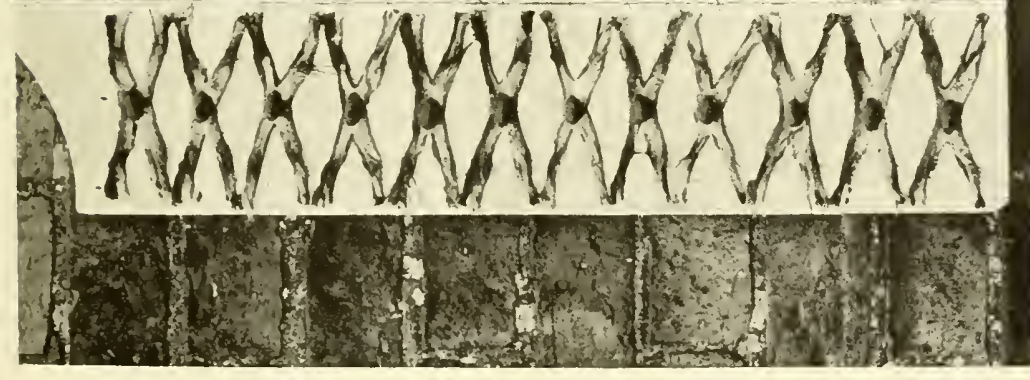

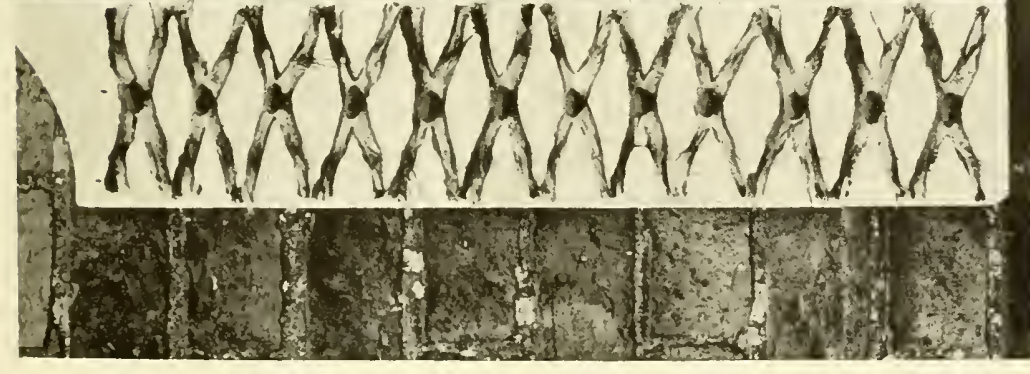



shoot where hounds never came. We knew, however, that he was quite wrong, but as he only shot on Saturdays, when the hounds of his particular district were on the other side of their country, it was only natural that he had never seen them. However, we did not argue the point, and he then remarked how good a thing it was for the shooters that so many packs of hounds did not even desire to have wild foxes kept for them. "I am told," he said, "that in the — - country they always run a drag, and turn a fox down after an hour or so, keeping a stock of foxes at home." He went on to say that he was told this suited the hunting people best, because they were always sure of a run, and generally had a kill as well ; and we let him exhaust the subject, and then asked him where he got his information. "From my keeper of course; he's a real knowing fellow; they cannot hoodwink him; he has found out all about it." This is a sample of the mischief which the inner consciousness of an unscrupulous man can evolve, and doubtless thousands of shooting men all over the country are hoodwinked in some degree or other.

And now to describe some of the common tricks of the worst class of gamekeepers, and first we may remark that amongst gamekeepers, as amongst men of every calling, there are thousands of the finest character, honest by nature and honest by practice, men who are scrupulous to a degree, and who would not dream of interfering with a fox in a hunting country. But on the other hand excessive game preservation has introduced another class as well, and these, partly because of their surroundings and the curious position in which they are placed, seem to be entirely without any sense of the fitness of things, and 
wholly ignorant as to what a fox will, or will not, do. In their own minds they will determine that no fox shall live within their beat, if they can help it, and they are often cunning enough to conceal their real line of policy even from their employers. We have known of keepers who had been brought up from infancy to regard foxes as their natural enemies; who had been taught when boys that every fox must be killed when opportunity offered, and whom it was practically impossible to bring to a proper frame of mind with regard to foxes. One such man had been employed almost from infancy on a big estate, where his uncle was head keeper. In due time he filled his uncle's shoes, and for a period of five-and-twenty years the shooting was let and foxes were religiously put down. Then a hunting man came into possession, kept the shooting, and informed the keeper that foxes must in future be strictly preserved. But there was practically no change; Scotch cubs which had been turned down mysteriously disappeared, and though the coverts were now drawn regularly, hounds never found except very occasionally in the spring of the year, when an odd travelling fox was on the move. The owner was in despair, and consulted the master of hounds, and told him that of course he could not solve the mystery, but village gossip still credited the keeper with vulpicide. The keeper was sent for and interrogated, when he quietly remarked that it was quite true, he had killed the foxes, and he supposed it was in the blood, for he really could not help it. He then and there wished to go, but his master did not wish to lose the services of a man who had been born and had worked all his life on the estate, and offered to give him another chance. Then, probably for the first time in his life, the man realised 
what was required of him, and in a year or two the coverts were the most reliable in the hunt.

Now it must be understood that this man was of retiring character, honest in every other respect except with regard to vulpicide. He never blustered or attempted to defend his conduct, but merely stated that he had been brought up in the idea that game preservation could not be carried on where foxes were allowed to live, and had acted accordingly. Another gamekeeper, a rough, bad-mannered man of very indifferent character, had charge of a biggish shoot for many years, and foxes were always scarce, though the coverts were first rate. He was far too lazy to go in for extermination, but he caught and killed what foxes he could, and sold the carcases to naturalists for stuffing. When this man was out of place, and working as a labourer, hounds ran a fox to ground in a field drain, on the very shoot he had so long had charge of. He knew all about the drain, and on his advice an opening was made in the middle of a field, and a terrier put in. But before the fox bolted we had some conversation with the man, who told us, with a sly wink, that he had taken between thirty and forty foxes out of that particular drain while he had been in charge of the shooting. He quite boasted of the performance, and, on another occasion, he opened his heart, and let us into a lot of tricks of the trade. As a matter of fact we did not believe all he told us, but he certainly opened our eyes in some degree, so that we were afterwards better qualified to estimate the position in subsequent cases of a suspicious nature.

But it is not the known fox-destroyer who causes all the trouble in those hunts where foxes are scarce, for almost as much mischief is perpetrated by the keeper 
who tampers with foxes, and does not allow them fair play. These men have been told by their masters that they (the masters) expect hounds to find when their coverts are drawn, and unfortunately many covert owners and shooting tenants are quite satisfied if a find does really take place, and are delighted when a fox is killed which has been found on their ground. What so many of them are unable to discriminate is that there are foxes and foxes, and that the fox they may have been rejoicing over has been a miserable apology for the real, wild fox. Of course if the covert owner is friendly with the master, or even with members of the hunt, the true state of the case will be generally revealed to him, but, as has been already stated, he is so often a comparative, and sometimes a total stranger, and to him a fox is a fox, that he duly credits his keeper with the find. That the fox was a bagman, or one which had been kept in captivity, he is quite unaware, and, as many of every large field are when this happens, also in ignorance of the real state of the case, it is more than likely that he will never be told.

One of the tricks where this half-hearted system of fox preservation is in vogue is to watch carefully in the spring of the year for the vixens, and when they have been located, to trap and destroy them, removing the cubs to some safe place where they are brought up by hand. The latter are fairly well looked after during the summer, because it is absolutely necessary that cubs should be forthcoming in the autumn. But they are semi-tame foxes, and the keeper knows that when they are turned out hounds will snap up most of them, and that the others, never having been taught to provide for themselves, will quickly die. What the keeper is looking for is a brave show of cubs at the proper 
time, and here it may be remarked that cubs of from six to eight months old, which have been kept in captivity, will often look just as well, at a cursory glance, as wild cubs. If they have been well fed, and kept in not too dirty a place, and have had some room in which to move about, they will hardly have begun to assume that shabbiness of coat which would, in an ordinary way, attack them a little later. Even if they have become infected with the germs of mange, they will hardly show it in the early days of cub-hunting, and in point of fact many of them will pass muster with hunting folk of experience.

And here it may be mentioned that the proofs we put forward in connection with the tricks played on foxes by certain gamekeepers are not gathered from stories, but are the results of personal knowledge and investigation, and in several cases the true state of the case was brought to light by the merest accident. Thus it once happened that we were present when a certain pack of hounds of great reputation drew a covert, also of great reputation, for the first time that season. The date was mid-September, the hour of meeting six o'clock, and as the weather was fine there was a very big muster. Indeed, there were quite a hundred riders drawn up in a grass field which bordered one side of the wood, and word was passed about that at least two litters of stub-bred foxes had their quarters in the covert. Hounds opened immediately, but no fox went away, and the master afterwards remarked that he had seen no old fox in the covert, nor had he heard of one. But cubs were so numerous a moment later that the fact of there being no old fox on the move was unnoticed. The covert was very dense, and there was little scent, but hounds killed a brace of cubs, if not 
more, and long before eight o'clock were taken elsewhere, the master being of opinion that there were at least two litters in the covert, but that as they were so backward it was most undesirable to remain longer.

The owner of the covert was congratulated on the fine show of foxes, and every one was deceived as to the real qualities of the cubs, and hounds did not draw the place again until the middle of November, when to the general surprise no fox was forthcoming. Nor did the covert furnish another fox that season, but as there were several coverts at no great distance away, which generally held, it came to be considered that the cubs had changed their quarters after the first visit of hounds. Indeed, this seemed to be an extremely probable reason why the covert was drawn blank some five or six times in succession; but during the winter an under keeper was sent away, and it appeared that he had quarrelled with the head keeper of the estate, the latter having discovered that the man had taken up two litters of cubs in the spring, had kept them in a disused shed all the summer, and had only turned them down a few hours before hounds drew the place. It was never properly discovered whether one or both of the keepers were in the plot, but the estate was a large one, and the man who looked after the covert alluded to was practically in sole charge of a very large beat.

In another country hounds had a long, slow hunt, late in the afternoon, when few were with them. At length they had made quite a big point, and as scent was improving, and a covert was in front which was in the draw for the following day, or the day after that, the huntsman and his whippers-in tried to stop 
them. But now they had their fox close in front, and were able to reach the covert, a large wood of nearly one hundred acres. Including the hunt servants not more than eight or ten were with them, and when the wood was reached the party became divided, each man choosing his own "ride." Hearing hounds in front we pressed on and found them baying at a cage, which was placed in the middle of the covert in a tremendously thick place, and inside of which were two foxes -evidently ready for the draw which was to be made in a day or two. The hunted fox had probably gone on, but the master and one of his men were quickly on the spot, so that the situation was thoroughly grasped.

We have heard on what appeared to be absolutely reliable information that another pack of hounds came upon one of these cages in a big covert, and that, owing to the wire not being strong enough to resist their weight, they got inside, and quickly disposed of the half-dozen foxes which were being bottled up for future use. The story was told us by a master of hounds, and we have little doubt of its truth, because we have actually seen three of these cages-the one referred to above and two others. One of these we discovered by pure accident during a summer walk, and the other we saw when covert shooting with a non-hunting host, who exhibited his toy with some measure of conceit, and who was totally unaware that he was offending against the canons of sport. "Look what an admirable contrivance I have for foxes," he said, and pointed out a wired enclosure of about one hundred feet by fifty, with a hovel at one end, just like a mammal-house at the Zoo. This cage was placed in a well-chosen situation, held a water trough, and a great 
quantity of dry sticks and other covert, to say nothing of bushes and trees. The wiring-in was irregular, but whoever designed it had done his work well, and there was little or no chance of a fox getting out or of a hound getting in. The mesh of the wire was carried up ten or twelve feet and the top turned inwards, so that a cub could not scramble over, holding on by his toes. The third cage was a little affair, being merely two old barrels inside an enclosure some twenty feet, and wired over so near the ground that there was only just room for a fox to run about. The place was empty when we found it, but it stank of foxes, and there was plentiful evidence that it had been very recently used.

The cage business is bad enough, but when the cage is a large one the foxes imprisoned therein can run about a little, and are not so likely to contract mange as those which are confined in an old barn or outhouse. It is the confined foxes which are really responsible for the terrible mange epidemic which has visited nearly every part of England during the last ten or twelve years, for if the disease did not actually begin with them, they have certainly been the cause of its continuance in many countries. We are not going to take on ourselves the responsibility of even suggesting the original fons et origo of mange, as it is now known among foxes, but there are certain facts in connection with the disease in epidemic form that go far to show that the wholesale spreading of the malady was absolutely entirely due to excessive game preservation, and we have often wondered whether the proprietors of great shoots, when they were killing their thousands of pheasants in a day, ever realised that they were reducing the sport of the local hunt to a 


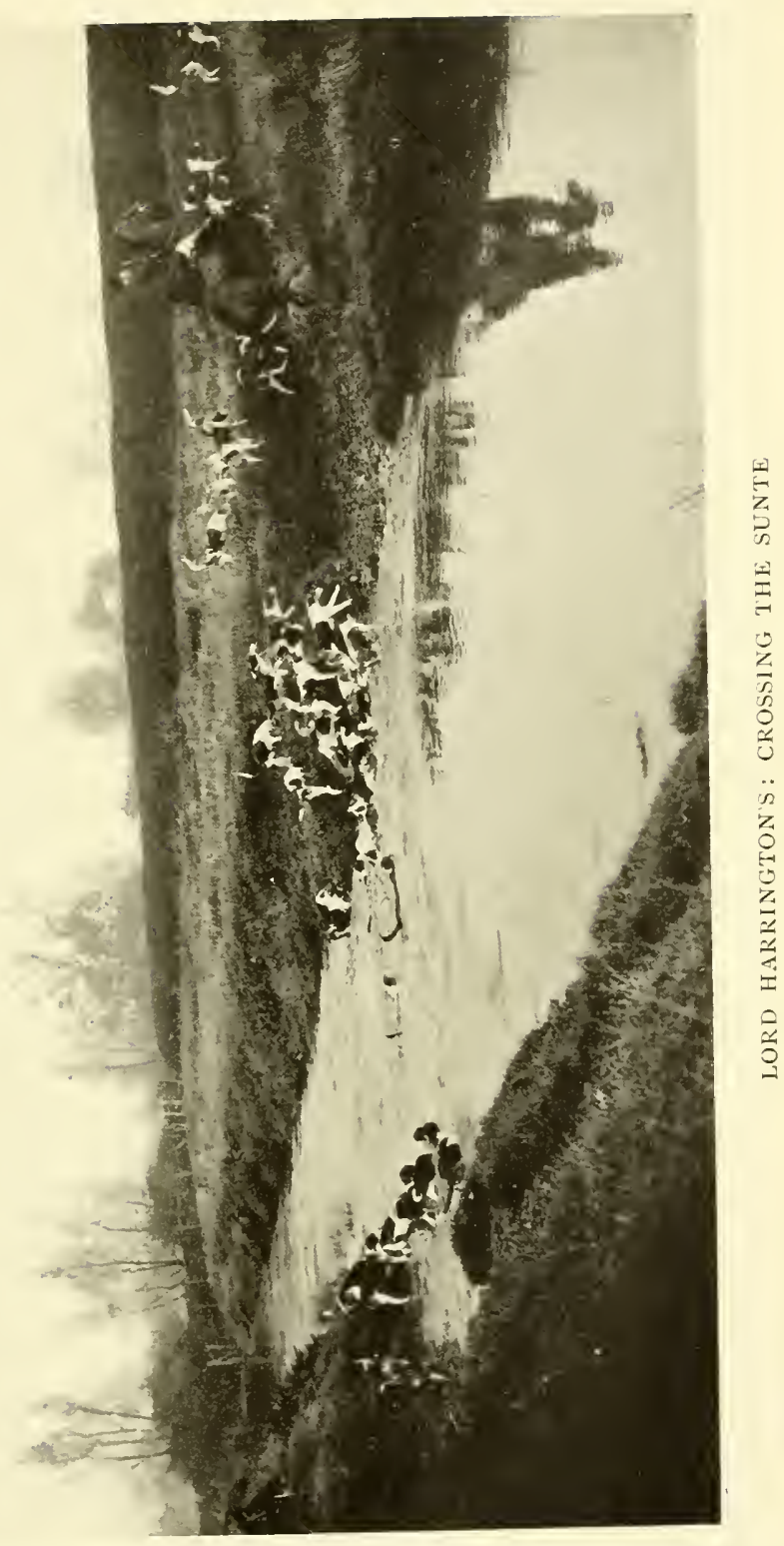



minimum, not for a day or two, but for three or four seasons.

To thoroughly realise what a terrible curse mange is one must have hunted in a country while the epidemic has been at its worst, and we need hardly say that in many countries, some few years ago, matters had reached so terrible a pitch that it was hardly worth while to be at the expense of keeping horses. There are doubtless many hunting folk who never thoroughly realised what was taking place, firstly because many foxes have been able to run pretty well while mangy, and secondly because the odd, clean fox never absolutely disappeared. It was the case, however, that for some seasons certain packs of hounds hunted three or four mangy foxes for every clean one, and to give chapter and verse the North Durham, in the season of 1903-4, only killed three clean foxes, against some twenty to thirty brace of mangy ones. We were, so to speak, present at the beginning of the outbreak (in a southern country), when it first began to be realised that the disease was an epidemic, and not a casual, quickly disappearing visitation.

Since then we have hunted in half a dozen countries, where mange could be studied in its various stages, and we have also been a good deal behind the scenes, and have been aware of the immense trouble which masters of hounds have had, not only in the matter of arranging meets, and drawing coverts where they knew the mange was bad, but in their attempts to restock their countries after the season was over. In fact, it may safely be said that to the ordinary foxhunter only one side of the mange question was ever revealed. If he was an observing sportsman he could not fail to notice the falling off in sport, but in many countries the 
rank and file of a big field only knew that foxes were scarcer than they ought to be, and that good runs came less often than formerly. The anxieties of the master, and those acquainted with the inner workings of a hunt; the anxieties of the genuine fox preserver, who found his cubs contaminated year after year; these were questions which hardly disturbed a great majority of the hunting community. Nor was there ever any great outcry made in the public Press, and on this point we have often thought that a bolder policy would have been all for the best. But, naturally enough, the most prominent descriptive writers on hunting were anxious to ignore the trouble as far as possible, and were also extremely careful not to write anything at which umbrage might be taken. Thus there was little or no mention of mangy foxes being hunted, and seldom any definite statement that sport on any particular day was spoilt by mange.

But what really occurred all too often was a total collapse of sport, and here we must go to personal experience, and state only what we have seen ourselves. Imagine, then, hounds meeting in a good country, where excessive game preservation was absolutely unknown, where foxes had always been exceedingly numerous, and as strong as wolves, and yet where mange had crept in, solely and entirely through infection from another country. Hounds draw covert after covert which a year or two before were certain finds, but two o'clock arrives, and not a sign of a fox has been seen or heard of. The master begins to get very anxious, especially when he notices that his hounds, which have been drawing for three hours-and who are only repeating the performance of several previous days-are beginning to show signs of slackness. He 
gives the order for a large covert where he knows there are foxes, and at length hounds open with the proper cry. The master hurries into covert to be met by a whipper-in, who tells him the fox is mangy; he breaks, however, and after twisting and turning for a mile or two, is run into, and found to be a miserable, half-starved specimen, and with his coat bare in places, and with no fur on his brush. Arrangements are made for his speedy burial, and hounds draw again, but fail to find a second fox. On many other days no fox is forthcoming, and at times mangy foxes are hunted, and lost or killed as the case may be, while just to show that the case is not altogether hopeless an occasional clean fox varies the performance by giving a run. Imagine also not one or two, but three or four seasons of this kind of thing, and further imagine the feeling of the master and his field, who know that mange was never indigenous to their hunt, but that their total lack of sport is neither more nor less than the outcome of a selfish system of game preservationpossibly more than a hundred miles away.

Mange of a sort has probably always existed in the vulpine tribe. Thirty years ago we knew of a baddish case of mange in a chained fox, but this yielded to treatment, a strong solution of carbolic being mixed with fish oil, and the fox gradually but very slowly recovered, but had a shabby coat for nearly a year afterwards. But except that a very old mangy fox was occasionally killed, the disease was practically unknown in the hunting field, and most certainly it never appeared in its recent epidemic form until the early nineties. It then broke out in certain southern hunts, and as far as could be ascertained at the time it was present in different districts 
of the south of England at much about the same period, the various places of outbreak being separated by wide tracts of country which were not infected. This, then, suggested that there was a common cause for the beginning of the epidemic, which was at work in more than one place. What exactly this common factor was has never been really proved, and even now two reasons are given by those who have studied the question. But first it must be mentioned that by this time there was a decided shortage of foxes in many countries, due entirely to the increase of game preservation. In many hunts there was little or no breeding stock left at the end of the season, and it was known that no litters would be allowed to live in certain coverts. It became, then, absolutely necessary that some portions of certain countries should be restocked, and that there should be litters of cubs where it was known that they would be properly cared for. It is no use blinking facts, and it is a fact that importation of strange foxes was a necessity, which had to be acted upon. Nor was there anything new in the idea. In many countries restocking had been tried with success well on to a hundred years ago, where hunting had become popular in districts where the fox had previously been regarded as vermin. Much later too, in the forties, fifties, and sixties, restocking had been resorted to (if it were necessary the names of countries could be given), and it was a very general opinion amongst those well versed in the habits of foxes that an occasional infusion of fresh blood was all for the good of the tribe. Doubtless, however, great care was taken both in seeing that the imported foxes were strong and healthy, and taken from a wild country, and 
similar care was exercised when they were turned down.

For a generation or two the trials of new blood were successful enough, but there came a time when owing to the fact that in many places foxes were no longer preserved, while in other districts they were destroyed in wholesale fashion, the demand began to exceed the supply, and then the foreign fox was bought in large numbers, and the mange era set in shortly afterwards. Most of these foreign foxes came, and still come, from various parts of Germany, and as foxes they are good enough. Indeed, we have heard of their giving the greatest satisfaction, but when the demand for increased numbers arose, the dealers, or consigners, began to be careless; the consignees (not the buyers) were equally so, and by the time the foxes reached the right hands, many of them, though not showing any signs of the disease, were infected by mange. That overcrowding, and foul kennels or cages, with improper food, were the original causes of virulent mange is almost certain, and there is reason to believe that very often a consigner of foreign foxes was collecting his cargo one by one, or in litters for weeks, and even longer, before they were dispatched. It is thought that during the process of collection too many foxes were herded together in dirty places, and that when the time for sending them off arrived they were packed too closely in dirty crates, and also that from the moment they were caught until they were turned into an English earth they were, to say the least of it, carelessly fed.

Mange takes some time to declare itself, but it is certain that some of the German foxes were mangy when they arrived, while it is also practically 
certain that others had contracted the disease. Small wonder, then, that after a while the infection spread to the wild foxes, and that the disease rushed all over the country. This is one view of the origin of the mange as known in epidemic form; the other is that the disease has simply arisen through the most objectionable and very common habit of catching the cubs when they were young and keeping them in confinement until they were required for hunting purposes. Foxes kept in captivity and fed on unnatural food are almost bound to go wrong, except, perhaps, the odd half-tamed fox, and he is always more or less of a pet, and well looked after, his bed being constantly changed, while as a rule he is fed as far as possible on his natural food. But supposing two litters of cubs are placed in a barn, say at the beginning of May, and kept there until the beginning of September, and are looked after by a man who is careless as to cleanliness, and ignorant as to the food he provides. In such a case it is almost hopeless to expect that the cubs will keep healthy, and as we have mentioned, there are hunting men who are strongly of opinion that this bottling-up of cubs for months at a time is responsible for all the mischief.

To tell the truth it is really of little consequence whether the mange came from Germany or any other foreign country, or whether it is a home-bred disease. It is in either case the outcome of excessive game preservation, because if the supply of foxes had been allowed to remain as it was, say a generation ago, there would have been no need for imported foxes, while if foxes had never been kept in captivity the belief that they (the captive foxes) are the source of 
mange would be an erroneous one. Look at it from every point of view, and one always works round to the same conclusion, viz. that the destruction of foxes, or keeping them in captivity, are the primary causes of mange, and that there would be no reason for destroying old foxes or kidnapping cubs were it not for the desire to have more game on the land than there was a decade or two ago.

To turn to another subject which still agitates the hunting community, barbed wire is now a recognised evil, but hunting people are becoming so thoroughly accustomed to it, and in some countries are so well able to cope with it, that barbed-wire troubles are in these days purely local, and seldom heard of outside the confines of the hunt in which they exist. Indeed, barbed wire is now such a necessary, under certain conditions, that it is no use attempting to ignore its existence, and yet it is very often possible to have it taken down during the hunting season. The fact is that barbed wire is cheap and lasting. It may cost more to put up a strong wire fence of several strands than to build up a timber fence of equal strength, but the wire lasts longer than the timber, and the process of putting it up does not involve so much labour. And on thousands of estates there is no timber available for good posts and rails, and then wire is used by owners and tenants alike, and this is a fact which hunting people have to face. But the plan of running a strand or two of barbed wire through an old fence is a most pernicious one, because the wire gradually destroys the fence. Few farmers seem to see the importance of this point, but as a matter of fact even the life of a decaying fence is greatly shortened when it is mended with wire, and a new, growing fence is often quickly 
ruined if an attempt is made to supplement its strength by the introduction of a couple of wire strands.

As far as a hunt is concerned its relations to the wire question depend on the local conaitions and on the character of the country. All over the Midlands barbed wire is used by the large graziers, but as a rule bullocks are only pastured between May and November, and it is only a very exceptional farmer who will not allow his wire to be taken down when the bullocks are off the ground. It is customary to mark the presence of all barbed wire which is left standing in these and in many other localities, but when danger signals are used the greatest care should be taken that they are put up in every fence where there is a single strand of wire, because in a marked country the unmarked fences are supposed to be clear, and are therefore ridden at in all confidence.

Yet accidents have been known to occur when the marking has been forgotten or omitted in one odd unmarked fence amidst a number of marked ones, and in such cases a certain amount of blame must accrue to the wire committee of the hunt, if there is one, and if not, to those who have charge of the barbedwire arrangements. It is, then, most important that in every country all the wire should be marked or none at all, but this is by no means a regular custom, and strangers who visit one of these half-marked countries must run a great risk. It is all very well to say that members of the hunt know where all the wire is, but every hunt is visited by strangers at some period of the season; and then, again, it is no easy matter, when a certain amount of wire is marked, to recollect exactly where there is unmarked wire, It seems to us, then, 
that it is better to have no danger signals than a short supply, but each and every hunt which sets about the wire question in a business-like manner can ameliorate the nuisance in some degree.

It may be pointed out that, in a great majority of cases, it is the best plan to treat with the owners of estates or with their land agents, when negotiating about wire. There are, of course, tenant farmers of repute and high standing in their particular districts, who have all such matters in their own hands, and, of course, when wire is used on a grazing farm, and the hunt wishes it to be taken down during the winter months, the matter rests entirely between the tenant farmer and the wire committee or authority of the hunt. But when farms are let on short leases, when tenants are being constantly changed, and when the holdings are small, a little ventilation of the subject with the owner or his agent often does a great deal of good. It is often the case that there is plenty of timber available for restoring old fences and making new ones, and, again, timber can in many districts be bought more cheaply than wire. But if matters are left to the tenant and the agent, and neither of them is a hunting man, wire (being the simplest form of fence) will be decided upon, when a fence has to be renewed or restored, merely because the wishes of the hunt have never been put forward.

When wire is largely used, and owners, tenants, or both decline to have it removed in the hunting season, then the hunting wicket or the invitation jump may be asked for, and leave to put this into a fence is seldom refused. Both are by no means new, for though wire has not been used for more than a generation, it is about fifteen years since we found 
gorsed hurdles placed in a wire fence, in the North Staffordshire country, and since then we have seen a variety of what are usually spoken of as invitation jumps; but when these are in vogue it is absolutely necessary that they should be looked at, and mended if necessary, after hounds have been over the ground, for if a hundred horses jump at even a low fence, the fence is almost certain to be damaged, while if the ground happens to be soft, it will be badly poached on either side of the jump.

The hunting wicket is not so convenient when fields are large, and causes more delay, especially when the wind is high and the gate swings back every time it is opened; but it is of the greatest use, especially in a boundary fence between two farms, where very often the obstacle has been so built up that it will either pound a whole field or be worked into two or three gaps, each of them big enough to drive a coach and four through.

One of the best and simplest ways to deal with the wire question is to divide the hunt into so many districts, and to appoint certain residents in each district as members of a wire committee. Care must be exercised in choosing men of tact, who will be able, or at least will have a fair chance of being able, to conciliate any irreconcilables there may be in any district, and hunting men who live on the spot, and are not too much away from home, should, if possible, be chosen; but the best thing of all is to have a committee which is largely composed of tenant farmers, who, whether they are hunting men or not, are kindly disposed to the hunt. When a country is so divided and things work smoothly, it will be found that wire does not increase, that there is no difficulty in marking 


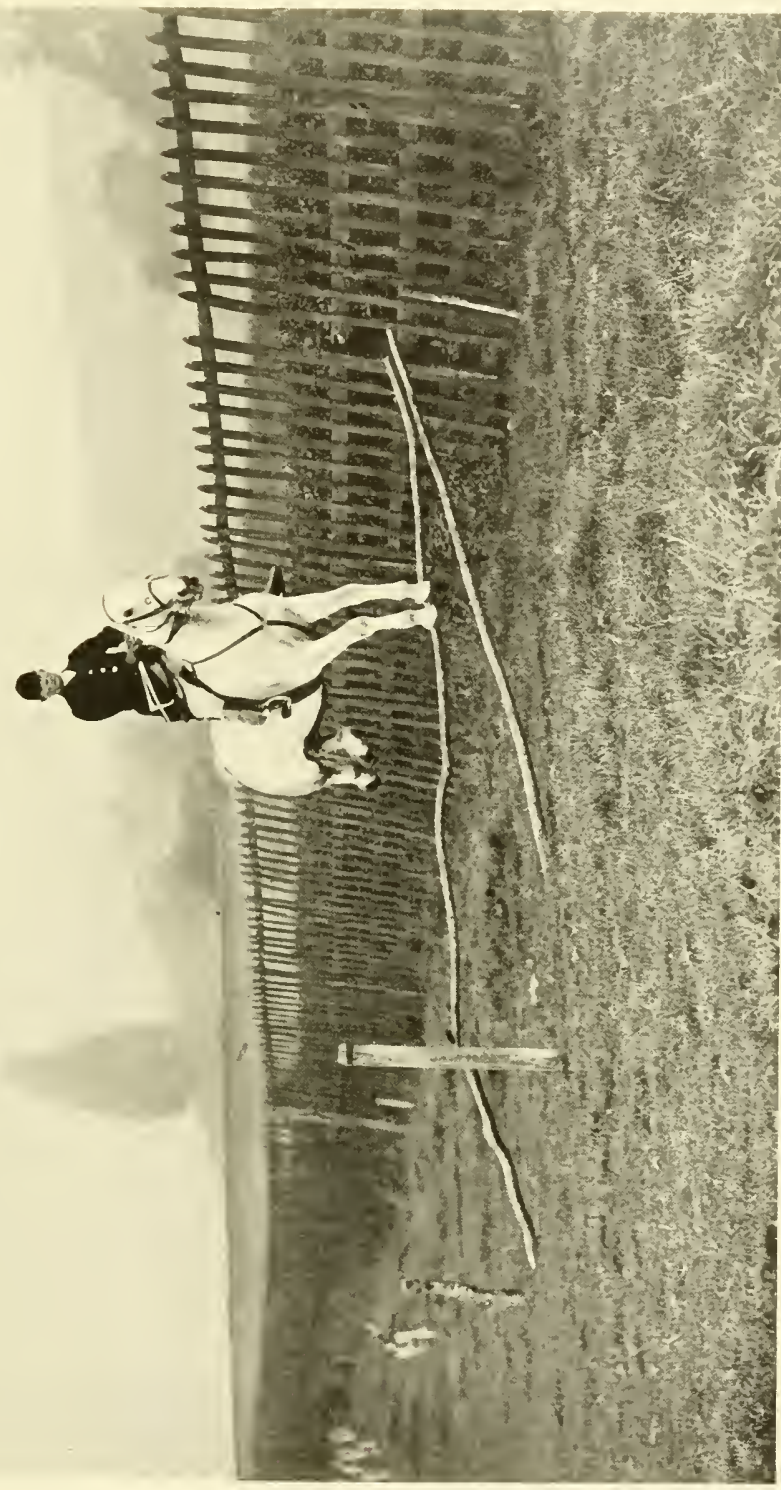

年 

what wire there is, and that when a farm changes hands, posts and rails will, as a rule, be provided for any new fencing, or mending of old fences which the new tenant requires.

Then, again, there are the numerous advantages to be gained by farmers who do not use wire; and these cannot be too often or too forcibly pointed out. In this connection we do not include the public collections which are annually (or sometimes bi-annually) made by the various hunts for the funds of the Royal Agricultural Benevolent Institution, but may mention that the society in question is in a very large degree supported by the contributions of hunting men and women. There are, however, the hedge-cutting competitions, which are immensely popular in the Midlands, and the many prizes offered by masters of hounds, and hunting people generally, at the local agricultural shows, in which the competition is only open to farmers residing within the confines of a certain hunt, or hunts. In many cases it is now the custom to bar all competitors whose farms are wired, and this has been found to answer well, there being a very strong feeling amongst farmers that those of their calling who do not favour the hunt in some degree should not be eligible to win a prize which has been given by the master of hounds, or by his followers. It is also in some cases the custom to omit farmers who use barbed wire from the list of puppy walkers, and when-as sometimes happens-a farmer, whose farm is wired, does get a prize his neighbours have plenty to say about it. But, after all, goodwill and friendly feeling are the keynote to a pleasant state of affairs between any hunt and the tenant farmers within its boundaries, and this, we are 
glad to say, is everywhere existent, the hunt being still looked upon not only as a necessary adjunct of each countryside, but as a welcome diversion of the monotony of country life.

It has been shown that moderate (or degenerate as they are usually called) foxes and barbed wire are two evils which the modern conditions of hunting entail, and, as has been suggested, the sport in many countries has been greatly altered by the advent of these two things. There are, too, several minor changes which have gradually taken place within comparatively recent time, but these will be treated of in the course of these writings, as they crop up. It may here be stated that on the other hand the hunting field is much more cosmopolitan than it used to be, and that hunting is in these days well within the reach of all who are inclined to the sport, and are able to afford the expense.

There are of course some provincial hunts which are still carried on as they were more than half a century ago, where the country is remote and far away from beaten tracks, and where the hunting folk are the third or fourth generation of the original founders of the hunt. Into such districts strangers rarely penetrate, and old fashions are adhered to merely because the conservative tone of the district has never been altered. But such hunts can probably be counted on the fingers of one's two hands, and in a very great majority of the so-called provincial countries all sorts of innovations have been adopted, chiefly because the composition of each hunt has so greatly changed. What was once -especially in the pre-railway days-the sport of the landed interest and the landowners and their tenants, has become the sport of the community at large, and in these times two-thirds of every field are business men 


\section{MODERN CONDITIONS OF HUNTING 57}

of sorts, while the remaining third is composed of men and women who are so well endowed with this world's goods that they have no need to work, but are able to live in the country throughout the winter, and maintain a stud of horses, a motor-car to take them to and from hunting, and a retinue of servants to administer to their wants in the hunting field. 


\section{CHAPTER IV}

\section{THE MASTER OF HOUNDS}

T $T$ is just possible that in these days there are not so many applications for vacant masterships 1 of hounds as there were five-and-twenty years ago, and it is also possible that the post, except in a few very important countries, does not carry quite so much prestige as it once did. We live in an age of levelling, and just as the old glamour which once existed all over the country with regard to the fox has departed, so in some minor degree have the dignity and importance which environed the mastership of all well-regulated packs of hounds disappeared. There are, of course, many hunting folk-mostly country-bred people who have hunted from boyhood -who still hold the master's office in the highest reverence, but on the other hand the spirit of the age by no means encourages this feeling, and it is now the case that much depends on local surroundings, and thus the master of one pack is a local hero, while the master of an adjoining pack is held in no particular esteem, except by his own following.

In what may be called a sporting country, that is to say in a district where the love of sport is really strong, where the hounds have a big reputation, and where a fair proportion of the residents are interested in the hunt, the mastership must necessarily carry with it considerable prestige. But where the country 



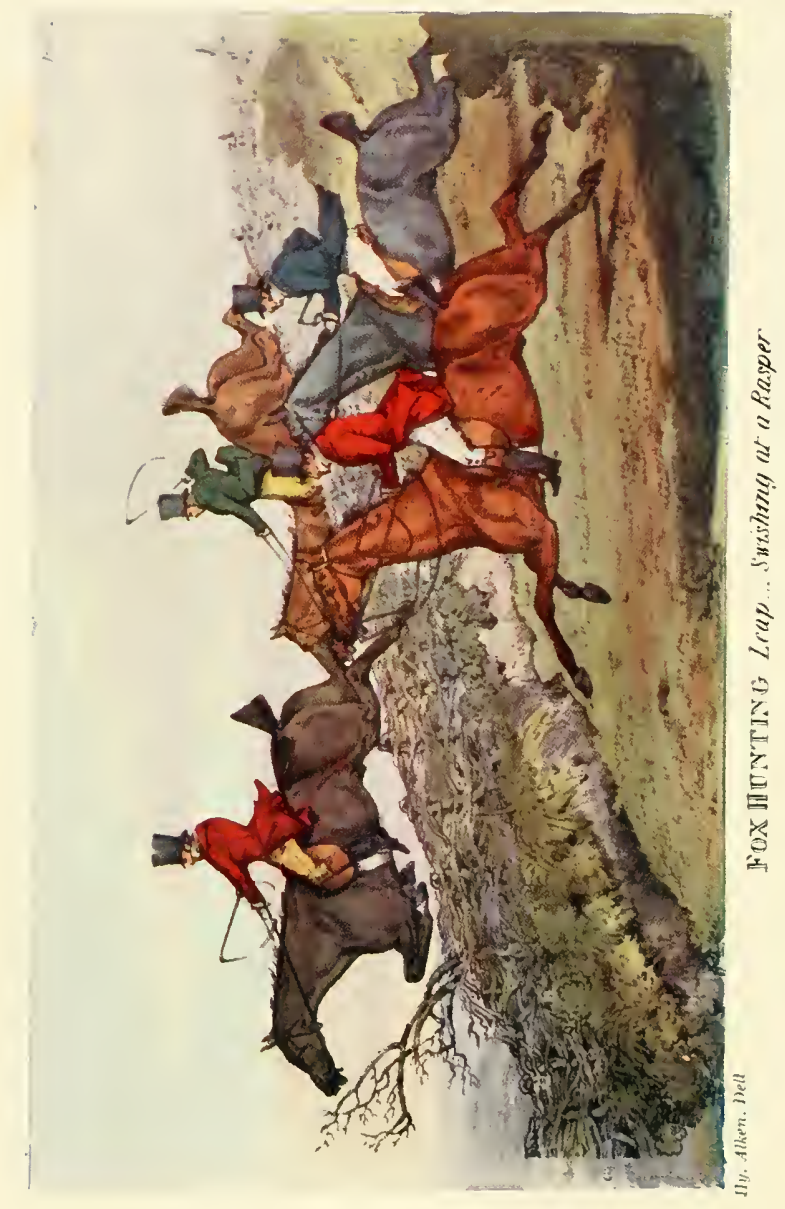


has an industrial as well as an agricultural population, and where the hunting element is small in comparison with the non-hunting portion of the community, there a mastership of hounds is thought less of than the chairmanship of a parish council; and this was suggested to us not long ago by the secretary of a country agricultural show. The gentleman in question was a hunting man (secretary to the local hunt), and the committee of the show were nearly all tradesmen and business men from the country town. Our friend canvassed the hunting people for subscriptions towards the prize list, and obtained such a goodly sum that he was able to promise the money for all the hunter prizes, and in addition to give half a dozen prizes to tenant farmers in the farm stock classes. Yet when the committee published their prize list it began with the names of a dozen councillors, none of whom had given more than a guinea, and the handsome sum collected by the secretary was lumped together, with nothing written to show that it had been subscribed by the hunting men of the district.

On the other hand we met a master lately who was inclined to think that the high office he held was thought more of than formerly. We naturally asked why, and were told that Who's Who had applied for particulars of this gentleman's career, and that, in fact, all the masters in the kingdom had been circularised.

Whether the height of glory is reached when one's name is included in the most curious of modern directories is open to doubt, but the real fact is that the country has undergone such manifold changes in the last thirty years that it is practically impossible for 
the present generation to have the same thoughts and ideas as the last. It may not be generally remembered, but it is the case that in the early seventies trade was wonderfully good all over the country, and these "good times" lasted for several years. And one of the chief consequences of the good trade was that there was a rush to the country on the part of thousands of townsfolk. Some bought estates, others rented them. Some again bought houses without land, and others bought land and built houses for themselves. Since that time the exodus has continued, and it is not only London but all the big residential centres which have sent hundreds of new-comers into the heart of the country. Some small proportion-really only a very small proportion when one compares the size of the fields of thirty-five years ago with those of the present day -of these new-comers took to hunting, and the second generation of the earlier new-comers (which forms part of the rising generation of the present day) has followed on, but, nevertheless, the fact remains that at this moment there are scores and scores of well-to-do people living in the country who neither know nor care anything about hunting, and that being so it is little wonder that a mastership of hounds is not held in the high estimation that it ought to be.

We do not wish to labour the case, however; and to get on to the master's position and duties, it may be pointed out that the office of master must vary greatly according to circumstances. Thus for the Shire packs it is no easy matter to secure the right man, especially for the Quorn, the mastership of which hunt is by many thought to be the very highest honour to which a 
hunting man can aspire.' First of all a master of the Quorn, or of one of the neighbouring packs, must have a well-earned reputation as a sportsman. He should have hunted in the Shires, and have thoroughly proved his knowledge of hunting. He should, too, be a firstflight man, and as a matter of fact all the recent masters of the Quorn (there have been six masters since i 884 ) have been really good men to hounds, and one or two of them absolutely first rate. He must be masterful and yet full of tact, quick at resource, and quick to make up his mind, otherwise he will never be able to keep the big fields in hand, and give his huntsman the chance of fair play. Bad language is out of fashion, and this is all for the best; but sarcasm was always a deadlier weapon than an oath in the hands of a clever man; and when direct remonstrance fails sarcasm is often a most efficient substitute for hard swearing.

In the provinces, especially in the smaller hunts, it is not an absolute essential that the master should be a fine rider to hounds, who is in the habit of taking his own line. It is, of course, better that any master should be always well up; but when the field is small it is as a rule fairly well behaved, and therefore it is not of so much consequence if the master is not actually on the spot when hounds check. . But in the Shires the case is very different, and it is practically necessary that the master should be there or thereabouts at all critical moments. No man can make a certainty of being always close up with hounds, and it often happens that a master has accompanied the pack into covert-if a wood is being drawn-and if hounds get quickly away he may lose a certain amount of start. If, however, he is in the habit of riding right 
up to hounds, and "taking hold" of a big field if any one is inclined to press on at a check, his absence on an odd occasion will not be missed. His field will know that he is generally there, and will, even if they do not see him, act as if he was bang in front.

It will perhaps hardly be credited in these days, but we once knew a master who, when he first took office, was actually under the impression that it was a point of honour with every master of hounds that he should lead his field throughout the day, and this man fretted sorely when any one rode in front of him even for a few minutes. It need hardly be said that the pack, though good enough in its way, and capable of showing excellent sport, was not a fashionable one, and the mastership often went begging.

Our friend was a rich man, who had come into sudden wealth, but who had previously been unable to indulge the passion for hunting, which he undoubtedly possessed. He was, too, a powerful athletic man, and a bold, fearless horseman; and as soon as he could afford it he not only got together a valuable stud of hunters, but took the mastership aforesaid. It was late in the autumn when he took hold, and we saw the pack only a fortnight after the season had opened. Hounds were running all day in a cramped country, and wherever they went the master was with them, jumping what were apparently impossible, and often unnecessary fences, and altogether giving such an exhibition of fearless horsemanship as is very seldom seen. During the evening we congratulated him on his prowess, and then it came out that he thought it was incumbent on the master to show the way at all times, and that masters as a rule were chosen because they were the best men to hounds. 
Other masters we have known who never rode over the smallest flattened gap in a fence, and others again who appeared to decline jumping, and who were yet always there or thereabouts when hounds checked. But as the fields are constantly very large, and there are often many strangers out, the master's duties in the Shires must be different from those of the master of the provincial pack, where the following is the same from day to day, and never of unmanageable size. On the whole, tact is perhaps the most essential requisite for the outfit of a master of hounds. Some men are so easily offended, and a hasty master who has not his temper under control may in the heat of the moment say something which may give offence to one of his field.

Too strong a point cannot be made of the unwritten law which forbids any member of the field to argue with the master, or indeed to retort if he is found fault with. The master may be right, or he may be wrong, but if he is well up in all the duties of his office it is good odds that he knows what he is talking about, and anyhow it is the stern duty of any one who is found fault with to apologise, or say nothing at all, but on no account to "answer back."

Discipline is absolutely necessary in any hunting field, and discipline can only be enforced by the master, or by a deputy who is acting as an authorised field master. There are in many hunts certain men who are constantly doing something to rub the master the wrong way. Such men will get too far forward when a covert is being drawn, will press on hounds at a check, and if the master is timid, too easy-going, or too indifferent, will follow the huntsman when he is casting hounds, so that they may not lose an inch of 
ground when the line is hit off again. As a rule these men are fearless riders, and when they are not held in check will do a vast amount of harm in the course of a season. All hunting men of any experience have met them, and will have noticed their tactics, and those who have hunted in several different countries will be aware that whereas one master is easily able to hold these insubordinates in check, his neighbour is often at their mercy, and allows his sport to be, in a great measure, spoilt by men who are constantly offending, and who must be perfectly aware of their offence.

It comes to this, then, that a man who is lacking in moral courage is hardly fit to be a master of hounds. The best sportsman in the world, the finest rider to hounds, the most popular fellow in the country, the man with the greatest knowledge of hunting; every one of these is out of place as master if he is not prepared to pull up an offender the moment he sees anything wrong. As we have already said he need not swear at the culprit, but he must have a certain command of language, and the power of showing that he will be obeyed. If a master is new to office and finds his field unruly his position is not a pleasant one. Naturally he does not care to begin his mastership by finding fault with his field, and therefore he has to work gradually before he attains the end he has in view. It will not take him long to find out who are the offenders, and when he is thoroughly sure of his men he can begin by remonstrating with them quietly, and if this does not bring about an improved state of affairs he can then find fault in the presence and hearing of the field. If this or some similar line of conduct is pursued it is quite certain that the master's action will be appreciated and approved, 
and that, in fact, he will carry all the best part of his field with him.

We have in recollection two cases of very young masters, both of whom began badly, but by degrees overcame their difficulties. In one instance the master was a mere boy, who came forward when no other master was forthcoming. He had, for one of his age, considerable knowledge of hunting, but he was shy and nervous, and his field quickly got out of hand. By Christmas-time many of the hard riders were doing exactly what they liked, and matters had become so bad that some of the older members of the hunt were visiting the adjoining country for their sport. Then there came a day when hounds ran so fast that for twenty minutes they were beating every one. At length they checked in a field of turnips, when one of the worst offenders calmly galloped round them cracking his whip to turn them back to the fence. The young master saw it, and suddenly coming out of his shell rated the wouldbe huntsman in such forcible language that he slunk away, and was not seen again that day. So hard had hounds been running that very few of the field were within hearing, but the story was soon spread about, and from that day no more liberties were taken.

In the other case the master was also a young man, but had had the experience of several seasons and also had considerable knowledge of foxes, and of woodcraft generally; he was, in fact (so most people thought), just the man for the place. But he began by ladling out indiscriminate and unmerited abuse to all and sundry, with a view to asserting his authority. From day to day he became more abusive, and gave more offence, and he had not been long in office before his field dwindled from something a little short of a hundred to 
about fifteen. He then asked an influential member of the hunt what was wrong, and at last he realised the situation. He at once changed his tactics, and as he was showing wonderful sport his field began to come back. Still it took him the best part of two seasons to live down his early mistakes, though on a certain public occasion he took the opportunity of explaining how he had begun his mastership on a wrong system, and how sorry he was that he had unwittingly given offence.

In the field, unless there is constant overriding of hounds, the master's lines may or may not be cast in pleasant places, nearly everything depending upon the style and custom of the hunt. In a country where there is no question about the fox supply, where every covert may be visited at the master's option, and where, in fact, game preservation is not unduly insisted upon, the carrying out of the prearranged programme of each day's sport is perhaps the most important matter which has to be considered. Where the field is well behaved and not likely to do anything stupid the master is, of course, well aware of the fact, and can devote himself to the pleasure which the sport affords. $\mathrm{He}$ is able to watch hounds, instead of being obliged to keep his eye on such members of the field as are likely to get into mischief, and he is in point of fact able to participate in the sport, instead of having to do mounted policeman's duty.

And before we go any further it should be mentioned that masters of hounds may be divided into several classes, each of which, though preserving the same broad principles, varies in some degree from the others. Briefly, then, there are the master who hunts the country at his own expense; the master of a pack which has so large a subscription that the hounds-as 


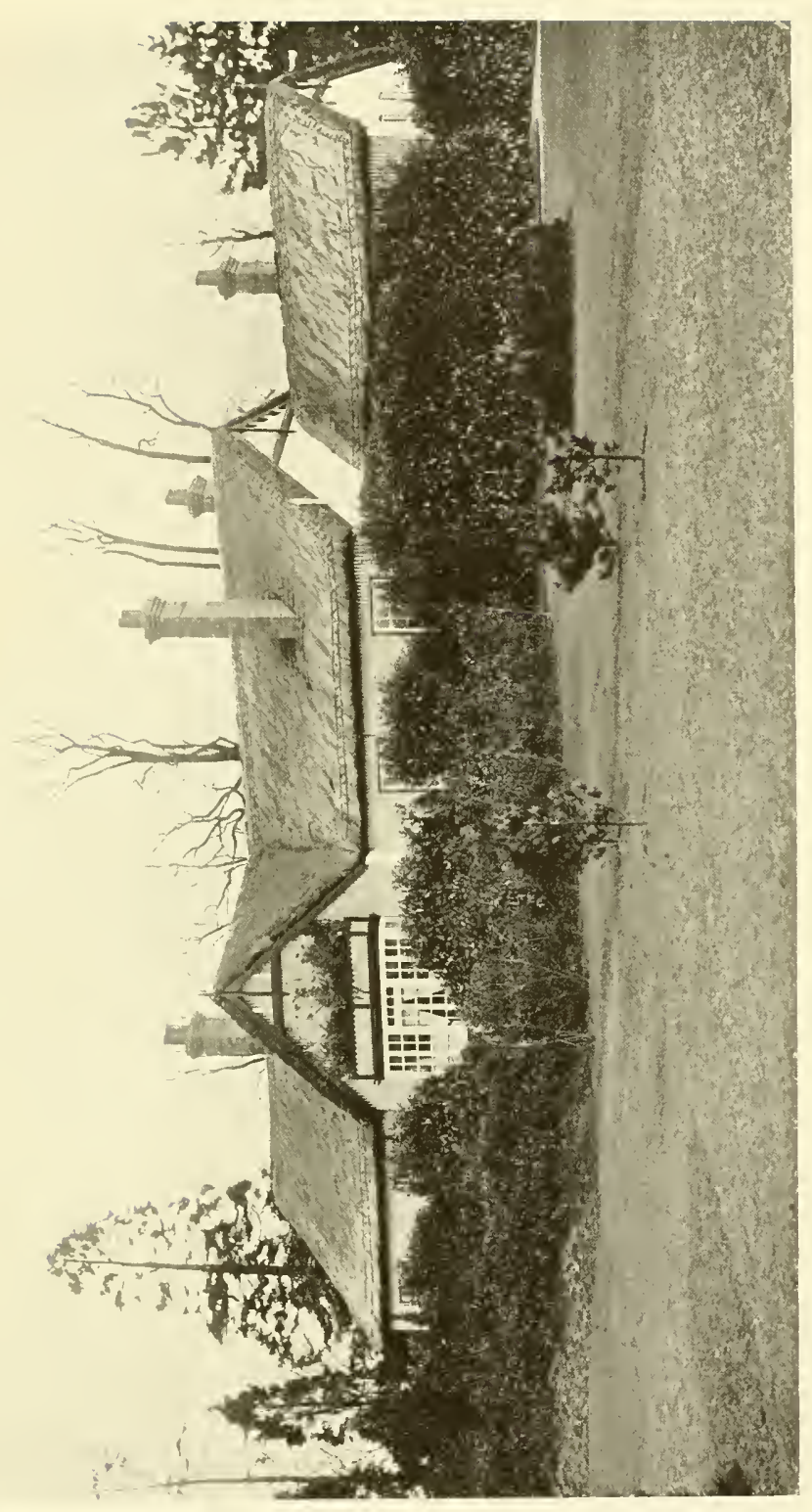

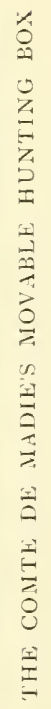



apart from his own hunting-should cost him nothing; and the master of a pack which is nominally a subscription pack, but where the difference between the subscription and the actual cost of maintenance is so great that a large sum must be forthcoming from the master's pocket. Then there are variations in the shape of masters who are their own huntsmen, and who are therefore not in a position to exercise all of the master's ordinary duties in the field.

There are hunting people who are of opinion that the position of each and every master should be the same, and that, whether a man receives a subscription or not, it is his duty to acquiesce in every suggestion made by an important member of the field. There are those, too, who appear to think that they have almost a right to dictate which coverts should or should not be drawn on a certain day, who are angry if they arrive late at the meet and find that hounds have moved off, who often interfere if hounds are taken late in the afternoon to a covert which is not on their way home, and who, indeed, from the beginning to the end of the season try to fix their will upon the master, instead of allowing him to make his own arrangements.

Such men, sometimes territorial magnates, are to be found in many hunts, and it is with such men that the master of the average subscription pack is often placed in a most difficult position. There is a very old saying to the effect that he who pays the piper may call the tune, and the man who hunts a country at his own expense is, as a general rule, allowed far more of his own way than the master of a subscription pack. But hunting men generally should understand that the master of hounds is in the same position as the captain of a ship, and whatever programme he chooses to adopt 
should be at once acquiesced in by the full strength of the field. A master receiving a big subscription is just as much a master as the man who does not receive a penny piece, and whilst he is in office his word should be law. It is true that at times men have been made masters of subscription packs who were unfitted for the position, but where there is a big subscription there is always a committee, and when members of a hunt are dissatisfied with their master he must only be approached through the committee. To interfere with the master in the field is just as much mutiny as when sailors refuse to obey their captain, and too strong emphasis cannot be laid upon the point.

At the same time it is undoubtedly the case that the master of a subscription pack will further his own interests by finding out, when he can, the wishes of his field as to the days of drawing certain coverts, and by meeting these wishes as far as possible. And it may safely be said that this line of conduct is pursued by ninety-nine masters out of a hundred all over the kingdom. At times, of course, the wishes of one man must clash with those of another, and the master will have to decide between them, but in the case of a new master of a subscription pack, when it is found that he is hunting the country fairly, he ought not to have much trouble in this respect, and when he has he must rely upon his tact alone. What is certain in these days is that every country must be hunted fairly, hounds being taken into every part of it at regular intervals. There must be no shirking of what are considered the worst parts of any country, unless the fox supply gives out, and there should not be too much requisitioning of the best country merely because it is the best. Coverts which are located in a central position will naturally 
be drawn much oftener than those which are on the borders of the hunt, but a preconcerted plan of action, providing for all coverts being drawn regularly, is of paramount importance from the master's point of view, and the members of the hunt should always back up a master who determines to work the country on methodical lines.

It is easy enough to write what should and what should not be done in the matter of giving each and every part of a country its fair share of hunting, but in these days it is not always such a simple affair as it appears to be, and much depends upon ancient custom, upon local surroundings, and upon the covert owners and masters. In old days the covert owners were all sportsmen; many were hunting men, and those who did not follow hounds were interested in the sport, and were perfectly willing that all the arrangements with regard to drawing the coverts could safely be left to the master of hounds. That gentleman, then, worked the country on a fixed plan, and it was only when exceptional circumstances occurred that a change in the regular routine took place. Hounds were in one portion of the country on one day of the week, and in another district on another day, and so forth. If the country was a large one with a four-days-a-week pack, it was apportioned into quarters, and hounds were taken into each quarter in turn. If a two-days-a-week hunt it was divided, and if hunting took place on three days hounds would probably have one day in either end, and a third in the centre of the country. That was the general idea, and the same plan is adopted in these days when the master has a free hand. But unfortunately the free hand is often wanting, and not 
long ago we heard a master of hounds complain that "the whole of his Tuesday country was closed until the end of November." This gentleman hunted a large country four days a week, and not wishing to disappoint the members of his field he kept to his regular days, but of course had much difficulty in fixing his meets, and more difficulty still when he tried to arrange his draw.

And we have good reason to believe that during the cub-hunting period, and much later, many masters have similar trouble to that we have just narrated, and are, in point of fact, at their wits' end to find suitable coverts open to them in the early part of the season. This, too, is much the most important time as regards coverts, for the simple reason that foxes, after the harvest is gathered in, do not lie out in such numbers as they do in the spring of the year. Where mustard is grown cubs will often be found after the corn harvest is over, but during the autumn months a huge majority of foxes are in the coverts, and thus from the hunting point of view the coverts are a greater necessity then than they are towards the end of the season-when foxes are found in the hedgerows, on bare fallow fields, or in any rough and secluded shelter, however small it may be.

It is also to be borne in mind that in most countries there are coverts which afford good lying for foxes in the autumn, but which are practically useless after there has been a severe frost, or a heavy fall of snow. Bracken, for example, makes good covert as long as it is standing, but a fall of snow or a few degrees of frost will level it to the ground, and when that takes place foxes will leave it at once. We have had some experience of coverts where bracken is almost the 
only undergrowth, and we have often heard hunting men express the opinion that foxes do not like bracken; but we do not agree with this idea, and can think of many large woodlands where bracken abounds, and where foxes have always been numerous. Most of our readers will probably remember the "Pinch Me Near Forest" of Handley Cross, in which Mr. Jorrocks and James Pigg were so often beaten by the "old Customer." Well, Chopwell Wood in the county of Durham-planted to grow navy timber more than a hundred years ago-is the original of "Pinch $\mathrm{Me}$ Near," and there the stunted oaks mentioned in Surtees' narrative may still be seen, very little larger than they were when the famous novelist lived a couple of miles away at Hamsterley Hall. The wood has always been a stronghold of foxes, and throughout its twelve hundred acres bracken is practically the only covert. In autumn it generally holds-or did until collieries were established on its borders-two or three litters of cubs, and up to Christmas certain parts of it were sure finds, but occasionally in the spring the foxes forsook it altogether, the bracken being by that time level with the ground.

When a new master takes a country he will, if he is a stranger, as a matter of course, consult leading members of the hunt as to how the country has been hunted, and find out all he can about the various arrangements as to drawing all the coverts in turn. He may then discover that whereas certain coverts have been drawn almost every week throughout the season, others have been greatly neglected, and some perhaps only drawn once or twice in as many seasons. He will be doing well by the sport if he then suggests that these possibly outof-the-way, and most probably unpopular places 
should receive a little more attention; and though it is possible that such views may meet with some opposition, it is quite certain that they are strictly correct. Unless foxes are regularly hunted, and a fair proportion killed in the poor-or what are considered poorparts of the country, there is sure to be an outcry on the part of some one, and it is bad for any hunt when it is talked about slightingly-say at the local market ordinary, or amongst the non-hunting population.

Many countries are greatly varied in their constitution, having vale, hills, woodlands, and perhaps even moorlands within their confines, and when this is the case the riding will be better in some districts than it is in others. But to neglect the bad country for the good is a great mistake, because it is unfair, and likely to lead to trouble. Farmers living in the best part of an average country have sometimes cause for the complaint that hounds are never off their land, and farmers, gamekeepers, and others who live in country which is included in a hunt, but to which hounds are seldom taken, are at times inclined to consider that because hounds visit them so seldom they are at liberty to kill foxes on their own account.

This view we have heard given out publicly by a tenant farmer at a puppy show luncheon. He simply stated that in his neighbourhood it was impossible to keep a good supply of foxes because some of his neighbours put them down, and he went on to say that this putting down was due to two facts, firstly that hounds did not come often enough, and secondly that when they did come they seldom killed a fox. The farmer who spoke was a hunting man, and the position was a peculiar one; for not only was the bit of country an outlying corner, very remote from the kennels, but 


\section{.}

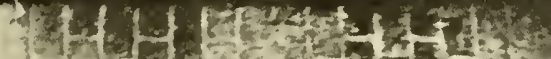

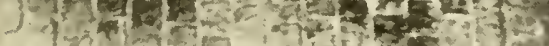

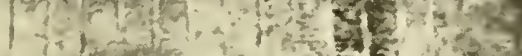

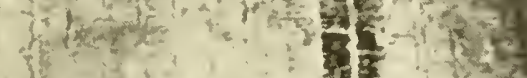
1. 1 tos

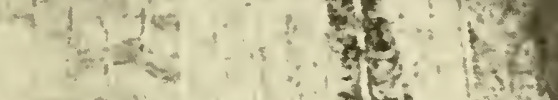

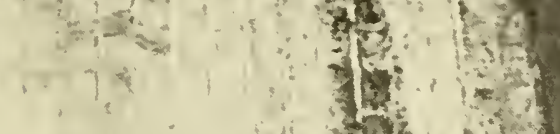
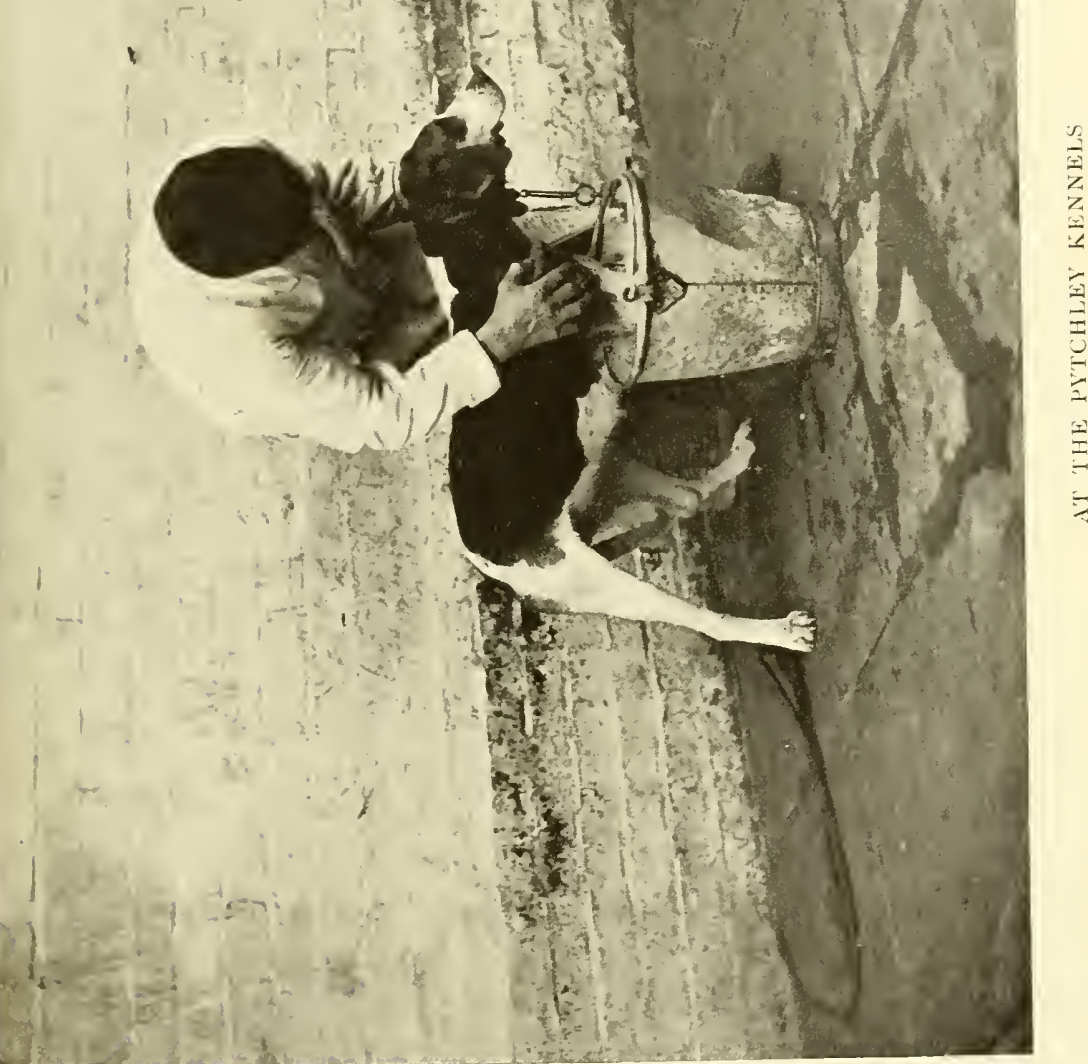

whenever the master suggested meeting there there was an outcry on the part of his field, and then, though he was most anxious to hunt the whole of his country fairly, his efforts were in a great measure checked.

That hounds did not kill often when they did go there was due to the fact that they always were a long time in finding a fox, and that there was absolutely no stopping done in the district. The upshot was that nearly every fox they found slipped into an open drain, or an earth, and of course the sport suffered, while the reputation of the district became, from a hunting point of view, worse than ever. This puppy luncheon speech, however, put the master on his mettle. He at once rode over, interviewed tenant farmers and gamekeepers (the whole district was owned by a non-resident landlord, and the shooting was in the hands of the farmers, or sublet by them in small lots), found out as far as he could what foxes were on the ground, and then told his field that he intended going there one day in every three weeks. This he did for some time, finding improved sport, and killing a fox or two-he had, of course, attended to the stopping, which though still indifferent had much improved-but still only a friend or two went with him on hunting days. After a while some of the field discovered that the master was in the habit of drawing a place or two on the way home which were in better country, and rumours of a fine afternoon gallop were voiced about. The result was that the next time hounds were advertised for the unpopular country about half the usual field rode out in the afternoon, on the chance of finding hounds in the better country. Many of them arrived in the neighbourhood of the covert from which the reported good run had taken place about two o'clock, and waited there. They did not 
venture further away, as they had no idea where hounds were, but just when they were thinking of going home a beaten fox came towards them with hounds close at him, which a moment later was killed in the covert fence. The master and two or three friends quickly appeared, and then it transpired that hounds had been running continuously for three hours in a wild, if rough, country, and that in fact the hunt had been an exceptionally good one, and had included an eightmile point.

It is needless to say that after this the long trot to the hitherto boycotted place was ignored, and to this day the district in question is yielding its fair share of sport. In another hunt there are many coverts along the banks of a river, a chain of woods, in fact, which are not very far apart, and sloping ground behind, with capital galloping country beyond. Foxes have always been numerous in these riverside coverts, but very often they stick to the low-lying land, taking hounds along the chain, or a part of it, again and again, and never going into the good country. At one time it was almost the fashion in the hunt for the field to remain on the high ground above, or to ignore the riverside meets altogether, but there came days, not so very far apart, when foxes made straight for the good country, and made long points, with few there to see what hounds were doing. Since that time the attendances at these meets have greatly increased, and though there are still days of riverside hunting at times, the occasional good thing is also forthcoming.

Not so long ago a master told us that during his long spell of office he thought he had actually seen the best runs from what were generally considered to be bad places. He said the good things did not come so often 
from these places as they did in the better country, and he was strongly inclined to think that the good runs from bad places were caused by the fact that when scent was really first rate, and he found a fox in a wildish country, where there was no one to head it, and only a small following, both fox and hounds had a better chance.

And as regards the bad places, or places of bad reputation in any hunt, it must be remembered that on some few days of each season scent is first rate. On some small number of days hounds fly when a fox is before them; on a fair number of days they hunt at a steady holding pace; and on many other days they can hardly own a line. Well, it is just as likely that one of these exceptional scenting days may be forthcoming when the unpopular meet is due, and then it happens that those who stay away because they dislike the covert, and do not like the surrounding country, may easily miss the run of the season. Many readers of Surtees' works will remember that in Hawbuck Grange $\mathrm{Mr}$. Neville's hounds had a great run from the Chase, and how "great Major Rasher, with a mouthful of moustache," tried to explain on the mess table by the aid of spoons, forks, and plates that such a thing was impossible.

One of the longest and best hunts we ever saw took place from a covert which had a bad name. It was in the Ledbury country, during the mastership of $\mathrm{Mr}$. Charles Morrell, and was after a long frost. Hounds were advertised for this big wood, on the first open day, and at that time the covert in question had so moderate a reputation that there was invariably a small field when hounds met there. Memory, or rather want of memory, will not allow of the name of the wood being given, but 
it was some four or five miles from Ledbury, and on the occasion referred to only about six or seven riders turned up. It was soft enough in the big covert, and as foxes generally preferred to stick to their native place hounds were allowed to draw. This time they almost at once found a travelling fox, who took them into the North Hereford country, passing by a covert named (if memory serves) Cowarne Gorse. We then turned southwards, and ran to Stoke Edith, and here we think Mr. Morrell tried to stop hounds, as they were a long way from home (by this time in the South Hereford country), but there was a great scent, and hounds got away from Stoke Edith and ran to Holme Lacey, on the banks of the Wye, where they killed their fox at dusk. This was the run of the season, probably of many seasons in that country, and we only remember that Mr. Morrell, the late Dr. Sheward, of Malvern Wells, and a Mr. Mason - who was then agent for Lady Emily Foley at Stoke Edith-lasted on to the end, and so long ago is it that we are not actually clear as to the particulars. The hunt, however, may be quoted as a striking instance of the good run from what was considered a bad place, and in this connection mention of it is not out of place.

Then, again, it may be stated with confidence that if a master hunts a country impartially he will be a gainer in the end. He may at times have to break through his rules, but the fact that he is acting fairly by good and bad parts alike will be quickly recognised and appreciated, and he will find that fox preservation and stopping are better looked after when the country is being hunted on a regular system. There is nothing so bad for any country as the absence of a system. The average member of every hunt should be able to guess 
with a fair amount of certainty where the meets for the following week will be, or if not the actual places of meeting, the coverts which are likely to be drawn. In one country lately it amused two or three of us to write down an anticipation of the meets in two countries a week in advance. In one of these the master was methodical and scrupulously fair, and knowing something of his scheme of hunting the country we could guess correctly about two meets out of every three, while the third was generally quite close to the place we had decided upon, and practically meant the same country. In the other case the master was guided by no sort of plan except (probably) the inclination of the moment. To anticipate his fixtures was pure guesswork, and to anticipate his draw when those fixtures were reached was simply impossible.

There should be-and is in many hunts-as much method in the arrangement of the draw as in the rotation of meets. Good and bad coverts alike must be drawn, if possible, at regular intervals, and the careful master duly considers, and maps out in his mind, each draw before he goes out. It may be that on arrival at the meet he is asked to draw some covert that he has not intended to go to, and that he cannot well refuse the invitation, but if he is a man of method he will tackle his originally intended draw as soon as he is at liberty -unless, indeed, hounds have taken him into another country. Last winter we were hunting with a provincial pack, and one day the first covert entered held a fox which took hounds steadily on at a holding pace for over an hour. Then, owing to a curious declivity in the ground, and the shoulder of a hill, hounds were lost altogether, but shortly afterwards their line was found, and we all followed on a long way behind. At 
length hounds were reached, marking at an earth on an open common, where the fox was left. Where to draw next was the question, and when the master considered the matter he found he was twelve miles from the covert he had second on his mental list, and ten from any covert in his intended draw. Luckily a second fox, and as it happened a good one, was forthcoming close by, where, curiously enough, a large head of breeding earths was open; but the case has only been quoted in order to show that it is not always possible for the most exact of masters to conform to his prearranged programme.

On the other hand we have known a master, at three o'clock on a late November afternoon, announce his intention of going back to the country he had just run from, to draw a certain covert, which in his mind he had mapped out as part of the draw. It was just six miles from where a fox had been killed, and further away from kennels, but master and staff had fresh horses, and so with two or three enthusiasts they cantered off, hounds being taken by short cuts at far beyond the usual covert-to-covert pace. Conformity to original ideas was well rewarded in this case, for hounds found at once, and had a pretty halfhour, killing their fox when there was just light enough to carry out the breaking-up process.

When the master is really master and has the support of his field the business of the draw is entirely his, and no one thinks of putting his oar in with suggestions. It may, however, happen that-especially in the afternoon-it is immaterial to him whether he goes to one of two, three, or perhaps even more coverts. All may be at about equal distance, and all may be about equal as to the number of times they have been 
drawn. A consultation with the field in such a case does good rather than harm, for members of the hunt will see that the master is anxious to oblige the greatest number, and will also recognise his feelings in the matter, viz. that it is of little or no consequence to the workings of the hunt which of these three or four coverts should be drawn.

The vacillating master, who comes to the meet in the morning with no fixed idea in his mind as to which coverts he intends to draw, is always unsatisfactory, and more likely to annoy his field and the covert owners near his place of meeting than not. It is often the case that a meet of hounds is fixed in a village, or at crossroads where numerous coverts are equidistant, and when the master of undecided views arrives at one of these places he is likely to go to the first covert which he hears mentioned at the meet, quite regardless of whether it is the proper place to go to, and whether his drawing it first will be approved by his field.

Then, too, if the master is known to be lacking in decision, and unlikely to have formulated any fixed plan of campaign, he is sure to be asked to go to two or three, or possibly even more different places, and at such times people will make the most unreasonable demands. Some masters are, like Mr. Puffington, entirely in the hands of their huntsmen with regard to the draw, and when the master has been an undecided man, and the huntsman has been gifted with sound common sense, this has been found to answer well; but the master who leaves such matters to others is not fit to be a master, and the master who relies upon his huntsman for everything is in similar case, and should resign at the earliest opportunity.

There are not many hunt servants who are fit to be 
trusted with all the arrangements which must be made in order that a country may be satisfactorily hunted, though if a master is unable to be present he can as a rule entrust his huntsman with his plans and ideas for the day. In that case he should request his man to communicate with the field master (if there is one) at the meet, and if there is no field master, with some important member of the hunt, whose adoption of the post of temporary master will be approved by the field. It is never wise to leave everything to the huntsman, unless it is quite certain that that functionary will state his intentions at the meet, informing the field at the same time that he is enunciating his master's orders with regard to the draw. When this is done every one will be satisfied, but if the huntsman deviates from the original plan when there seems to be no necessity for such deviation he will certainly hear of it again, for there are always people who think they have a grievance, and who will not let such an occasion pass without interfering.

If it is thought advisable by the master to appoint some one to take command, if only for a single day, he must, as far as he possibly can, get hold of the right man, and never must he delegate the duties to more than one man. An instance of a divided authority we witnessed many years ago, which almost resulted in the loss of a good huntsman, and we have never forgotten it. It was with a county subscription pack of which there were joint masters, one acting as master in the northern and the other in the southern part of the country. On the day in question only one of the masters was present at the meet, and he was an elderly man and in very moderate health. Hounds were put into covert close to the place of meeting, and 


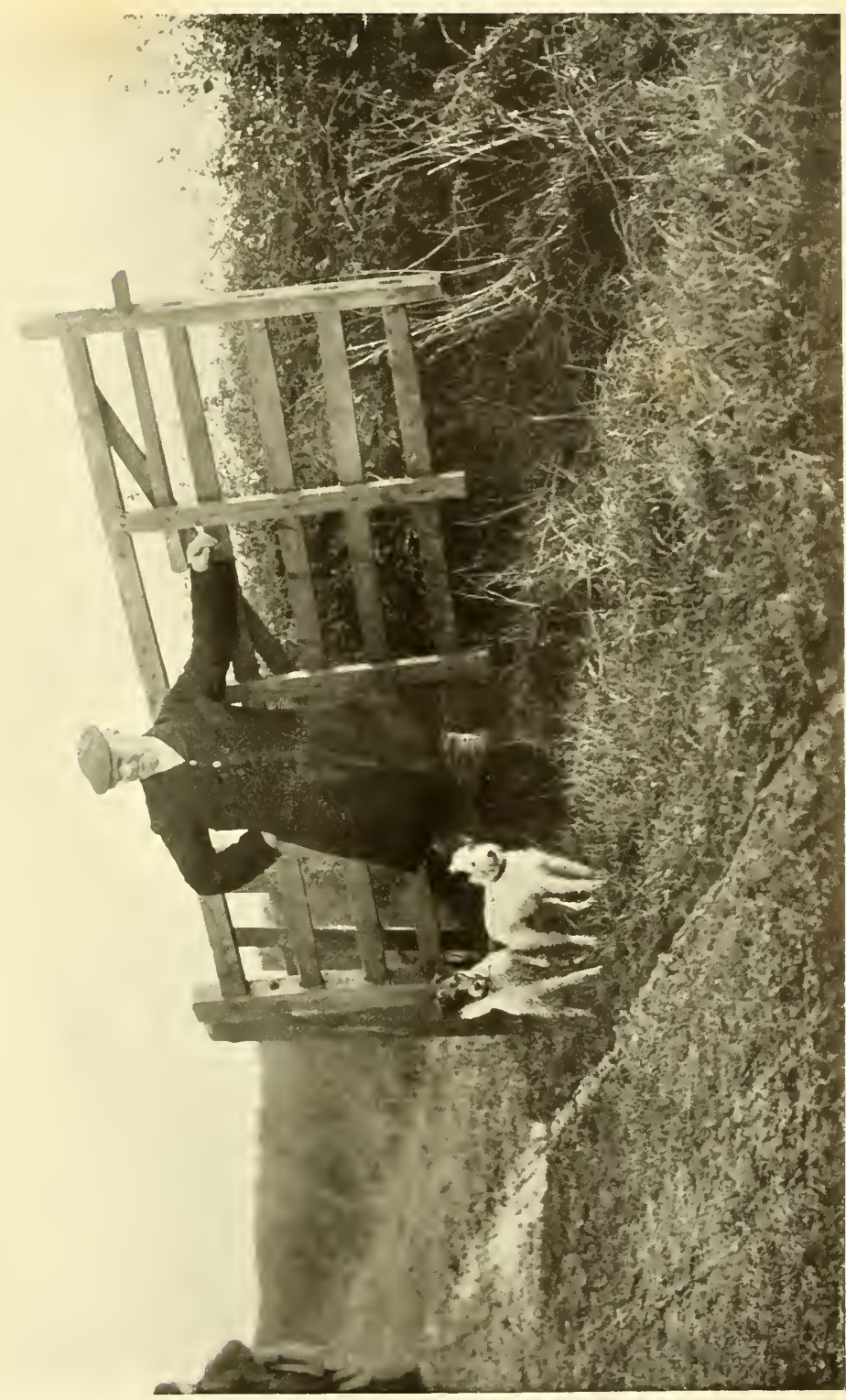

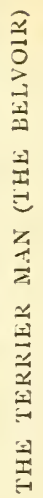



before they had drawn it the master felt chilled and decided to go home; in fact, he never left the place of meeting, and was out of sight when hounds came out of covert, and had not asked any one to take his place for the day. Well, as it happened, there were three magnates of the hunt who owned coverts in the neighbourhood of the first place drawn. One of these men, realising what had happened, caught the huntsman as he called hounds out and told him that the master had gone home, and that he was to go to his (the magnate's) place, which was nearly three miles off.

Now there were other coverts, quite as good and much nearer, and when magnates two and three found out what was being done, they each suggested their own coverts as the best draw. Meantime huntsman, hounds, and whippers-in stood in the road, the huntsman merely observing, "Settle it amongst yourselves, gentlemen, and then tell me where I am to go." The three, however, argued the matter, and the argument gradually worked up into a quarrel. Other members of the hunt were appealed to, but declined to interfere, and at length one of the quarrelling trio peremptorily ordered the huntsman to go to the covert which he had suggested. The owner of this covert was a pillar of the hunt, a liberal subscriber, a committee man, and a keen sportsman, but was also a domineering man and not personally popular. His command was promptly capped by similar loud-voiced commands by each of the other parties to the quarrel, and thus the huntsman was placed on the horns of a dilemma. He, good, honest soul, tried to calm matters down, and suggested that lots should be drawn; but all the trio had fairly lost their tempers by this time, and the 
huntsman was abused by two of the men for not obeying orders. He (the liuntsman) was an elderly man, mild in character, and most unwilling to give offence. But he could not stop the quarrel, and at last he fairly broke down, and leaving hounds with the whippers-in rode homewards to send in his resignation.

Matters were now at a deadlock, but a deus ex machina appeared in the person of a fourth covert owner, a much younger man than the three who had been quarrelling, but quite as important a member of the hunt. When this gentleman had been told what had taken place, he signalled to the whippers-in, who followed him with hounds until they overtook the old huntsman on his way back to kennels. He was quickly cheered up by the new-comer, who kept pressing on until a likely covert was reached. As it happened, the country was full of foxes, and a quick find caused the scene of half an hour before to be forgotten-for the moment at all events. Only one of the three disputants had come on, the two others having gone home in dudgeon, but certainly two of the three wrote ample apologies to the master and also apologised to the huntsman, and possibly the third did likewise, but it is so long ago that the details are difficult to remember.

The story, however, illustrates the suggestion that a divided authority in the hunting field cannot possibly be maintained. If there are joint masters, they have, of course, a mutual understanding. One hunts hounds and the other takes charge of the field, or if a professional huntsman is employed they divide the master's duties in some other fashion. Perhaps the country is a large one, hounds being out on four days of the week, and in that case joint masters will indi- 
vidually undertake the two divisions of the country, each making a point of attending on his particular days, and notifying his co-master if he is unable to hunt. A joint mastership where one master attended to hounds, horses, and all kennel matters, while his partner took charge in the field, has also been known; and, again, a joint mastership has been heard of where one man attended to everything, both at the kennels and in the field, while the other supplied a large part of the sinews of war and hunted occasionally.

And now a very important point comes up, viz. the question of a field master, and this question is every day a more serious one. Time was when the master's duties in an ordinary field were very simple, consisting in the main of instructing his huntsman where he had to draw. In the average provincial country, when the same men were hunting day after day, a regular routine in the matter of drawing coverts was generally observed. The field knew exactly where to place themselves, and the master was fully aware that the regular order of procedure would be carried out, and that in ninety-nine cases out of a hundred there was little chance of a fox being headed by some member of the field who was in the wrong place. If strangers appeared, they, naturally enough, remained with the crowd, and if they knew no one there was always some one to give them a welcome, and put them up to what was going forward.

The master could therefore go into covert with his hounds or remain with his friends, as he liked. He knew that the discipline of the hunt was such that, unless something exceptional occurred, everything would be done in order, and that, in fact, there was only a remote chance of things going wrong. If he 
was unable to be present, he was in the habit of delegating his official duties to some important member of the hunt, and, to put the case briefly, his duties in the actual hunting field were often the least important and most easily achieved of all the responsibilities of the mastership.

But in these days matters are very different in a great number of the most important countries. There are some out-of-the-way, provincial hunts in which there has been little change, and where things are carried on much as they were a generation or two ago. But these hunts are now few and far between, and are very quickly disappearing altogether. The multiplication of railways, the increase in the population, the extension of the provincial, and even the small country towns, to say nothing of the many comparatively new industrial districts which have of late years come into being, have greatly altered the face of the country generally, and only in the wildest parts has there been little increase in the size of the fields, or alteration in the conditions under which hunting is carried on.

It must be understood, then, that in discussing the lines of conduct pursued by the average master and the average field, the remote country hunts are not being taken greatly into consideration. As a matter of course many lines of conduct must apply to foxhunting generally, but what we are about to say is called forth by the altered conditions of the sport, which have to a great extent involved altered relations between the master and his field, and have, in many countries, caused the office of master to be a more difficult task than it formerly was.

And as regards change it may safely be said that in 
the Shires and their immediate neighbourhood the conditions are constantly changing, while "fields" come and go much more frequently than they did. And this applies, but perhaps in a smaller degree, to all the good and fair provincial countries where the number of people hunting has increased even more than it has in the Midlands. In the earlier days of the sport hunting was, to a very great extent, confined to men and women who spent all their lives in the country, to country-bred people, and to a few enthusiasts, like Mr. Jorrocks, who, though town bred, were so liberally endowed with the bump of "foxhuntitiveness" that they could not be kept from it. Now the average hunting field is composed of men and women, of whom perhaps almost a majority have taken to the sport long after years of discretion have been reached, while it is only a minority-and often a small one-that were bred up to hunting, and have been thoroughly intimate with all its peculiarities since the days of their childhood.

Not so long ago nine hunting men out of ten, and nearly all the women who hunted had done so almost from childhood. Many of them had begun as soon as they were old enough to sit on a pony, and throughout their boyhood had seen hounds regularly enough at holiday times. It stood to reason, then, that they had during youth gained a certain amount of knowledge as to the sport itself, and also as to the manner in which it ought to be conducted. The average field when increased was increased by those who were not novices, but who had served an apprenticeship, and the average master was, as a rule, in no wise troubled when each new season brought a few recruits to the ranks of the regular supporters. 
But the times have changed all over the kingdom. Much of the land has changed hands; many of the old hunting families have disappeared, and probably the ranks of hunting farmers are far thinner than they once were. Yet in spite of this there has been a huge increase in the size of "fields," and as many of the new-comers commence their hunting in a happy state of ignorance as to how the sport is or should be conducted, it follows of necessity that the master's task is not always the simple one which it once was, and therefore that, when the master is not present, there should always be a field master. But most important of all is it that there should be a field master when the master is his own huntsman. In such cases it is almost imperative that the field should be placed under the charge of some responsible man. We have used the word almost advisedly, because we do know of a country, in which fields vary from fifty to a hundred riders, where the master carries the horn, where there is no field master, and yet where matters have worked perfectly smoothly for many years past. The case referred to is, however, in all probability an exceptional one, for though the hunt is a smart one, a huge majority of its members were broken to hunting in childhood, and the master has a certain peculiar individuality which seems to control his field when he is out of sight, with the result that riot or mischief among the riders is almost unknown.

And here it may be stated that when we write of many of the new-comers to a hunting field being ignorant as to the sport they are attempting we have no desire or any intention of being invidious. We are merely stating a fact about which there can be no dispute. If a man or a woman takes to hunting after 
he or she is of mature years it stands to reason that he or she can know little of the sport. Hunting literature and general theories in connection with hunting matters may have been carefully studied, but until there has been a considerable amount of real experience knowledge must be strictly limited. And moreover people vary greatly in their power of assimilating knowledge of this description. To one man there may be an inherited knowledge of woodcraft, a mind capable of taking in all the ins and outs of hunting with great rapidity, a bump of locality, and, in fact, all the essential qualities which will enable him to know as much at the end of his first season as another man can hardly attain in his lifetime.

There is perhaps nothing more curious in connection with hunting than this varied capability for understanding it. Two men may be equally imbued with a love of the sport, and while one of them gains some fresh knowledge on almost every hunting day of his life, the other will very gradually arrive at a small amount of knowledge, which will be perhaps just sufficient to prevent him from making a fool of himself. Both may be equally enthusiastic, but one has the capability of receiving and storing up impressions, while the other plods along, no doubt enjoying himself as much as his neighbour, but gathering no knowledge by the way, and in fact, after a certain time, not benefiting in the least by his experience.

Some men become weatherwise; others are always vague and uncertain, and will go to a meet when it is far too hard to hunt, and stay at home on a doubtful day. The weatherwise man will always know when the ground is fit and when it is not, and he will also know to a nicety what the master's views are likely to 
be in similar case. If he knows that the master is careless and indifferent about a slight fall of snow or a few degrees of frost he will turn out on most unsuitable mornings, while if he knows that the master is extremely cautious it is good odds that he will be able to anticipate the master's decision when there is just a doubt about hunting. But the man who hunts with the ears and eyes of his understanding partially closed will be drawn to the stables and trot on to the meet if the sun is shining and there is no snow on the ground, quite oblivious of the fact that there has been a dozen degrees of frost overnight.

Again, the knowing man will know the shortest way to a meet, and the best way home from wherever hounds leave off, while the slow-witted one is never sure of his road in the morning, and often quite at a loss to know where he is when the sport of the day is over.

We have slightly deviated from the point at issue, for in truth it is of little consequence to a master of hounds whether individual members of his field are quick or slow to learn the ins and outs of the sport. What is certain is that in the average hunting field there are many men and women who were not brought up to hunting, and that, no matter how sharp a small minority of these may be, the rank and file take more looking after than did the members of any particular hunt-say fifty years ago. The master's duties are therefore more formidable than they once were, because of the twofold combination of a larger and a more ignorant field. The increased numbers tend to the field being much more scattered than it ought to be, and the ignorance chiefly takes the form of pressing to the front at wrong times, and is most certainly the greatest difficulty which the modern master of hounds has to contend with. 
It is in many countries absolutely imperative that the field should be massed together when certain small coverts are drawn, but nowadays there are many people hunting who will not, or cannot, see the importance of this point; and thus it often happens that when hounds leave a meet to draw a certain covert, certain people will go to the covert by some pet way of their own, instead of following on behind hounds. Others, again, will dawdle at the meet, or arrive late, and, following on, find the field drawn up in one place, in reaching which they stand a fair chance of heading a fox. Later in the day, too, when a morning of sport has been got through, the careless ones will wander all over the country, and even when going home will often succeed in getting where they are at all events likely to head a fox.

This sort of thing frequently occurs, whereas it was practically unknown when foxhunting was followed with a greater general knowledge than now exists. To give an example of what we mean, one day last season a certain pack of hounds hunted a fox most of the morning at a slow pace, and finally killed him about two o'clock. Only one covert had been drawn, and hounds were some five miles from the gorse which was next on the list. The master decided to go to this gorse, and after the obsequies were over the order was given, and about half of the field sought the high road to begin their homeward journey, while hounds and the rest of the field proceeded towards the gorse by an occupation road.

Half an hour's quick trotting, and the gorse was in full view on the slope of a hill nearly a mile away, but glimpses of scarlet were also in view, and it was plain enough that some of the field who had been left behind 
in the earlier hunt had gone there. The master sent a second horseman to clear them away, but the mischief had been done, for on the evidence of a man who was ploughing quite a number of people had been laughing and talking round the small covert for half an hour, and a fox had stolen away.

At two or three fields' distance there was another small gorse, and after the first of these two coverts had been drawn blank hounds spoke to the line of the fox which had stolen away on the grass, and gradually took it towards the second covert. But, alas! the high road was close to the boundary of this covert, and as the fox tried to break he was headed by various small groups of riders, who were going home from the kill of nearly an hour before, and dodging back into shelter was quickly chopped. And even as it was he might have succeeded in crossing the road and giving a run, but he had been holloaed the moment he was seen, and had turned tail at once. Not a single man or woman of the various parties who were going leisurely homewards had tried to get out of the way, or even to keep quiet, and when one or two of them were informed of the mischief they had caused, they really did not seem to see the heinousness of their offence. "We were going quietly home along the high road," they said, the niceties of the situation being entirely ignored.

Now we venture to say that such an incident as the one we have narrated would have been impossible a generation or two ago. In the first place, there would have been no wholesale breaking up of the field so early in the day. An odd man might have been obliged to go home for some reason or other, but it would have been against the grain, and as for the bulk of the field being satisfied with half a day, such a thing would have 
been impossible. The odd man who had to go would, as a matter of course, have found out before he left where hounds were going to be taken, and would have himself taken the greatest trouble and gone a long way round rather than risk the chance of heading a fox. He would have considered the matter as he rode off, and such consideration would have been quite natural, but in these days a portion of nearly every large field is composed of what is often called the "air-and-exercise division," and many of these individuals hunt quite regularly without ever taking in the niceties of the sport.

Where the field is really well drilled there will be no straggling at the covert side, and when this happens the master's duties are perceptibly lessened, but some fields have to be driven into position like a flock of sheep, and even then, if a sharp look out is not kept, some riders will move away too soon, in order that they may poach a bit of start. But the manœuvring of the field at the covert side, though difficult enough at times, is child's play compared with the trouble which is brought about by the over-anxious ones when a fox breaks covert. It will perhaps hardly be believed, but it is by no means rare for some one to commence galloping after a fox long before a single hound is on its line, and when one man begins to gallop there are always many others to follow suit, many of whom have failed to grasp the real situation, and think that hounds must have got away unobserved.

Just fancy the feelings of a master who sees a fox literally chased by an irresponsible member of his field before a single hound has left covert. When a picture of this sort appeared in Punch some few years ago many hunting people laughed at it as an impossible 
state of affairs, but quite advisedly we repeat that it is a fairly common occurrence, and therefore only one more proof of how men go out hunting who have not the haziest idea of what may be called the rules of the game. We have heard a master who had had experience in three different countries, widely separated, and he told us that the fields he had to manage varied greatly as to their knowledge of the sport. He had found in the west of England most extraordinary backing, and a community where every one had great knowledge of hunting, and where, as far as the field were concerned, he never had a moment's uneasiness from the beginning to the end of the season. He told us of another country, where provincial townsmen formed a large part of the field, and the knowledge was neither widespread nor of the right kind. "They had no wish to do anything wrong," he observed, but many of them were in a hopeless state of ignorance, and required to be shouted at by some one in authority all day long. And he had more pleasant recollections of a big country within hail of London, where all the field manners were perfectly orthodox, where the damage bill was small, and where two hundred horsemen and women took less looking after than forty or fifty in his previous country.

But in these days the better the country is from a riding point of view, so much more difficult it is for the master to keep order. Where there is a big field of hard riders of both sexes, where there is good galloping ground, and where a majority of the fences are innocent of wire, and are standing there to be jumped, any and every master must have an infinity of trouble. Many men and women there are who offend by getting too far forward, and though some err in ignorance, 
others who do wrong must be fully aware of the enormity of what they are doing.

The wilful over-rider who habitually gets too far forward is the greatest pest which the modern master of hounds has to contend with. $\mathrm{He}$ is to be found in many countries, and when the field is really large he is often present in considerable numbers. He is often a fine horseman, or at all events a bold one, and it seems to be his one idea that he should be first into and first out of every field, and that no one should head him between the fences. When there is a great scent and hounds can travel faster than horses these men are of course harmless as long as there is no falling off in the pace, but as all hunting people are aware the slowing down must come in time, and then it is that the over-rider becomes such a nuisance.

If hounds run into their fox at the end of a quick burst, well and good; but it more frequently happens that after a few minutes at top speed the pace slackens down a little. Perhaps the fox has turned abruptly after going through a fence; perhaps he has crossed a field where sheep are grazing which have foiled the line; perhaps an area of bad scenting ground has been reached, or hounds which have been running hard over grass have entered on a tract of ploughed land. Any of these alterations in the conditions of the hunt may cause a check, or if not an actual check, a decided change in the pace at which hounds have been travelling. The over-rider has probably been in front all the way, but he is not content with that, his chief idea now being to maintain his place as soon as hounds begin to run hard again. For that purpose he keeps pressing on, and if he does not see the master he is quickly too far forward, and in a position to force hounds beyond 
their noses. If there is really a check and a general pulling up he soon finds that others are now as well placed as he is, and when that happens he begins to edge away from the crowd, when he should be standing perfectly still. In the excitement of a run he apparently studies no one's feelings or desires but his own. His knowledge of hunting, his respect for the master are thrown to the winds, and he is governed for the time being with the one idea that he must beat every one.

But on a day of moderate scent when hounds can only run at times he does even more harm than on a good scenting day, for he is always too far forward, and will not give hounds a chance. On a really bad scenting day he may not think it worth his while to give an exhibition of his riding prowess, and when he has made up his mind to this course of action he is the most harmless of the field, spending his day amidst the rank and file of the crowd, and not attempting to go near hounds unless some unforeseen change in the conditions of hunting should occur.

There are, however, days when scent is not good, nor yet very bad; days on which great pace is maintained for three or four fields, with a total collapse immediately afterwards; days on which hounds start from covert time after time, on good terms with a fox, and yet come to a check in eight or ten minutes. On such occasions scent is best described as "catchy" ; brilliant for a few minutes, and then almost non-existent for a time. When this happens hounds will fly for the first few fields, and, if let alone, will do their best to work out the puzzle afterwards, but when there is a huge field and over-riders are prominent they have little chance of doing themselves justice, and in many countries it is the over-rider who is alone to blame, 
At the moment, however, our business is with the relations of the master to the over-rider, and it cannot be too gravely submitted that each and every master of hounds in the kingdom owes it as a duty, not only to himself and his field, but to the whole foxhunting community of the kingdom, to put down this most serious menace to the sport. In some countries over-riding has become so common a thing that on nearly every hunting day the sport suffers in some degree, while on others-those of catchy scent, no doubt-it is completely spoilt. Possibly some of our readers may think that our remarks take too gloomy a view of the subject, and where there is little or no over-riding it may indeed be difficult to conceive that want of discipline and insubordination are quite common in some hunting fields.

But we do not speak without the book, and have had for some years past an overwhelming mass of evidence on the subject-evidence gained at first hand through having witnessed serious over-riding and having noticed how the sport suffered in consequence, and evidence at second hand from many masters of hounds who have been victimised. And if the weekly accounts of sport which are published in the Field are regularly studied, no one can possibly help being aware of the frequent complaints which are made, more especially from the Midlands. Many of the correspondents, doubtless anxious to give no offence, and perhaps unwilling to paint the picture as dark as it really is, make references to what is almost a daily occurrence in terms that are very mild. We are told that "a check took place, for which possibly emulation among the first flight was in some degree responsible," or we read that " the pace dropped to slower hunting, and the master realising that an impetuous field was giving hounds 
very little chance of working the line out, decided to go to - " and then comes the name of some covert. At times certain writers have spoken out strongly, but there has always been a feeling that the over-riding in any particular hunt is a matter to be settled between the master and his field, and that outside interference is not required.

With this feeling we are greatly in accord, but we are writing of hunting generally, and with no particular country in our mind, and thus we realise that we are at full liberty to point out what a baneful thing this spoiling of sport is, when it is merely the outcome of jealousy or the result of a desire to show off. And if over-riders could only be brought to realise the true state of affairs, they would know that the men who gradually earn great reputations as fine riders to hounds are men who never offend the master and spoil the sport by riding too far forward. They would be aware that the quiet rider, who takes his own line, often wide of hounds, and always far enough away to be in no danger of doing harm, is the man who survives in all the long runs, who really sees most of the sport, and who is often in a position to give important knowledge to the huntsman at a check. They would also know that all their efforts in the over-riding line were noticed and loudly commented on by members of the field, and lastly they would know that so far from being thought heroes because they were often first over a big fence, they were in reality looked upon as unmitigated nuisances, whose presence was little desired by any of the self-respecting members of the hunt.

Another nuisance which the master has to contend with is the man who habitually creeps forward when 
hounds are drawing a covert, in order that he may secure an advantage if the covert holds a fox. Like the over-rider he, too, is to be found in many hunts, and very often he combines the two characters. But he is often a covert owner or local magnate, and if that should be the case his offence is a double one, because he must know that if he is not called to order it is very likely his worldly position which has saved him.

It is, of course, an understood thing that some licence is allowed with regard to certain individuals, especially when their own coverts are being drawn, and in a woodland country there is seldom any vital reason why the field should not be trusted to move on through a big covert when hounds are drawing. But in the open, when the coverts are small, the same does not hold good, and whatever the master's desires are, they should be implicitly adhered to. The master's great difficulty, both with the over-rider and the man who gets too far forward when hounds are drawing, is that when individuals are rated, they, as a general rule, apologise, and promise amendment if it is demanded. The master is thus disarmed, but the incorrigible offenders are always known, and when members of the field realise that any particular man is constantly giving trouble, they should support the master by adding their representations to his, and if these have no effect by showing their personal disapproval. The extreme course is to inform the field that if over-riding continues hounds will be taken home; but to announce this line of action and not to act on it when a flagrant case occurs shortly after the announcement is worse than nothing, because the offenders will look upon the threat as so much bluff, and will in no wise amend their conduct. 


\section{CHAPTER V}

\section{THE FIELD}

\section{SUBSCRIPTIONS}

T $\mathrm{N}$ a majority of the works which have been written on hunting the "field" has been little treated of, 1 and in the earlier days of the sport there was probably no necessity for any discussion concerning the crowd of men which followed hounds every day, and whose subscriptions, in nine hunts out of ten, kept the hunt on its legs. But in these days the field is a most important factor in the well-being of any hunt, and it must therefore be considered from various points of view.

In earlier times masters of hounds, and occasionally a few bigwigs of the district, managed a hunt much as they pleased, and whatever they did was, if not actually approved of, acquiesced in by the field as a matter of course. But various changes in the methods of conducting the business of a hunt, and the altered conditions under which country life is carried on, have brought out - in many, but not in all districts-a different state of affairs, and in point of fact fields have as a rule increased very largely everywhere, while subscriptions have been raised, and many hunts are no longer private affairs, but are really managed by a committee, the master's duties being confined to showing sport in the field and to directing matters at the kennels. 


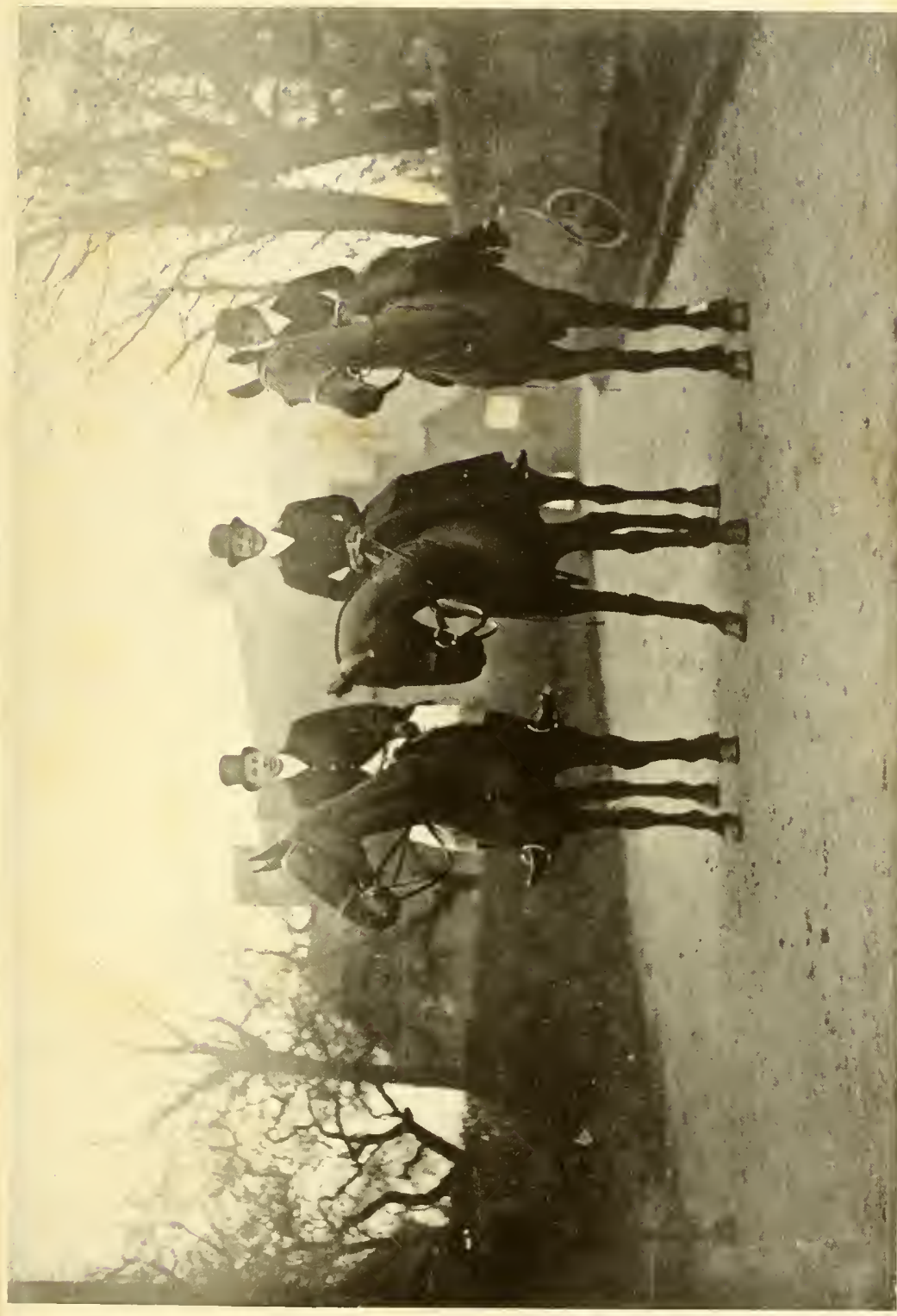

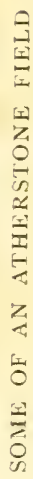



Many of the old family packs have become subscription packs, and nearly everywhere the list of subscribers has been increased numerically, so that even where the actual amount subscribed is no bigger than it was formerly, the number of subscribers of small amounts is far in excess of what it used to be. And when there is a large subscription to a pack of hounds there is generally a hunt committee, though where the subscription is small all matters relating to finance are often still left to the master and his secretary. And nowadays the matter of subscription is a most important one, because so many men make a point of hunting with more than one pack, while others like to change their quarters two or three times in a season.

In many hunts hard-and-fast rules with regard to subscription have been made. In some hunts there are minimum subscriptions, and these range from $£_{5}$ to $£ 40$, the lower sum being, in a moderate country where expenses are small, comparatively as high a sum as the $£ 40$ is in a crack hunt. Then, again, another plan is for subscribers to pay at the rate of $£ \mathrm{io}$ per horse, or at $£$ io per day, for each day of the week on which they hunt. Such plans as these work pretty well in many countries, but where the minimum subscription is large, local hunting folk of small means should always be allowed to contribute, according to their means, to the poultry or damage fund, and their subscription to one of these funds should be considered as conferring upon them as free a right to hunt as if they paid the minimum of $£ 30$ or $£ 40$.

There is always some tendency in these days to make every sort of field sport available for the rich only. In foxhunting there is, perhaps, less of this tendency than with regard to certain other sports, and it should always 
be remembered that when very hard-and-fast lines are drawn with regard to subscription some one must suffer badly. Hunting folk there are whose circumstances have caused them to come down to one day a week, when they had hunted on three or four days for perhaps half a lifetime. When this has occurred and a lower subscription has been offered it has generally been accepted, but cases have been known in which it was intimated that no one was expected to hunt who did not pay the minimum subscription, and this has had the effect of causing men to cease hunting altogether, or of moving into a country where matters were differently arranged.

There can be no greater mistake than to attempt to stop the one-day-a-week man, who is willing to subscribe $£$ Io, from hunting; £io probably means as much to him as $£$ Ioo to his rich neighbour, and were it in his power he would doubtless be out far oftener than he is. But it is abuse of the system of subscription which puts a hunt committee in a difficulty, for it is a fact that many rich people pay far less than they ought to do, while a good many expect that if the head of a house subscribes, his subscription entitles not only himself, but his wife, grown-up sons and daughters, and a string of children to hunt as well. Sometimes a party of well on to a dozen will hunt from one house, man, wife, and half a dozen children, who, with second horses and grooms attendant on the children, make at least a dozen horses in the field. On the other hand there are houses from which the subscription is more varied-where the head of the house, his wife, and all sons and daughters above the school boy or girl stage subscribe individually, where foxes are well looked after, and puppies are regularly walked. Such 
establishments are a godsend to any hunt, and one can only wish that there were more of them scattered about the country. When a whole family are enthusiastic the amount of good they do in their own district is simply enormous. Their enthusiasm infects their neighbours, and many who are naturally inclined to be half-hearted about hunting matters are brought to take great interest, not only in the actual hunting, but in the affairs of the hunt, and to help it by all the means that lie in their power.

It is now generally understood that individual members of a family should subscribe to hounds after they have attained what are perhaps erroneously called years of discretion, and it is also generally agreed that ladies who hunt should subscribe almost as if they were men. With all due courtesy to the fair sex, it may be pointed out that in earlier days when hunting women were few and far between, and when each hunt contained only some two or three regular lady followers, their subscription was hardly looked for, though as a matter of fact a majority of those ladies who hunted regularly did subscribe. But the times have changed, and now there are often as many women as men to be seen during the early part of each hunting day, and if some of them go home early, the hard-bitten ones remain to the end of the proceedings. Many women have attendant grooms, too, and a great number of second horses (we are not writing of the Shires in particular, but of hunting generally), so that they form no small part of the field.

But in some countries ladies expect that their grooms shall be allowed to follow them wherever they go, and where the master is not disposed to object the custom is very regularly carried out. Some of these ladies' 
grooms are obliging enough, and will hold a gate for those coming behind them, or will assist any one at an emergency, but others are simply an unmitigated nuisance, as those who have suffered from the wild career of a galloping groom have often found out to their cost.

One season a whole field suffered from the pranks of a lady's groom, who came out day after day, in attendance on his mistress, mounted on the family brougham horse. The man had no manners, and the horse, though probably excellent in harness, was quite out of place in the hunting field. He was a great, strong, underbred brute with a will of his own (when out with hounds) and a mouth like iron. As soon as hounds found and an era of galloping set in, he took charge of his rider, and went very much where he liked. How he managed to escape the notice of the master was a mystery, but the field was nearly always large, and somehow the groom succeeded in keeping out of the master's way. The girl was "spoken to," but her ignorance of hunting was only equalled by her love of a gallop, and she merely replied that her father would not let her go out without a man, and that as no other man or horse was available she was obliged to bring the pair. That settled it as far as she was concerned.

And as regards ladies' subscriptions, we know that we are on delicate ground, but the fact is that in many countries some ladies who hunt just as many days as men do, do not pay at so high a rate, and seem to be quite unaware that they ought to do so. This has been pointed out to us, with the necessary proof of many lists of subscribers, and we have little hesitation in writing that, taking the country generally, the aver- 
age hunting woman pays half, or less than half, what the average hunting man does. But in this estimate one includes the many women who hunt on their father's, husband's, or brother's subscriptions, and this in some degree increases the average of those who hunt on their own subscription, and are independent of male belongings. If ladies were properly approached, if there was no mock modesty about asking for the full subscription-whatever it might be-there would probably be little difficulty in the matter, and the rank and file of ladies who hunt would pay as do some, in most hunts, who are more generous or more business-like than their sisters. There are ladies scattered about the country who are very large subscribers to hounds, and there are others who make a point of paying according to the regular scale of the hunt; but again there are others, as has been suggested, who do not pay their proper share, and yet participate in and enjoy the sport fully as much as the men.

Two other questions in the matter of hunt subscriptions are important, one of these being the difficulty with regard to people who subscribe well to one pack and wish to hunt occasionally with its neighbour. It is only since fields have become so large that this question has cropped up. Time was when the members of one hunt were welcome guests in the neighbouring country, but in many hunts this friendship has been to some extent discontinued, and in some places it is understood that hunting with the neighbouring pack, as a guest, will only be allowed once a month, or on two or three days of the season. The man who lives on the border line of two or more countries is, of course, in rather a quandary if he wishes to hunt with all the packs within his reach. If he should be a rich man his 
line of action is simple enough; he has merely got to subscribe to each of the packs he intends to visit, and then go where he likes.

But the man of moderate means who is located in a similar position had far better subscribe to and hunt with one particular pack, even if he sometimes has to go a dozen miles to covert, while the other pack is meeting only half the distance from his home. Broadly, it may be taken that the man who can afford to hunt two or three times a week is, or should be, in a position to subscribe to two packs. He may have two days a week with one and a third day with the other, and if (supposing there is no fixed subscription with either) he gives $£ 20$ to the pack he hunts twice a week with and $£$ Io to the other, he is doing the proper thing by both. We have in our mind the resident in a little country town where three hunts converge; he keeps three horses and hunts on an average seven days a fortnight, and he subscribes $£_{\mathrm{I} 5}$ to each of two packs and $£$ Io to the third (with which he hunts least), and can therefore pick and choose his meets; and when he told us this he went on to explain how he would double his subscription if it were not for "the litter of puppies he had out at walk." For a moment we did not understand the allusion, but when he explained that he had a boy at Haileybury, another at Clifton, a third at Cheltenham, and a "brace of young vixens" at a finishing academy at Brighton, we really understood him.

Another prominent question with regard to subscription is of quite recent origin, and not very easy of solution. It is what may be called the short-time subscription, and at present it has taken no very definite form, but we can see that it will be a matter for consideration in the very immediate future of many 
countries, and our knowledge is derived from the fact that during the last two or three years we have received a very great number of inquiries on the subject. What we have been constantly asked is whether in such and such a hunt it is allowable to subscribe pro rata for a month, six weeks, or even two or three months, without having to pull out the full yearly subscription.

Where capping is in vogue the solution of this difficulty is simple enough; the temporary visitor merely makes a point of paying the cap at the meet, and the matter is finished. But caps take a range of from 2s. 6d. to $£ 2$, and there are many who think that $£_{2}$ a day is too much to give, and would prefer some such arrangement as a fixed subscription for a month, two months, and so forth.

Where the minimum subscription is $£ 25$ and the cap $£ 2$ per day there is, of course, some discrepancy in the figures, because it would only take twelve cap payments to make up the annual subscription; but the fact is that the cap was not organised to meet the case of temporary visitors, but rather to rid the field of certain individuals who hunted regularly without subscribing to hounds. And if no great amount of money is collected where a cap is regularly taken, the moral effect of the innovation has been extraordinary. We have been told that in one important hunt the first year of capping brought in no more than $£ 50$, but that within a period of two years the subscription list had risen $£ \mathrm{I}$ 700, because all sorts of people had begun to subscribe for the first time.

It need hardly be stated that in every hunt there are many occasional hunting folk, people who come out regularly for two or three weeks, and then perhaps go abroad for the rest of the winter, or who have so much business to attend to that they can only find time for a few 
odd days' hunting in the course of the season. Many who are thus placed are, and always have been, first-rate subscribers, and in this connection it may be pointed out that in every hunt there are large subscribers who are seldom, if ever, seen out with hounds. But on the other hand there has always been a class of individual who has considered it fitting that he should hunt a little without paying a subscription. And in the case of the really poor man, who is occasionally given a mount, but is unable to keep hunters of his own, it is allowable that no subscription should be looked for, but the occasional sportsman who can, if he likes, but will not pay because he is not a very regular hunting man, should be made to pay, and so far as can be judged this can only be done by resorting to the capping system.

In many ways the capping system is not a pleasant one, but after it has been in practice for a week or two in any hunt it does not give much trouble, except in one or two exceptional places where fields are always large, and where strangers are frequent. In the average hunt, where capping has been instituted, rather to compel the subscriptions of residents who did not pay than to catch the stranger, there is little difficulty in the working arrangements, for, of course, the secretary knows every one personally, or at least by sight; but where there is a huge crowd to be inspected the attention of two or three individuals must be taken up, often when hounds are drawing the first covert, and we have known of an enthusiastic collector, who grieved over the fact that he had lost half a dozen runs in a month. "After that," he said, "I began to run cunning, and if I had not passed the whole crowd in review before hounds moved off, I waited until later in the morning, 
and I do not think I lost any sovereigns by waiting, while I certainly lost a lot of sport through remaining too long at the meets."

In these days the many who are desirous of hunting for short periods, and who are undecided where to go, can find out what subscription is required in nearly every hunt, because the amounts are very often published in Baily's Hunting Directory. Thus for those who hunt regularly the minimum subscription to the Quorn is $£ 40$, to the Pytchley $£_{25}$ (and a $£ 2$ cap for non-subscribers), to the Woodland Pytchley $£ 20$, and to Mr. Fernie's £25. Here we have the subscriptions to four of the six Shire packs, but the amounts required in the Belvoir and Cottesmore countries are not made public. Then in the Atherstone the minimum is $£ \mathrm{I} 5$, in the Warwickshire there is a $£ 2$ cap (landowners, farmers, and subscribers of $£$ io excepted), while in the North Warwickshire there is no minimum subscription, but a $£ 2$ cap is taken from non-subscribers. In the Meynell country a subscription of $£ 25$ qualifies for the hunt button, but smaller sums are taken, and in the Duke of Beaufort's country those who are not land or covert owners are expected to subscribe $£ 10$ per annum for every day per week they hunt. In the Essex country the minimum subscription is $£_{30}$, and no cap is taken; in the Garth Hunt $£ 1_{5}$, and a cap of $\mathcal{E} \mathrm{I}$ for non-subscribers; while in the Bicester country £Io per horse is expected of all visitors, but not from covert-owners or landowners. In the Blackmore Vale subscriptions are also governed by the number of horses kept, and the number of days on which subscribers hunt, and in the Burstow the minimum is $£_{25}$, with a $£ I$ cap to strangers, this being a very high subscription for a two-days-a-week pack, 
but fully warranted because of the extreme popularity of the hunt.

We have given enough instances to show what the average rate of subscription should be all over the kingdom, and on this point little further need be said. But secretaries of popular hunts should, perhaps, be prepared to take monthly subscriptions from chance visitors, unless, indeed, their fields are so large that they are obliged to discourage new-comers. Perhaps the Devon and Somerset Staghounds have best solved the visitor question, but their position is a unique one, for they have a succession of visitors throughout their season proper, and in point of fact the hunt is almost entirely maintained by the contributions of these visitors, who in August, September, and early October are to be seen out with the hounds in numbers which vary from one to beyond three hundred per day. Some of the regular visiting subscribers give largely, but the broad rule is that strangers should pay Ios. 6d. for each day's hunting, and as the hotel proprietors and others act as receivers to the hunt, it is a simple matter to pay at the fixed price.

\section{GENERAL EXPENSES}

Of all expenses to be incurred in hunting the subscription should rank with every hunting man and woman as the first and most important, for the subscription is in these times a far greater matter than it was years ago, owing to the greatly increased cost of maintaining a country. It may be that the kennel bill for keep of hounds has not greatly increased, though even on that score there is room for doubt, 
and one master was heard to say at a recent Rugby hound sale, that not only was his meal bill heavier every year, but that he was paying double the price for dead horses that he had done when he began his mastership a dozen years before.

Forage is not much higher than it was, but straw is often more expensive than formerly, and it costs far more to mount hunt servants well than it did a generation or two ago. Wages, too, have risen a little, and rates a great deal, and some kennels are now very highly rated indeed. But it is not so much a question of increased price of raw material which has caused the price of hunting to rise, but rather that a somewhat higher standard is maintained in nine hunts out of ten than was formerly the case. It need hardly be said that with all the really swagger packs-we dislike the adjective, but it is expressive-a very high standard has always been maintained, and a similar remark applies in a great degree to many of the best provincial packs; but if we look at hunting generally, we can think of dozens of countries where far more money is spent on the establishment than was once thought to be sufficient, and this extra expenditure is doubtless demanded.

Then, again, we have the charges outside of maintenance of hounds, horses, and men to consider, and these have risen enormously everywhere. Claims for poultry, claims for damages, rent of coverts, cost of earth-stopping, finds and litters, cost of taking down and putting up barbed wire, and many other little matters have to be provided for by the executive of every hunt, while the master's hand is never out of his pocket, as he is continually making small disbursements which never figure in the hunt ac- 
counts. Then, again, there is the puppy show, the expense of which is almost invariably borne by the master, and the cost of which-prizes and luncheon to two or three hundred-often amounts to $£ \mathrm{roo}$.

In many hunts the master is guaranteed so much, but when this arrangement is made it, as a general rule, means that the various funds are kept separate from the hunt accounts, and the master has nothing to do with them. Thus a master may be guaranteed £isoo or $£ 2000$ per annum. But this is very often only supposed to absolve the field from liability in the matters of maintenance of horses and hounds, wages, clothes for the men, and expenses which belong to the kennels and stables. Sometimes there is rent of kennels to be paid, and this may or may not be included in what the master is liable for, the rent being generally made a matter of arrangement. At one time in subscription packs it was a general custom to give every penny which was subscribed to the master, who then had to pay everything, but as the extra expenses of the hunt increased it was found that this was impossible, many masters, though willing to take over all liabilities in connection with maintenance, being unable to pay all the extra charges as well.

As far as can be gathered the poultry bill was the first "extra" which came to be considered as beyond the ordinary expenses of mastership, and much about the same time a custom grew up in many countries of members of the hunt sharing amongst them the rent of coverts. This custom is at least sixty years old, and readers of Surtees' works will recall how at Sir Moses Mainchance's hunt dinner the rent of a covert was foisted on to Billy Pringle by Mr. Smoothley, "the jackal of the hunt." And to this day the custom 


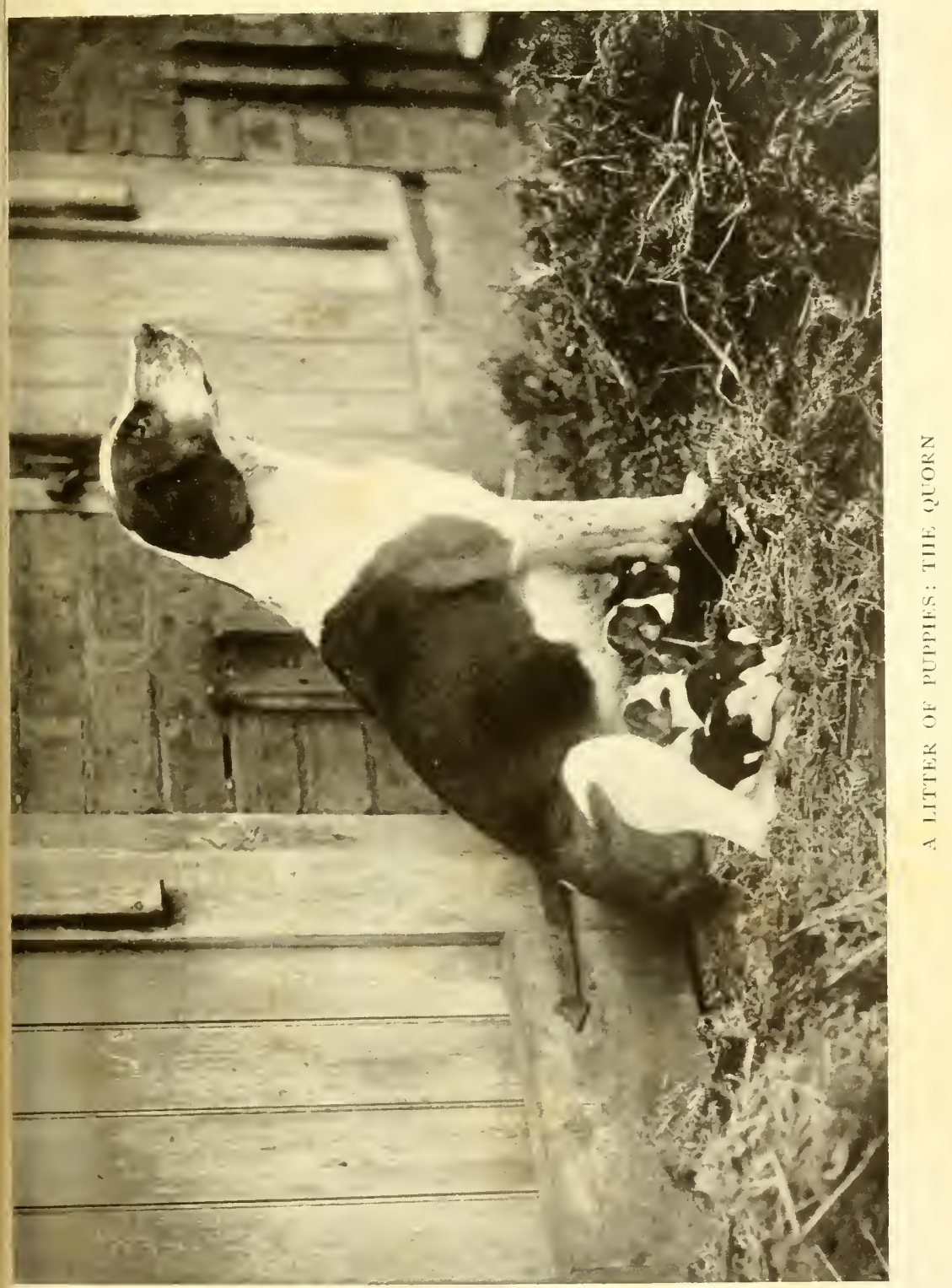



remains in force, and to give an example, in the Tynedale country there are many gorse and other coverts, the rent of which is paid by the various members of the Tynedale Hunt Club, the amounts varying from $£_{3}$ to about $£ 20$ per annum, according to the size of the coverts. As a rule these Tynedale gorses are located in an open country, and one can always see a board, placed on a ten-foot post in a prominent position, which at first glance a stranger would take to be an ordinary trespass notice, but which when examined will be found to bear the notice that "This covert is the property of the Tynedale Hunt Club."

Poultry and damage claims are, broadly speaking, the most serious "extra" which members of a hunt have now to find. In some places the covert-rent charges are high too, but in other districts these have become smaller than they used to be, simply because masters of hounds, individual members of hunts, and syndicates of hunting men have taken shooting primarily with a view to maintaining a fair head of foxes. This taking of shooting by the hunting section of the community has done an extraordinary amount of good in some countries, and in one or two cases it has been the actual saving of the country.

In one instance we have a vivid recollection of having five consecutive days with a pack of hounds, during which exactly two foxes were found. As it happened both were wild ones, and whilst one gave a fast gallop of about forty minutes, the other was hunted for over two hours, and not killed until a very big tract of country had been covered. But the outlook seemed to be miserable in the extreme, for the season was nearly over, and there seemed, as far as we could judge, to be no vixens anywhere. We were staying 
with the master, a very silent man who kept his own counsel, and it was not until the conclusion of our visit that he unburdened his mind. He then told us that matters had been going from bad to worse for several years, but that he and a few friends had put their heads together, and he thought had succeeded in stopping the rot. He himself had taken 7000 acres of shooting, and his friends, individually, in twos, and in syndicates, had taken 20,000 additional acres. They had some three or four years before found means of ascertaining who had the shooting rights in every part of the country; they had next approached the owners or their agents, and had secured the reversion in dozens of cases, and at the moment of our visit they were just entering into possession. It was a country of huge woodlands, with good hunting country interspersed, and luckily for the hunt many of the members were wealthy men, who were keen on both hunting and shooting. Moreover, a majority of the best and most central coverts had been secured, and we know that there was a quick improvement in the fox supply, and that in spite of a mange visitation matters have gone on well since. Our friend, the old master, has been dead many years, but quite lately we had a couple of days in the very country where the blank days occurred, and foxes were numerous everywhere.

Poultry fund, covert fund, earth-stopping, and wire fund are sometimes lumped together, and sometimes separately maintained, but whereas at one time it was customary for the officials of a hunt to pay all hunt subscriptions of less than $£$ ro, or of $£ 5$, as the case might be, to the credit of this fund or funds, it is now customary in many hunts for the members to make an extra donation to each of these funds, or to the lot 
collectively. Thus many balance sheets show that men who subscribe $£ 40$ or $£ 50$ to the general fund of the hunt will give an additional $£ 5$ or $£$ Io to the damage fund, or will pay the rent of a covert, after the fashion which prevails in the Tynedale Hunt. There are masters, even of subscription packs, who are willing and able to take over every liability which the hunt incurs, and pay the difference between the subscription and actual cost of everything; but it is not always the best thing which can happen to a hunt to get hold of one of these masters, for sometimes the mean ones give far less than they ought to do, and no accounts can be demanded of a master who takes a small subscription and pays a huge difference out of his own pocket.

Indeed, in these days the plan of keeping the cost of maintenance of hounds and horses strictly to itself, and of putting all extra expenditure into a separate account, has much to commend it, but of course the arrangements must vary according to local conditions. In one country, for instance, the hounds may be maintained by some magnate at his own expense, but even when this state of affairs exists it is now usual to have damage and poultry funds. Again, the master may ask for a very small guarantee, and in that case the subscription is smaller all round than it might be, but it is only a few favoured countries which are absolutely independent of financial trouble, and one far oftener hears of a hunt being hard up than of one which can always be sure of a surplus. Countries, naturally enough, vary greatly, some being rich, others comparatively well off, while others again are desperately poor. We know of really good countries as far as sport is concerned, countries which are good to ride over, and where foxes are religiously preserved, while only a few hundreds 8 
can be raised for a hunt subscription, and which are therefore practically maintained by a wealthy master, or have a continuous struggle to keep their heads above water.

But there are, on the other hand, countries where double the subscription which is required could be obtained were it necessary. The whole thing is a matter of wealth. In a good residential district money is generally forthcoming freely enough, but there are hunting countries where hunting men and women are limited in number, and few of them are even moderately rich. In such districts the hunt is carried on somehow, and of course there cannot be much smartness about the establishment. The men are not so well mounted as they might be, and horses have to come out twice a week; there may easily be a shortage of both horses and hounds, but if the members of the hunt are imbued with a true sporting spirit the hunt will continue to struggle on, and very often these struggling establishments show wonderful sport. The difficulty generally occurs when a new master is required, for men who are able and willing to pay largely for the prestige of mastership are generally anxious to take a country which stands well before the world, and where the society may be considered good. It happens, then, that the very provincial country, no matter how good it may be, is often obliged to fall back upon a local master, and though a local master is, as a rule, the best master, if none of the local men can afford the expense the services of a stranger are requisitioned.

Half a century ago it used to be broadly stated that certain masters lived out of the hounds, and doubtless many attempted to, but failed, while it is possible that some few did succeed in actually paying their ordinary 
living expenses out of the hunt. That many of them got their hunting for nothing is fairly certain, but times have changed, and what could be done fifty years ago cannot be done now. In those days the master of a subscription pack would have, say, £I 500 for three days a week, and no damages of any description to make good. Possibly, too, he had kennels and stables rent free, having nothing to pay beyond wages, keep of horses and hounds, and the incidental bills such as the tailor, bootmaker, saddler, and blacksmith. By maintaining as small a pack as possible, by bringing all the hunt horses out at least three days a fortnight, by never using a second horse for himself and his men, it was possible, provided he was a good manager, to keep well within the limit, and to bring the cost of his own hunting into the $£ 1500$, but nowadays it is generally reckoned that each day's hunting of the week costs a thousand per annum.

In other words a two-days-a-week pack will cost $£ 2000$ per annum for maintenance, and so on. The calculation is, however, an erroneous one in detail, for it is certain that a pack hunting two days a week should cost less proportionately than a pack which hunts three days. In a two-days-a-week country a single pack of hounds is required, while if hounds are out on three days two packs are maintained. We need not go into this question of cost, for so much depends upon management. One man will secure a bargain every time he is in the market, whether it is for horses, hay, oats, or meal for his hounds. Another man will always pay the top price, and be sometimes swindled. Then, again, one man hunts a country extravagantly, giving too much for his own and servants' horses, and keeping far too many. Some masters delight in a perfect army of 
scarlet-clad second horsemen, pad grooms, sending-on grooms, and extra whippers-in (to take a lame hound home), while others go to the other extreme, and try to work a big country shorthanded and short-horsed. The happy medium is no doubt the thing to cultivate, and it is good odds that the man who strives for and obtains the happy medium is also the best buyer of horses and forage, and in the long run the most economical of masters.

But the members of the field need not concern themselves with the financial arrangements of the master. We have stated at some length what are some of the systems with regard to subscription, and we have pointed out what the expenses of hunting a country now include, but this we have done so that hunting men and women may be thoroughly aware of the paramount importance of the subscription list. No hunt can be carried on without ample funds, and therefore it is the duty of every one who hunts to contribute to the subscription lists as freely as possible.

\section{CONDUCT IN THE FIELD}

It is, too, within the power of some members of every hunt to make the master's task an easier one in the matter of arranging meets and drawing coverts. This question we have discussed in another part of the book, but in every hunt some of the regular hunting men are landowners, or renters of coverts, and such men should, we think, always consult the master before fixing their covert shooting days. In a country of big woodlands masters have extraordinary difficulty in arranging meets all through November and December, while at Christ- 
mas-time they often have two-thirds of the coverts in the country closed to them. If the season is an early one, and the leaves come away quickly, most of the covert shooting, in an ordinary country, is got through in November; if the leaves are slow to fall the latter part of November and the beginning of December are the busiest times with the shooter, but almost every owner or renter of coverts keeps some of them for Christmas.

Very often there are boys from school or college; nearly always there are Christmas guests, and thus it happens that a master of hounds a week or two before Christmas has received notices by the dozen that certain coverts are going to be shot during the holiday period. Only last winter we met a master of hounds in London, during the week between Christmas and the New Year, and as we knew that it was one of his hunting days, and that he had the greatest aversion to losing a day's sport, we asked him why he was not at work. He then told us-his is to a great extent a woodland country - that he had attempted no meets for the week until Saturday, owing to the Christmas shooting parties. Now we are not going to write a word against shooting parties, especially those held at Christmastime, but surely some of the hunting folk should compare notes at the particular time of the year, and try to arrange that some country should be left for hounds.

In many countries Boxing Day and New Year's Day meets are special features of the holiday season, when hundreds of people come out for their annual hunt, and when dozens of horses are taken from their daily routine of harness-work and become hunters for the nonce. Perhaps these occasions are made more of in those countries where hunting is the foremost and most 
prominent sport of the district, but we have actually heard of a master who was requested to change his Boxing Day meet because a certain magnate-not a hunting man, but a good preserver of foxes-wanted to shoot. The master wrote that he thought he could not change the meet, because it was a fixture of fifty years' standing, and the whole countryside would be up in arms : but he went on to say that from the meet he would take hounds into quite another district, and that the coverts in question would not be interfered with. The magnate then realised what he had not thought of before, viz. that his shoot was likely to interfere with the sport of the occasionals who came out on Boxing Day, and he at once sent a message to the master to the effect that he had forgotten all about Boxing Day, and that he would postpone his sport for a week.

\section{HORSEMANSHIP}

In regard to manners and conduct in the field some few well-recognised precepts may be set down, but it must be understood that in this particular case we are addressing ourselves not to hunting men and women of experience who know quite as much about the sport as we do, but to people of little or no experience. There are always men and women who desire to hunt, but who have not been in the way of seeing any sport. To such it may be pointed out that a certain proficiency in the saddle is absolutely necessary, and that to go out hunting before this has been attained is a most rash and injudicious proceeding. It is not all men and women who are born riders, but the average English man or woman who wishes to hunt 
can learn to ride, even if he or she has not begun as a boy or girl on a pony.

Those who have ridden from childhood have, of course, an immense advantage over those who have taken to riding later in life, but real hunting enthusiasm will surmount a variety of obstacles, and people who find the desire to hunt absolutely imperative (perhaps there are not many of this class) will not let the fact that they have not learnt to ride be an obstacle in their path. It must then be fully understood that no one should attempt hunting until the rudiments of horsemanship have been mastered. So many books have been written on this subject that we shall not go at any length into the matter, but we have a rather strong opinion to the effect that grown-up people who wish to hunt, but have not been in the habit of riding, can attain proficiency more quickly in the open air of the country than they can in a riding school. The school is all very well in its way, but school-educated riders learn a lot of tricks which are out of place in the hunting field, and in many schools are taught to ride with far too long a stirrup.

The best and simplest plan for a man or woman who has actually never been on a horse is to go and live in some quiet country spot during the summer, a farmhouse for choice, and to go there provided with a goodmannered, easy-mouthed horse, who is unlikely to give any trouble. But it is also necessary that the services of some instructor should be available for the earliest lessons. The beginner wants to be shown how to mount, how to sit, how to hold his reins, and to grip with his knees-and indeed with the whole leg-but not how to ride by balance. What riding by balance may amount to where it is practised we do not know, and 
care less, but no one can attain a proper hunting seat unless he grips the horse firmly between his legs at first. As time wears on the grip naturally relaxes, and when a man finds himself thoroughly at home in the saddle he will discover that though he has what is in reality a grip seat, he is only using pressure at certain times, say when he is galloping over rough ground or negotiating a jump. As he approaches a fence he will find that his legs are mechanically closing on his horse, and that he is, in point of fact, holding the horse tight between his knees.

It is practically impossible to ride over a big fence, with a drop on the far side, without a strong grip, and we have witnessed endless "voluntaries" incurred by men who had not recognised this fact. Some of these had been taught to ride by balance, but as far as we can judge this must be almost an acrobatic performance, and, anyhow, it is quite out of place in the hunting field. Shortish stirrups should be used, and a very simple guide to the length which best suits nine men out of ten is to have them so that when one gallops the foot is well home (or well through the stirrup), and when one trots the pressure comes from the ball of the foot, and not from under the instep as in galloping.

Some men, of course, ride shorter than others, but a long seat is seldom seen on a man who is really good across country, for if knee-pressure is used at fences the long stirrup will slip off the foot. And, by the way, some men with the strongest leg-grip will often lose an iron when jumping, merely because they are in the habit of almost curling their legs round their horse's body. We remember a new huntsman coming into a country, and we quickly heard some one say that 
though he was a hard rider, he was no horseman, because he often lost one, and sometimes both stirrups when he jumped a fence. Only a few minutes later he elected to jump a big fence with a deep drop (he was casting hounds), and though he sat as tight as wax, one iron was dangling as he rode on. But we had watched him carefully, and it was just such a case as we have described; the stirrup had slipped off the foot while it (the foot) was turned right back. Moreover, the man had a tiny foot, and the stirrup was large and heavy. Light stirrups are a terrible delusion when hunting; a tight stirrup is to be avoided at all costs because it sticks to the foot in a fall, but a very loose stirrup is also uncomfortable and awkward, because it slips off the foot so easily. Indeed, great care should be taken in the matter of stirrups, which should fit easily, being neither too large nor too small.

We once saw a raw four-year-old out with hounds for the first time, ridden by a light lad, who managed him fairly well, but was not quite at home. After a while the owner of the horse, a biggish man and a first-rate horseman, came up, and seeing what a lot of trouble the youngster was giving, changed mounts with his man. Some time after hounds were drawing a hanging wood on a very steep hillside, and as they went outwards at the top the field rode up the hill (alongside the covert), where there was such a gradient that one had to go zigzag. The four-year-old plunged about, reared and fell over, backwards, and as the saddle girth snapped his owner landed on his back, still in the saddle, while the horse galloped away. The farmer was not hurt, but had the girth not given way he would probably have been killed, as his feet were fairly wedged into the stirrups, so that it took several minutes 
and a great deal of pulling to get them off his feet. He had, of course, omitted to change stirrups and leathers when he changed horses with his man, and for an hour or two had been riding in a pair of irons which were far too small for his rather massive boots. It was a lesson to him-as he has often told us since-and it must also have been a lesson to all who witnessed the accident.

It is hardly within our province just now to go further into the riding question, for we have pointed out that a man or woman who cannot manage his or her horse is even more out of place in a hunting crowd than elsewhere, because all horses are inclined to be excited when hunting, especially during the early part of the day. Horses which are in regular work, which come out about three times a fortnight, and which have passed the first bloom of youth, will be as steady as a rock after the season is a week or two old, but if for some reason or another they are short of work, through having been a good deal confined to stables, even the most staid of veterans will at times give way to an ebullition of feeling, and it is no uncommon thing to see an old and proved hunter kick off, or try to kick off, his rider at a meet. "There is no fool like an old one," and there are horses who never get over the habit of showing a little playfulness when they first see hounds, or first get on to grass in the morning.

The new beginner must then see to it that he is not likely to commit himself in any way as regards horsemanship, and on this point he should be fully assured before he attempts to follow hounds. Quite lately we heard of a man who never was on horseback until he was over forty years of age. By that time he had bought a little place in the country, where he quickly 


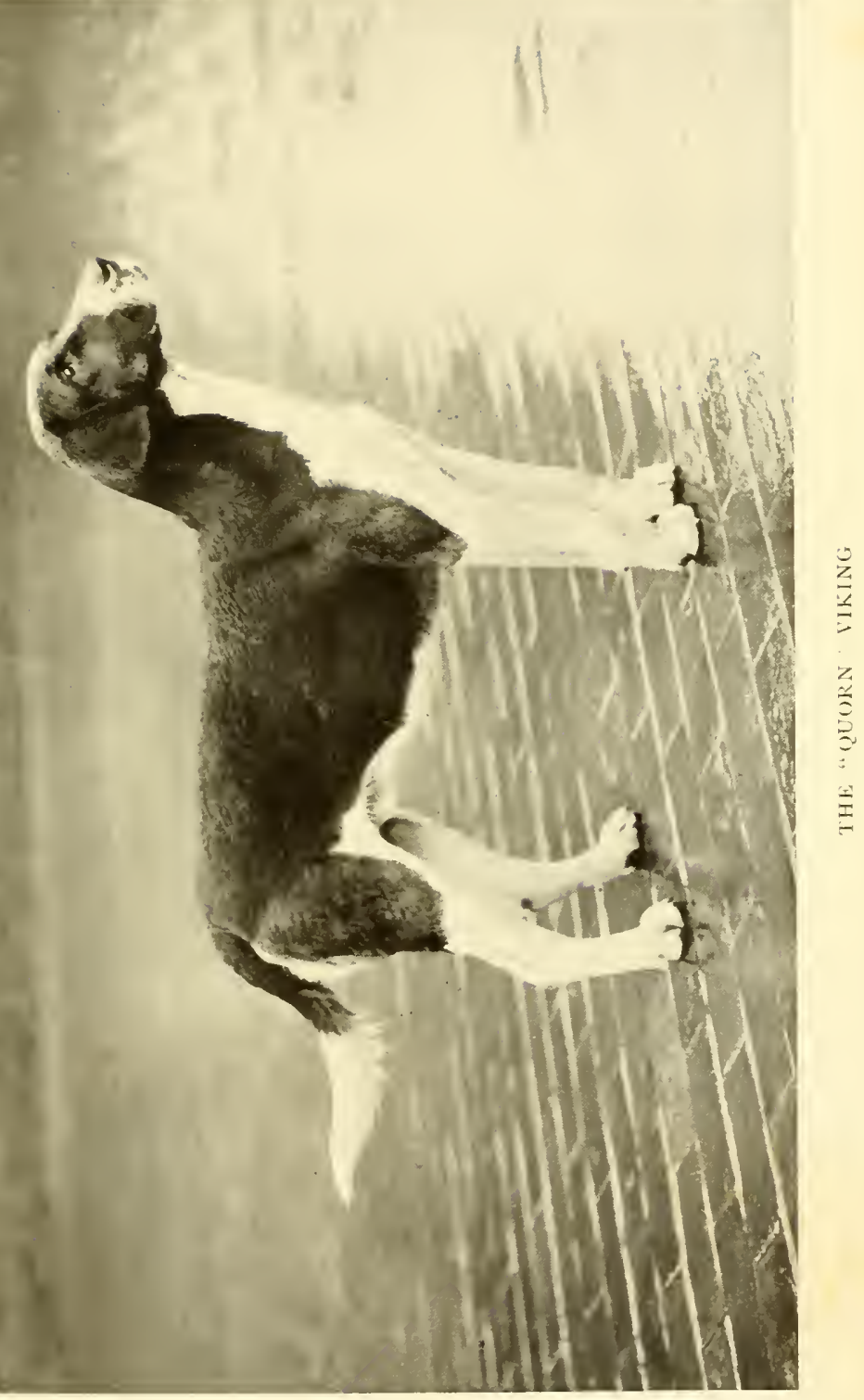



found that for half the year hunting took first place in every one's mind. By pure accident he found himself living in a community where every one talked about hunting, whilst most of his neighbours followed hounds. He quickly caught the enthusiasm, and went out on foot; then he thought he would like to ride, so he bought a steady old crock, and was not long in mastering a primary knowledge of riding. But being a somewhat retiring man, and being also particularly anxious not to make a fool of himself, he conceived the idea of going out in the afternoon at first. He would leave home about twelve, trot on to where hounds had met, and try to fall in with them about two o'clock. As he afterwards explained, he thus had the advantage of joining in when the day's work was half over, when horses had settled down, when the field had thinned considerably, and when he was less likely to attract attention than in the morning.

At first, too, he was content to follow the line of the hunt very quietly, either when they were drawing coverts or hunting a fox, and thus he was able to observe for himself what was taking place, and to watch how others conducted themselves. This line of conduct he pursued for half a season, and then he took the bull by the horns and made his appearance at a meet.

\section{EQUIPMENT}

Having made his mind easy on the riding question the new beginner should be careful as to the appearance of both himself and his horse. A man who is badly turned out is likely to create an unfavourable impression, and this should be avoided at all costs. It need 
hardly be said that if either man or woman makes a debut in the hunting world under the auspices of some one who has hunted enough to be an authority there is little chance of anything going wrong, but it may happen that the average new beginner of mature years is really new to hunting because he has not been in the way of seeing it or hearing it discussed. Had he lived amongst hunting people he would, even if he had not hunted, have known something about the sport, and in the event of his suddenly taking to hunting it would be almost impossible for him to commit himself in the matter of general turn-out. But the average recruit is not only ignorant in some degree of what he is about to participate in, but is very often not in the way of procuring sound advice. He may possibly not know enough to apply for advice in the right quarter, and may easily seek the assistance of some one who is only a little less ignorant than himself. Or he may rely solely upon his groom, and this is a most risky business, because many grooms, even after they have lived in good places where everything was correctly done, are little able to discriminate between good taste and bad.

A really first-rate groom, who has taken mental notes of what he has seen, and who is able to decide correctly on matters connected with turn-out, is a treasure, but such treasures are few and far between, and it is little use a new beginner relying upon his groom unless he knows that the groom's opinion is sound enough to be followed.

The matter of saddles and bridles is to many men an unimportant one, but a bad saddle and a coarse heavy bridle, with the reins buckled instead of sewn on to the bits, will spoil the appearance even of a really goodlooking horse, and a clumsy ill-fitting saddle, the 
pommel of which stands up too high, is in equally bad taste. Gaudy girths, too, are to be avoided, as are those bits which are "coated" with some shiny preparation, and which are said to involve less cleaning than steel bits. All saddlery for hunting should be procured from a really good saddler, who is in the habit of supplying hunting men. Any saddler, no matter how good he may be, should be avoided if he does not do a hunting trade, for he will not know the niceties of the business. A good man should then be looked for and found, and if he is an honest tradesman his advice will probably be worth following, firstly because he is honest, and secondly because it would be against his interest to turn out a customer badly.

A really well-made London saddle, which is comfortable and roomy and yet of no great weight, is a joy for ever, but a clumsy thick saddle is not only uncomfortable and stiff, but a cause for constant dissatisfaction. If a man can do without knee-rolls so much the better, for a plain flap saddle is neater and much more sporting than one which is padded out under the knees. And apropos of knee-rolls, it is a fact that some few London saddlers can put them on so neatly that they are hardly noticed, while the average country saddler invariably puts in so much stuffing that the knee-pad bulges out in unseemly fashion. Bits, stirrup irons, and curb chains should all be of the best steel, and should be kept well polished. A dull bit or irons look slovenly, and it is a remarkable fact that even if one little thing in a general turn-out is untidy or dirty, that will instantly catch the eye. And it is not every groom who can clean a saddle properly, though at a superficial glance it may appear to be all right. The inside of the saddle 
is the most important, for when a horse comes home from hunting the inside of his saddle is more or less soaked from the horse's sweat, and this has to be not only carefully but very slowly dried. In the hunting season there is often little chance of allowing the drying process to take place outside, and under any circumstances it is dark, or very nearly so, when hunters are brought back to stables. The saddle, after the girths have been loosened, should be left on the horse's back for a while, so that the back may become reasonably cool before it is removed. Any mud which is sticking to the flaps should then be removed, and the saddle placed, not on a peg, but on its pommel, in the saddle-room, or wherever there is a fire burning, and consequently a dry atmosphere. In all large establishments there is a cleaning and drying room, in which all saddles, bridles, etc., are cleaned, as well as a saddle-room, and where there are the two rooms only saddlery that has been cleaned and is ready for use is admitted.

It is most necessary that a saddle should not be used two days in succession, for if it has been worn throughout an average day's hunting it will hardly become thoroughly dry, unless the room is heated with hot air. Neither should the process of drying be a quick one, and thus a damp saddle should not be placed close in front of a hot fire, for this is apt to cause the front part of the inside to become hard, and has also a tendency to draw the stuffing into knots. If a saddle has been some hours in a warm atmosphere, it may be placed nearer the fire at bed-time, but a gradual, all-night drying in a warm room is best, and on the following morning, if there is any wind or sun, the saddle should be taken out of doors, and the inside 
turned to the sun or the breeze. The outer or leather part should be well dressed, with plenty of hand rubbing, and all the grease of the dressing should be carefully removed before the saddle is used again. We have seen saddles brought out which shone all over, but were as slippery as glass, and in which their users either slipped about all day, or to which they almost stuck when they had established a seat.

Stirrup leathers, too, need careful treatment, a good deal of dressing, and a lot of hand rubbing. A stiff stirrup leather is more apt to snap than one which has become pliable through treatment. And apropos of stirrup leathers we heard a very hard rider say last winter that he invariably broke half a dozen in the course of a season, and that he could in no way account for it, except on the ground that bad leather was used. Had our friend been a duffer we should have understood that he went to a bad saddler, but as a matter of fact he is quite an exceptional man, and possibly at the moment has won more point-to-point races than any man in the kingdom. He has, too, hunted since he was a child, and has always been a four and five days' a week man, who has looked over all details of his hunting establishment himself. It was not surprising, then, to hear that he had had consignments of leathers from some of the best-known saddlers in the kingdom, and therefore one was obliged to conclude that the frequent breakages were brought about in schooling young horses over awkward places, and that the strain imposed by a half-fall and recovery was in a considerable degree accountable for the breaks.

The beginner, then, must see to it that his saddle and bridle are good, well cleaned, and properly put on, but he must also make a point of having his horse well 
groomed, so that it shines from the combined effect of good condition and much strapping. It must be neat, too, about the mane and tail, and if the mane happens to be hogged care should be taken that the machine is constantly taken over the neck. A hogged neck is not quite to our liking, but so many horses are hogged now that a beginner is just as likely to buy a hogged horse as one with a mane; and when a horse has once been hogged it is a most difficult job to secure a mane again.

Such a thing should not be attempted in the hunting season, because of the unsightliness of the growing stage, but if a hogged mane is to be allowed to grow again hogging should be ceased towards the end of the season, and then there is just a chance that the new mane will be respectable in six months' time. But it is a slow and difficult process, and with some horses it is impossible to grow a decent mane after they have once been hogged. The owner of a grey horse should look to it that his hunter is really properly groomed, for grey horses do not take the outward polish which can be given to bays, browns, chestnuts, or blacks, and a careless groom will always slur over the toilet of a grey, thinking that the colour of the horse will cause his slovenly grooming to remain concealed.

And second only to the smartness of the horse is the smartness of the rider. All hunting people should pay great attention to their toilet, and in many countries smartness is the rule. There are, however, untidy countries as well as smart ones, and though the absolutely comic sportsman apparently did not long survive the Surtees and Leech era, there are still hunts in which curious fashions and curious old customs prevail, and again there are others in which many of the 
field buy good enough clothes, boots, and hats, but have no idea how to wear them, or keep them in order, and they present a most untidy appearance.

The beginner, no matter where he intends to hunt, should at least have a look at a good country before he commences operations. He should spend a week in the Shires, go early to the meets, on wheels or on his own legs, and should take thorough stock of everything. The hounds he need not trouble about unless he has a special leaning in that direction, but he should mark the horses, their condition, saddles, bridles, how they are brought to covert, and make himself master of what constitutes a proper appearance. $\mathrm{He}$ should then turn to the men, and study their coats, boots, breeches, hats, neck-wear, spurs, hunting-crops, and in fact every factor in the whole turn-out. He will then observe which cut of coat suits a long, lean man, which looks best on a short, stumpy figure, or the sort which can hardly be made to look becoming at any cost. A few days of this sort of thing, and his mind and vision will be attuned to what is correct and what is bad style in hunting costume, and he will be in a far better position to tackle the subject with his tailor and bootmaker than if he went to them perfectly innocent of how to dress for hunting.

And beginners should remember that many excellent tailors are not hunting men, and have no real knowledge of the subject; they can cut and make hunting clothes, but the greater part of their knowledge is derived from ascertaining and quickly noting the opinions of hunting men who are particular about their clothes, and though tailors have a knack of altering the fashions as often as they can, it is only in very small matters that they can bring about any 
change, and even the slightest change is of no use until its usefulness or comfort has been approved by some unquestioned authority. If the new beginner is going to hunt in the Shires he must go to the best (and most expensive) men in the trade for everything, and if he does this he can safely leave himself in the tailor's hands. If he is in a big way of life he will of course have a valet who can clean leathers and topboots as they should be cleaned; but the average beginner is about to hunt in the average country, and the best London tailors and bootmakers are as far out of his reach as the Shires are. $\mathrm{He}$ it is who should study the matter carefully, or fix upon a good model to dress by, for few ordinary country tailors can do justice to hunting clothes, while provincial bootmakers are for the most part hopeless as far as good top-boots are concerned.

There are now in some country towns good tailors and breeches makers, who are largely patronised by hunting men, and who supply the clothes for many hunt establishments, and if the beginner is in the way of trying one of these well-known men he cannot do better. But if he is not so situated he should, if possible, put off buying his hunting clothes until he is in London; if he does this he will probably be far better turned out than if he went to country tradesmen. And in these days London is not the name it used to be to many hunting men of two or three generations ago. It is practically within a few hours of all the English hunting countries, and the man who can afford to hunt can also afford a journey to town for the express purpose of being properly dressed when he makes his debut. Dark frock-coat, and breeches of the same stuff, with a tall hat for choice, should satisfy 
the new beginner until he has become thoroughly at home out hunting. He can then advance by easy stages to white breeches and top boots, and lastly to scarlet and leathers, but above all things he should avoid mufti after the season proper has commenced.

Hunting mufti was at one time to be procured of a fairly sporting cut, and which was at all events inoffensive, but of late years the mufti which is seen at cub-hunting fixtures, and which is worn even later in the season by those who have no proper sense of what is due to hunting, is quite without the pale. We do not mean to say that it is impossible to turn out looking neat and respectable unless one is dressed in orthodox fashion, but it is most difficult, for the simple reason that the clothes which look well enough and suitable for a man hacking about the country are terribly out of place when one forms a unit of a properly dressed crowd. A short jacket of a loud pattern may do to wear at a horse sale, but when it is accompanied by a pair of white polo breeches, brown jack-boots, and a hideous peaked cap it is an insult to a hunting field-after the first of November. If mufti must be used let it be a whole suit of very dark whipcord cloth, and let the jacket be cut long in the waist. A short jacket is, under any circumstances, unsightly on a horse, and a short jacket on a thickbuilt, short-waisted man makes him look quite at his worst. And, again, if mufti is imperative, special attention should be given to details. Whip, spurs, luncheon case and flask should all be correct, and the horse turned out as a hunter should be, and not looking like a cab horse out for the day.

But, as can be gathered, we dislike mufti except at cub-hunting, when orthodox clothes are equally out 
of place. The man who appears in full hunting rigout before the season proper has commenced is a rara avis, but he has been seen, and we have a vivid recollection of a five-o'clock cub-hunting meet on August 27th (we have forgotten the year, but remember the date of the month) with the Ledbury during Mr. Charles Morrell's mastership, when a tremendous swell appeared, wearing a scarlet coat, tall hat, white breeches, and very yellow tops, almost orange in colour. No one knew who he was, but he stood about with the half-dozen who formed the field, on the rides of a big covert, and at length some one opened conversation with him. He could ride well enough, but he had never even seen a pack of hounds before, and therefore did not know the ropes as regards dress; but he had some time before made up his mind to hunt, and had procured hunting clothes, and possibly such a thing as cub-hunting had never entered into the tailor's calculation. Another man we know who to this day goes cub-hunting in topboots, but with them he wears dark cloth breeches until the Ist November, and then changes them for white ones. $\mathrm{He}$ is, however, a privileged character in his own district, and nothing particular was said when he sat for an hour or two on horseback one very hot morning under a white green-lined umbrella.

Coats and breeches are a matter which must be decided between the hunting man and his tailor, but any cut of coat which is unusual, or any uncommon pattern of breeches, should never be attempted by the beginner. There is in some hunts one man in fifty who can come out in almost anything, and can carry off with equanimity what would be regarded as an absurdity if exploited by any of the other forty-nine. Such men 
may unknowingly inaugurate a new fashion, but the chances are that they have few followers in their eccentricities, and yet such men will, year after year, introduce some new detail-probably a very insignificant one-of costume. In one popular hunt a hard-riding squire always uses white evening ties for boot garters, while a neighbour, also a very hard man to hounds, invariably carries a twenty-inch "swagger" cane, such as a soldier uses, instead of a crop. A third member of this hunt used, a year or two ago, to appear in a very high, flat-brimmed tall hat of French appearance, and occasionally this same man was seen in a hunting frock of orthodox cut, but made of the roughest and gaudiestpatterned Harris tweed. In both of two different hunts, three hundred miles apart, a most important, nevermiss-a-day man invariably dresses in black boots, a whipcord suit, and a bowler hat all the season through, and each of these men is a pillar of his hunt, whose opinion on any point would carry as much weight as the opinion of any man but the master.

Another eccentric we know of carries all sorts of things, and when his long coat-flaps are not hiding his saddle, his horse looks more like a troop horse than a hunter. He has holsters on either side, a large whisky and soda in one, and port in the other; he has of course a sandwich case, a shoe in a leather case, a pair of wire nippers, and a little leather "first-aid" case fitted with one or two simple instruments, a roll of lint, and other things likely to be useful in case of accident. He also carries a huge knife, with a foot-picker, and several nails for horses' shoes, has a watch in the handle of his crop and another on his wrist-one to check the other-while his pockets are full of cigars, ginger nuts, sweets for the children, etc. We once 
travelled to a meet by train with this worthy, and when our horses were boxed, an out-of-place groom who had assisted at the boxing slipped into the box with them. On arriving at the little station where the unboxing took place, this man stole away, and some time later our friend discovered that both his holster flasks were empty. He was very irate for a moment, and then, diving his hand into an inside pocket of his coat, produced a third fairly large flask, with the words, "Thank God, I still have the old brandy safe."

But a man who handicaps himself with all this luggage must be uncomfortable, and when the field know that a sort of riding "stores" is in their midst he will be bothered all day long for something or other. To the eccentric of a certain bent of mind no doubt it is amusing to go out as the White Knight in Alice in Wonderland, but the beginner need take nothing more than a sandwich case and flask, fastened to his saddle, and as little as possible in his pockets. Watch, small change (both silver and copper), and a handkerchief are all that a hunting man must carry, though a knife is often useful enough. Spurs should be of the best quality, and not too small, but the rowels are quite unnecessary with every one who is not a skilled horseman, and in the habit of "breaking" young horses, and they should either be filed to bluntness or removed altogether, or threepenny pieces may be substituted, if the shell is big enough for them to be enclosed without looking conspicuous. A clumsy crop is an ugly thing, and perhaps there is no accessory of hunting with which it is so easy to go wrong. Indeed, a very cheap hunting whip is almost sure to be bad, unless it is an ash plant, and it is better in the long run to buy good crops from a first-rate maker than to procure the cheap 
ones. Even the best makers in the trade only charge seven and sixpence or half a guinea for an ash plant and thong, and when these are bought they should be chosen of the right size, with a handle suitable for holding a gate, and studded with screws.

A weak, light handle on any crop spoils it at once, for even the hardest of riders must open and hold gates at times, and the short, light handle slips through, especially if it has no knob, or no screws. The best whalebone crops which can be procured are usually used by masters of hounds and hunt servants of the best-turned-out packs, and these whalebones vary greatly in their powers of resistance, while, as is only natural, one man will get through three or four, his neighbour may carry one for many seasons. Then, again, there is a certain amount of luck about a whalebone crop, and though the makers of crops are doubtless good judges of the article it is certain that some whalebones will stand far more wear and hard usage than others. A whalebone crop is sporting, but not the most satisfactory whip for the rank and file of hunting men and women, firstly, because it is far heavier than cane; secondly, because if really good it is more expensive; and thirdly, because it has a shorter life.

Good cane crops, with the best thong which can be procured, are quite the most serviceable whips, and the thong should not be too long, and of fair thickness in the middle. A thong which is the same size throughout its length is very useless; there should be what hunt servants call a good "belly" in the middle, as this ensures force when the thong is cracked. It is, too, by the way, the heavy weight of the whalebone crop which causes it to be in general use amongst hunt servants, because their whips must 
be cracked continuously, and it is not an easy matter to make a reverberating crack when the crop is light -but this is of little consequence to ordinary members of the field.

Fashion in whips changes, or is changed by the whipmakers far too often. A good hunting crop must always be a good hunting crop, but one season they are worn long, another season shorter, and quite lately the shop windows of the best-known makers have been full of short, stumpy crops, which are, we think, both heavy and awkward. Medium length and medium thickness should satisfy every one, while a very long crop is rather clumsy, though handy enough for a persistent gate-opener, especially if he be a short-armed man who is accustomed to ride big horses.

\section{CONDUCT IN THE FIELD}

But, after all, the most important thing which the beginner of either sex has to consider is his or her early conduct in the field before he or she has had time to acquire knowledge of what to do and what not to do, where to go and where not to go, and so forth. And by beginner in this connection we mean the man or woman who has taken to hunting late in life, and who has not been in the way of obtaining much knowledge as to the sport. Some such people will quickly accommodate themselves to their new surroundings, and will in a few weeks be quite at home in a hunting field.

Not every one has the happy knack of taking up a new sport or pastime all at once and of grasping all the details of something which they have not been accustomed to, and though the quick-witted will soon learn 
a great deal, there are others who will be at a loss how to act. The beginner, then, should understand that he owes a duty to the master, a duty to those he hunts with, and a duty to the farmers whose land he rides over. As regards the master, he must be particular not to do anything which is inconsistent with the unwritten laws of the sport. He must not thrust himself forward; he must keep his horse well clear of hounds, especially at the meet, or on the way to covert; and if in the course of the day he happens to be in a gateway or in a road where hounds have to pass, he must get as far away as possible and turn his horse's head towards them. This is most important, especially if the beginner's horse should happen to be as new to hunting as he is, for in that case the horse might easily lash out and kill a hound.

Indeed, one is inclined to think that more hounds are kicked by the horses of novices and by the horses of grooms on carriage horses than by the horses of ordinary hunting folk, and this is remarkable because novices and grooms on carriage horses form a very small portion of any field. Carriage horses, when taken out hunting occasionally, very often misbehave themselves in all sorts of ways, and the beginner should always avoid this stamp of nag, unless it happens to be one of the general utility sort, which are as much at home in the hunting field as they are in harness.

It may be pointed out that nothing creates a worse impression than a faux pas at the commencement of a hunting career, and about the worst thing which can happen to a beginner is for his horse to kick, or even kick at and miss, a hound. In a country where fields are always large, and where some strangers are present 
every day, the beginner will not be noticed; but where there is no great crowd, a new face will raise inquiry as to its identity, and all sorts of questions will be asked, and comment probably passed on the new-comer. But in an ordinary way the beginner will not be brought much into contact with the master, unless that individual happens to be a man who concerns himself as much with his field as with his hounds.

Where the fields are really large, and especially if the master should happen to be a person of great importance, a man may hunt for years without even becoming acquainted with the man in office. On the other hand there are masters who make a point of knowing all their field personally, and a master who went out of his way to speak to strangers has been heard of. What the beginner must bear in mind is that loud talking when hounds are drawing a covert, or when they check, is not only bad form, but may at times cause a lot of mischief. A babbler amongst the followers of a pack of hounds is just as great an evil as a babbler in the pack.

The beginner should commence his hunting with his mind properly subordinated to the importance of the sport he is about to follow. He should understand that although much fun is to be got out of foxhunting, it has also a serious side. Not that it has to be approached with a long face, or that no one has to speak above a whisper, but that there is a time for laughing and talking, that plenty of opportunities will be found during the day for working off any excess of spirits he may have, and that if he cultivates an even demeanour he will find that it helps him greatly in the long run.

It is never wise to expect too much of any particular 
day or of any special covert. In hunting, as in racing, the unexpected frequently happens, and the good days often occur not only from unlikely meets, but when the general conditions have suggested that sport will be poor. Besides which the man who expects much in hunting is frequently disappointed, and vice versa. Let the beginner reflect that if he has the leisure and the horse, no meet should be missed, especially in the middle of the season. He should not miss a Monday meet because hounds are in better country on Tuesday -unless, indeed, the Monday meet is so far away that attending it would make a toil of a pleasure. For it may be good hunting weather on Monday, while snow, frost, or a deluge of rain spoil Tuesday altogether.

In this connection we are always reminded of the advice of a veteran hunting man, who is still riding after hounds though in his eighty-seventh year. We once remarked in his hearing that we were saving a horse to go with the — on Friday. The veteran got quite excited. "I once did that," he exclaimed; " but on Friday they were skating instead of hunting. The frost did not last long, and on the following Friday hounds were at the kennels. That was twenty miles off, and I did not go, but I sent a horse on on Friday night for the Saturday meet, and drove there the next morning. When I got to the place the hunter was lame, so I put his saddle on the trapper, and an hour later he fell with me at a little place, broke his knees and lamed himself. I had to leave him at a farmhouse, where I borrowed a horse to drive home with. He slipped upon some newly laid stones, cut his knees, and I had to walk him the last three or four miles. Hounds had the run of the season on the Friday, and the second best run of the season on the Saturday, and 
I missed both, and was a hundred pound poorer man on Saturday night."

We have, however, been rather off the line, and to return to the beginner, there are certain little things as regards his conduct to his neighbours in the field which may be pointed out, though a careful man is unlikely to ignore such small matters as we have in mind. It may be pointed out, then, that except when galloping in the open, and in the course of a run, it is not polite to pass any one at a fast pace, more especially when travelling up or down a muddy lane, or along the "ride" of a covert. If the ride is narrow single file is always observed, and this applies when hounds are running as well as when they are drawing. If in the former case the beginner is impeded by some slow coach immediately in front he may ask that individual to push on a little, or to make way, but it is not good form to shove past-unless the ride is a very wide one with plenty of room for two or three horses abreast.

And whenever the shout of "Hounds, please" or "Huntsman, please" is heard the beginner should look about him, and if he is likely to be in the way should quickly step aside. It is often possible to move amongst the trees of a covert for the moment when hounds are being taken past, and if this is impracticable because of a ditch the rider should move his horse as near the ditch as possible, and stand there until hounds have passed. When hounds are running-we assume that the beginner has mastered the art of riding across country-he should be extremely careful not to cross any one who is riding at a fence, and when he himself comes to the fence he should look round on either side, to see that he is not likely to come into collision with any of his neighbours. He should, too, where it 
is possible, pick his own place in every fence he jumps, but if the fence is one of those doubtful ones where a gap or two are quickly made, and the field go through in single file, he should, when he reaches the gap, patiently await his turn, and not attempt to go in front of any one who has arrived at the place before him.

Less than a month from the time of writing hounds were running a fox in a high-lying grass country where all the fences are stone walls. Three or four came in succession, and then an extra high one with a boggy take-off. The first horse to reach it hit the wall hard, but got over with a scramble, knocking several big stones -it was a dry wall_off the top as he went over. The master of that particular pack went next, but one of his field cut slightly across him, and just touched his horse as it jumped. Down went the horse and down went the master, the former rolling over the latter, who was considerably knocked about. This was a pure misunderstanding, for the culprit was a lady, and each had hesitated to make way for the other, and had then gone on again. But the moral of the story is that "First come first served" is a good motto-though in the particular case we have quoted the master was entitled to precedence, because he was hunting hounds.

We once met an astounding novice when hunting with the Heythrop. Quite late in the afternoon hounds went to draw Tar Wood, and we followed them there after a visit to a blacksmith, not being certain whether they had drawn the covert and departed. There were no signs of them on the side we approached by, so we followed the footprints, and were soon in the depths of the wood. At some cross rides we waited for a while, when there suddenly appeared a gentleman in a blue suit, with wide loose trousers, riding a tall horse, and 
evidently not in the least at home on horseback. "Have you seen the hounds?" we asked. "No," he replied, "but the man with the instrument passed me just now." Some minutes later we heard hounds not far off, and realised that they were running in covert. Then a brace of foxes crossed the ride, to the intense delight of the gentleman in blue. They were shortly followed by the pack, and the horse of the novice became excited, began to plunge violently, and quickly got rid of its rider, who was more frightened than hurt when he fell. By this time a dozen riders were on the spot, and one of them going to the assistance of the stranger found that in his fall he had torn the blue trousers right up the outside seam of one leg, and that underneath he was wearing leathers and top-boots, both brand-new, and of the best London make.

There were several undergraduates amongst the crowd which collected, and they began to chaff him about his kit, when it transpired that this was his first day with hounds, that at the last moment he had funked going out in his new clothes, and so had covered his grand new boots and breeches with a pair of old yachting trousers.

One or two other little matters will quickly present themselves to the beginner, one being the importance of waiting one's turn at a gate. There are in these days many gates to be passed through in the average day's hunting, even in the course of a run, for barbed wire and at times boundary fences have made riding across country without deviation in many places impossible. Then, too, canal bridges often have one, and sometimes two gates, and the same thing applies to branch railways, and lines connected with collieries, quarries, and so forth. Main lines are almost univer- 
sally protected, and transit is seldom possible except over a bridge or under an arch, but all over the country there are lines of smaller importance, which are constantly crossed at field gates by a hunting crowd.

Then, too, there are the hunting wickets, which are exceedingly common in some parts of the country, and these and every other sort of gate will be met with. As long as hounds are only drawing or going from one covert to another, the question of precedence is of little importance, though even then, if a lot of men and women are riding close together, the order of arrival at the gate should be observed. But it is when gates come at the beginning of a run that the crowding and struggling for precedence always occur. Men there are, and one is obliged to state that there are hunting women also, who will push through when a gate which cannot be avoided comes into the line. We have seen a huntsman obliged to wait while a couple of dozen of the hard-riding division struggled for pride of place at the gate, and it goes without saying that the more people fight for their turns the longer the delay in getting through.

We know a veteran who prides himself that if he arrives at a gate with fifty in front of him he will be through about tenth or twelfth; but he never pushes or annoys any one; he has merely a plan of his own for getting past the struggling crowd, and this we are not inclined to give away for obvious reasons. Nor do we exactly approve of the line of conduct which our friend adopts; but there it is, and we have seen it "come off" a score of times.

Another matter that the beginner should remember is to help, or attempt to help, any one who falls. It is a fact that men have died in the hunting field with 
no one near them, though this is a rare occurrence. It is always possible that any one who falls may be dangerously hurt, and a simple rule to adopt is to see the victim on his legs again before going on. If falls take place where there is a big crowd, there is, of course, no reason for every one to pull up; but where a fall occurs when only one or two other riders are near, it is imperative that one at least should not go on until he has ascertained whether the damage is serious or the reverse. If any one falls at a fence, the rider immediately behind him should deviate from his course, or pull up if he is unable to choose another place, for scores of accidents-not necessarily serious ones-are caused by riders being far too near each other at the fences.

It is also a good plan to slacken speed when about to pass by any one who is dismounted in the course of a run. It may be that the dismounted man is in need of a moment's assistance; possibly his saddle has become shifted, or his curb-chain has become loose. He may, in fact, have got off because of some little thing happening to his tackle, or because his horse has become lame. On the other hand he may have dismounted to do something for the common good of the field. At such a time his horse may stand perfectly quiet, if no other horse is very near it, but if horses go galloping past it may become upset, and set about playing the fool. It may also be difficult to mount in the open field, and under any circumstances it stands to reason that the rider will not have dismounted without good cause, and the man who comes next should certainly pause to inquire if he can be of assistance, while no one should on any account gallop past a dismounted horseman at top speed. 
Then, again, if a locked gate, or one which has to be lifted, comes in the line and some one gets off to open it, no one except the huntsman has any right to go through until the good Samaritan is on his horse again - unless the good Samaritan happens to be a groom, who can pull his horse aside until the "field" is through the gate. This is an unwritten law of the hunting field which is very strictly adhered to, and an infringement of it is always severely commented on.

As for catching loose horses, that is a matter of practice, and some men can nearly always do it quickly, while others may chase a horse round and round a field for an hour and be beaten at the end of the time. It is a thing the beginner should try to learn, for he may want his own horse caught some day. Besides, there should be unlimited give-and-take in the hunting field, where all are in pursuit of pleasure, and where it is every one's duty to mould his line of conduct so that it tends to the general comfort of the field.

Perhaps, however, the most important thing for the beginner to bear in mind, after he has mastered the rudiments of the sport and feels that he is able to hold his own in all ordinary circumstances, is that good sport cannot be forthcoming every day. $\mathrm{He}$ must not go out expecting that there will be a fox in every covert, that there will always be a holding scent, and that hounds will invariably have a brilliant forty minutes in the morning, and a steady hunting run of an hour and a half in the afternoon. Of such ideas he must disabuse his mind altogether, and then when the good things do come he will enjoy them all the more.

And above all things is it necessary to cultivate a cheerful demeanour, and not to allow oneself to be downhearted because of a few bad days. We once 
knew a Colonial who was extremely anxious to see a little English foxhunting. He was a superb horseman, but had no idea how hunting was conducted in this country. He bought a couple of horses from a dealer on his own judgment, and good, honest horses they were, though they had not been taught to jump a wire fence. He also procured some quiet hunting clothes and good saddlery, and took himself and his horses down to a well-known hunting town on the outer fringe of the Midlands.

As it happened he came in for a succession of good things, for he hit upon a fortnight of wonderful scenting weather. He got about three days out of each of his nags - it was in the middle of the season, and they were in hard condition when he bought them-and then he felt that he had discovered his mission in life, and in a week or two he had added three or four fresh horses to his string. He then went at it again, but the sport had changed, and about three weeks of poor days sent his spirits down to zero. Neither did he seem to understand that all foxhunting was unequal and uncertain, and this was entirely the result of his having been so greatly favoured at first. He disposed of his stud (at a loss) and, as far as we know, has never hunted since. 


\section{CHAPTER VI}

\section{HUNTING LOCALITIES}

\section{THE MIDLANDS}

T $T$ is an undoubted fact that the hunting countries of England vary in what may almost be called an

1 extraordinary manner, and many men and women there are who have followed foxhounds during the best part of their lives, and yet are unaware of the great physical differences which exist between one country and another. No doubt in the early days of the sport a huge majority of hunting men were content to remain at home, and saw no countries except their own and its immediate neighbours. Now people go about much more, and the average hunting man of to-day has a far bigger experience of localities than his father or grandfather had, but all the same a big majority of the hunting community hunt from home, and are very much in the dark as to what goes on in that part of the hunting world which does not come under their notice.

And no doubt nine men out of ten always like best the country they have known from childhood, and would rather remain where they are than go elsewhere, provided, of course, that a fair standard of sport is maintained. Others are from disposition wanderers, or from the force of circumstances have the chance of seeing many countries, and such men after a while as a general rule find that they prefer one particular 
hunt, or group of hunts, and if possible stick to the place of their choice. A man who has hunted early in life in a grass country rarely takes kindly to plough, and those who have been accustomed to big woodlands and a hilly country are seldom at home in a flat low-lying district, even if they find the foxes run straighter and the sport superior. The liking or disliking of a hunting country is in fact greatly a question of early habits and of environment, and it is lucky that this is so, for if all hunting people who could afford it went to what are considered to be the best galloping grounds there would be ridiculous overcrowding in certain places, and very meagre support for such countries as were not highly favoured from a riding point of view.

As it is the best riding countries are sometimes far too crowded because of the great number of visitors, while some of the provincial hunts suffer because certain of the residents go elsewhere to hunt. But there is probably less of this than there used to be a few years ago, firstly because people tire of hunting in a great crowd, and secondly because so many of the provincial packs have been so greatly improved that the sport they show is good enough to keep people at home. We are not going to urge that there has been an all-round improvement in sport all over the country, for such is most certainly not the case. Hounds doubtless are faster than they used to be, and horses are on the whole better, but mange, barbed wire, increase of population, new railways, excessive game preservation, and a dozen minor matters have had considerable effect upon the hunting in nine courtries out of ten, and it is because the conditions are more equal than they used to be that the land- 
owner, resident in a country of no great reputation, now so often hunts from home instead of taking up his abode for the season in a fashionable hunt.

In earlier days men who could afford it chose their hunting quarters in a locality where they were not only practically certain of seeing good sport, but where they had every reasonable chance of being able to enjoy that sport, without being unduly hustled. They perhaps knew that the hunting they left behind them was good enough in its way, but the country did not allow of a sufficiency of galloping and jumping, and possibly the "fields" were so small that the days of moderate sport were dull. During the last fifty years, however, the provincial packs have been greatly improved. Hound breeding has been more carefully studied, and where there was one enthusiast there are now a dozen. The style of hunting has changed too. Hunt servants in the provinces are nowadays carefully chosen, and for the most part far better mounted than were those of a generation or two ago. Kennel management is superior to what it used to be, and the whole turn-out of an average provincial pack is so greatly superior that, in spite of the modern drawbacks to sport which have just been mentioned, as regards the establishment a much higher all-round standard is maintained.

Of course there are exceptions to every rule, and it need hardly be stated here that in fifty countries, other than the Shire countries, a high standard has always been maintained; but the number of fairly smart packs has been absolutely doubled within our recollection, and, to look for a moment at the reverse side of the question, it would be possible to pick out some few, very few, packs which have fallen from a 
fairly high estate to very moderate efficiency. In proof of this we may mention two cases which we have lately noticed in different parts of the country. One southern pack we saw very frequently in the very early seventies. About twenty couples of hounds were at the kennels. The stables never contained more than six or seven horses, including those of the master, who was also his own huntsman. Hounds were out on two days of the week, and the fields used to average from eight or ten to fifteen or twenty on the most thinly-populated side of the country, and from five-and-twenty to forty on the other side, which extended to a fashionable inland watering-place, though then never spoken of as a hunting centre. In spite of this small establishment the country was pretty good, and the sport very good, and almost immediately after the date named the conditions, as distinguished from the sport, began to improve. Now in this particular country hounds are out on four, and sometimes on five, days a week, there are fifty couples of hounds at the kennels, and about thirty horses at the hunt stables, the subscription has been more than doubled, and the country has acquired so good a reputation that the mastership of the pack is eagerly sought, and the letting value of houses and stabling has (we are told) greatly increased. Yet the country (not being a populous one) has undergone little change, and though the sport is spoken of, and written of, as very good, it is probably no better than it was five-and-thirty years ago.

Another case is that of a semi-private pack, which has greatly changed as to its style of hunting, and its following. Thirty years ago the master and two servants had a horse apiece for two days a week, and a following so small that it often did not 
include a single man who was properly dressed for hunting. The master was an enthusiast, but his enthusiasm was not quite the same as other people's, and though he was himself immensely popular, and had a wonderful huntsman, his fields were of the smallest, and his turn-out very rough and ready. The horses were screws, the hounds suffered from curious experiments in breeding, and there was a lack of smartness about the establishment, though very good sport was at times forthcoming. In these days there is a small subscription to the same pack, and the country has not improved, wire being far too common and foxes all too scarce, but the establishment would pass muster anywhere, and considering the difficulties which the country presents, the sport is very good indeed. A beautiful pack of hounds has been bred, master and men are mounted on valuable horses, each always having two out, and the smallest details of equipment and appointment are as carefully considered as they are in the Quorn or the Pytchley hunts. Fields are ten times as large as they used to be, and -as is generally the case where the master sets a good example-both men and women are well mounted and well turned out. A slovenly master often has a shocking effect on his field, for so many think that what is good enough for the master must be good enough for them-a point of which a good deal was made by Surtees in his various books.

And now we propose to give some brief description of the hunting districts or localities. Scores of books on hunting have been written, and quite lately an important work, The Foxhounds of Great Britain and Ireland, has given a historiette of every pack in the kingdom, but the countries have never been grouped, 
nor all the hunting localities described. The various hunts have been treated in alphabetical order, and thus in such works as that first mentioned one reads of the Belvoir on one page and the Badsworth on the next. Then, again, in Brooksby's Hunting Countries of Great Britain no regular order was maintained, and each individual country was described on its merits and with little reference to its neighbours. But the fact is that in some localities there are groups of hunts in which the country is for the most part similar, while in other places the country varies in half a dozen ways within the confines of a single hunt, and again there are many good hunting quarters of which little is heard, while certain other localities are perhaps slightly overrated. That one man should be fully acquainted with all the physical conditions of every hunt in the kingdom is practically impossible, but when a system of observing the peculiarities of many countries has been carried on for many years, and when actual field experience has been gained in half the existing countries of England, then the result of such experience should be of some small value.

To all who are versed in hunting knowledge it is known that certain packs hunting in Leicestershire, Lincolnshire, Rutlandshire, and Northamptonshire are spoken of, written of, and generally known as the "Shire" packs, but how the description arose, and who was the author or godfather of the phrase, is not known, nor could the talented writers of the Badminton Library Hunting Volume elucidate the mystery. What is certain is that those packs which alone have a right to be called "Shire" packs are the Quorn, Cottesmore, Belvoir, Mr. Fernie's (which was originally part of the Quorn), the Pytchley, and 


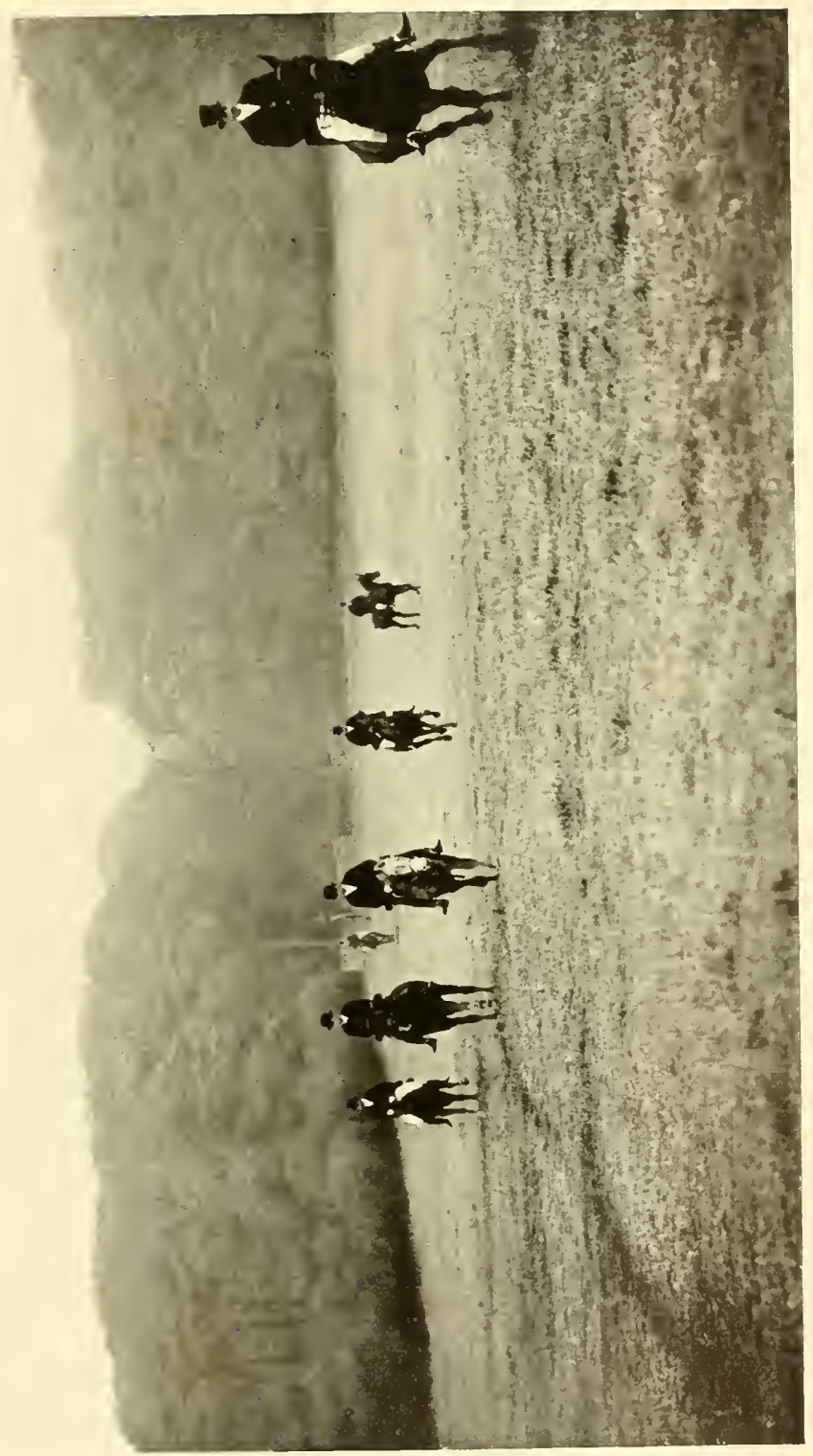

$\frac{1}{0}$
$\vdots$
$\frac{1}{x}$
$=$
$=$
$=$ 

the Woodland Pytchley, which is an offshoot of the Pytchley proper. By many these Midland hunts are termed the grass countries, and there are those among hunting men who will not allow of any other country being classified in a similar manner, though in point of fact it is a matter of considerable doubt as to whether there are not other countries in which the percentage of grass is not as great as it is in the Shires. Indeed, with regard to the Belvoir, plough predominates on the Lincolnshire side of the country, and hounds are practically two days in each week on the grass (on the Leicestershire side of the country), and two days in country in which plough is in the ascendant. As for the Quorn possibly four-fifths of it is grass, but it is impossible to determine the exact proportion, and a very similar remark applies to the country hunted by Mr. Fernie, of which the compiler of the descriptive matter in Baily's Hunting Directory states that quite five-sixths of its area is grass, with very little plough and woodland. The Cottesmore, like the Belvoir, has a good deal of plough on the eastern side of the country, but a greater part of the hunting takes place in pasture land, and as a matter of fact this country extends a long way eastwards, and has a great deal of Lincolnshire fen country within its rightful area, though hounds are seldom there.

The Pytchley has two large sections of grass, in the northern and southern districts of the hunt, some plough mixed with the grass in the centre, and a good deal of plough on the eastern side, while the Woodland Pytchley is three-quarters pasture and onequarter plough and woodland.

Now following up the descriptions of countries which are to be found in Baily's Hunting Directory, the 
Blackmore Vale is spoken of as "chiefly pasture, there being very little plough," the Cattistock as "chiefly pasture, with a little light plough and some downlands"; the Morpeth has " $70 \%$ of pasture, $5 \%$ of plough, 15\% of woodlands, and 10\% of moorland," while the description of the Tynedale states " north of the Tyne it is practically all grass; south of the Tyne it is woodland country." (Hounds only go south of the Tyne during cub-hunting and late in the spring.) Then in Ireland the Meath country is "nearly all pasture with very little plough." The Kildare country is " practically all grass," the Galway is "nearly all pasture, there being no plough and no great extent of woodland." The East Galway is "chiefly grass with a good deal of moorland," the Muskerry has "about $80 \%$ of pasture," and the Tipperary is " practically all grass, there being little woodland, and neither moorland nor plough."

Thus we see that there are other grass countries beyond the Shires, but nevertheless that group of Midland hunts to which the first place for excellence of country is always given, is beyond doubt the finest hunting arena in the kingdom. To begin with there is a far bigger tract of the really first-rate country in Leicestershire, Northamptonshire, and Rutlandshire than is to be found elsewhere. Haif a dozen hunts, all closely adjacent to each other, may be said with truth to form the grass countries, or "Shires," and as to which of these half-dozen is actually the best there is, and there always has been, great diversity of opinion. Pasture lands, strongly fenced, are the galloping grounds of these highly favoured countries, and when it is added that the enclosures are for the most part of wide extent, that during the winter there 
is very little wire to be found, that big woodlands are remarkably scarce, that there are few obstructions in the way of gills, or ravines, and that a bold rider can follow hounds almost everywhere, it will be understood that a foxhunter's paradise still exists in this particular part of the Midlands. Then, too, the coverts are generally small, and foxes seldom hang to them, but go away at once, and the grass on the majority of hunting days carries at least a fair scent. Drawbacks there may be to the Shires, but there are drawbacks of sorts to every hunting country in the kingdom, and probably there are fewer in the extra-fashionable hunts than elsewhere. There are those who object to the ridge and furrow of the grass, but this is a matter which troubles new-comers more than the habitués, and those who hunt in the Shires hardly notice the uneven ground after they have had some experience of galloping over it. Where hunting in these particular Midland hunts differs from hunting elsewhere is in the pace. It is not to be supposed that hounds actually run faster in the Quorn, Pytchley, or Cottesmore than they do in other countries, but they are more favoured by open country than in many other hunts, and as they so often find their foxes in small gorse coverts they as often have the chance of what is generally called "getting away on the top of their fox." It therefore results that time after time foxes have to fly for their lives the moment hounds are in covert, and in consequence the quick hunt is commoner in the Shires than it is in countries where the coverts are larger, and the fox is able to take a turn or two before he slips away.

Whether the average of sport, looked at from every point of view, is better in the Shires than it is in some 
of the best provincial countries is a question which cannot be answered offhand, as so much depends upon individual ideas of sport. That there is more quick galloping, and that there are more big fences to be jumped in Leicestershire and Northamptonshire than there are in the average good provincial hunt, admits of no doubt, but there are hunts in which hounds can certainly be seen to greater advantage, and in which the average number of kills after really good runs would work out quite as well. In fact, in these days the question of individual taste enters largely into the matter, and whilst men who have been brought up in the Shires, and have hunted there from their earliest days, will not allow that any other countries can approach them, there are those who have tried the crack Midland hunts and have afterwards gone elsewhere. What really is the chief drawback to the Shires is the overcrowding. To those who have hunted there all their lives the large crowd is a matter of course, but for all that the great numbers which attend the most popular meets of the most fashionable packs cause the sport on many days to be poorer than it ought to be. Hounds, in fact, are constantly overridden on days of moderate scent, and are in consequence driven beyond the line of their fox. At times the master has his field in hand and is able to stop this over-riding, but it frequently happens that the front of the field is widely spread, and if hounds are checking in every enclosure, it is impossible for a master or field master to be everywhere, and therefore much harm is done.

Then, too, where so many riders are in the field it is no easy matter to get near hounds merely because of the great numbers. Some there are who, no matter 


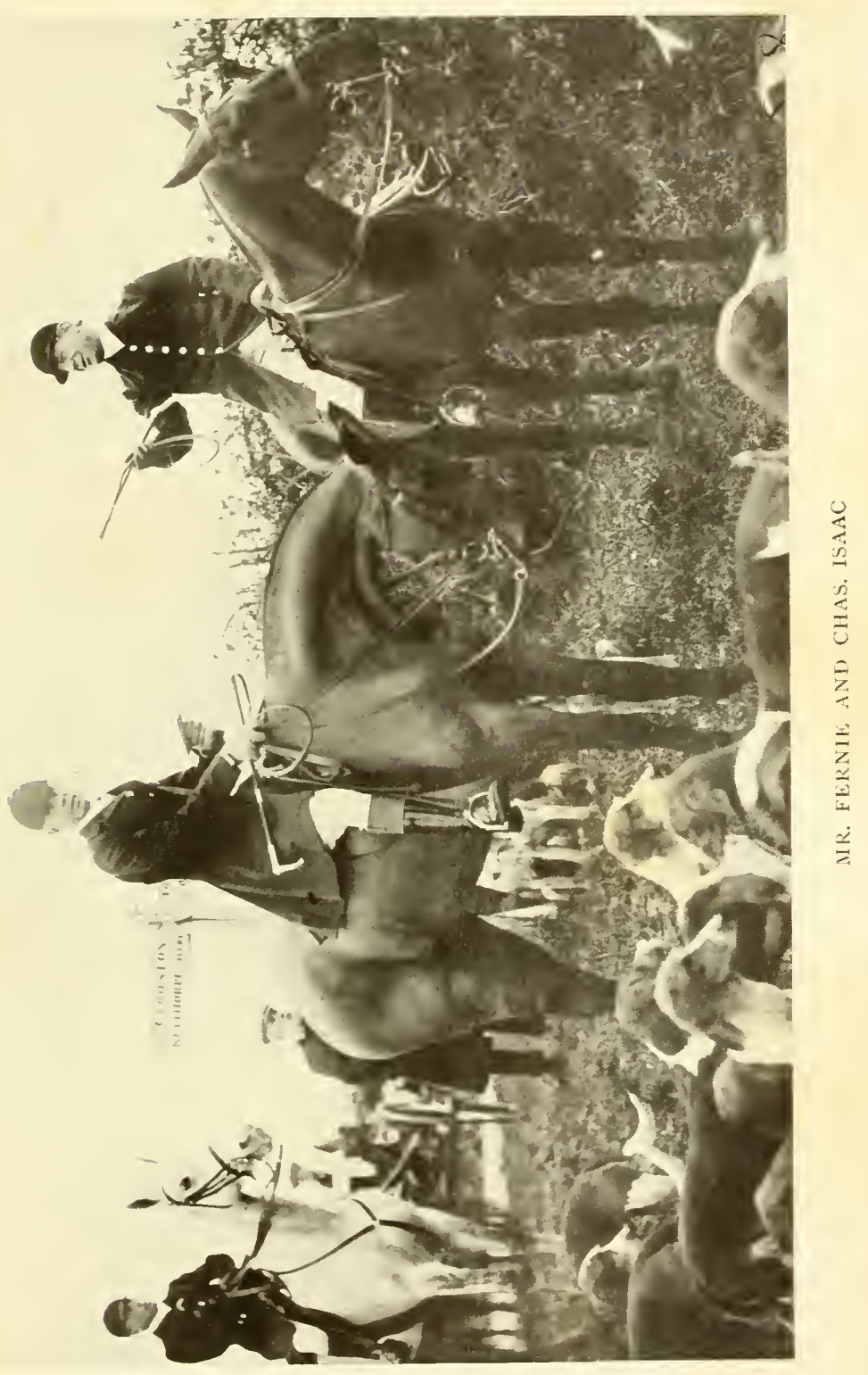



how large the crowd may be, invariably shoot to the front immediately hounds begin to run, but these men and women are gifted with a certain knack, and not once in a dozen times are they stopped from taking their customary places at the beginning of a run.

Strangers who visit the Shires in these days must not only be good men to hounds, but must be quick to make up their minds, or they will indubitably be left. Just at the moment, however, we are not discussing hunting from a riding point of view, and to get back to the subject in hand, the Shires are doubtless the best place for what may be called the unattached hunting folk whose social position is very good. By unattached in this connection we mean those well-to-do hunting men and women who have no location or ties in any provincial country, but are at liberty to hunt where they like. Such men and women can probably get bigger value for their money in the crack hunts of the Midlands than they can elsewhere, but they must be prepared to pay at a fairly high rate for their sport. High-class hunters, well bred, well conditioned, and gifted with stamina are an absolute necessity for ninety-nine men out of a hundred in the Shires. There is, of course, the odd man in a hundred and the odd woman in a thousand who can get to the front on horses which no one else can ride, and which can probably be bought for $£_{50}$ or less. But because one man is at home on a horse which the average hunting man cannot ride with comfort, it does not follow that the latter can buy anything fit to live with hounds over a galloping country at the same price, and as a matter of fact the rank and file of a Leicestershire field must either be well mounted, or be content to ride half a mile or more behind hounds all day. 
Underbred horses are as much out of place in the Shires as a selling plater is in the Ascot Cup, and though there are men who can even go to the front on very moderate horses in some of the provincial hunts, the same trick cannot be performed in the Shires. Doubtless readers, will remember Mr. Sawyer's wonderful ride on Marathon, as described by Whyte Melville, and if they do it will not be forgotten that Marathon was only a common, underbred beast, who merely distinguished himself because he got through an apparently impossible fence.

Not only are good horses a necessity, but a smart turn-out is imperative, and though good clothes and good saddlery cost little more than indifferent ones, Leicestershire requires quantity as well as quality, if hunting is to be indulged in on four or five days of the week. Boots, breeches, coats, and habits cannot be brought out day after day without becoming all too quickly shabby. Should the rider come home wet, too, the drying of his or her clothes should be a very gradual process, and the same thing applies to saddlery. Indeed, after considerable experience, and much consideration of the subject, we have come to the conclusion that all hunting men and women should, if they can afford it, be provided with a full rig-out for each day of the week on which they hunt, and if economy is an object they should at least be prepared with two sets of clothes for every three days of sport. As regards saddles and bridles much depends upon the horses. We have known men who on every occasion of their getting a new horse had a man down from a crack London saddler to measure the new purchase for a saddle, and we have known others who managed well on to a hundred days a season with one good saddle, 
and a deputy which was only employed when the good saddle had had a thorough soaking. The saddle question is indeed one which varies greatly according to the skill and care of the stud-groom, but some ladies are very particular, and not long ago we saw an acquaintance on a railway platform whose maid was watching over a pyramid of luggage, amongst which was a palpable saddlery chest. "Where are you going?" we asked, and were told that the lady was going to stay in Hampshire, and that she hoped to hunt two days a week with foxhounds, and two days with harriers. She was taking three saddles with her, and we may add that she was a consummate horsewoman, and thoroughly well versed in all that pertains to stable management. She knew in fact that she was not carrying useless luggage about the country, and that absolutely dry saddles are a necessity if sore backs are to be avoided.

And here it may be appropriate to remark that more sore backs are caused by using a damp saddle than by anything else. Broadly speaking, no saddle should be used two days in succession, for a saddle can hardly become thoroughly dry in a single night. Of course we do not mean to suggest that if a saddle is used on Monday and again on Tuesday the last wearer of it is bound to have a sore back. But as a matter of fact every horse who goes through a run sweats freely enough to make the inside of his saddle very wet, and in a general way the saddle is not really dry for at least twenty-four hours. We remember many years ago going, in company with a well-known artist of horse and hound, to look over a pack of hounds in kennel. It was at the end of the season, and a brilliant spring morning, and below the saddle-room window 
was a row of saddles, which had been used on the previous day, with the insides placed to catch the sun. We pointed it out to the artist, who promptly made a sketch, and this duly appeared in the Graphic, but how long ago we do not remember.

Once when visiting the Devon and Somerset country in September we were struck with the extraordinary number of sore backs we found, or heard of among the hirelings, and discovered that business was so brisk that even if the horses were rested once or twice a week the saddles were always in use, and were brought out almost every day. The consequence was that not sufficient time was allowed for the drying process, and as has been remarked, very often a damp saddle will give a horse a sore back, more especially if the saddle is lined with leather. Leather takes even longer to dry properly than the ordinary padding of the average saddle, and in this particular case leather-lined saddles, or leather rummalls, were largely used.

The would-be Meltonian, then, must grudge no expense in horseflesh, in hunting clothes, and in saddlery. He must also subscribe liberally to each pack with which he hunts, and must also be prepared to subscribe to the many funds which are maintained by hunting men. Beyond the ordinary subscription there are in many packs extra funds for rent of coverts, poultry, damage of all sorts, and the removing and replacing of wire. There are, too, the Hunt Servants' Benefit Society and the Royal Agricultural Benevolent Institution, and the hunting man of means should make a point of subscribing to all these. Then, too, local agricultural societies, testimonials, and tips to the hunt servants must all be borne in mind, and in point of fact the stranger who goes into any country with 


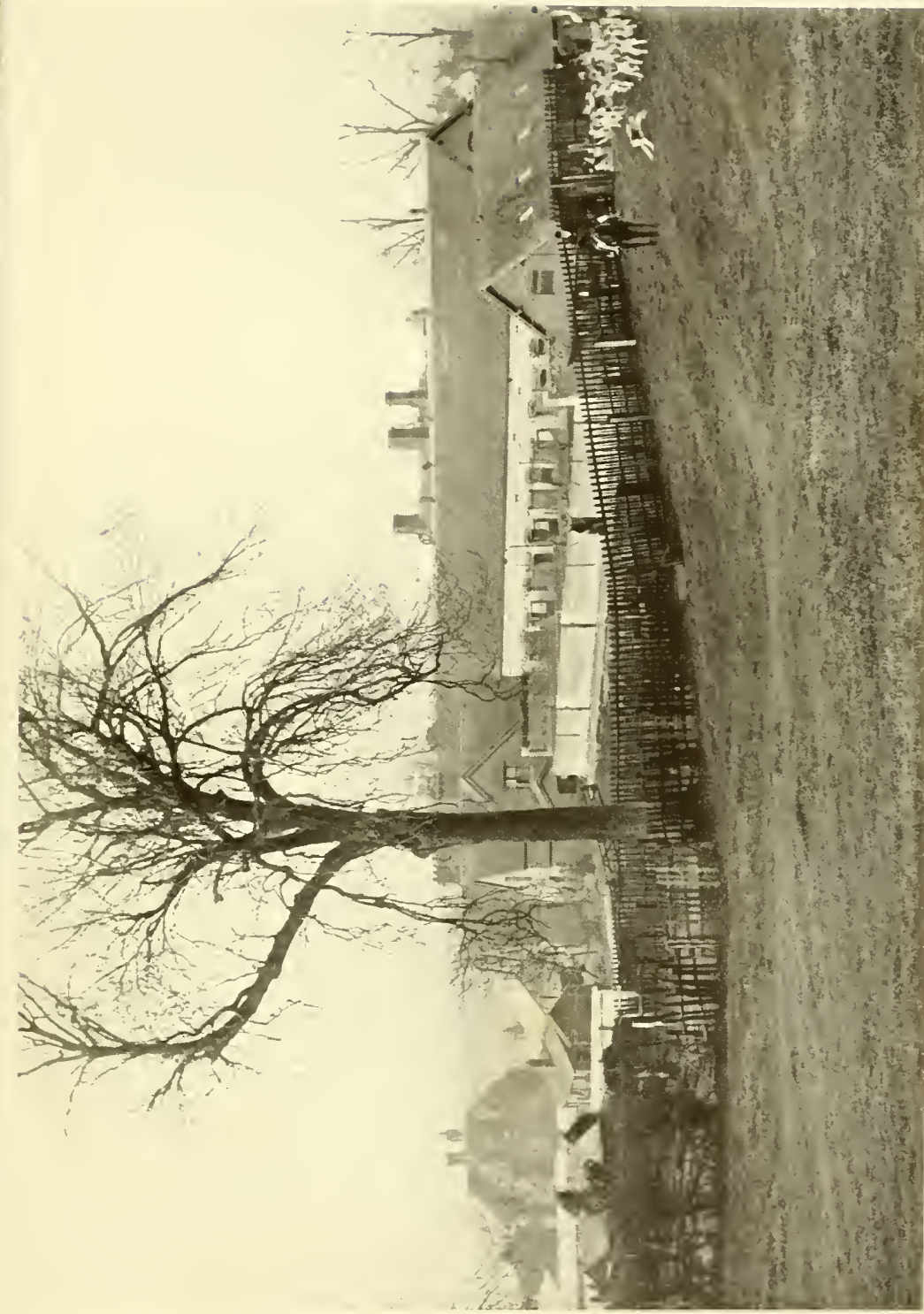

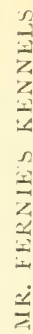



which he has no connection for the express purpose of hunting must be prepared to put his hand into his pocket for all sorts of objects. He need not necessarily be imposed upon as Mr. Puffington was when he bought the Hanby House estate and became a master of hounds, and if he has doubts as to the bona fides of any particular fund he is asked to subscribe to, he will always be able to find out the genuineness (or otherwise) of the affair by applying to the secretary of the hunt.

Another matter of considerable expense in the Shires is house rent, for the best houses are quickly snapped up, and only those which are wide of a majority of the meets hang fire. Melton Mowbray is undoubtedly the best and most popular centre, because four of the Shire packs are within reach, and it is possible to hunt on six days of the week, without, except perhaps on Thursday, having to go very long distances to covert. On Monday and Friday the Quorn is chiefly patronised by those hunting from Melton. On Tuesday the Cottesmore are generally handy, and on Wednesday the Belvoir are in the Croxton Park country, and seldom meet more than half a dozen miles from the town sacred to foxhunting and pork pies. Thursday is as a rule the most difficult day of the week. The Cottesmore and Mr. Fernie's hounds are both out on that day, but meeting them often involves a somewhat long journey to covert. The Quorn do not profess to hunt on Thursdays, but frequently have a bye day, and all the Quorn country can be reached from Melton by any one who is determined to get all the sport he can. Friday has been already alluded to, and is the most popular day of the week with the Quorn, while on Saturday the Meltonian hunts with the Belvoir or 
Cottesmore, and as a rule one or other of these packs meet close to Melton on this day.

Much of the Quorn country, too, can be reached from Leicester, and Mr. Fernie's hounds also come right up to this Midland town, while a corner of the Atherstone country is well within riding distance. But whereas Melton Mowbray is still of no great size, and retains its countrified appearance, Leicester has become a huge manufacturing town, with a large industrial population, and though placed almost in the heart of the Shires, it is by no means a sporting place. We have seen Mr. Fernie's hounds in the outskirts of Leicester more than once, and have a vivid recollection of their crossing the racecourse at Oadby, in full cry, while a steeplechase meeting was in progress; and whilst this speaks for the fact that Leicester is a handy enough place to hunt from, it is nevertheless the case that no one who can have his hunting quarters in the pure, undiluted country will care to spend the winter in a manufacturing town. There are, of course, nooks and corners in the town of Leicester which are redolent of foxhunting, and legend galore of the early days of the Quorn hangs round the old Bell Hotel, which was once well patronised by hunting men, but new bricks and mortar, electric trams, steam foundries, and tall chimneys have caused such an alteration in the place that even the Quornites of the mid-Victorian period would fail to recognise it now.

And this was vividly brought to our notice by a stranger we met in the train. Journeying from St. Pancras we had for vis-à-vis an elderly man of sporting cut, who at once gave tongue, and was soon hard at work on the line. After five minutes of generalities he whipped on to fox, and he told story after 


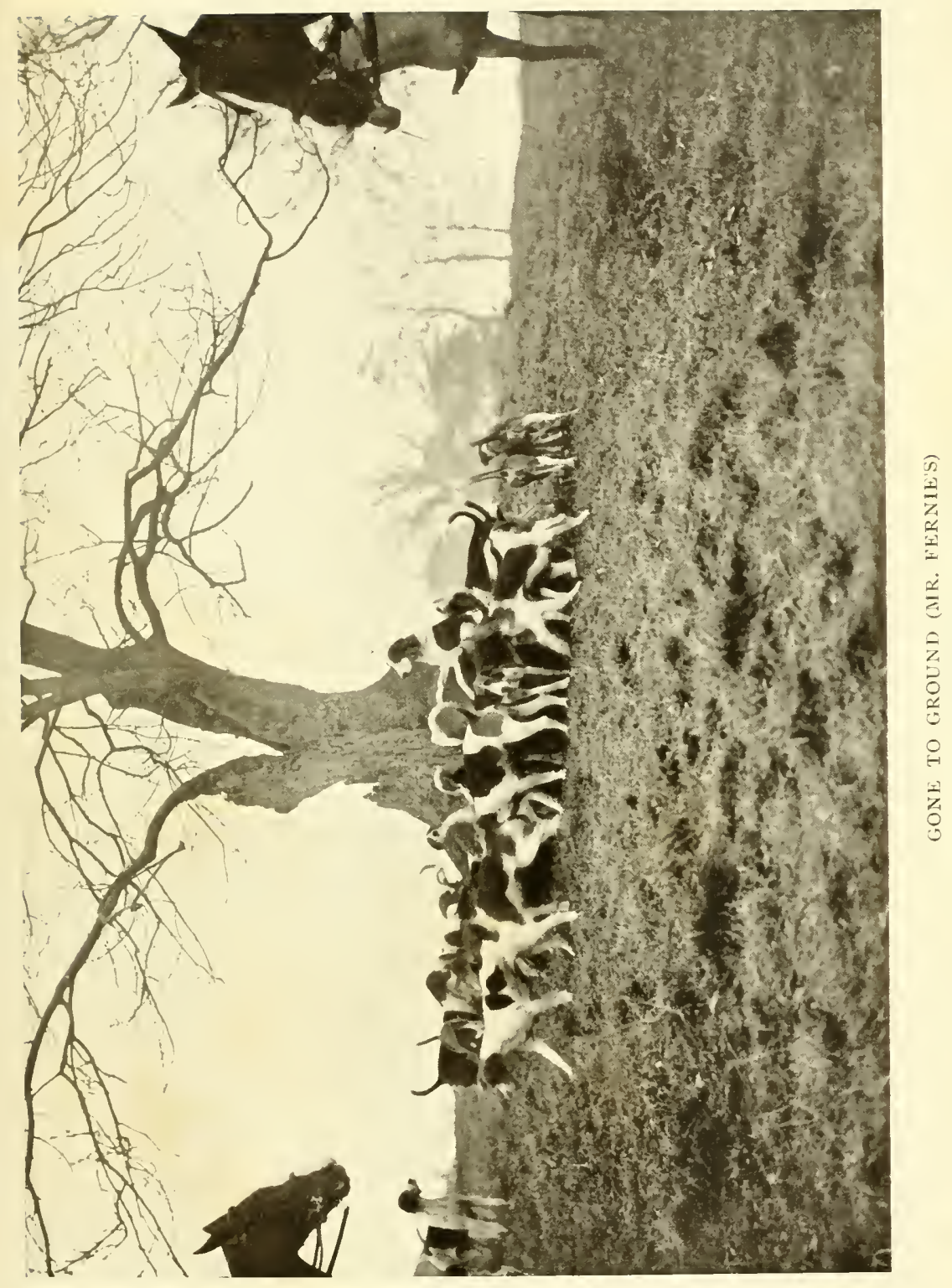



story of Devonshire hunting. He also observed incidentally that he was a doctor, and that nearly fifty years before he had for a time acted as assistant to a country practitioner in the neighbourhood of Syston. He was travelling for pleasure, and was going to revisit Syston merely because he had never been in Leicestershire since he had left it half a century before. We were going to Loughborough, and our friend left us at Leicester, intending to drive from that town to Syston. Curiously enough, on the evening of the following day the old gentleman got into the train by which we were returning to town, and all the babble of horse and hound had gone. He was sorry he had revisited the country which he knew in Lord Stamford's day, and his chief cause for sorrow was that Leicester had grown out of knowledge, that the road to Sileby was a street for a great part of its distance, and that much of the country about Syston and Sileby had succumbed to the builder, while the limeworks and brickworks had greatly increased in size. "Indeed, if all the Quorn country has changed as it has between Leicester and Barrow-on-Soar, I don't know where hounds can hunt," he exclaimed; but he brisked up when we told him he had seen the most populous district in the hunt, and a few minutes later he was drinking the toast of "Foxhunting" in as good a glass of champagne as the Midland dining-train could supply.

Loughborough, too, commands practically all of the Quorn country-indeed, we might say with truth that any one who wishes to hunt all four days with the Quorn, and does not care about any other pack, could not do better than pitch his tent at Loughborough. It is quite in the centre of the hunt; the old kennels were 
close to it, and the new ones are situated at no great distance away. But it is a dull spot on a non-hunting day, and unless a man happens to be hail fellow well met with the whole countryside, he will find time hang very heavy on his hands.

After Melton Mowbray, however, Market Harborough has undoubtedly the strongest claims of any of the Shire resorts. It is some twenty miles south of Melton Mowbray, and about half the distance from Leicester, and the Quorn are almost out of reach, except by boxing, or sending on horses overnight. On the other hand, the Pytchley, Woodland Pytchley, and Mr. Fernie's all come together hereabouts, and the Cottesmore country is only a few miles away.

There are those who are of opinion that from a riding point of view the country round Harborough is the most difficult in the Shires, and most certainly one can easily find ox-fences of the most formidable character; but the whole district is well gated, and it is not absolutely necessary that all the biggest fences should be jumped. And by the way, it is a good thing that only a portion of every hunting crowd is in the habit of riding straight to hounds. In every field in every country there are men and women who will go quite straight until they are pulled up by some impossible ravine, or by a fall, but it is also the case that in every hunt there is a contingent, varying more or less in size, which attempts to see as much as possible of what hounds are doing, and which yet "declines extra risk," as Jorrocks put it. Were the full strength of a big field all to ride, or try to ride the exact line of hounds an enormous amount of damage would be done, for every fence would be flattened in half a dozen places before every one got over or through, and there would 
in consequence be trouble with the farmers, or unwarranted expense incurred by the hunt.

And that the Shires are well gated is probably well known to all hunting men. Occupation roads are exceedingly numerous, and very often where there is a strong boundary fence between one farm and the next there is also a mode of exit by gate. We thoroughly realised this when staying near Market Harborough in the month of July not many years ago. The weather was exceedingly hot, and our host was in the habit of riding for a couple of hours every morning at a very early hour. We accompanied him on several mornings, visiting many of the most famous coverts in the district, and invariably riding by country lanes, occupation roads, and through fields. The high roads we never seemed to touch, and though the country was at a casual glance quite impracticable to a comparative stranger who wished to ride from one covert to another by means of gates, our friend, who knew it well, was able to find his way everywhere, and was never pounded, not even when he showed us the first few miles of the line taken in the great Waterloo run during the late Colonel Anstruther Thomson's mastership of the Pytchley.

As regards the hunt just named Market Harborough is on its north-eastern border, and though much of the best of the Pytchley country is within reach of the town, the hunting man who takes up his quarters at Harborough will probably hunt as often with $\mathrm{Mr}$. Fernie's pack as with any other, while for the Pytchley itself there are other places which are much more central. These will be mentioned just now, but first of all reference must be made to the Cottesmore country, of which Brooksby wrote: "For the truest 
sport, the straightest foxes, for long runs and fast runs, commend us to the wild pastures of the Cottesmore." Extending a long way from east to west this country does not actually touch Market Harborough, but its south-western corner is within four miles of the town, and certain meets are within easy riding distance. But Harborough residents, like those of Melton, must hunt with several packs, if they attend all the meets within reach, and of the four countries they can choose from the Cottesmore is the least handy. Oakham, on the other hand, is in the centre of the best of the Cottesmore country, and any one wishing to devote four days a week to this particular pack would be best placed there. Stamford, too, is just within Cottesmore domains, and handy for much of Mr. George Fitzwilliam's country, and Uppingham is also a Cottesmore town, from which Mr. Fernie's and the Woodland Pytchley can be easily reached.

Another Midland town which attracts hunting folk in considerable numbers is Rugby, between which place and London there is a wonderful train service by two lines of railway. Rugby is actually within the limits of the North Warwickshire Hunt, but the Atherstone boundary is within two miles of the town, the Pytchley country is not more than double that distance away, while the Warwickshire and Mr. Fernie's are both within riding distance on one day of the week. Those who hunt from Rugby cannot confine their operations to the Shire packs proper-unless indeed they choose to hunt by train on two or three days of the week-but the Atherstone and the two divisions of the Warwickshire are good countries, and as a matter of fact there are those who place the Warwickshire country in its 


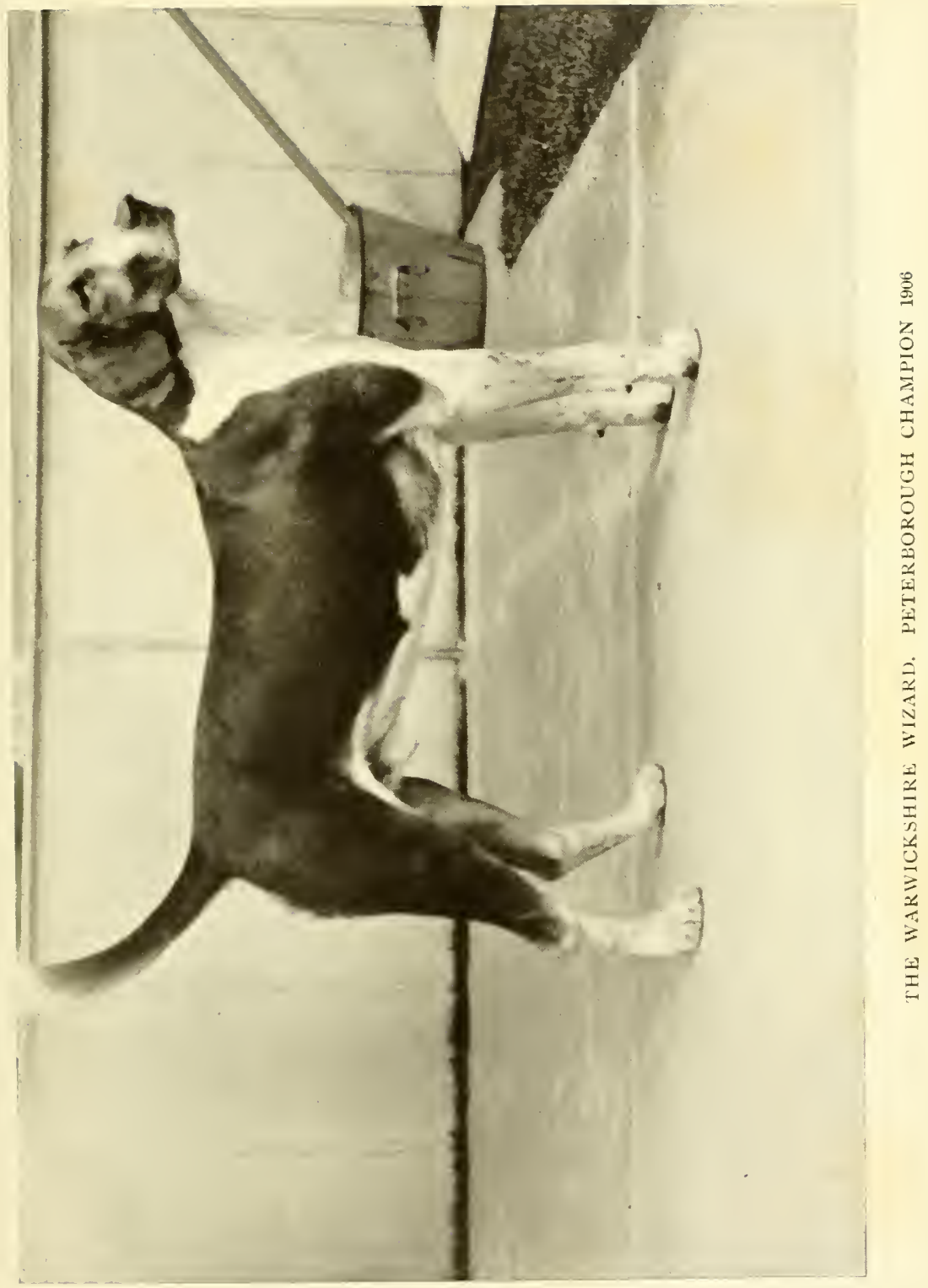



entirety on a level with any country in the kingdom. It is for the most part a grass country, and in this respect it is better than the Atherstone or North Warwickshire, but it is a country of great extent, and some of the best of it is wide of Rugby. The drawback (if there is any drawback to hunting in the Midlands) to Rugby as a centre is that, like Market Harborough and Melton Mowbray, it involves three or four subscriptions to those who hunt four or five days a week. Otherwise the place is a pleasant one, which gains in popularity every year, and where there is perhaps a little more life on non-hunting days than there is at Market Harborough or Oakham.

For the two Warwickshire packs Leamington and Warwick are very handy, and the first-named town, being an inland watering-place, offers attractions which are not to be found at the purely market towns. Indeed, hunting men and women who do not care for the great crowds, and the heavy expenses connected with hunting in the Shires, who have no country location of their own, and are not more interested in one hunt than another, but who are yet desirous of obtaining a fair amount of sport, should look for winter quarters at an inland watering-place, and the best of these are to be found in the Western Midlands.

Many hunting folk there are, of both sexes, who can pick and choose their quarters, and who yet are hardly desirous of obtaining what is generally considered to be the very best sport. Some of them may be too old for the flying bursts so often met with in Leicestershire or Northamptonshire; others may have been entered to smaller fields and a quieter style of hunting, and may be content with two or three days a week. The Shires are right enough for the man or woman who 
has a strong stud, and desires to hunt on every available day, but for the ordinary individual with leisure and a certain amount of means such towns as Leamington, Cheltenham, and Malvern particularly appeal, because there is plenty of society in these towns, good clubs, and bridge, which is probably unlimited as regards the quantity of it to be had, and limited as regards the points which are played.

It is argued that Leamington is in these days to some extent a suburb of Birmingham, and Coventry, though situated in pleasant country, and very handy for the Atherstone and North Warwickshire, is not quite a watering-place, being, in point of fact, a manufacturing town; but Cheltenham and Malvern are watering-places and nothing else, and both are good if provincial hunting centres. Hunting from Cheltenham means for the most part hunting with the Cotswold hounds, though other packs can be reached with a little trouble, notably the Berkeley (Lord Fitzhardinge's), the V.W.H. (Earl Bathurst's), the Croome, the Ledbury, and the North Cotswold. The kennels of the Cotswold are close to the town of Cheltenham, and hounds are out three and sometimes four days a week, all the meets being within riding distance of the town.

Malvern is, perhaps, a better centre than Cheltenham, for it is almost at the division of the Ledbury and Croome hunts, and the Worcestershire can be reached at times, as can the North Herefordshire, occasionally on the Bromyard side of the country. The Ledbury and the Croome, however, are out four and three days in each week respectively, and the former pack often have an extra day; nearly all of the Ledbury country is within reach of Malvern if an occa- 


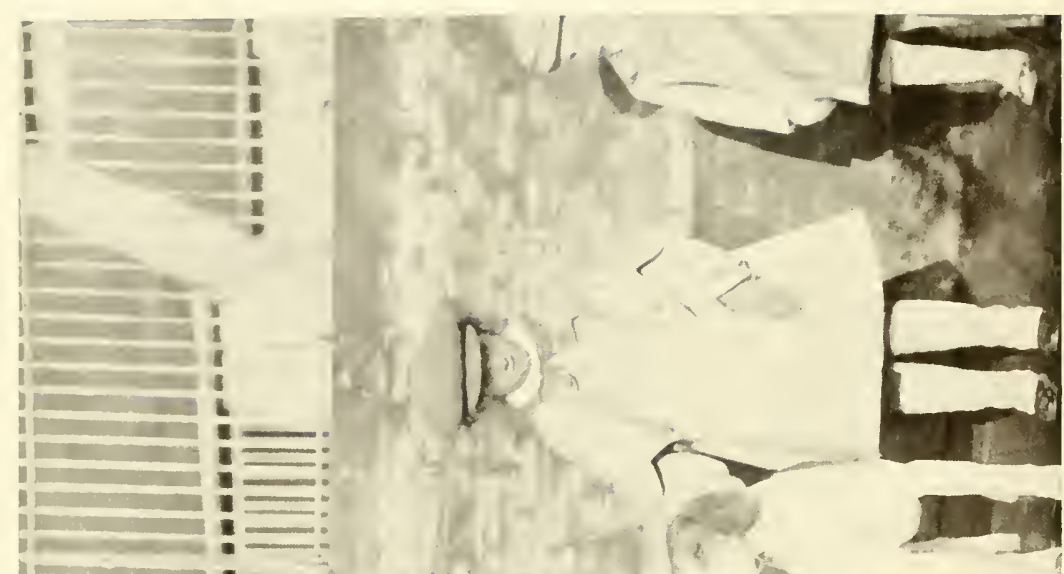

Bin

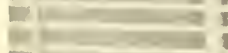

In

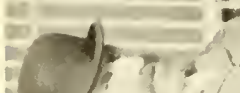

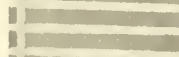

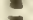

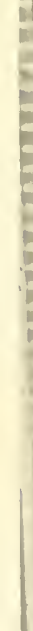

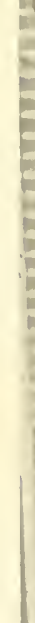

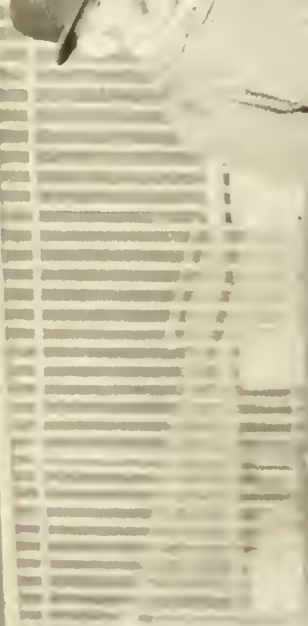

Com $=$ 
sional long trot to covert is not objected to, while the same remark applies to the greater part of the Croome country, so that any one living on the famous hill can, if he is so disposed, hunt every day. And the hunting is wonderfully good, there being a fair amount of grass in both Ledbury and Croome domains, while the plough is not particularly deep. Some big woodlands there are, but for all that the bulk of the hunting is in the open, and the Ledbury is, on the whole, a fair scenting country, while the Worcestershire has a bad reputation in this respect.

Bath, another inland watering-place, is not very well placed for hunting. It lies on the boundary of the Duke of Beaufort's Hunt, but there is seldom any foxhunting on the Bristol side of the town, and thus the Badminton pack are not very often within an easy ride of the city. There is a pack of harriers at Bath, and some few of the northern meets of the South and West Wilts are not very far away, but any one living there, and wishing to hunt several days in the week, would have to hunt by train very often. Still, the Duke of Beaufort's hounds attract many visitors every season, and these, as a rule, take houses, or find quarters at Chippenham, Cirencester, Tetbury, or Chipping Sodbury, and devote a portion of their time to one of the two V.W.H. packs. Chippenham and Calne are the most important towns near the centre of the hunt, and there is an hotel-the "Portcullis"-close to one of the gates of Badminton Park.

But hunting quarters from which several important packs can be reached are very numerous in the Midlands, and mention may be made of other places which from time to time are visited by strangers, and where the letting of houses, chiefly for hunting purposes, is 
common enough. Thus Broadway and Evesham, in the North Cotswold country, are suitable centres, especially the first-named, which commands some of the Warwickshire Vale. Banbury, too, which is close to the junction of the Heythrop, Bicester, and Warwickshire, and by no means remote from some of the Grafton country; Moreton-in-the-Marsh, where the best of the Heythrop and much of the Warwickshire are the nearest countries; Faringdon, where hunting with the Old Berks and V.W.H. (Cricklade) can be enjoyed; Burford, where the two last-named packs and the Bradwell Grove country (in fact, all the Southern Heythrop country) can be reached; Oxford, from which hunting with the Old Berks, South Oxfordshire, Heythrop, and Bicester can be chosen; Bicester, in the centre of the country of that name, and Buckingham, handy for some of the Bicester, the Grafton, and Whaddon Chase. Then there are Bletchley and Leighton Buzzard, in the Whaddon Chase country, but also handy for Lord Rothschild's staghounds, and Aylesbury, where there is a wide and grand grass vale, hunted over by the Whaddon Chase, the South Oxfordshire, and the Old Berkeley (West), as well as the aforementioned staghound pack. The vale of Aylesbury justly bears a very great reputation, both as scenting and galloping ground; it is practically all grass, and is strongly fenced, with many brooks meandering about it, and the best of it is within reach of Leighton, Winslow, and Bletchley, though Aylesbury is perhaps nearest its centre. 


\section{THE HOME AND SOUTHERN COUNTIES}

Of hunting centres close to London there are some which are convenient enough, but none of the countries can compare with those to be found in the Midlands, big woodlands and steep hills being all too common on the south side of the Metropolis, while more open country with much cold scenting plough is the chief feature of those hunts which lie to the north of the capital. Still, hunting is carried on most vigorously in nearly a score of what may be called metropolitan hunts, and nearly everywhere there are large fields of regular followers, and an enthusiasm which is far beyond that to be found in a really fashionable hunt. And of boxing from London there is practically none in these days, nineteen-twentieths of the London hunting community having long since taken up their quarters in the particular hunt they incline to, while the odd twentieth, if he trains up and down from town, keeps his horses in the country.

Dealing first with the north side there are the two divisions of the Old Berkeley, the Hertfordshire, the Puckeridge, the Essex, and the Essex Union, all of which have country, even now, within about twenty miles of London. Time was when some of them hunted much nearer to the suburbs than they now do, and notably the Essex used to come within eight or ten miles of the centre of the city, while within the last few years we have ourselves seen the Old Berkeley within a mile of Uxbridge, and only fifteen miles from town. The Hertfordshire, too, come a long way south occasionally, but the Puckeridge country has its southern boundary further away, north of the River Lea, 
on its course between Hertford and Broxbourne. Bricks and mortar have driven all these packs back, but, curiously enough, when once a certain limit is passed many of the metropolitan countries are fairly wild, and by no means populous. Indeed, nowhere in the Midlands is there a country of so small a population as that to be found right across the northern part of the Puckeridge Hunt, and a similar remark applies to the extreme north of the Essex country.

Excessive woodland is the weak point of both divisions of the Old Berkeley country, there being a great deal of it, with light plough and a little pasture as well. The plough carries a moderate scent, but, as has been stated, part of the famous vale of Aylesbury is within the confines of this hunt, and between them the two packs are out on four different days of the week. Amersham is near the centre of the Old Berkeley West, and Rickmansworth is a handy spot for the eastern side of the country. The recently made Great Central Railway has opened out the western portion of this hunt very much of late years, and a good deal of building is being done in districts that were rural and primitive to a degree less than a dozen years ago. The Hertfordshire is a plough country, and mostly cold scenting land; there are considerable woodlands, and a little pasture, but the country is a big one, hunted by a four-days-aweek pack, and when the land is wet sport is often first-rate.

Indeed, this is the case in the adjoining Puckeridge country, and to some extent in the Essex country also, but if one may write from personal observation the Essex country carries a better scent when the land is dry than does the Puckeridge or the Hertfordshire. Like the Hertfordshire, the Essex and Puckeridge 


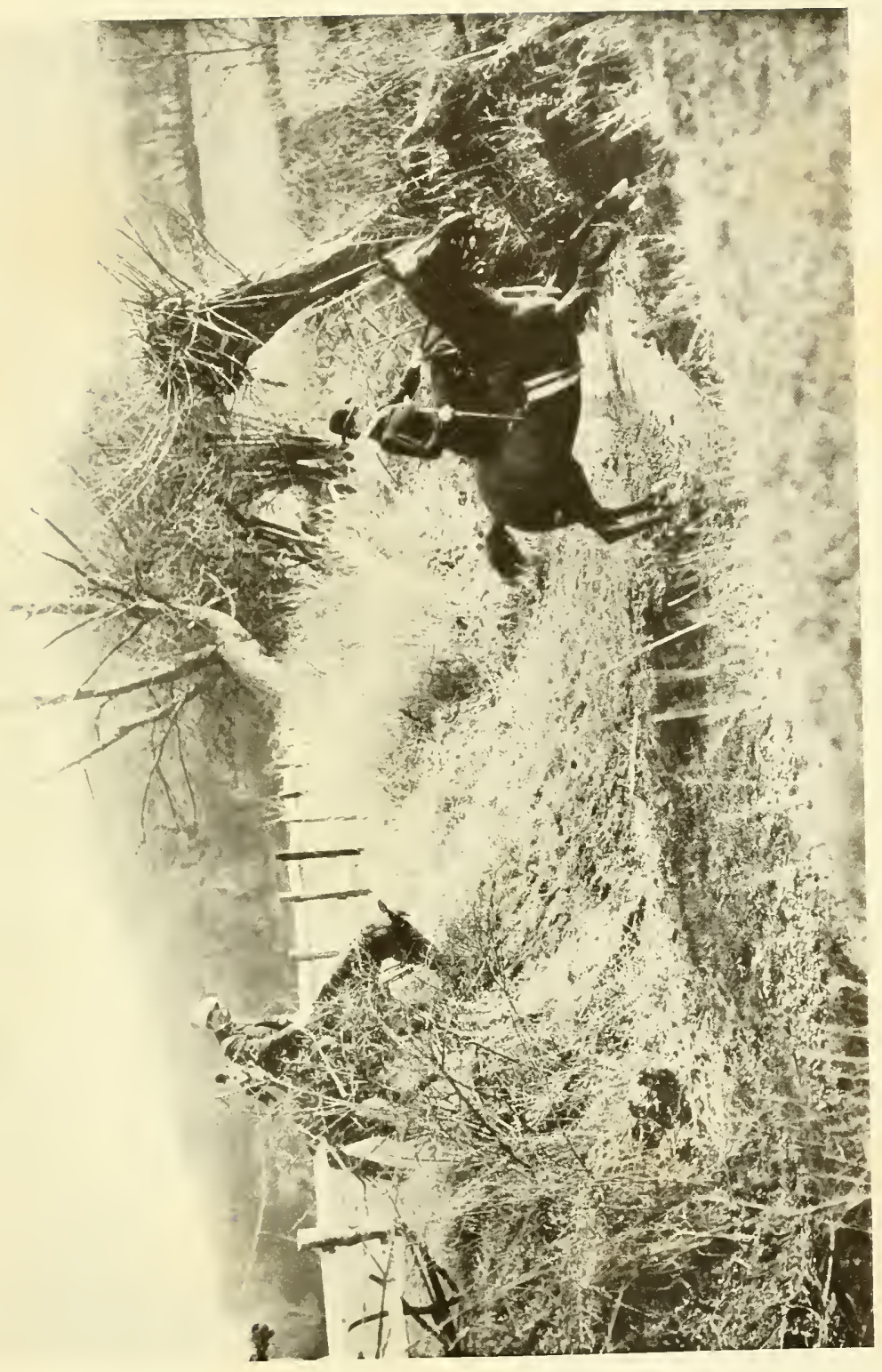

3
$\square$
0
0
0
$\vdots$
$\vdots$
$=$
$=$
$=$ 

are four-days-a-week packs, with countries which are large in area, but the two last named have far less woodland than the Hertfordshire, and the Puckeridge is one of the most open countries in the kingdom, especially on its northern side.

Fields are very large at times with both packs, and Bishop's Stortford is probably the best centre, as from this place an industrious man can hunt every day in the week with either the Puckeridge or the Essex. The town first named is within Puckeridge limits, but some of the nearest coverts are neutral to the two hunts, notably Takeley Forest, the finest cub-hunting ground we ever saw. Of plough countries the Essex and Puckeridge are generally considered to be the best in the kingdom, and it may be mentioned that during the autumn the stubbles afford grand galloping, and, naturally enough, with so much arable land in the district much of it cannot be ploughed until quite late in the season. Londoners form the bulk of the field with both packs, but they are Londoners who reside in either of the countries.

The Essex Union is also a four-days-a-week pack, with a country which is being rapidly acquired by the builder in some districts, and is remarkably wild in others. It contains rather more grass than its neighbours, and has good scenting land on the extreme east, nearest the sea, but the biggest fields are to be found on the Chelmsford side of the country, where many of the hunting residents divide their favours between this pack and the Essex, some of them occasionally going to the East Essex as well. The pack just named is hardly a metropolitan one, a remark which also applies to the Essex and Suffolk, the Suffolk, the Cambridgeshire, and the Newmarket and Thurlow. Nor are any of the countries good enough 
from a riding point of view to attract strangers, for in all of them there is more plough than grass, and excessive game preservation is a feature of many districts in each of these hunts. The following in each is fairly local, but very good sport is at times obtained, and both the present and the lately retired master of the Essex and Suffolk are great enthusiasts and most successful breeders of hounds. Perhaps the Cambridgeshire has more grass than the Essex countries, and not only has this pack a fine history, but it has some famous names on its bead-roll of past masters, and it can boast of being almost entirely free from wire.

The Newmarket and Thurlow country was hunted at one time by the famous Mr. George Osbaldeston, who held the then Thurlow country concurrently with the Pytchley, and journeyed to and fro the two countries, travelling at night, and very often doing the distance on hacks, which had been sent forward to various towns on the road. Saffron Walden, it may be mentioned, is almost at the junction of this hunt, the Essex, and the Puckeridge, and any one living there can command the Puckeridge Monday country, some of their Tuesday or Wednesday country, one day with the Newmarket and Thurlow (generally Thursday), while the Essex Fridays are always close at hand. There is something comic about the idea of Saffron Walden being a good hunting centre, but for a man who must be in town two days a week, and can hunt on the other four, it is by no means to be despised, and personally we have seen rattling good sport, both with the Puckeridge and Essex, within a few miles of the town.

On the west side of London, in addition to the Old 
Berkeley, which have already been mentioned, there are the Garth and the South Berks hunts, of which the first named comes nearest to London in the country about Chertsey and Virginia Water, or in the neighbourhood of Maidenhead Thicket, or Hawthorn Hill. The country is a large one, but its hunting operations do not extend to the London side of the Thames, so that its northern or eastern boundary is over twenty miles away, while in a southerly direction the country reaches almost to Odiham in Hants, where it joins the H.H. Though some of its area has been lately built over to a considerable extent, there is still much good country in the Garth Hunt, and none better from a riding point of view than that which lies immediately to the south of the Bath road between Maidenhead and Reading, as far as the South-Western Railway line from Staines to Reading. South of this railway Chobham Ridges is a huge open common, but the heavily wooded Swinley Forest is also of vast extent, and the latter is hardly an ideal foxhunting district. On the Hampshire side of the country there is little population, but the meets are somewhat remote for the average follower who resides in the Ascot and Windsor district, and hounds lie out every Thursday night before hunting in the (often known as) Hartford Bridge district. The pack hunt four days a week, and the fields are generally large, though perhaps largest in the Windsor district. Strangers, naturally enough, visit this pack a good deal at odd times, but the bulk of the following is composed of residents, and when it is stated that Windsor, Ascot, Maidenhead, and Wokingham are actually within the hunt, while Henley, Reading, Aldershot, Farnham, and other important residential places are on its boun- 
daries, its success and great popularity can be easily understood.

The South Berks Hunt is really too far from town to be called a metropolitan hunt, and it should perhaps be included in a group with such hunts as the Vine, the Craven, the South Oxfordshire, and the H.H., as hunting people reside within its confines who are also able to hunt with one or other of these packs. The headquarters of the hunt are practically at Reading, the kennels being situated some four miles to the west of the biscuit town, but many of the regular followers of this pack live in the Kennet Valley, as far south as Newbury, while others are scattered amongst the Thamesside towns. Part of the country is north of the Thames, the market-place at Henley being an occasional fixture; and here it may be stated that Henley is a fair hunting centre, as it is only six or seven miles from the Garth kennels, can command all the Oxfordshire and some of the Berkshire country of the South Berks, and is only four or five miles from the South Oxfordshire boundary in the neighbourhood of Nettlebed. There is also a smart pack of harriers in the immediate neighbourhood of the town.

Continuing with the London hunts, and approaching from the west side, we have the Surrey Union, which joins the Garth Hunt near Chertsey and Ripley, and the Old Surrey further east. Practically the Surrey Union hounds hunt the whole of West Surrey, though the Garth come into the country about Chertsey and Windlesham, and the Chiddingfold have their kennels and some part of their country in Surrey. The Surrey Union may fairly be termed a London hunt, seeing that it comes (very occasionally now) as near to town as Worcester Park, and is frequently within 
a mile or two of Esher. Not so long ago the suburbs ceased at the village first named, but huge areas of land have now been requisitioned by the builder in the neighbourhood of Weybridge and Woking, and the hunting line has been gradually forced to the south of the Guildford railway. At Cobham, too, building estates are being laid out, but for all that the Surrey Union have a great deal of wild, thinlypopulated country, which, though hilly in places, is productive of capital sport. Those who know the district will be aware that there are comparatively few railways in Surrey. On the eastern side of this hunt there is the Brighton line to Dorking, Horsham, and Portsmouth, and on the extreme west the SouthWestern line to Portsmouth. Between these two there are no railways beyond the loop line from Surbiton and Leatherhead to Guildford, and as a matter of fact one may hunt all day with the Surrey Union hounds without seeing a railway, or even a village. Indeed, in the greater part of the country one might be a hundred miles from town instead of within thirty, and this is accounted for by the fact of there being (as stated) few railways, no towns except on the outskirts of the hunt, many large residential estates which are too far away to attract the builder, and lastly because of the physical conformation of a great part of the country. Fields are largest, perhaps, in the country nearest Leatherhead, or where hounds meet near the old Surrey boundary in the neighbourhood of Walton-on-the-Heath or 'Tadworth, but the best country is vale land below the hills, and possibly the best of this is on the Burstow boundary, east of Dorking, about Betchworth and Leigh. Hounds are generally out three days a week, and it is the case that hard riders are in this hunt as 
plentiful as blackberries in autumn. The field live, for the most part, about Leatherhead, Dorking, Epsom, and Guildford, but of course some of them reside further south; all are enthusiastic, and the establishment is conducted on the most orthodox principles.

For many years we have marvelled over the wordpictures which Surtees drew of the Old Surrey hounds, and have never been able to realise how much of his descriptions was true and how much chaff. For our own part we saw the pack in question as long ago as during the mastership of Messrs. Mortimer and Nicholl, and the Surrey Union, when Mr. Francis Scott or Mr. J. Barnard Hankey were in office. We never had more than an odd day at that time with either pack, and indeed we rode from London to more than one Surrey Union fixture. We had, however, previously seen all the Shire packs in the field, many of those which hunt in the Western Midlands, and several of the most important northern packs. We had therefore some experience and some knowledge of how things should be done, and having always been great readers of Surtees' works we had come to believe that we should see something comic in the Old Surrey Hunt, in spite of the fact that Surtees had written his accounts of hunting in Surrey some thirty years before. But we had not been five minutes at a meet before we discovered that if the accounts which Surtees gave had been true thirty years before, they could not be reconciled for a moment now. The turn-out of the establishment was just like that of any other hunt. The men were better dressed and better mounted than we had seen the servants of much more important hunts; the packs were good-looking and level, and the hunting was conducted on correct enough lines. 


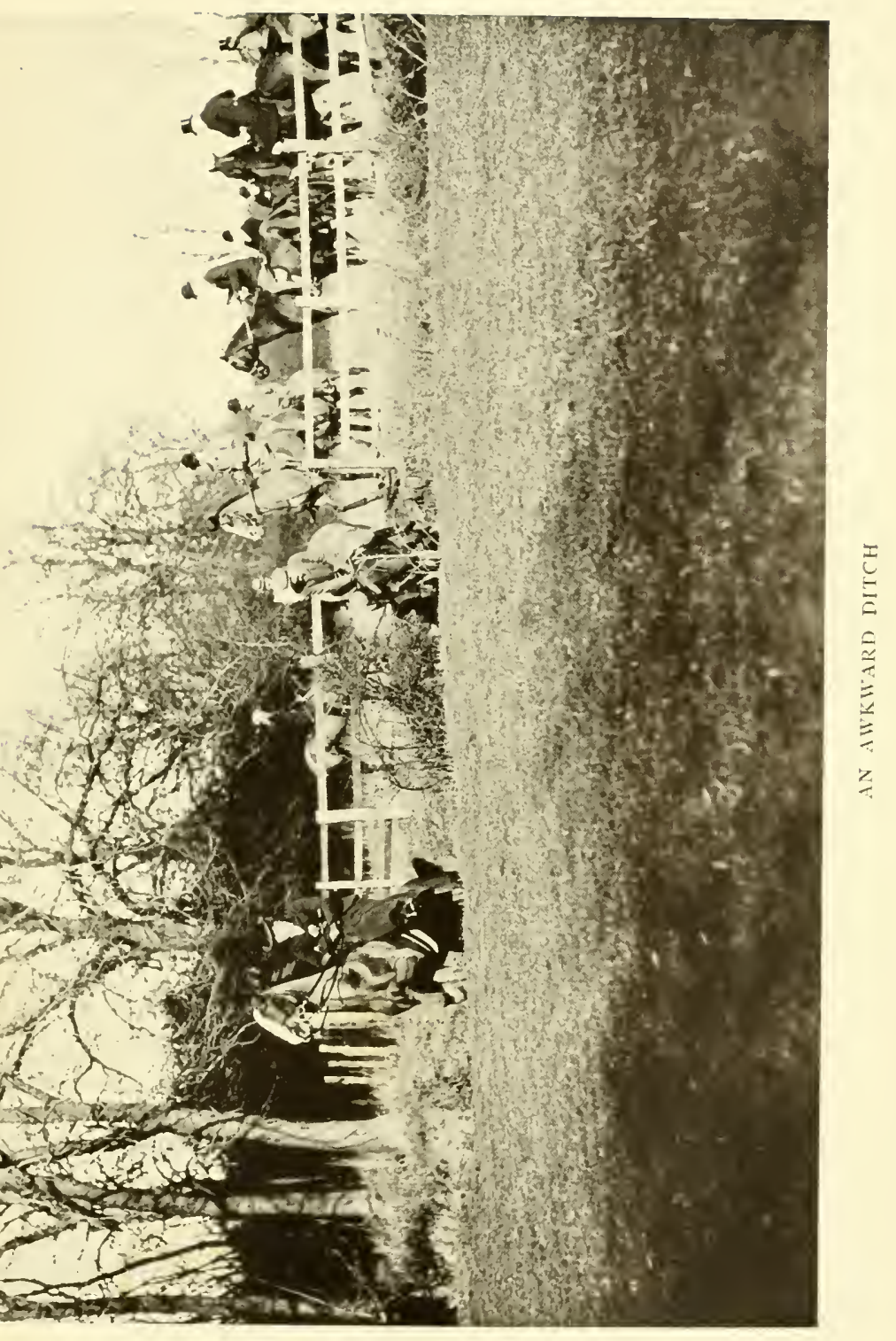



One remembers the story of the great hunting critic who went on a visit of inspection to a provincial pack, and who, after speaking of the correct way in which the hunt was turned out, went on to say that, " in fact, there was nothing ridiculous about the establishment until they threw off." But with regard to the Old Surrey there was nothing ridiculous at all, and as for the discussions concerning markets and trades-subjects on which Surtees enlarged at length-we never heard a word of them. Indeed, we may say here that thirty years ago, and in much more recent times, when we have hunted with all the Surrey packs, we have found in each of the three-Surrey Union, Old Surrey, and Burstow -not only the best behaved, but the most enthusiastic of hunting people, and more hard riders in proportion to the full strength of the field than in any other hunt.

It is true that the Old Surrey are not possessed of a really good country; they have a nice bit of vale, parallel with and north of the railway from Redhill to Edenbridge, but the northern side of the hunt is hilly, flinty land, which does not often carry a good scent, and in places there are very big woodlands, while much of what was, not many years ago, good hunting country has fallen into the hands of the builder. Neither are foxes too plentiful, but still a fair average of sport is maintained, and the present pack is a wonderfully good-looking one, great attention having been paid by Mr. Boileau to their breeding.

Years ago Croydon was a sort of headquarters for the Old Surrey, and the Saturday meets were always within an easy ride of that town. Of late much of the original Saturday country has been abandoned, and the followers-as in all the hunts near London-reside all over the country. 
Reigate and its neighbour Redhill are, nowadays, practically the head-quarters of hunting in Surrey. Both the Surrey packs, the best of the Burstow country, and much of the country hunted over by the Surrey staghounds are within reach of the town, and hunting men by the score have taken up their quarters in and about what is really one of the pleasantest and best situated of small southern towns. Many hunting men from all parts of the kingdom have lately come to know Reigate on account of its most successful and well-managed hound show, but they only visit the place towards the end of May, and can have little idea how different the country looks during the winter months.

To explain what we mean we may mention that the plain on the southern side of Reigate, of which the larger part is Burstow, while the Old Surrey has the northern strip and the Surrey Union the western portion, is for the most part grass, with fair jumpable fences, and a good deal of water. The coverts are not large until the next line of hills, ten miles away, is reached, and there are no towns or villages of any size except Horley. It is, in fact, a really capital piece of hunting country, which lies in a sort of basin of the Surrey Hills, and to give some idea of its flatness it may be mentioned that the main road to Brighton intersects it, between Reigate or Redhill and Crawley in Sussex. How good a galloping country this is the famous Lonsdale-Shrewsbury driving match testifies, for five miles of the road between the two towns just named was chosen for the performance, and as every one knows Lord Lonsdale drove his horses twenty miles within the hour, yoked in four different styles, over the ground.

But the country is pretty from a picturesque point 
of view, as well as good galloping ground. It has numerous tiny copses, of a few roods in extent, occasional belts of trees, and many small spinneys, while grand old elms and other forest trees are to be found standing alone in the centre of the fields or scattered up and down the hedgerows. The upshot is that at the end of May, when all the leaves are in their early luxuriance, the view, when one is actually on the plain, is very much obscured, and trees are to be seen everywhere, whilst tiny spinneys assume the proportions of big woodlands.

This was very forcibly impressed upon us some few years ago when we were coaching to Brighton one day in July. Our host, who was driving, expressed approval of the country from the scenic point of view, but was altogether sceptical when we remarked that it was a good hunting country also. "Why, it's all woodland!" he exclaimed, and we could not persuade him to the contrary, though we admitted that there were woods enough and to spare as soon as the Sussex border had been crossed. Well, as it happened, during the following winter our friend-who when at home hunted in Cheshire-was in town, and one day we chanced to tell him that we were going to hunt with the Burstow on the morrow. He at once replied that he had lately bought a horse, which he still had in town, that he would send it down that afternoon, and-remembering our conversation of the previous summer - that he would then find out which of us was right about the character of the country. Next morning we travelled by an early train to East Grinstead, and having breakfasted there, trotted on to the meet a few miles away. Our old hunting diary makes no mention of the earlier sport of the day, and probably 
it was only moderate, but what is written about the afternoon causes us to remember exactly what took place. Hounds got a fox away from Cutandly Wood, and ran to Horne, and thence northwards almost to South Hale, but they turned towards the Brighton railway, and as far as we remember the fox got to ground either under or close to the line, but of that we are not sure. Our friend, who came to grief at a brook early in the run, was much impressed, and declared it was the best gallop he had had that season. Anyhow the line followed was a good one, and in those days that part of the country was fairly free from wire.

Unfortunately the whole of the Burstow country is not like the Vale, for when once the Sussex border is reached big woodlands are very numerous, and included in these is Ashdown Forest. Perhaps the most central place of residence in the hunt is East Grinstead, but if any one wishes to be with these hounds in their best country only, the neighbourhoods of Reigate, Horley, or Lingfield would do equally well, and other packs could also be reached. Saturday is the great day with the Burstow, when the field is four times as large as that of Wednesday, and the hunting is always in the Vale. To give some idea of a really good day in the Vale we may go back some twelve years, to the last day the late Mr. Gerard Hoare (master from I88I to 1896 , and huntsman for fourteen years prior to $188 \mathrm{I}$ ) was out with these hounds. The meet was at Lingfield, and a fox was found in the copse which is situated in the centre of the racecourse. It crossed the brook, and hounds got away by themselves, the field being held up by wire a field or two beyond the racecourse boundary. This was perhaps a good thing, for hounds were able to settle to their fox, and when the front rank 
got in touch ten minutes later, were going best pace westwards, over a good country. In some fifty minutes they arrived at the Brighton main line, which they crossed at Gatwick racecourse, the field riding through the paddock, the gates of which were open, and out on to the course. Near the top bend of the course hounds turned southwards, and the fox began to dodge for the first time. But scent was very good, and exactly an hour and twenty minutes from the find he was killed on the outskirts of Crawley, just where the Burstow and the Crawley and Horsham countries join.

It was quite early in the day, and Mr. Hoare decided to go back to the country he had come from, so that a trot of something like an hour and a half was the next item on the programme. Many of the field dropped off, and it was after three o'clock before another fox was found in a covert near New Chapel Green. There was a tremendous row in covert, and Mr. Hoare came on to the road saying that hounds had divided, that he had seen both foxes, but that he did not feel well, and was going home. After a while hounds got away with one of the foxes on the eastern side of the covert and ran by the Bellagio estate to Hammerwood, and thence to Cowden in the West Kent country. Beyond this place it is impossible to say where they went, for none of the few who were left knew an inch of the country, and it was rapidly becoming dark. But hounds were carrying such a head that White (their huntsman that season, and before that with the defunct Goodwood pack) was unable to get very near them. Luckily they killed their fox in a hedgerow, and he was quickly disposed of in the twilight, and then came the question of getting home. No one of the small party knew where he was, and it was long enough before we found a 
country lane, and longer still before we discovered a house. At last we got our bearings, and hounds were well over twenty miles from kennels, and did not get home until ten o'clock, while the rest of us reached East Grinstead a little before eight, and leaving our horses there for the night, went home by train.

This was one of the best days we ever had with any hounds, and we always regretted that most of the usual Burstow field did not see it. The fact is that in those days-we do not know how it may be now-few of the followers of these hounds had a second horse out, and that being the case two-thirds of the field had gone home before this second run began, while many others had fallen out of the ranks near the West Kent border, being of opinion (and rightly too) that a single horse had had quite enough for one day. Poor Mr. Hoare never hunted again, and in point of fact only lived a few weeks after the day we have been describing. $\mathrm{He}$ was a rare sportsman, who carried the horn until he was over seventy years of age, and he was fairly worshipped by the farmers of his hunt. He did much towards making the pack what it now is, as he hunted them for twenty-nine seasons, being master also during the last fifteen. He had a wonderful manner with horses, and when he was getting too old to ride over a big fence he would get off and lead over, if it was possible.

Brighton and Lewes are fairly central for the Southdown, as are Steyning and Hassocks, while Eastbourne residents now have their own pack, and those who hunt from Hastings can reach all the East Sussex country. Chichester is a poor hunting centre, though the southern meets of the Crawley and Horsham are available, as are-since he extended his country-some of 



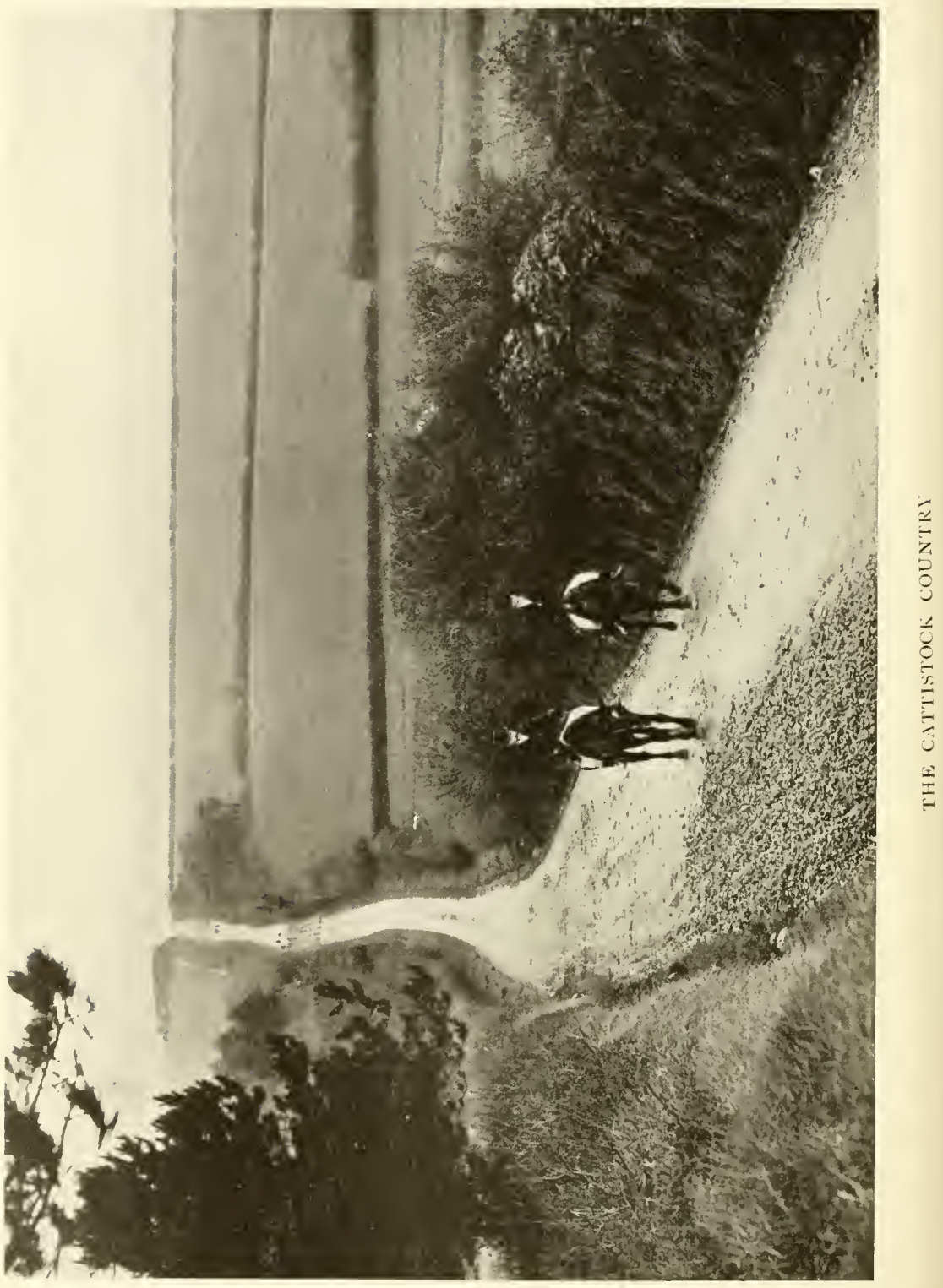


Lord Leconfield's. At Winchester plenty of hunting is obtainable, with the Hursley, Hambledon, and H.H., but Portsmouth is not well placed, except for the southern portion of the Hambledon Hunt.

By train, however, the New Forest can be reached from Portsmouth, and much of it from Southampton by road. Here there are both foxhounds and staghounds, the staghounds hunting on Monday and Friday, and the foxhounds on Thursday and Saturday. Brockenhurst and Lyndhurst are the most popular centres, but hunting men are scattered all over the Forest, and in the spring of the year many visitors arrive to secure the benefit of hunting - with both packs-right through the month of April. The hunting is, from a riding point of view, quite unique, but it has, like that of Devon and Somerset, a charm and fascination of its own, and nowhere in the kingdom can the real lover of hound-work see more to please him.

Farther down the south coast most of the hunting is confined to the local population until the Blackmore Vale and Cattistock countries are reached. Both of these packs have first-rate country, and show sport that is good enough to attract strangers, and, for the Blackmore Vale, Sherborne is undoubtedly the most popular centre, though Yeovil is fairly handy. Maiden Newton is the most central town in the Cattistock country, and certain meets of the pack are within reach of Dorchester and Weymouth.

As for Devonshire, a wonderful hunting country, and yet, except in one corner of it, extremely local as regards the following, it is difficult to mention any town or district where good sport cannot be enjoyed, though the hills are almost everywhere, and the riding lines quite different from those which are to be found in 
the Midlands. From Exeter the East and Mid-Devon are accessible; from Torquay and Totnes the South Devon and Dartmoor; from Tiverton the pack which takes its name from the town; and from Lynton, Lynmouth, and Ilfracombe the Exmoor. Even now the list is nothing like exhausted, but from the stranger's point of view hunting in Devonshire generally means hunting with the staghounds, which are located in the extreme north of the country, and hunt as much in West Somerset as they do in Devon.

All through the staghunting district the stranger comes in hundreds, chiefly in August and September, and in smaller numbers in the spring. Dunster, Minehead, Porlock, Porlock Weir, Lynton, Lynmouth, Ilfracombe, Exford, and Dulverton are all prepared to furnish quarters for horses and their riders; and though Exford is much the most central for the operations of the Devon and Somerset staghounds, it is a somewhat dull spot on non-hunting days, whereas the seaside towns allow of a more varied life. Those who go westward in the late summer, and who are paying a first visit, should go prepared for long journeys to the meets, long hunts which often come late in the afternoon, and long rides home after dark. Of course no one is bound to exert himself by these long journeys, but any one who goes to Exmoor and intends to hunt thoroughly, and not merely to look on at the tufting, should be in fair condition, and able to stand some eight or ten hours of saddle-work on occasions. It is not every day that is a long and hard one, but the country is a wide one, and hounds may easily meet twenty miles or more from the place where one is staying. The meet may be a good one, and the weather conditions favourable, and so an effort is made and 
arrangements concluded for sending on one's horse and driving the whole or a part of a distance to the fixture.

Luckily for some of the visitors the meets do not take place until the forenoon is well advanced, but the sport may come quickly, or it may come late, and when one has travelled a long way one hardly likes to leave until one has seen something besides the tufting. This may last a few minutes, or two or three hours, and a slow, dragging hunt may work up into a quick one, with the result that a stranger may find himself at an immense distance from his quarters, with a tired horse, and a very indistinct notion as to how he is going to cover the long, weary miles. No sport that we have seen is quite so uncertain as this staghunting. We have been for two or three hours amongst the heather on Croydon Hill, and hounds have suddenly got away in the afternoon, and made a fifteen-mile point. At other times-when fat stags were in evidence-we have spent a whole day within a radius of two or three miles, and again we have had to ride a tired horse home from a spot midway between Dulverton and Tiverton to Porlock Weir.

But the fascination of Exmoor and its hunting is extraordinary, and this is proved by the fact that many hard-working business men spend their annual holiday on Exmoor, hunting as often as they possibly can with the staghounds, and filling up their spare time with the Exmoor foxhounds, or Minehead Harriers. Hunting men, too, come from all parts of the kingdom for a week or two of the sport, and one has seen half a dozen masters of foxhounds from far-away countries at a September meet at Hawkcombe Head. 


\section{NORTHERN HUNTING LOCALITIES}

Going north from London by what Jorrocks called the best covert hacks in the world, viz. the great main lines which have their termini in the Euston Road, one reaches the Midlands of which mention has been made as far as the Shire countries and some of their neighbours are concerned. On the eastern side of the Shires the Fitzwilliam (Mr. George Fitzwilliam's) Hunt is a most important one, and Peterborough is the town which is nearest to the kennels, while on the western side of the country Oundle and Thrapston are handy, and allow of hunting with the Woodland Pytchley. Visitors from Cambridge hunt with these hounds, too, but they mostly utilise the railway; in the south-east of the country Huntingdon is not a bad centre, for the Cambridgeshire are also available, and there is a good deal of grass land hereaboutswhich, however, is frequently submerged in times of flood.

Bedford is not far from the centre of the Oakley country, and Grantham is a really good centre, where plenty of good accommodation can be obtained. It is in the Belvoir country, but much of the Blankney country is close at hand, and there is a railway into Leicestershire, so that both the Quorn and Cottesmore are within reach. Further north, Newark, though a fairly big town, much given over to industrialism, is quite a good hunting centre. It is within Lord Harrington's (the South Notts) country, but is close to the Belvoir borders, and handy for some of the Rufford, and the Blankney. Cathedral towns are often situated in good hunting countries, and Lincoln 


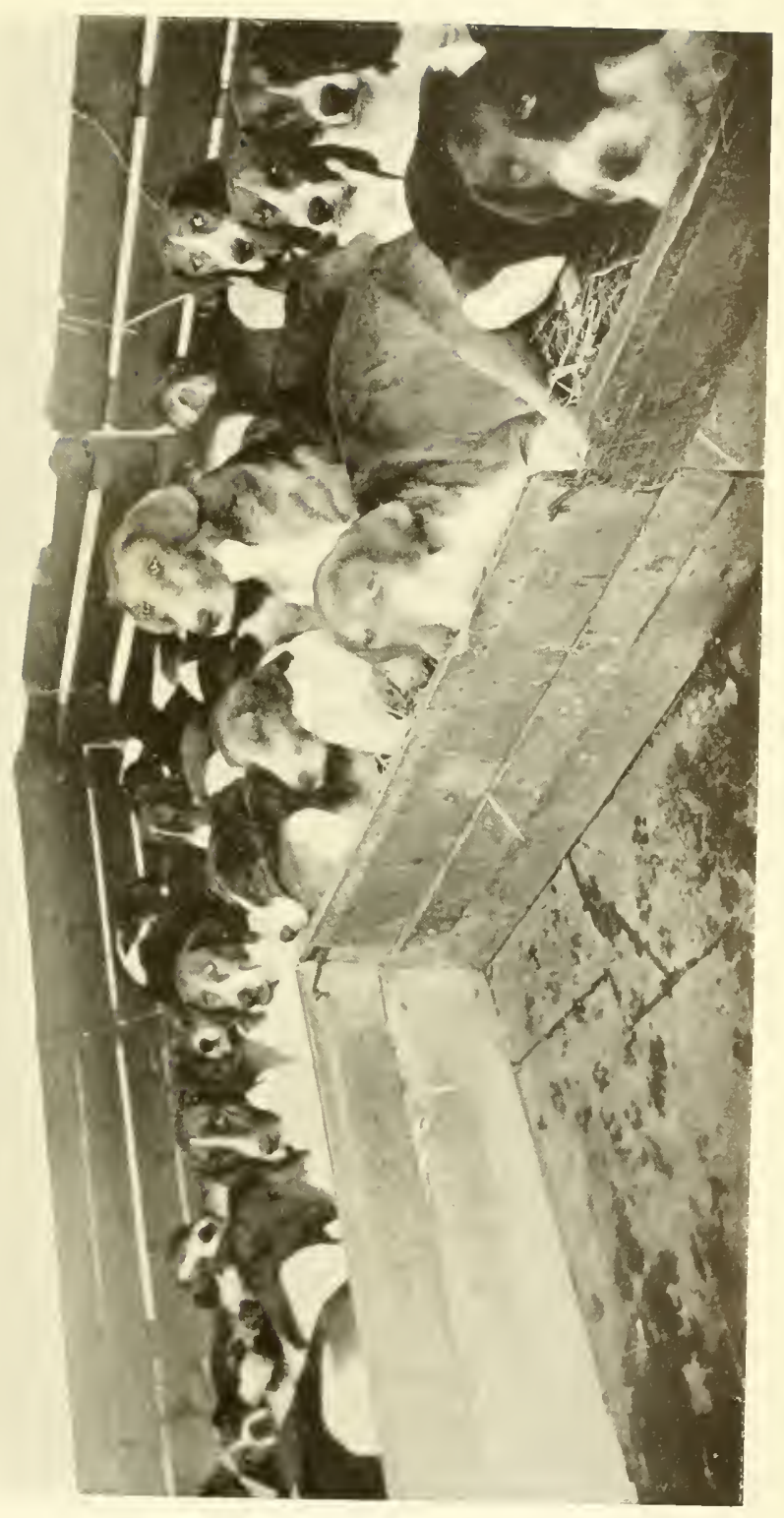

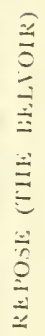



is no exception, as it is in the heart of the Burton country, not far from the northern part of the Blankney, which was at one time part of the Burton country, and within reach by rail of some of the Brocklesby.

For the last-named pack Market Rasen is the most central town, but Lincoln is, after Grantham, the best hunting centre in Lincolnshire. From Louth, on the borders of the Brocklesby and Southwold, it is also possible to see a good deal of sport, but to secure all the four hunting days of $\mathrm{Mr}$. Preston Rawnsley's capital pack (the Southwold) Horncastle is the best-placed town, as it is in the centre of the country. Retford is in the centre of Lord Fitzwilliam's Hunt (the Grove), and from Worksop, a few miles to the west of Retford, the Rufford can also be reached. Both countries are mixed, but plough land-some of it heavy clay-is much in evidence in the Grove country, whereas the Rufford have a lot of grass on the Derbyshire side of their country.

Continuing north, Doncaster is a poor quarter, being too near the fag end of two or three hunts. The Badsworth and Lord Fitzwilliam's countries are nearest to it, but the best country of either pack is not very near the great racing town, on the southeast side of which one quickly reaches salt marshes, and other unhuntable country.

If Doncaster is a poor, York is a good hunting quarter, where the busy man can, with a little trouble, hunt nearly every day of the week. York is situated in the heart of the curiously shaped York and Ainsty country, but so narrow is this centre that the Bramham Moor come to within seven miles on the west side of the city (the boundary is on the Weatherby road near Rufforth, where a year or two ago we saw chalked 
up on a gate, "This man shot the fox." Who the man was we do not remember, but he had to leave the district) and Lord Middleton's to within four miles on the east side. Indeed, the last-named pack meet frequently at the "fourth milestone, Stockton Forest," and this fourth milestone means the fourth out of York. Moreover, a resident of York can reach some of the Holderness, the Sinnington, Lord Zetland's, and the Hurworth by train, if he is not content with the hunting the immediate neighbourhood provides. As for the York country, it is very varied. In some parts of it there is a great deal of plough, which becomes almost hock deep in wet weather. But on the other hand there is also a fair amount of grass, and the whole country has a fair reputation as regards scent. The Bramham Moor Friday country, which lies within easy riding distance of York, is full of foxes, and very popular, and all things considered York is a good hunting centre.

Possibly, however, Harrogate is better, for it is close to all the best of the Bramham Moor, which from a riding point of view is superior to the York and Ainsty, there being more grass on the western side of the country than there is anywhere near York. Moreover, a corner of the York and Ainsty Hunt comes close to Harrogate, on the north side of the River Nidd, and all this district is within from five to ten miles of the sulphur town. For a casual visitor Harrogate is a really first-rate hunting quarter, for there are hotels galore, which are open in the winter, and any number of horses to be hired-though if a hunting man owns horses it pays him best to take them about with him when he travels. Then, too, at Harrogate one can hunt, and hedge against attacks of gout, 
and lastly the train service to and from London has been greatly improved in recent years, and now the traveller can go through in about four hours without the trouble of changing at York or Leeds.

On the eastern side of the county of broad acres Malton is undoubtedly the best hunting quarter, and this we say advisedly, and without wishing to ignore the Holderness. But the fact is that Malton is on the borders of three countries, Lord Middleton's, the Sinnington, and Sir William Cooke's (formerly Sir Hugo Fitzherbert's, before that Mr. Penn Sherbrooke's, and before that Sir Everard Cayley's), and it is handy for the best of the Sinnington, which is a fine grass vale, and for the best of Sir William Cooke's in the vale of the Yorkshire Derwent. Moreover, Lord Middleton's kennels are only four miles from the town, and nearly all his best meets within riding distance. The wold country (Lord Middleton's) contains a great deal of plough land, but is far lighter plough than that met with on the plain of York, and the hounds are beyond reproach, being one of the half-dozen best packs in the kingdom. The best centre for the Holderness is Beverley, and any one living in the Driffield district can reach a good deal of Lord Middleton's wold country.

Scarborough as a hunting place is much better than are many seaside watering-places, for there is a railway from it right through Lord Middleton's, and another right through the Holderness country. Then, again, Lord Middleton's hounds are within riding distance on one day of the week, and Sir William Cooke's on about two hunting days out of three, and there is also a railway line from Scarborough through the lastnamed country to the Sinnington at Pickering. Lastly, 
the Stainton Dale hunt the coast, and if the more pretentious packs are not within reach one may see capital hunting with this trencher-fed pack.

All over the northern part of the plain of York there is a fair amount of hunting to be procured, but Thirsk is not exactly a good centre; for though it is within reach of the most northern meets of the York and Ainsty, and of some of the Bedale fixtures, it is rather wide of both. The Sinnington, the Bilsdale, and the Hurworth could also be reached from Thirsk at times with a little trouble, and some of Lord Middleton's meets are within hacking distance to an energetic man, but on the whole Northallerton is a better place, for it commands much of the best country of both Bedale and Hurworth, as well as the hill packs. Bedale itself is central for the Bedale hounds, and at Ripon the southern Bedale country and certain parts of the York and Ainsty are available, while Catterick, or Catterick Bridge, which is on the border line of the Bedale and Lord Zetland's, commands much of the best country of either pack.

For many years "the Bridge," as Catterick Bridge is called locally, was a most popular place with hunting visitors, and at one time it was no easy matter to obtain quarters at the hotel, so great was the demand. The hotel in question was originally one of the several hunting boxes which Lord Darlington caused to be built in his huge country, and the big room in which the hunting visitors dined has the arms of the Vane family carved on the ceiling. But unfortunately the house is no longer an hotel-though it is understood that accommodation can still be secured, and there is still a vast range of stabling. Any one living in the Catterick neighbourhood can hunt on Monday and 


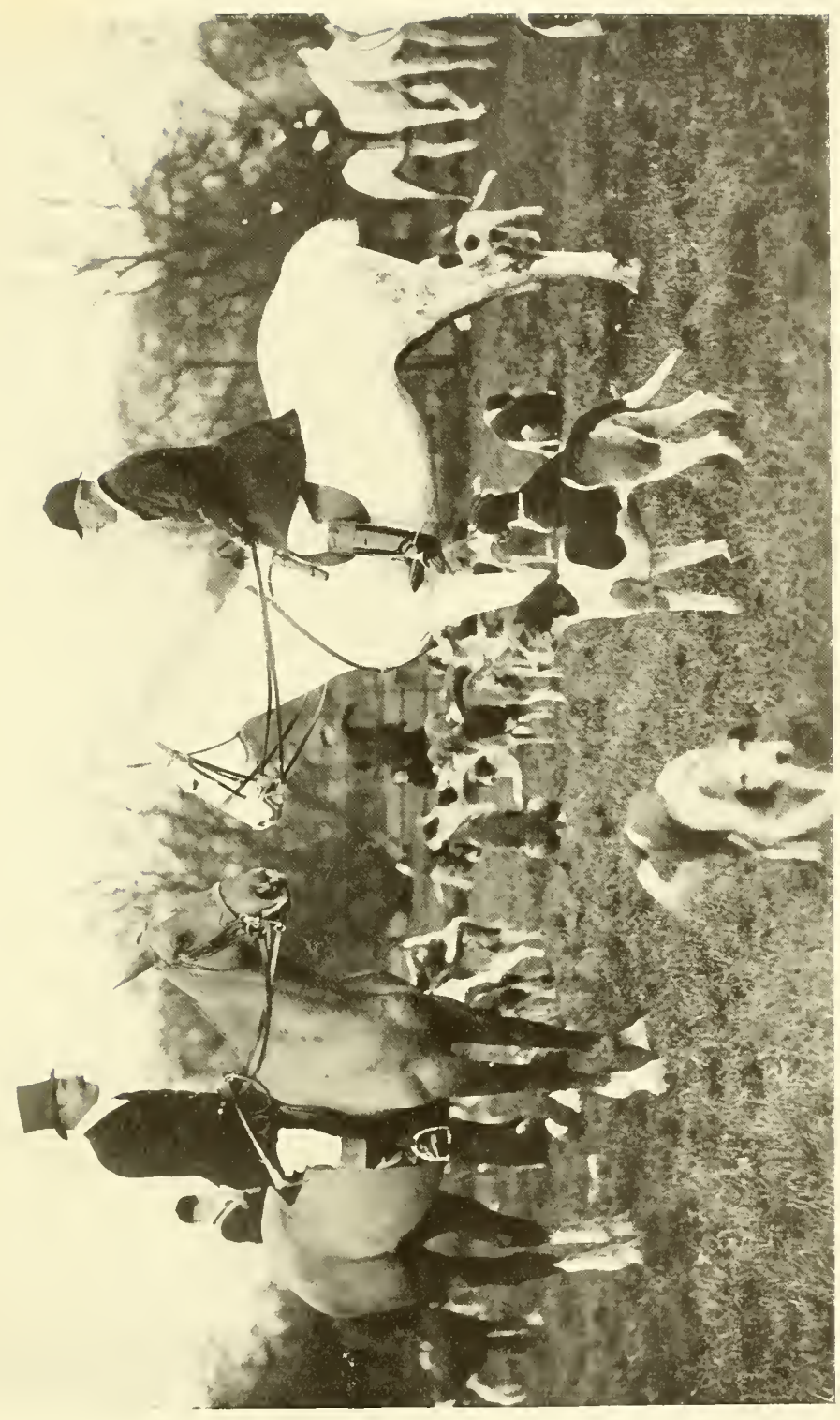

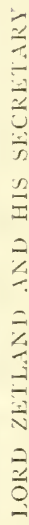



Thursday with Lord Zetland's hounds, and on Wednesday and Friday with the Bedale, and, as a rule, will have no great distance to travel to covert. On Tuesdays and Saturdays Lord Zetland's can also be reached, but the distances are greater, especially on Saturdays. Catterick is in a pleasant rural district, and there is a polo club, whose ground is the Catterick racecourse, the gates of which are exactly opposite the Bridge House. This tends to make the place popular, especially with young hunting men, but as a matter of fact there is no more sporting neighbourhood in the kingdom, and we shall never forget a week's visit to the place some years ago. The races were then held in the early part of the week, and we arrived on Monday evening, were at the races on the two following days, hunted with Lord Zetland on the Thursday, and with the Bedale on the Friday, finishing the week with an early morning visit to the Middleham training stables on Saturday. Motors had not then come into fashion, but our host drove a smart team, which we had out every day, either to bring a party to the races, to drive to covert, or to the training stables. One wonders if there is a single coach in daily use in Yorkshire, as this one was some twelve or thirteen years ago.

But from the point of view of variety Darlington and Croft are undoubtedly the best hunting centres in the north of England. The two places are less than four miles apart, and both are on the main York and Edinburgh line, but whereas Darlington is a big town, Croft -or Croft Spa, as it is properly called-is only a village, and so far it has not been spoilt by the building mania. It is, moreover, a pretty village, well placed on the banks of the Tees, and what is more to the point, it is at the right side of Darlington. And here it may be explained 
that Darlington is in many ways a unique town, and quite unlike any other town in the north of England. It has a residential and an industrial district, but the residential part of it is very large, and contains not only the ordinary good houses which are usually found on the outskirts of a large town, but many noble mansions in huge parks as well. The roads are mostly tree lined, in boulevard fashion, and everything is on a spacious scale, the town-almost to its centre-being full of fine forest trees. The industrial end is so far from the centre of the town that one may be in Darlington for a week without ever finding out that there is such a place, and the road to Croft is through pleasant scenery, as are all the approaches (but one) to the town which one uses in hunting.

Croft has a single drawback, and that is that the Hurworth and Lord Zetland's hounds hunt on the same days. Lord Zetland's are out on Monday, Tuesday, Thursday, and Saturday, while the Hurworth hunt on the three last-named days. But as it happens, Lord Zetland's hounds are generally within a mile or two of Croft on Thursday, and a long way off on Saturday, when the Hurworth are nearer. On Tuesday Lord Zetland's are in their best country on the north side of the Tees, but in four weeks out of five within fairly easy riding distance of Croft. Then on Monday the same pack can be reached with a little trouble, while on Friday there is choice between the Bedale and the South Durham, the Bedale Friday country extending to within three or four miles of Croft.

Darlington being so near Croft the hunting procurable is much the same, except that the South Durham are nearer, and the Bedale further away. There are good hotels and excellent stabling-as there are also at 
Croft-and not only do the residents hunt in great numbers, but many visitors keep horses in the town, and come by train three or four times a week to hunt. On a Thursday when Lord Zetland's are at Willow Bridge or Cleasby-the nearest meets to Darlington on the Yorkshire side of the river-or on a Tuesday when hounds are at Walworth or Coniscliffe in their Durham country, the influx of visitors is very great, as they come from Newcastle-on-Tyne, Sunderland, from the Stockton and Middlesborough districts, and at times from York. We have even known a man to hunt with the pack (by train) from somewhere near Windermere, travelling once or twice a week by what is known as the Tebay route, and, on the other hand, we heard lately of a man living at Richmond (in Yorkshire) who hunted once or twice a week with Lord Middleton's hounds. The fact is that where fast mainline trains are available it is nowadays possible to hunt in countries which are very remote from one's own residence-more especially when horses are stabled in the country where they are used.

Anyhow Lord Zetland's hounds attract far more visitors than do any other northern pack, and this is not to be wondered at, for the country is really good, and the sport, taking one year with another, far above the average. The Yorkshire country carries a good scent, and though there is a good deal of plough in places there is more grass, and as a rule the going is good even in wet weather. Close to Darlington, on the Durham side of the country, there is some strong land, which at times becomes holding, but the country improves every mile as one goes westward, the land gradually rising, and grass taking the place of arable land. Barnard Castle is within the boundaries of the 
hunt, but only two days in each week would be available, without boxing or long road journeys, and the same remark applies in a lesser degree to Richmond, from which some of the Bedale meets can be reached.

Durham is not a good hunting centre, for the best country of the North Durham, which is hunted on Mondays, involves a long ride to covert. On Thursday hounds are usually close to the city, and on Friday the South Durham are generally within reach. Nor can it be claimed that Newcastle-on-Tyne is a good centre, though, if the horse-box is freely used, hunting on every day of the week is possible. The Tynedale, the Morpeth, and the Braes of Derwent each meet within seven or eight miles of the town, but each pack is then at the end of its country, and any one who rides to the nearest meets from Newcastle might easily have double the distance to travel on his homeward journey. Still an industrious man can hunt three days a week-one with each of the packs named-from Newcastle-onTyne without using a horse-box.

As a matter of fact there is no convenient centre for the Tynedale hounds, except quite a small village named Stamfordham, and here the accommodation is exceedingly limited. There is plenty of stabling (but all this is requisitioned by hunting people who live wide of the best part of the country), and there is no hotel-only one or two public-houses of the ordinary village type. Whalton, some ten miles north-west, is more of a residential village, and here it is possible to get the best of the Tynedale and the best of the Morpeth countries. Indeed, Whalton is a really good centre, for it is placed in a big grass country, and is well away from all population and industrialism. Its drawback is that it is not very easy of access, the nearest 
station being on a branch line, where there are no great number of trains. Still a really energetic man could hunt every day in the week from Whalton, dividing his time between the Tynedale and the Morpeth, and on rather more than half the hunting days he would be well within hacking distance of the meets. About five days in every fortnight he would have to send horses on overnight or very early in the morning, but even then there would be no boxing, and a long drive behind a horse or a short one in a motor-car would carry him to the extreme boundary of either country. As a matter of fact, Mr. Edward Dent, of Shortflat Tower (near Whalton), so well known at one time in the coursing world, was until quite lately in the habit of attending every meet of either pack, and he may be doing the same thing now for all we know to the contrary.

Further north in Northumberland the hunting becomes more localised, chiefly because of the physical conditions of the country. The country all along the coast is low-lying, pasture being in excess of plough, but the hills and moors are not very far away inland, and thus it happens that such countries as the Coquetdale and Glendale are rather self-contained. Alnwick and Alnmouth are central spots for the Percy, and any one located at either place can reach the Morpeth or the North Northumberland by train; indeed, some meets of the Morpeth are within hacking distance, and residents in the eastern part of Coquetdale-say between Weldon Bridge and Warkworth-are well placed for hunting with both Percy and Morpeth, and could at times reach the Coquetdale as well.

It is hardly worth while to mention the hunting centres further north, for most of the Scotch packs are in some degree isolated, though the Duke of Buc- 
cleugh's, the Jed Forest, Mr. Scott Plummer's, and the Berwickshire join each other in places. The Duke of Buccleugh's is a big country, both as regards area and importance. Hounds are out on four days of the week, and though there is a good deal of wild moorland in parts of the country, there is also a fair amount of vale, a good deal of which is strong arable land. St. Boswell's and Kelso are handy centres for the Buccleugh hounds. The Dumfriesshire is practically isolated, except that it joins the Eskdale on the east, and this (the Dumfriesshire) is a three-days-a-week pack, the best centres for hunting with which are Annan, Lockerbie, and Dumfries. Lord Eglinton's is also a four-days-a-week hunt, with no neighbour but the Lanarkshire and Renfrewshire in the north. The Fife and the Berwickshire hunt on three days of the week, but all the Scotch packs which have not been mentioned hunt on two days of the week only, and seldom attract strangers, except those who may be visiting members of the hunts.

The Cumberland and West Cumberland can be best reached from Carlisle and Cockermouth respectively, but south of the Lake district there is a big stretch of country which contains harriers and staghounds, but no foxhounds. Parts of Westmorland, the western dales of Yorkshire, and the whole of Lancashire are included in this country, and thus on the north-western side of England it is the case that there are no "countries" between the Cheshire and the hill packs of the Lake country.

The Cheshire is a big country, as it practically embraces the whole county of Cheshire and takes in a little bit of Shropshire as well. The Wirral peninsula, between the rivers Mersey and Dee, is given over to 
harriers or beagles, but otherwise the Cheshire pack go all over the county, hounds being out every day of the week. For thirty years (until 1907) the country was divided into North and South Cheshire, and hounds were out four days a week in the northern and three days in the southern division of the hunt. Now the country is in one hand again-as it was prior to $1877-$ with the Duke of Westminster as master, and by the aid of railways and motor-cars it is possible for any one who is centrally located to attend all the meets. Indeed, there are men living outside the county-in Lancashire, for example-who hunt regularly with these hounds, and there are also many-including the master-who are wide of much of the country.

Chester, for instance, is at one end of the hunt (Eaton Hall, where the Duke of Westminster lives, is only four miles from Chester), and at a great distance from some of the country, but the Delamere Forest district is very central and extremely popular, and Tarporley, which is on the borders of the forest, may be said to be the head-quarters of the hunt. All about the forest are hunting-boxes, varying from the mansion in a park to the pretty roadside cottage, the stabling of which at times makes a bigger block of buildings than the house itself; and much the same state of affairs exists all through such portions of the country as are well placed for some of the good fixtures. The main line of the London and North-Western Railway to Holyhead goes right through the country between Crewe and Chester; the railways from Crewe to Liverpool and Manchester bisect other portions of the hunt; and the railways of the Cheshire Lines Committee meander about the district. Indeed, Cuddington on the C.L.C. is close to the kennels at Sandiway, and 
hereabouts many of the hunting folk are located. Nantwich, Northwich, Malpas, and Crewe are also central for many of the best meets, and in the southern and western parts of the hunt it is an easy matter to find places from which not only the Cheshire, but Sir Watkin Wynn's, the North Staffordshire, and the North Shropshire are within reach.

Thus from Whitchurch (in Sir Watkin Wynn's Hunt), the Cheshire, Shropshire, and North Staffordshire are all available, while from Crewe (in the Cheshire Hunt) the North Staffordshire can be reached at least two days in the week. Wrexham is a nother good centre for Sir Watkin Wynn's hounds, and Shrewsbury is central for the South Shropshire. From Stafford both the North and South Staffordshire and the Albrighton are within reach; from Bridgnorth the Albrighton and Wheatland; from Much Wenlock both the Shropshire packs and the Wheatland ; from Church Stretton the United, South Shropshire, and Wheatland; and from Tenbury the Ludlow, Radnorshire, and West Hereford, Teme Valley and United. Indeed, Shropshire and Staffordshire (apart from the Black Country) are fine hunting countries, well supplied with foxhound packs, and affording a great deal of sport. But south of Whitchurch there are, perhaps, not so many strangers hunting as there are in the Midlands, on the eastern side of England, or in the neighbourhood of the watering-places, and in neither county are any of the fields anything like so large as those which are to be found regularly with the Cheshire hounds. 



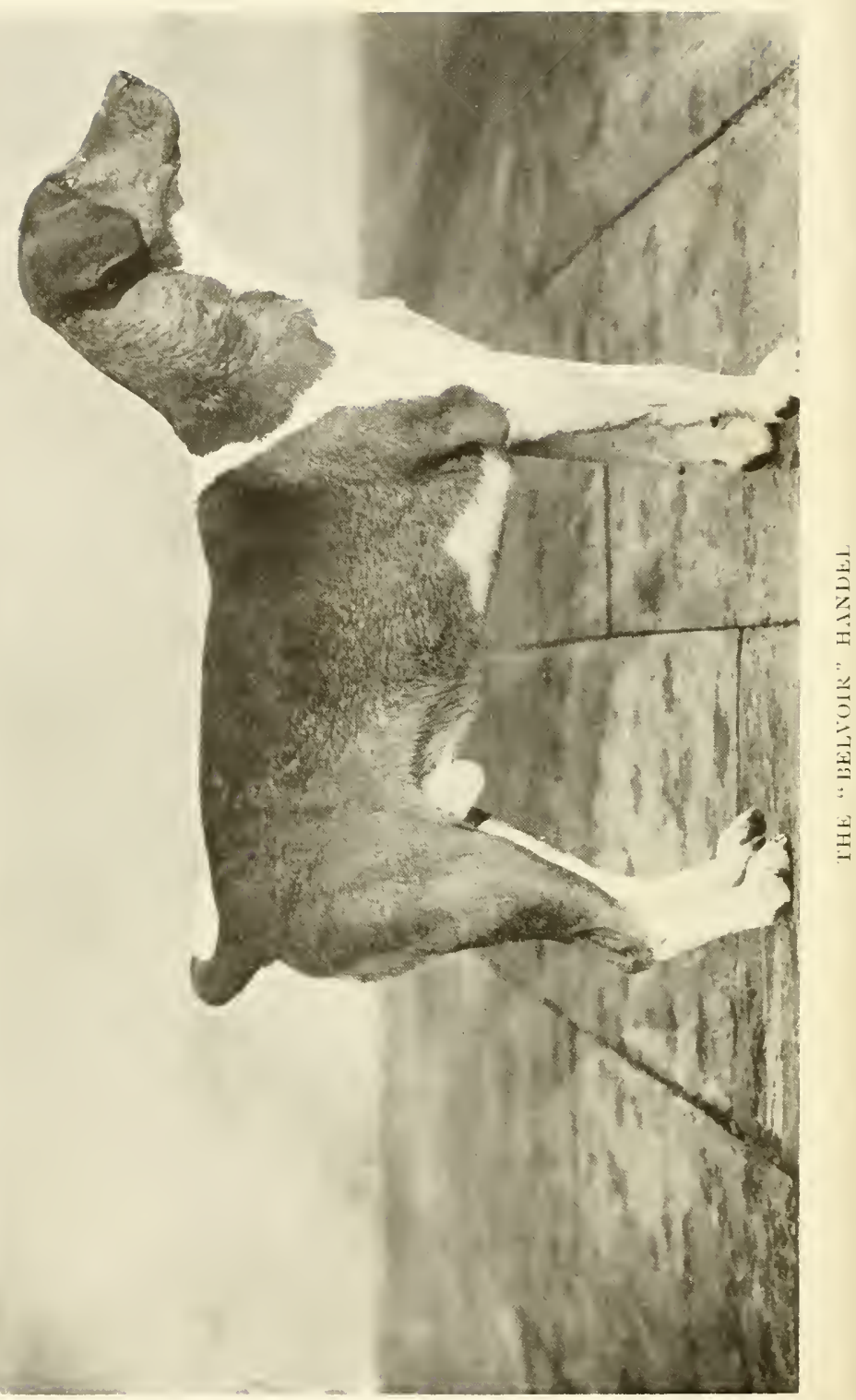




\section{CHAPTER VII}

\section{FOXHOUNDS}

T $\mathrm{T}$ is a curious, but at the same time incontrovertible fact that the origin of the foxhound, 1 as he is known at the present day, has never been thoroughly ascertained, but there is plenty of evidence to show that hounds have been bred expressly for hunting foxes for something like two hundred years. And there is also some considerable amount of indirect evidence which suggests that the old southern hound, and the beagle-or northern beagle as he was frequently called-were the two distinct varieties of hounds from which the foxhound was evolved. Unfortunately early writers on hunting make little or no mention of the origin of foxhounds, but in a small volume of anonymous essays on hunting, the following passage occurs: "The most satisfactory reply to every hunter is that his own kind is best; but such as are setting up a new cry, I would advise to begin to breed on the middle size dogs, betwixt the Southern Hound and the Northern Beagle." This volume, two copies of which I have seen, appears to have been published by T. Baker at Southampton, but no date is given. In the hunting volume of the Badminton Library there is, however, a bibliography of hunting, and the essays are referred to as having been published in London in 1782 . This makes the book contemporary with Beckford, but I am inclined 
to think that the edition I have, and which I bought for sixpence at a bookstall twenty years ago, is a good deal earlier than the work written by the "Immortal Peter," as Jorrocks dubbed Beckford. This date of the book is a matter of little consequence, and now it rather looks as if the origin of the foxhound would never be decided, the question being just as difficult to answer as that concerning the actual first pack of foxhounds. What we do know is that in the early days of foxhunting hounds varied locally, and, in all probability, for long enough there were hounds of different types in such localities as were remote from other hunting districts. But when foxhunting became an almost universal sport, and people began to visit strange packs, interchanges of blood naturally took place, and this gradually increasing as the years wore on, masters of hounds and other experts evolved a certain type, which came to be recognised as the best sort of foxhound. And in these days the type referred to exists almost everywhere, there being two districts only where what may be called ordinary foxhounds are not used. The districts referred to are certain parts of Wales and the Lake country of Cumberland and Westmorland, where hounds of a distinctly different type are still used. Some of the Welsh hounds bear a high character for nose and speed, and doubtless are better adapted to rough, rocky, precipitous country than are the ordinary, much heavier foxhounds. The Fell hounds in the north are light framed, and very light in colour, but their owners have a great opinion of them, and only a year or two ago certain gentlemen in West Cumberland were anxious to run a match against hounds any of the Midland packs could produce. Little notice 
was taken of the challenge, and one is inclined to think that on their own native fells the Cumberland hounds would have had the best of it, while in any ordinary enclosed country the boot would have been on the other leg.

But when foxhounds are spoken of, it is, as a matter of fact, only one type which comes into consideration, viz. the hound which is entered in the Foxhound Kennel Stud Book, and which is used all over the kingdom, except in some half-dozen or more remote countries. Every modern foxhound may now almost be said to be of the same family, so much inbreeding has there been in the last fifty or sixty years, and so much out-crossing on the part of the old family packs. Perhaps Mr. Robert Vyner, whose Notitia Venatica was published just sixty years ago, was the most interesting writer on foxhounds, and he appears to have known a good deal as to the original foxhound, but even then he did not think it worth while to put his knowledge into writing. He said that "since the commencement of hunting the fox in the open, so many different descriptions of hounds have been bred for the purpose, that to describe all the sorts, and to give a statistical account of the divers strains of blood which have been celebrated in their time, would be far too tedious for my readers, and quite foreign to my present purpose; the following short account of the pedigrees of some of the principal packs of the present day will suffice." Vyner then goes on to state that the original stocks from whence the most fashionable sorts were descended were from the packs of Lord Yarborough, from that of Lord Fitzwilliam; the Duke of Rutland's (which were bred from the packs purchased of Mr. Heron and 
Mr. Calcraft), Mr. Osbaldeston's (descended from the celebrated pack of Lord Monson), Lord Vernon's crossed with the Duke of Rutland's and also with Lord Yarborough's and the Duke of Beaufort's, which were in Vyner's days reported to be the steadiest and best pack in existence; Lord Lonsdale's descended from Mr. Noel's and bought by Sir W. Lowther for Iooo guineas, and the old Pytchley blood, descended in a great measure from the famous Beaufort Justicewho, according to the lately published Vol. I of the Foxhound Stud Book, went to Badminton in $1 \mathrm{So}_{3}$, in a lot of two and a half couples from Sir Thomas Mostyn's kennels. This Beaufort Justice-who will be well known to readers of Surtees' works in connection with Mr. Puffington and the Hanby hounds-was by the New Forest Justice out of Hopeful, and his blood has been handed down through many channels to the foxhound of the present day.

Mr. Vyner's book was published sixty-one years ago, and yet we find that the first three packs in his list are the Brocklesby, the Fitzwilliam, and the Belvoir, each of which has maintained its reputation to the present day, and now stands just as high in public estimation as it did then. Of the Badminton pack the same thing can be said, but Lord Vernon's and Lord Monson's have long ceased to exist. It is clear, however, that as far back as Mr. Vyner's day, when railways were as new to the country as motor-cars are at the present time, certain packs were being resorted to by breeders because of the reputation they had acquired. Transit of hounds from one part of the country in the early days of last century could only be achieved by road, and yet the earliest volume of the Stud Book plainly proves that even a hundred years 


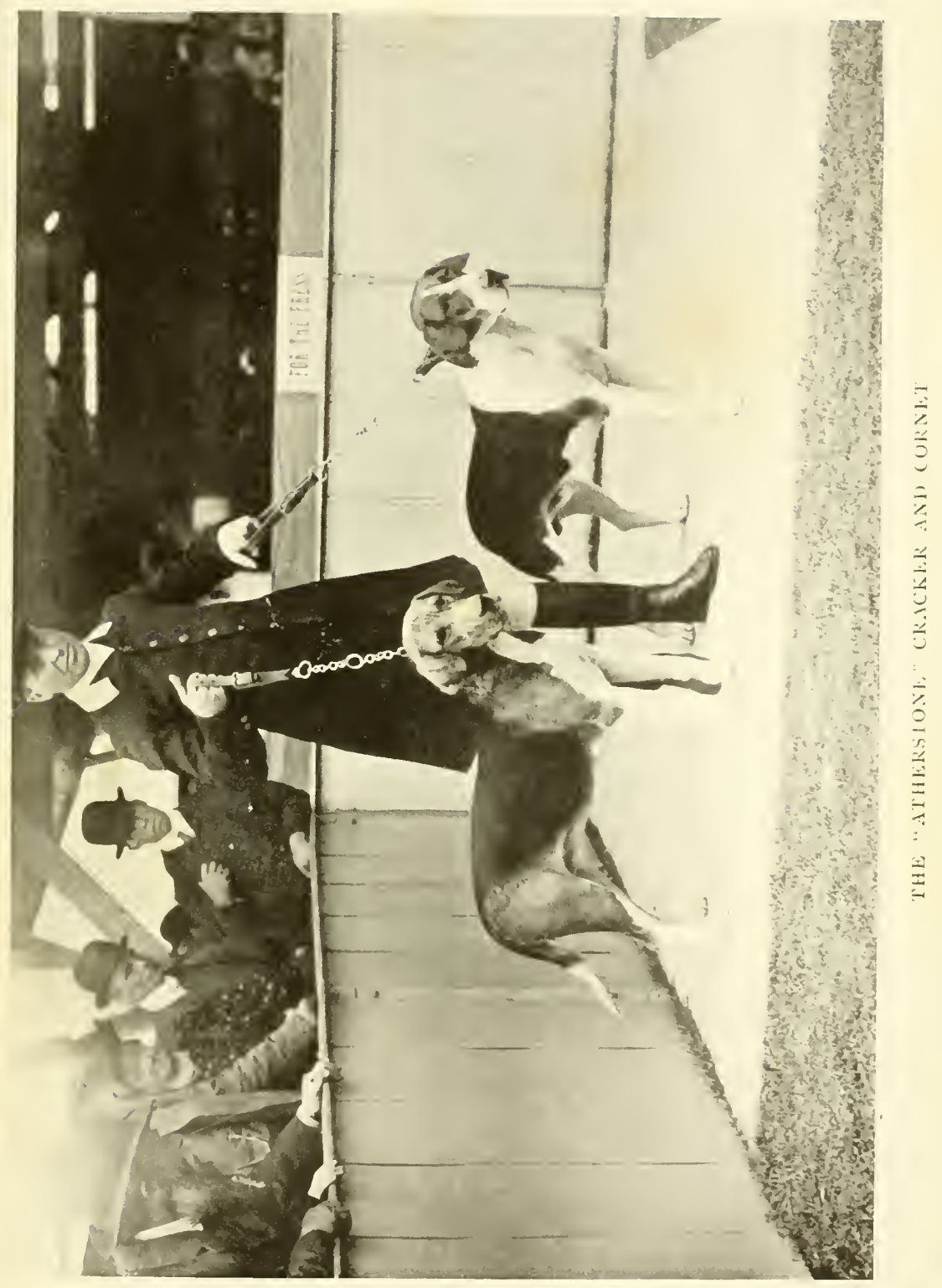



ago there was a certain amount of crossing the blood of one kennel with that of another. What the Stud Book cannot tell is from which kennel came the excess of drive, the tongue, the bone, the straightness, or any of the really strong points of the modern foxhound. These qualities have, as a matter of course, been enormously developed by the great breeders of the last half-century, but historians of foxhunting have given but scant information as to what were the strongest points in the various early packs, and it is no easy matter to form a very strong opinion on what can be gathered from old pictures or prints, chiefly because in forty-nine out of fifty the hound was subordinate to the horse and his rider.

Possibly the well-known picture of the "Earl of Darlington and His Foxhounds," painted by Marshall in 18ro, gives one a pretty good idea of the foxhound of almost a hundred years ago, and of the three and a half couples which are included not one appears to be in the least deficient in bone. But it should be mentioned that there is a second well-known (through the prints) picture of the Raby pack in kennel at feeding time. The painter of this picture was H. B. Chalon, who described himself as animal painter to the Prince Regent and other members of the Royal Family (and the prints are dated I8I4), and all the hounds in the painting were portraits, their names being Craftsman, Benedict, Merryman, Baronet, Mahomet, Modish, Symphony, Maynard, and Governess -and Jasper, the terrier, a dark-coloured, smoothcoated, prick-eared, and very verminty dog, but whose breed it would be difficult to name in these days.

Now in Marshall's picture hounds are clustered round their owner, who is on horseback, and pre- 
sumably all are portraits, but we have no evidence on the subject, as we never saw a print in which the names of the individual hounds were given. It is a fact, though, that in the outdoor picture the hounds painted have very much more bone than those painted in the kennel scene, and one cannot help thinking that one of the artists must have misjudged or exaggerated what he saw. (The question of "bone" in a foxhound would hardly be within the ken of an artist of a hundred years ago, though at least two modern delineators of hounds know just as much about it as do the authorities on the breed.) Both pictures give ample evidence of careful portraiture, but in both hounds are in working condition, so fine drawn that all their ribs can be counted, and not in the least got up for show. The feet seem higher, and not quite so catlike as those of the modern foxhound, and there is more white in the colouring than there is in many of the present-day packs. All the hounds are rounded; some are branded with a "D" on the near flank, and all have fair make and shape, and plenty of foxhound character. Indeed, if all the packs of a hundred years ago were as good to look at as those of Lord Darlington, hound breeding cannot have made the great advance with which it has been credited; but there is just a suspicion that in Chalon's picture one or two of the hounds were a little back at the knee, while in Marshall's hounds there is a tendency to heavy shoulders.

Unfortunately there is no record of the old Raby pack in the earliest volume of the Stud Book, but Baronet, mentioned above, was used by Mr. Ralph Lambton, and appears as the sire of Billingsgate in I815. And apropos the book it may be mentioned 
that Mr. Vyner compiled the first Stud Book in the year I84I, when the lists of forty-six packs of foxhounds and of the Royal Buckhounds were given. This book has been long out of print, but Mr. Cecil Legard a year or two ago brought out a new edition of Mr. Vyner's work (with considerable additions), and this now forms Volume I of the modern Foxhound Stud Book. And if any hound of the present day can trace back to the old packs, of which carefully kept kennel books were treasured, its pedigree can be, in many cases, further extended to the beginning of last century, and in the case of Badminton, Belvoir, Brocklesby, Milton, and Lord Middleton's blood a good deal further back, though the pedigrees previous to 1800 are not given in the Stud Book, but have been merely filed by Mr. Cecil Legard. The question of foxhound pedigrees has become a really important matter, and now there are, one may safely say, at least two dozen kennels where the very highest standard of excellence is maintained, and twice as many more where the pack would pass muster.

Amongst foxhound breeders the dog show pure and simple is not liked, but for fifty years or so hound shows have been approved of, strictly on the understanding that only masters of hounds are to judge, and that no hound show shall be in any way connected with an ordinary dog show. The upshot of this is that Peterborough, Reigate, and Clonmel in Ireland fill all the requirements of masters of hounds, and it is exceedingly unlikely that the number of shows will be increased, though at times one hears suggestions of a show in the north of England, to act as a test show for Peterborough amongst the northern packs, as Reigate does amongst those of the south of 
England. ${ }^{1}$ The great safeguard in connection with the hound show as conducted at the present time is that the classes are only open to hounds from any established pack in the United Kingdom. This prevents any one but a master of hounds exhibiting and does away with the hound fancier. Not that such a man can be said to exist, for practically no foxhounds are kept in any part of the kingdom except for hunting purposes. At the same time if there were many hound shows, exhibiting would become a business, as it has done-with disastrous effects-in connection with other varieties of dogs used for sport, and therefore a very close curtailment of the number is absolutely essential.

To glance at the reverse side of the case it is probable that the Peterborough shows have done a great deal of good. They are held at a time of year when there is no hunting, and when masters of hounds and hunting folk generally can attend, and they are conducted on the soundest and strictest lines. There can be no question of pot hunting, for the prizes are of little value, and in fact the winning of three or four at one show would hardly pay for the cost of sending hounds and men from a distant part of the country. The honour and glory of winning at Peterborough is then the great goal which ambitious masters of hounds aim at, and it can fairly be said that in all its thirty years of existence there has been no real change with regard to type. In fact, the best hounds of thirty years ago were of much the same stamp as the best hounds of the present dayfrom the onlooker's point of view. Peterborough does not-cannot, in fact-point out which in every class are

1 In July of the present year a hound show, confined to packs hunting in Somerset, Dorset, Devon, and Cornwall, was held at Exeter, and met with a fair measure of success. 


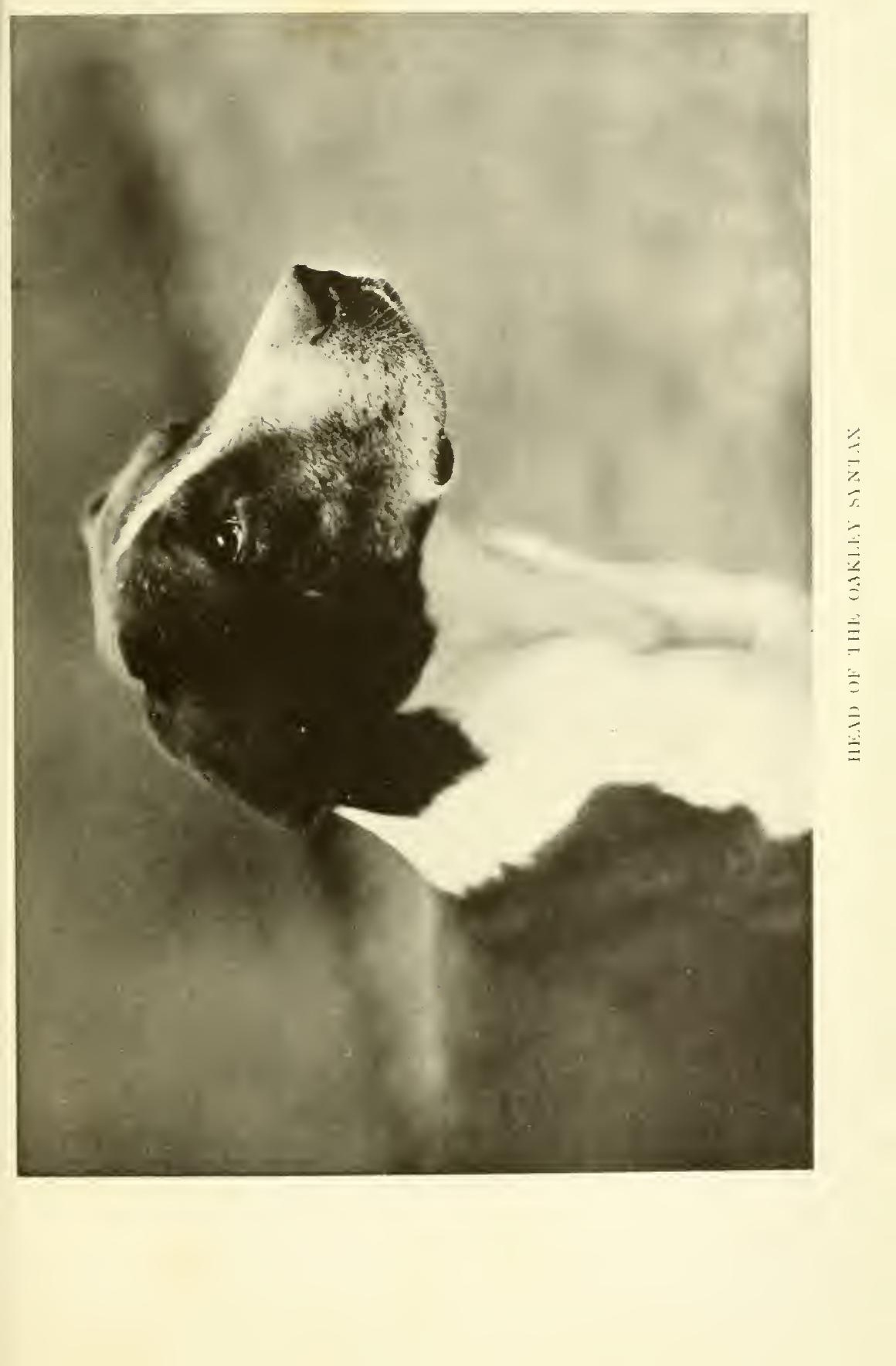



the best workers, but it can indicate year by year the type which breeders should aim at, and this is what it faithfully does. Some critics there are who affirm that too much attention is paid to bone and straightness, but bone means strength and constitution, and these are absolutely necessary if a hound has to go through a long day, and travel home at night with his stern up. Moreover, there is no evidence to the effect that excess of bone in any way depreciates speed, for on certain days in every season, when scent is of the sort which is aptly termed breast-high, hounds will beat horses altogether, even if the ground is in first-rate galloping order, and there is nothing formidable to hinder the progress of the field. There are those who urge that the lighterbuilt Welsh hounds can travel faster on a hot scent than the foxhound which is used in other parts of the kingdom, but this has yet to be proved, and meanwhile it may be confidently stated that the modern foxhound goes quite fast enough. Indeed, some will have it that nose has been sacrificed to speed, but an apparent delicacy of nose is very often due to over-riding, and the otter hunters prefer a foxhound to an otter-hound for the purposes of marking an otter in his holt.

Then as to straightness; it may easily be that a hound which is not quite straight can go as fast and as far as his brother or sister which is really straight, but a shapely limb is better than a malformed one, and lack of straightness is to some small extent a malformation. In these days of plenty of money, and a high standard as regards hounds, a hound which is not perfectly straight should never be bred from, for physical defects of sire or dam are very often reproduced in the progeny, and so on ad infinitum. The only way to get rid of legs which are ever so crooked is to ignore 
the bitches so disfigured at breeding time, and, as a matter of course, to use no sire which is not straight. In a big kennel the hounds which are not straight should be drafted before they are entered, but in a small kennel it may not be convenient to get rid of an otherwise good-looking hound for a fault which will not affect his working powers, and in such a case the hound which is not straight can certainly run with a pack.

That hounds which are not straight are religiously drafted in some kennels need hardly be stated, because hound men know it to be a fact, and we can safely say that we have been right through a kennel in which it was impossible to discover a crooked-legged one. On the other hand we have visited a kennel of some reputation, and failed to find a single straight hound in the pack, and the huntsman-a new-comer-was bound to admit it. "There ain't half a dozen of 'em which are biscuit straight," he lamented, and yet many of them were otherwise good-looking, and they are supposed to kill quite as many foxes as their neighbours. If, then, Peterborough tends to cause an elimination of light boned and crooked-legged hounds it must do good. But it also sets the standard of that mysterious thing called quality, which in a foxhound means make and shape, elegance of outline, clean neck and shoulder, gay carriage, and a general appearance of high-bred activity. Quality is to be found in larger or smaller quantities in all good-looking foxhounds, and it only arrives in a kennel after the greatest care in breeding has been- exercised for some years, and when hounds with palpable faults have been religiously drafted, or at all events not put to the stud.

It has been said that there is in these days one type of foxhound, but this is not exactly true in every sense of 
the word, and though the standard aimed at is undoubtedly the hound which is good enough to win at Peterborough, the type varies in some degree, especially in the matter of size. In some kennels the doghounds range between 23 and $23^{\frac{3}{4}}$ inches, while the bitches are at least an inch less, but there are packs in which a much greater height is maintained, where the dog pack will average $24 \frac{1}{2}$ inches, and the bitches are all very nearly 23 inches. Then, again, one master goes in for a lengthy and yet upstanding hound; another insists upon fair height, but is not so particular about length, while a third favours the short-coupled compact hound, who would probably be called "jumped up" by the admirer of the other sorts. At Peterborough the happy medium is fairly well hit off. Small hounds have no chance of winning, and very big ones would not be approved, but still the tendency of the critics rather favours size, and most of the Peterborough winners are fairly big, though not of abnormal height or length. Indeed, the 25-inch hound-and there are many of them in the country, some of which are extremely good-looking-is seldom seen on the show bench, and he is, one thinks, rather out of place. Why he is out of place may be explained by saying that he seems to gain no particular advantage from his extra size. He probably goes no faster than the hound which is an inch less, and certainly does not hunt better because of his stature. Neither does he look well unless the whole pack is of his height, and worst of all when used for stud purposes he is apt to get stock that are even bigger than himself, and which are in consequence ungainly. But whether a pack be big or small they must be as far as possible of the same size. If a pack is really level it fills the eye at once, whilst when 
the height and size vary an uneven appearance is presented which, to the hound critic, is most distasteful.

In a mixed pack of dogs and bitches it is of course less easy to maintain a standard size, unless the doghounds of a kennel are small and the bitches large. When that happens the smaller dog-hounds and the bigger bitches will be much of a size, and uniformity can be achieved. But in a small, two-days-a-week hunt, where something like an equal number of both sexes are kept, a level mixed pack is rarely seen, simply because not enough hounds are bred to ensure a level in sexes. Then, too, it must be remembered that in houndbreeding like throws like, and therefore if the bitches of a kennel are big their dog-puppies will also be big, and probably those which are entered will be at least an inch and a half higher, and proportionately bigger all over, than their mothers. But one is inclined to think that in the case of a small mixed pack uniformity in size is not a very important matter as long as both dogs and bitches-either half of the pack, in fact-are level.

Again, even in a small establishment a very big or a very little hound should be drafted, if any standard of neatness is to be obtained. We have seen, years ago, when hound-breeding was not attended to so carefully as it now is, a great lashing 25 -inch hound, and a little, wriggling, 2 -inch, harrier-like bitch contending for the lead, each hunting with equal keenness. But the sight of these two, and a pack behind them, in which every type of hound was to be seen, was very unsatisfactory, even if it had its comical side. "I expect you are laughing at my pack," said the master, "but this is our first season, and they are all drafts, got in a hurry at the eleventh hour." This explained the 


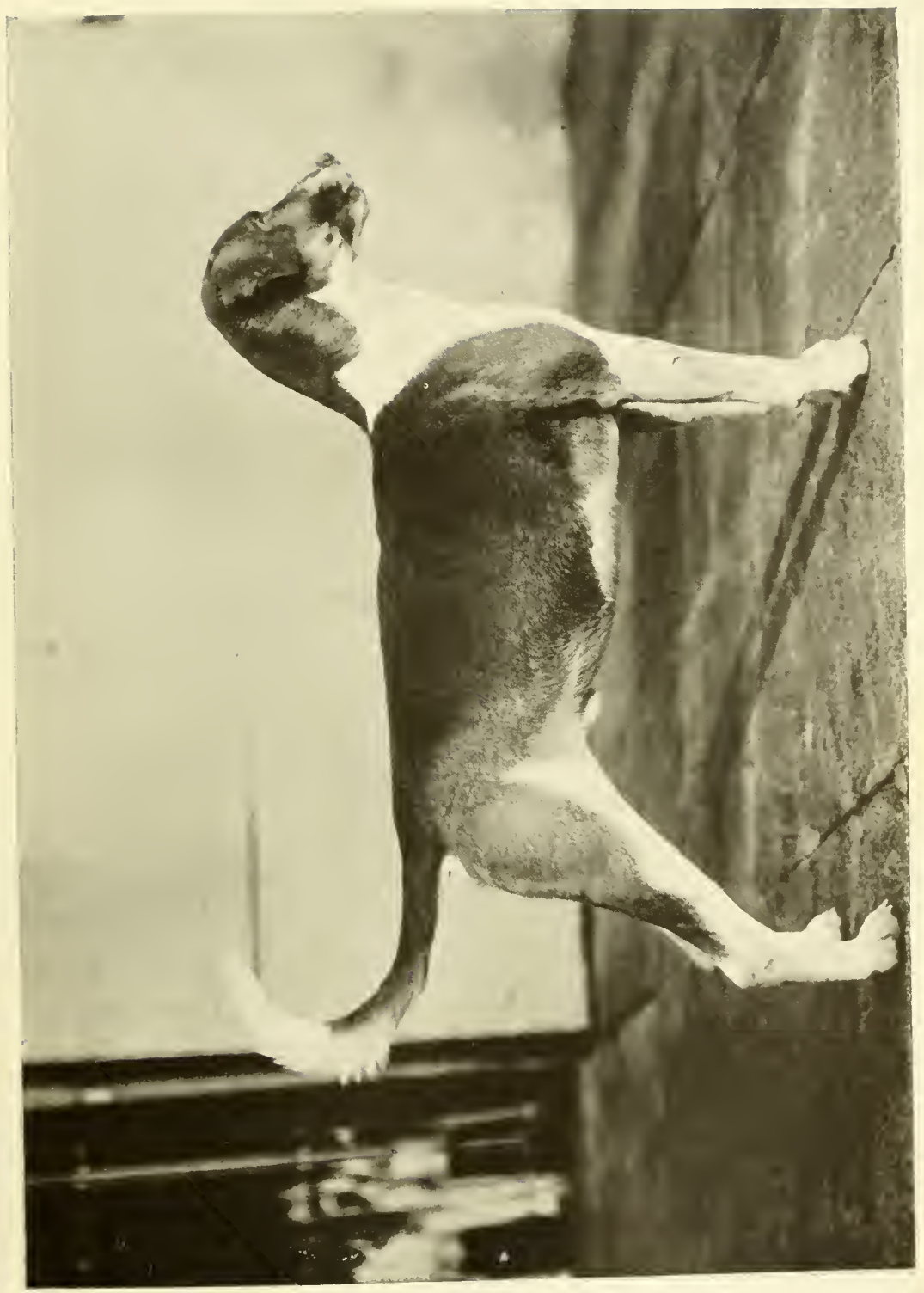

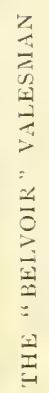



situation, for the pack had a reputation, and we had not been told that the late master had taken his hounds with him to another country.

As regards hound-breeding, there is no royal road to success, and very little can be done until a considerable amount of experience has been gained. One man will breed a good pack of hounds in half a dozen years. Such a performance is very rare, but it has been done more than once in recent years, and notably Mr. Charles McNeill, the present master of the Grafton, bred a pack of bitches during his five years' mastership of the North Cotswold, which he sold for something like $£_{4000}$, and with which he won prizes at Peterborough. Another breeder will achieve no better result in twenty years. Both may have studied the science of breeding with equal care; both may have spent the same amount of money on drafts from famous kennels, and both may have sent bitches to the best stud hounds of the day, but one of the two may have that indefinable knack of always doing the right thing, while the other may be unlucky in his attempts at mating, or may, with the best intentions, be without the grasp of hound points and pedigrees which is almost necessary if success is to be achieved.

A young master of hounds may, when he first takes office, know something of hounds and their breeding. He may be the son of a master, and have spent much time in the kennel. When such are his antecedents there is nothing to prevent his being a successful breeder as long as he really works hard at the business. But the average young man who takes a pack of hounds for the first time probably knows nothing whatever of hounds, and can have had no experience of breeding. $\mathrm{He}$ is, naturally, fond of hunting, or he would not 
have accepted the mastership of a pack, and very possibly he is inclined to be fond of hounds.

But real knowledge can only be arrived at through experience, and that is why a comparatively young hunt servant so often knows far more than his master at first. The hunt servant in nineteen cases out of twenty has been bred at a foxhound kennel, and has been among hounds since he was able to crawl on all fours into the kennel precincts. He has heard hounds discussed all his life, and in all probability he has been employed amongst them ever since he left the Board School. He may possibly be prejudiced in favour of certain forms of kennel management, especially if much of his life has been spent in one kennel, but he will be thoroughly at home amidst his surroundings, whereas a new beginning master and amateur huntsman combined is seldom the kennel man that the professional huntsman is. Nor is there any reason that he should be, for a man may become a consummate judge of hounds, and yet know little about how to manage them in kennel. He may, too, have the quickness, resource, and rat-catching cunning which combine to make him a good huntsman, and yet neither know nor care much about the hounds which he hunts. It is in point of fact necessary for the professional to be both huntsman and houndsman, and though the amateur will do better if he combines the double character it is not absolutely necessary that he should do so.

We once knew a good amateur huntsman who killed quite an average number of foxes, but often a lot of time was wasted over the kill. The fact was that if the kennel huntsman was not up our friend was unequal to removing mask, brush, and pads, and 
therefore he waited for his servant. No doubt this was a rather extreme case, and it may be put forward that no one should attempt to hunt hounds unless he has mastered these little things, and is prepared to perform the post-mortem rites in legitimate fashion. At the beginning of the season the kill is a most important function, for the young entry have to be blooded, and many young hounds do not take very kindly to breaking up and eating their fox, even though they may have hunted it fairly enough.

At times one hears both masters and huntsmen complain that otherwise good hounds show very little keenness when the kill has once been accomplished, and in fact take very little interest in the subsequent proceedings. This is undoubtedly true, and one is inclined to think that if any pack is carefully watched from the moment a fox is killed until they move away after he has been eaten, it will be seen that certain hounds do not go near the centre of interest, and seem to care nothing for blood. On the other hand the majority of the pack will tear their fox to pieces and swallow him up in hearty fashion, as if they thoroughly enjoyed the business. And if all the hounds which appear to take no interest in the kill were slack in their work, it would be a simple matter to draft them, but hounds which can find a fox, which can run at head, and which can put the pack right on a cold scenting day have been known to decline eating fox, and this is a somewhat remarkable thing, which has puzzled many huntsmen in the past.

But the great question of the day with regard to hounds-of which brief mention has been made a few pages back-is whether the modern hound is lacking in scenting powers, compared with his ancestor 
of from fifty to a hundred years ago. This is a matter on which it is almost impossible to form a really definite opinion, because we can only judge the capabilities of the hound of a former generation by what has been handed down to us in writing. And most of the reliable literature of foxhunting goes to suggest firstly that hounds were a little slower-say in the days of Nimrod and Surtees-than they are now. No doubt there was more variation between one pack and another as regards speed, but that (if it occurred) was due to the fact that certain kennels took the greatest pains over the breeding of their hounds from a very early date, while with many of the country packs the niceties of hound-breeding are only of comparatively recent date. But the veterans of 'the present hunting worldor at all events some of them-are of opinion that nose has deteriorated since they began to hunt, and that in consequence the sharp burst is in these days so much more common than the long hunting run. Some of the critics even go so far as to suggest that the clean necks and the disappearance of throatiness have impaired scenting powers, and they are of opinion that bloodhounds, and even the old blue mottle, and in fact any hounds of the "Southern" type, had much more "throat" than the modern foxhounds are possessed of, and better scenting powers.

We have said that it is impossible to form an opinion on the subject which is absolutely definite, but nevertheless it may be pointed out that there is plenty of evidence in favour of the modern hound being as well off for nose as his ancestor. In the first place it is quite certain-admitting of no contradiction-that whereas the foxhound has improved the fox has deteriorated, and there are far more miserable, half-scentless animals 

running about the country than there were fifty years ago. Indeed, Mr. Vyner more than sixty years ago wrote of the foxes of the last century (the eighteenth) "being far stouter in their nature than many of the mongrel-bred vermin of the present age, stained as they are by the introduction of French blood." $\mathrm{He}$ then went on to explain that in the time he referred to-viz. the eighteenth century-there were so few game preserves that foxes travelled great distances for their food, and were wilder and shyer in their habits than they would have been if they had been enabled constantly to procure their food close at home. Now this was written something like a generation before what is now known as excessive game preservation came into fashion, and almost two generations before mange amongst foxes made its appearance in the epidemic form which has ravaged the country during the last ten or twelve years.

If foxes were degenerating in Vyner's days they must have been singularly magnificent animals at some earlier date of the hunting period, but one is inclined to think that there was not much amiss with the vulpine tribe until comparatively recent times, and that even now it is only a proportion of foxes which are bad, and that the best of the species are as good as ever they were. Those who had hunted regularly for some years before mange became bad, and who hunted through a genuine mange visitation, could not help seeing the difference between the foxes they first knew and many of the foxes they encountered during the mange period. But even when matters were at their worst an occasional fox of wonderful stamina was found, which fox just merely suggested that all the breed had not become degenerate, that an odd good one was left. Since 
mange conditions became improved-say three or four seasons ago-the odd good fox has multiplied, and therefore the long point is again of fairly frequent occurrence.

Still hounds either could not or would not hunt all the mangy foxes with the fire which they showed when in pursuit of the clean, healthy fox, and doubtless on many bad days, in various parts of the country, they were blamed for slackness when the quality of the foxes was really the cause of indifferent sport. But, after all, the great point in this connection is that on certain days hounds run so hard that horses cannot live with them. This, of course, is due to scent being extremely good, and it allows of "the field" going their hardest, without being able to get far enough forward to interfere with hounds. But the day of firstrate scent only comes very occasionally, and it is often followed by several days on which scent is of extremely moderate character. The "field," put on their mettle by the good scenting day, do not at once recognise the different conditions a day or so later, and pushing on after the same fashion quickly drive hounds over the line. And on some days in many hunts this is done repeatedly, the upshot being that hounds appear to be working slackly when in reality they are not getting fair play.

Then, again, when there is much over-riding many a huntsman lifts his hounds far too often, not because he wishes to lift them, but because they are being unduly pressed by the crowd. One result of this is that hounds which are accustomed to being lifted will, the moment a check comes, look round for assistance, or will be prone to go to any "holloa" which they may hear. In this case also they are at times blamed, when, 
as a matter of fact, they are being gradually demoralised, because no real opportunity of hunting out the line has been afforded them. Proof of this can easily be procured, for the sceptic need only take note of what occurs after a popular meet of one of the Shire packs on a really bad scenting day, and then go and hunt for a week or two in a provincial country where fields are always small, but where hounds are invariably allowed room to work in.

Apropos, we remember some years ago during a good season in ante-mange times that a small party went from the provincial country where we were hunting to Melton for ten days. They were men of some experience, and each of the trio had paid more than one previous visit to Leicestershire. This time, however, they returned with a sad story. They had each been out about half a dozen times, had seen three of the Shire packs, but had never come in for a gallop of more than a few minutes' duration. They had, as it happened, hit upon a period of poor scent, and hounds had been badly over-ridden, with the result that sport had been practically nil. But the curious part of it was that the local pack they had left behind them had had during the same period their big week of the season, when scent, though not exactly brilliant, had been good enough to allow of hounds running on all day long.

To sum up the question of nose, bad foxes make (or appear to make) bad hounds, and constant over-riding is answerable for a great deal of exceedingly moderate sport, for which hounds are often, in some degree, blamed. 


\section{CHAPTER VIII ${ }^{1}$}

\section{THE VALUE OF FOXHOUNDS}

\section{BY EDWARD PENTON}

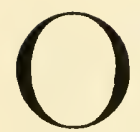

$\mathrm{NE}$ of the interesting things a hunting man can do after a hard day with the hounds, when he has changed and dined, and sits back in his arm-chair in front of the fire, smoking a cigar and feeling at peace with all the world, is to call to mind accounts of the great hound sales which have taken place in the past. The full and complete history of the dispersal of great packs is yet to be written, though, of course, the story will be found scattered in the contemporary literature, and also in the various hunt histories, but to dig out knowledge in this way requires much time and more patience than some poor mortals are possessed of, for to-day the desire is to have everything ready to one's hand, and so there may be a fortune awaiting the hunting historian who selects for his subject the sale of hounds. Quién sabe?

Without attempting in the present chapter to give a full and complete history of the great sale of every pack which has taken place in the past, the relation of some of the principal transactions may prove of interest, and it may be here pointed out that prices of foxhounds have fluctuated quite as much as stocks and shares are doing at the present day. Bargains in

1 The material for this chapter has been taken, by kind permission of the proprietors, from the Field. 
hound-flesh have been made many a time and oft, while, on the other hand, purchasers have had on more occasions than one to pay very dearly for the hound of their choice.

In the year I808 Lord Althorp wrote to his father, "I have to tell you that I have concluded the bargain with John Warde, and am to give him £rooo for the hounds," and few readers of hunting history will need to be reminded that the last-named celebrated master, eighteen years later, parted with another pack to $\mathrm{Mr}$. Horlock, who followed him in the mastership of the Craven, for 2000 gs. Taking a leap to the year I845, one reads in Cecil that when Mr. Foljambe parted with his establishment Messrs. Tattersall sold his hounds for him at the kennels, the sale realising the sum of $£ 3500$, while, when Captain Williams, who was master of the Rufford for twenty years ( $184 \mathrm{I}-6 \mathrm{I}$ ), gave up, the same well-known firm sold his pack for 2681 gs. As many hunting men know, the celebrated Quorn Hunt has seen its hounds sold on several occasions, and in his first season (1806-7) Mr. Assheton Smith gave Mr. Musters $1000 \mathrm{gs}$. for several couples, while later on Lord Suffield purchased Mr. Ralph Lambton's hounds for 3000 gs., or 1000 gs. more than had ever been given for a pack up to that time. His lordship, however, found that it was quite one thing to buy and another to sell, for when the auctioneer's hammer ended his régime, his expensive purchase is said to have realised no more than 1000 gs., while some hunting historians indeed declare that the amount paid for them was only 490 gs., when the pack went north to hunt Mr. Robertson's country in Northumberland, afterwards that of Lord Wemyss, but for the last forty years known as the Percy country. When Mr. Hodgson left Leicester- 
shire Lord Ducie, of the Vale of White Horse, became the owner of his bitch pack for Iooo gs., and Mr. Greene, of Rolleston, paid 200 gs. for ten couples of dog hounds. The retiring master, however, bought some in himself, and in the end fifty-seven couples of working hounds, fifteen couples of unentered hounds, and six brood bitches realised the total sum of $220 \mathrm{I} \mathrm{gs}$. At another sale in the same country, caused by the death of that fine sportsman Sir Richard Sutton, in I855, the Quorn hounds realised the sum of I 806 gs., Mr. Morrell giving 2 Io gs. for five couples, and Mr. R. Sutton $300 \mathrm{gs}$. for five couples and $260 \mathrm{gs}$. for another five.

Three years later, on April I4, Mr. Morrell sold his Old Berkshire hounds at the Tubney kennels, near Abingdon, through the agency of Messrs. Tattersall, and those who knew the pack were of opinion that while the bitches were all that could be desired, many of the dogs were heavy, and a little inclined to be throaty and coarse, though taken all round they formed a very useful lot and found no lack of purchasers. The then Duke of Beaufort bid for some of the best, and eighty-one couples realised 2481 gs., which gives an average of a little over $30 \mathrm{gs}$. a couple. In the June of I859 occurred the death of Sir Robert Williams Vaughan, of Rhug, a calamity which necessitated the breaking up of his hunting establishment. For nearly forty years Sir Robert had kept hounds, commencing his career, as so many masters of foxhounds have done, with harriers, but on the death of his father he succeeded to the command of the foxhounds in the year 1843. It is said of him that he was a fine old English gentleman of the best type, who kept a pack of foxhounds for the amusement of his wealthier neighbours, 


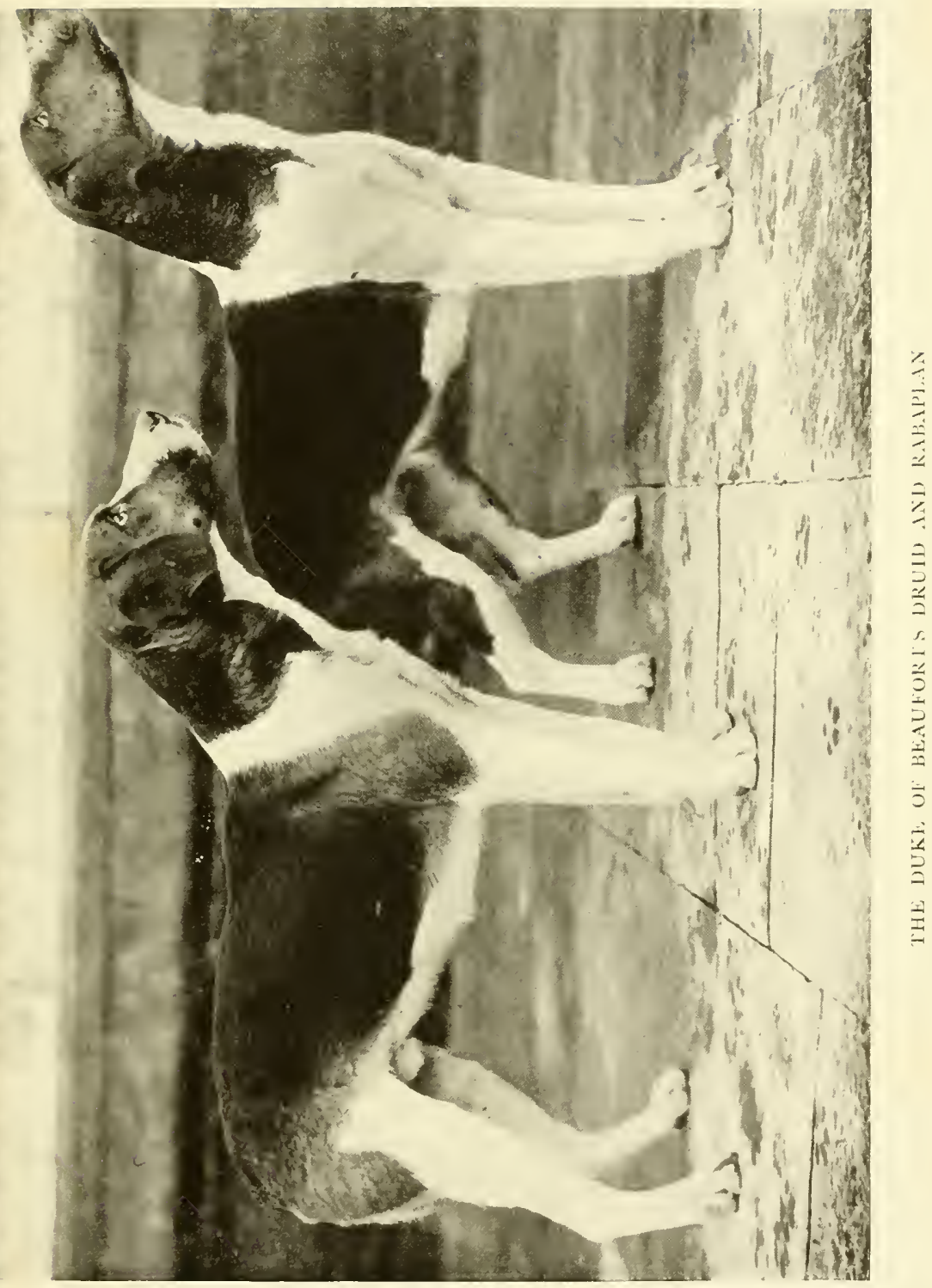



whilst for the poor he provided constant employment by purchasing everything in his own immediate vicinity, by having every article used in his large establishment made, as far as possible, in the adjacent towns and villages, by maintaining a large retinue of servants and a stud of hunters with means and appliances to boot, by distributing alms where alms were needed, and by occupying his leisure hours in the pursuits of agriculture. At this sale the lots were not very well sorted, hounds of every description forming part of the old-fashioned kennel, so buyers desirous of possessing a particular couple had perforce to make a bid for a lot and leave it to further consideration whether the "undesirables" should be destroyed or parted with. The black and tan hounds were reported to be capital in the pursuit of a mountain fox, and it seemed to be a strain from an original cross between the ancient dewlapped southern hound and the blue mottled harrier, looking capable of hunting anything from "an elephant to an earwig," but the thirty-eight and a half couples only realised the insignificant sum of $£ 44$ Is.

In the June of this same year the hounds which for two seasons had been hunting the Vine country and the Herefordshire respectively were parted with for $£ 66$ i4s., the pack consisting of twenty couples, one and a half couples of unentered hounds, and six puppies, so 1859 can hardly be reckoned an auspicious year for hound sales.

Another sale worthy of note was that which took place on 2 April, 1861, when Mr. W. Fielder Croome, on giving up the mastership of the Vale of White Horse, dispersed his hunters and hounds at the Cirencester kennels, six lots realising I I 79 gs., three brood bitches 23 gs., and two couples of unentered hounds 
$7 \mathrm{gs}$. The thoughts of the hunting world were soon, however, turned to more important considerations, for before this same month of April had run its course all the horses and hounds belonging to the Raby Hunt were sold by Messrs. Tattersall at the Corner. The event was brought about by the Duke of Cleveland giving up the country, and a famous company were present at the sale, including the Dukes of Cleveland and Rutland, Lords Chesterfield, Dacre, Doneraile, Middleton, Stamford, Curzon, and H. Bentinck, Messrs. G. Payne, White, Whieldon, Montague, Baker, Duffield, Giles, Henley Greaves, Marriott, Treadcroft, Villebois, Petre, Rigden, Causton, and J. Payne, Colonel Berkeley, Major Fletcher, and Captain Hankey, while of course many huntsmen and whippers-in of note also attended. The retiring master sat in the auctioneer's box and made a note every time a lot exchanged hands, the best price being given for the first lot of five couples, viz. Ioo gs., the eleven lots (fifty-seven and a half couples) fetching the sum of 6 I 4 gs.

Apropos Mr. Osbaldeston, who bought Lord Monson's handsome pack for 800 gs., it may be mentioned that the Squire never sold all his hounds till he gave up the Pytchley, when his pack was transferred under some arrangement to $\mathrm{Mr}$. Harvey Coombe. In I840 the pack was advertised for sale, and Lord Cardigan, who was desirous of buying the whole lot, gave his agent carte blanche, but was surprised to find that the first lot of five couples realised $720 \mathrm{gs}$. and the second lot $1020 \mathrm{gs}$, the total sum realised by these ten couples being, in the opinion of good judges, in excess of the value of the whole pack. The total nominal result was 6300 gs., but a dispute led to only three lots 
being actually disposed of. There appears to have been some mystery connected with this sale, and it may be noted here that in I84I an action between $\mathrm{Mr}$. Osbaldeston and Mr. Harvey Coombe was heard in the Court of Exchequer. It then appeared that some years previously Mr. Coombe had advanced £Iooo on the pack, a memorandum drawn up at the time setting forth that the hounds had been purchased by the lastnamed gentleman, but that if $\mathrm{Mr}$. Osbaldeston should by March Ist, I 837 , repay the loan, he was to have them back. As a matter of fact he obtained a further advance of $£_{500}$ on the understanding that $\mathrm{Mr}$. Coombe was to consider the hounds as his property, while if they were sold for anything over $£$ isoo the Squire was to have the surplus. The defence was that a sale was arranged with the intention of getting rid of the rubbish and buying in the best, to be kept until a favourable opportunity presented itself for selling the pick of the pack at a remunerative price, the Squire treating the sale, on the other hand, as a bona fide transaction and suing for the difference between the $£_{1500}$ and 6300 gs. In the end, however, the jury found for the defendant a verdict which showed this was not a bona fide sale, consequently the prices counted as nothing. It should be added that at the sale the first four lots fell to the bid of a Mr. Allen, who was not a master of hounds, and that gentleman was all through the sale remarkable for his assiduous biddings, subsequent events arousing the idea that he had bought in the dog hounds.

In the April of 1862 the Messrs. Tattersall were called upon to sell Mr. Drake's well-known pack, when fifty-six couples were dispersed at Stratton Audley, the average being $47 \mathrm{gs}$. per couple, while the majority of 
the lots consisted of four couples each. Amongst the purchasers, it may be mentioned that Mr. Morgan Jones, Lord Eglinton, and Lord Euston became the possessors of the first three lots at I20 gs. each; Lord Middleton took two at 285 gs., Captain Peyton four at 720 gs., Mr. Tailby two at 405 gs., Lord Eglinton two more at 480 gs., and Mr. Musters one at $225 \mathrm{gs} .$, the total amount realised (including the unentered hounds) being 287 I gs. In the same week, at Hyde Park Corner, the Old Berkeley, then Lord Lonsdale's hounds, were sold, with the exception of one lot, to Sir David Baird, to take into the Lothians, but that gentleman obtained thirty-nine couples of working hounds at an average of something under 8 gs. per couple, the total, together with three unentered hounds, amounting to 319 gs. Before the expiration of this same month $\mathrm{Mr}$. Selby Lowndes, who had a short time previously purchased the pack from Lord Southampton, sent twentythree couples of dog hounds to the hammer with a not very satisfactory result, though the celebrated huntsman, George Beers, said of one lot that "with twelve couples like them he would kill a fox against any other pack in Europe." The top price, I85 gs., was paid for four couples by Lord Eglinton, and altogether $675 \mathrm{gs}$. were realised. In the succeeding May the North Warwickshire were sold on the death of Mr. Baker, when once more moderate prices ruled, 855 gs. being paid for sixty-nine couples, Lord Curzon leading the way with 180 gs. for six couples.

About this time several crack packs were for one reason or another brought to the hammer, and in the month of April, I863, after one year of joint mastership, Sir Algernon Peyton and Mr. Richardson put up the Bicester hounds for sale at Stratton Audley. 


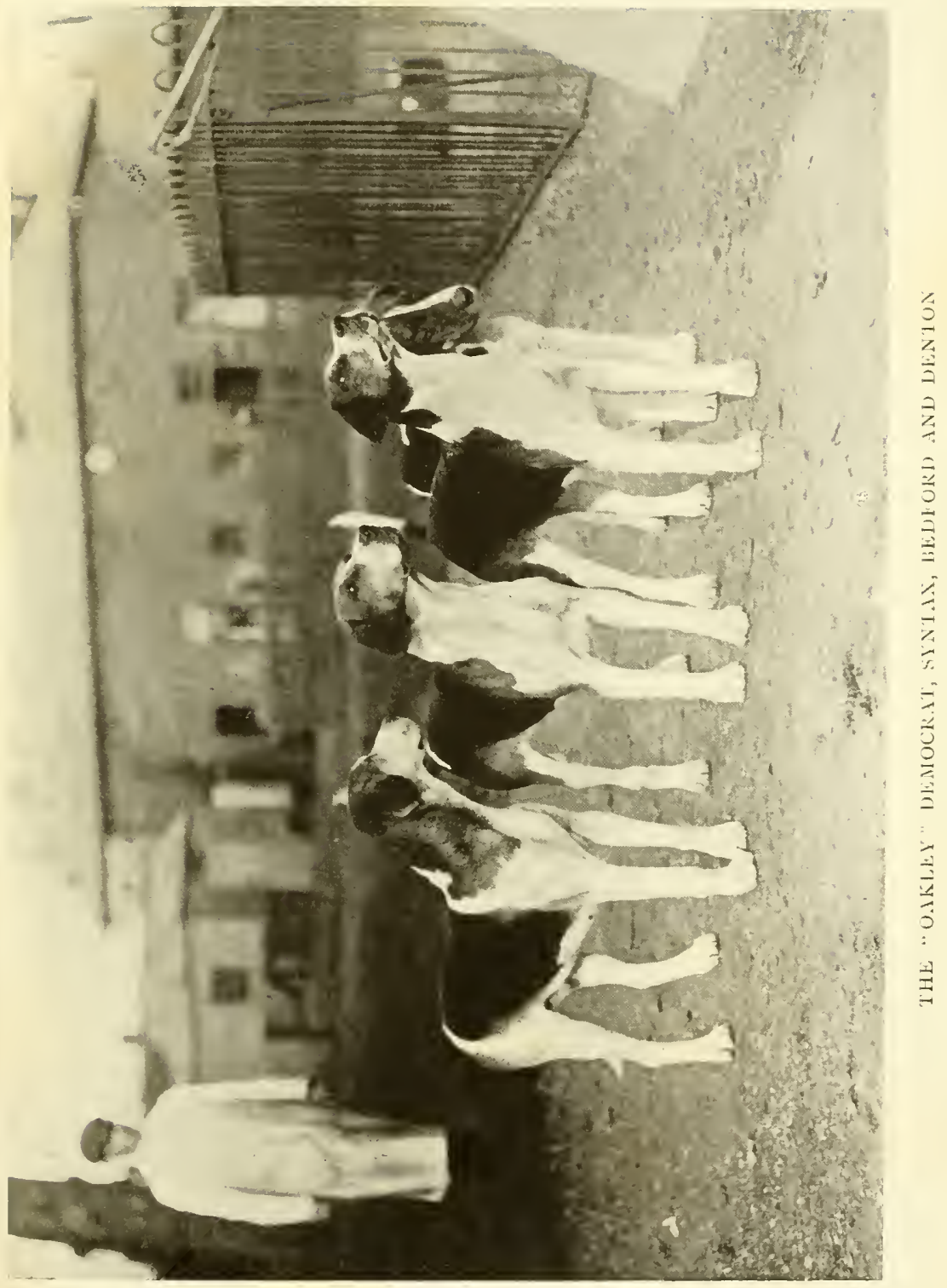



The great majority of the lots consisted of four couples each, and the total sum realised was ror 3 gs., Mr. Selby Lowndes paying the top prices, viz. 160 gs. and I50 gs. In the succeeding May a very fine pack was sold at the Corner, when Lord Doneraile sent up his foxhounds, which had been bred entirely from the kennels of the Duke of Rutland, Lord Yarborough, Lord Henry Bentinck, and Mr. Foljambe. Fourteen couples of unentered hounds realised the sum of $45^{8}$ gs., fifty-three couples of entered hounds realising 876 gs., or a total of 1334 gs., and the best price (140 gs.) was paid by Mr. Buckley for four couples of old hounds.

At the end of the following season Mr. Villebois commissioned Messrs. Tattersall to sell the West Norfolk, and thirty-nine couples of entered hounds changed hands for $55^{\circ} \mathrm{gs}$., fourteen couples of unentered hounds for $140 \mathrm{gs}$., and seven brood bitches for $122 \mathrm{gs}$, giving a grand total of 8ra gs., Mr. Hammond paying the top price of $135 \mathrm{gs}$. for four couples of entered hounds. Another Quorn sale took place at the kennels in the April of 1866, when Mr. Clowes gave up, and twenty-one lots made up of fifty-seven couples realised 1401 gs. The Marquis of Hastings was the highest bidder, paying $155 \mathrm{gs}$. for one lot.

April was a favourite month for holding a sale of hounds, and in I 867 Captain Jarrett, who had purchased the South Wilts from Mr. Pain, his predecessor, for $£$ rooo, now sold them for $£ \mathrm{I} 500$, twenty-five couples and seven brood bitches going to other establishments. At this sale the best price was $340 \mathrm{gs}$. , bid by Mr. A. W. Hall, then master of the Heythrop, for four couples, and the pack possessed plenty of good blood from the Belvoir, the Duke of Beaufort's, Lord 
Poltimore's, the Puckeridge, Lord Portsmouth's, and the Cheshire, while it may be added that Mr. Pain had bought largely at the above-mentioned sale of Sir Robert Vaughan's hounds. A few days afterwards Messrs. Tattersall were again in request, this time in the Crawley and Horsham country, where Mr. Stanford was giving up, but the bad weather no doubt affected the sale, for only three actual purchasers put in an appearance, and only forty-three and a half couples were parted with for 430 gs.

When Lord Feversham was the Hon. E. Duncombe he had been master of the Bedale, which pack he had formed with purchases from Lord Panmure's Forfarshire country, the Quorn, Mr. Drake's, Mr. Henley Greaves', the Burton, Bramham Moor, Holderness, and York and Ainsty, but here again low prices ruled, $5^{80} \mathrm{gs}$. being the amount realised by forty-four couples, the highest bid being I 25 gs. for four couples. The year I868 saw another Quorn sale recorded, and old Tom Day, who was one of the company on this occasion, stated that he had been present at seven previous auctions where packs which had hunted this country were sold. On this occasion the dispersal was brought about by the resignation of the Marquis of Hastings, the sale taking place in the paddock adjoining the stables, and at the extremity of the railed-off space a building fashioned in the shape of a little Chinese pagoda had been built. On the day, in question thirty lots realised 1057 gs., Lord Rendlesham paying I $55 \mathrm{gs}$. for four couples.

In the May of I 869 two packs were sold which may be said to have gone cheaply. In the first instance Mr. Richard Marriot parted with the East Essex at Abbott's Hall, Braintree, when twenty-nine and a half 
couples went for 194 gs., the top price being $30 \mathrm{gs}$. for four couples. Then a few days previously Messrs. Tattersall had sold Mr. Radclyffe's dogs and bitches at Dorchester in five lots of four couples each, together with three couples of unentered hounds, purchasers being few and far between. Mr. Lywood paid 94 gs. for four couples, Mr. Hall of the Heythrop So gs. for another lot, and the three others were bought in at 80 gs., $77 \mathrm{gs.}$, and $70 \mathrm{gs} .$, but the puppies found no bidder. On the 3 Ist of May the North Staffordshire were brought to the hammer at Trentham, owing to the death of Mr. William Davenport, when thirty-six couples of entered and eight couples of unentered hounds realised 82 I gs., Colonel Buller being the largest purchaser for the York and Ainsty.

On April 13, ז87o, an historic sale took place, when Lord Poltimore disposed of the establishment which he had started in 1858 with drafts drawn from the Vale of White Horse, Craven, and Vine, the remainder of the packs being taken by Mr. Luxton, of Brushford, who, however, very shortly afterwards sent on his portion to Lord Poltimore, so that the Portsmouth and Poltimore kennels had a common origin. Both packs were of first-rate excellence, and yet within twelve years they had assumed characteristics essentially distinct. The principal strains of blood in the first instance came from the Duke of Rutland, Lord Yarborough, Lord Fitzwilliam, Lord Portsmouth, Mr. Assheton Smith, Mr. Foljambe, Mr. Meynell Ingram, the Craven, and the Vine; but the great success of the kennel was through the Belvoir Comus, who came in an unentered draft from the Duke's establishment to Eggesford. In 1859 Lord Poltimore had purchased eighteen couples of the Atherstone bitches from Mr. Selby Lowndes for 
700 gs., Lord Curzon taking the dog pack with the larger bitches. At the r 870 sale, which took place at the kennels, it need hardly be said that the bidding was keen, the chief buyers being the Duke of Grafton, Sir Algernon Peyton, the Hon. Mark Rolle, and Major Browne, twenty-one and a half couples of old hounds realising $3170 \mathrm{gs.}$, or an average of nearly $148 \mathrm{gs}$. a couple, while the young hounds sold for $195 \mathrm{gs}$, or nearly 22 gs. a couple. Sir A. Peyton purchased three and a half couples for 600 gs., a similar sum being paid by Major Browne for three couples. Within the same week the Atherstone came to the hammer, owing to Lord Curzon giving up, but here fifty-eight and a half couples of old hounds only realised $565 \mathrm{gs}$, , or rather under Io gs. a couple, and fourteen and a half couples of young ones I 40 gs., making a grand total of 705 gs., Sir A. Peyton paying the best price, viz. Ioo gs. for five couples. Though the pack in shape and make were not in those days quite up to the standard of what is considered a first-class kennel, it certainly was not expected that many lots would go at draft price, or little over it.

On the 26th April, I870, another great hound sale took place, when for the second time in four years the Bicester kennel was broken up. Better fortune attended the venture, however, for fifty-one and a half couples of entered hounds, six brood bitches, and twenty-eight couples of unentered hounds, realised 1400 gs., or an average of about $17 \mathrm{gs}$. a couple, the best price being paid by Major Browne, who bid $150 \mathrm{gs}$. for five couples of entered hounds. The last sale of this season took place on May 6, when Lord Rendlesham's pack was sold at Ipswich. Owing to the unsatisfactory arrangements of the various lots, however, poor prices ruled, for then six, seven, and eight year old hounds were 


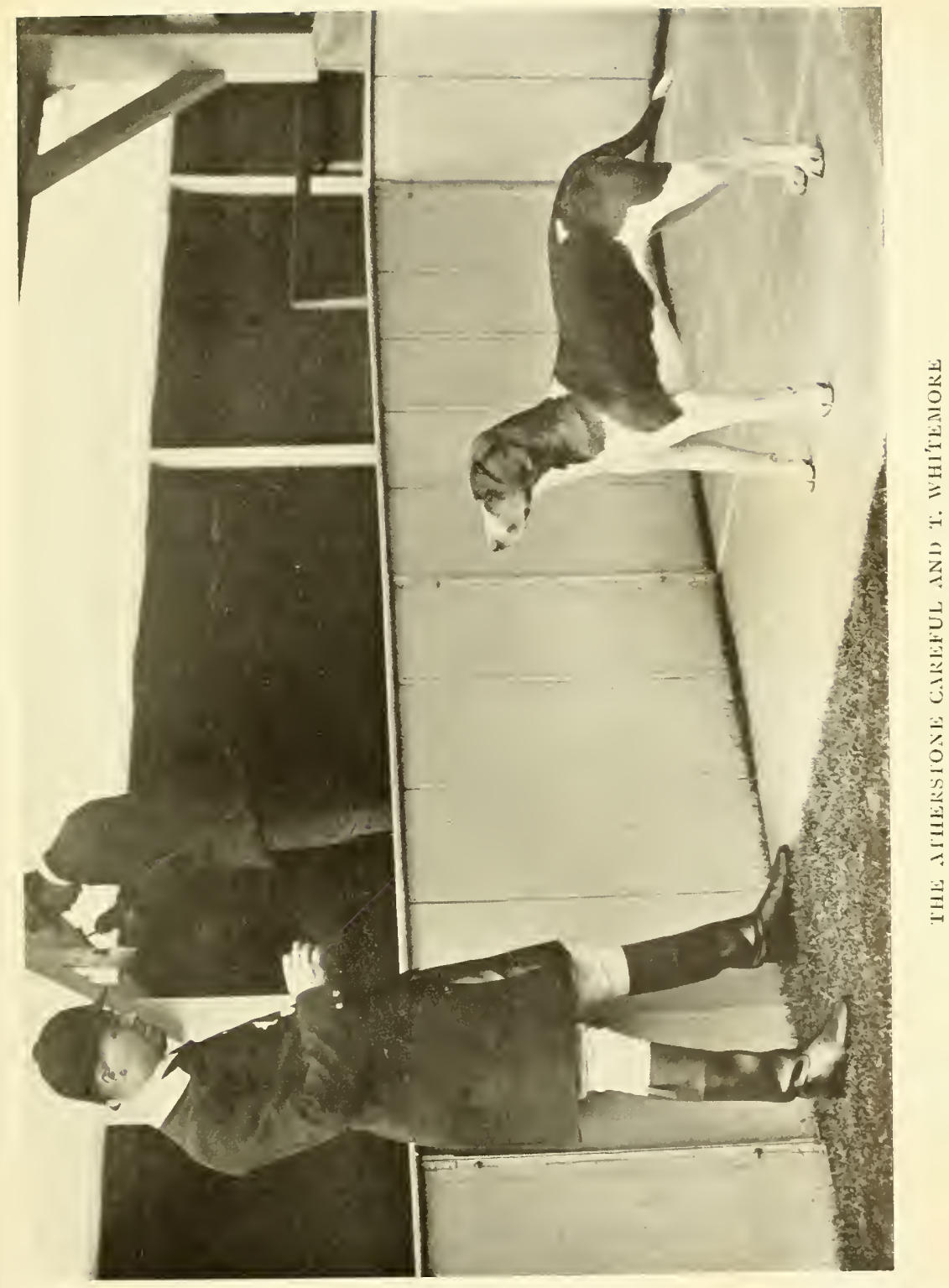



sold together with young ones, so as to leave some lots with an undue proportion of worn-out veterans; buyers could not be expected to run into high figures. Twentyone couples of entered, fourteen and a half couples of unentered, and two couples of brood bitches were sold for $730 \mathrm{gs}$, I $30 \mathrm{gs}$. being the highest bid, for which price Mr. Burton became the owner of three couples.

On April I8, I87 I, Lord Hastings' horses and hounds were sold, but the fine pack did not fetch the prices anticipated, for twenty-five couples of entered hounds, and two brood bitches, bred from the foremost kennels of the day, and sixteen couples of unentered hounds only realised 348 gs., 80 gs. being bid by Major Barlow, for Sir Edward Kerrison, for four and a half couples. Better luck attended the sale of Lord Wemyss' establishment in the same month, some of the well-bred hounds selling very well. For instance, Mr. Askew gave 4 I 5 gs. for five couples of bitches; six couples of dog hounds made 250 gs., two other lots of six couples each, bitches from the large pack, fetched I $50 \mathrm{gs}$. each, and the two kennels sold altogether for about 1200 gs., but higher prices might have been realised if the lots had been better put together.

Prices were not high during this year and the next, when the Rufford were sold at the Gonalston kennels, on which occasion the attendance was limited and the bidding languid; fifteen and a half couples of dog hounds, fifteen couples of bitches, six couples of unentered dog hounds, and seven couples of unentered bitches only realised $795 \mathrm{gs}$., Lord Lonsdale making the bid of the day ( $50 \mathrm{gs}$.) for three couples of bitches. A very different story, however, was told when, in this same month of April, Mr. Tailby sold his dog hounds at Skeffington Hall, for both masters and huntsmen 
came thither from all parts of the country and bid keenly for the various lots put up for auction. Twenty-four couples of entered hounds realised $1625 \mathrm{gs}$. ( $67 \frac{1}{2} \mathrm{gs.}$ a couple), and eight and a half couples of unentered hounds 335 gs. ( 392 gs. a couple). Lord Lonsdale bought three lots of three couples each at $380 \mathrm{gs}$, 3.50 gs., and 300 gs. respectively, besides giving I $70 \mathrm{gs}$. and Ioo gs. for two lots of three couples of unentered hounds. Then on October 24 Mr. Brunskill's foxhounds were sold at Totnes, when twenty-six and a half couples and eight couples of puppies, selected from Lord Coventry's, the Blackmore Vale, Heythrop, and Worcestershire kennels, realised 236 gs.

$\mathrm{Up}$ to the middle of May in the next season no hound sale was held, but on the $\mathrm{I}$ th of that month, on a very unpleasant day, Sir Edward Kerrison's establishment was dispersed, when forty-three and a half couples changed hands for 755 gs., or a little under i7 gs. a couple, Sir D. Roche paying I 20 gs. for three couples of dog hounds. When Mr. J. H. Arkwright resigned the North Herefordshire the hounds were brought to the hammer at the White Cross kennels on May 20, I874, on which occasion thirty-four couples realised 700 gs., and Mr. Rigden bid 105 gs. for three couples.

On 14 April, 1875, Mr. Humphreys sold at the Horse Repository, Cheltenham, draft hounds belonging to Lord Fitzhardinge and Captain A. H. Sumner of the Cotswold, the former sending twenty-seven couples of unentered hounds, for which 307 gs. were bid, $\mathrm{Mr}$. Corbet paying $27 \mathrm{gs}$. for one couple and $14 \mathrm{gs}$. for two couples of working hounds. Captain Sumner obtained $48 \frac{1}{2} \mathrm{gs}$. for eleven and a half couples, and $12 \mathrm{gs}$. for four couples of working hounds, Mr. Roote giving I 2 gs. for one couple of unentered hounds. In the following May 
the dog pack belonging to Mr. Mark Rolle were sold at Lillie Bridge, when twenty couples of dog hounds and three and a half couples of bitches, constituting fourteen lots, realised $745 \mathrm{gs}$., two couples of dog hounds being purchased by Lord Fitzwilliam for $105 \mathrm{gs}$.

Owing to the death of Mr. Talbot the Glamorganshire hounds were sold at the kennels on August 8, I 876 , the pack consisting of thirty-six couples of old hounds, fifteen couples of unentered hounds, and four lots of puppies, three and a half couples of old hounds passing into the possession of the Marquis of Worcester for 155 gs. Altogether 1695 gs. were realised, the old hounds averaging $28 \mathrm{gs}$. a couple and the unentered $38 \mathrm{gs}$.

The year 1877 witnessed the dispersal of the Craven and the resignation of Mr. Harcourt Capper, when fortysix couples of old hounds, twelve and a half couples of unentered hounds, sixteen and a half couples of puppies, and one and a half couples of brood bitches realised I 75 gs., Mr. Boughey giving 200 gs. for four couples of old hounds, and it may be mentioned that the forty-six couples alluded to above realised 86I gs. Shortly afterwards Major Browne sold his Northumberland pack at the kennels near Lesbury House, when eighteen couples of working and two and a half couples of unentered hounds realised $590 \mathrm{gs}$, the old hounds averaging a little over $£ \mathrm{I} 6$ a head. On this occasion Mr. Cookson paid IIo gs. for one and a half couples of working hounds, which was the best price of the day. On I May, I877, the North Herefordshire were sold at the kennels, owing to Mr. Platt giving up. The bitch pack consisted of twenty-seven couples, and the auctioneer said that, much to the honour of Mr. Platt, he was anxious that the country should have them, and on the part of the county $600 \mathrm{gs}$. had been bid, so if there 
was no advance he would, in accordance with $\mathrm{Mr}$. Platt's wishes, knock them down at that price, which was done. Twenty-three couples of dog hounds were then put up, eleven couples of the younger hounds fetching I8I gs., Mr. Merrick giving 95 gs. for three couples.

To-day the Rugby Hound Sales, which are held every year by Messrs. Tattersall, have become a feature in the hunting world, but of course everything must have a beginning, and in the Field of April 30, 1881, the following paragraph appeared:-

Many masters of hounds having found it almost impossible to get rid of their drafts privately asked Messrs. Tattersall to hold a sale at Rugby. We cannot speak too highly of the accommodation and arrangements, and both masters and huntsmen agreed that they never saw so good a place for a hound sale. There were 120 couples of foxhounds from many good packs in the catalogue, and ... hopes were entertained that a few foreigners would put in an appearance. Mr. Pain began business before a small audience, and there were very few buyers even at the low prices. It is something to say, however, that every lot of the foxhounds was sold, much to the relief of the masters present, and the huntsmen who were with them. . . Messrs. Tattersall should continue this sale, as when times improve and it gets known abroad, it is sure to be a great convenience to both buyers and sellers of hounds.

In May, 1884, Messrs. Tattersall sold the East Sussex at Rugby for $830 \mathrm{gs}$., while twenty couples of the Pytchley realised over 550 gs., but in the following September some remarkably low prices were recorded. On this occasion Messrs. Walton and Lee sold the Haydon hounds at Grove Park, Kingsbury, owing to the retirement of the late $\mathrm{Mr}$. Nicholas Maughan. In the dim twilight twenty-one couples of hounds were brought out, and it was said "on looking round the now scanty ring of spectators there was only one gentleman who had any more use for a hound than for 


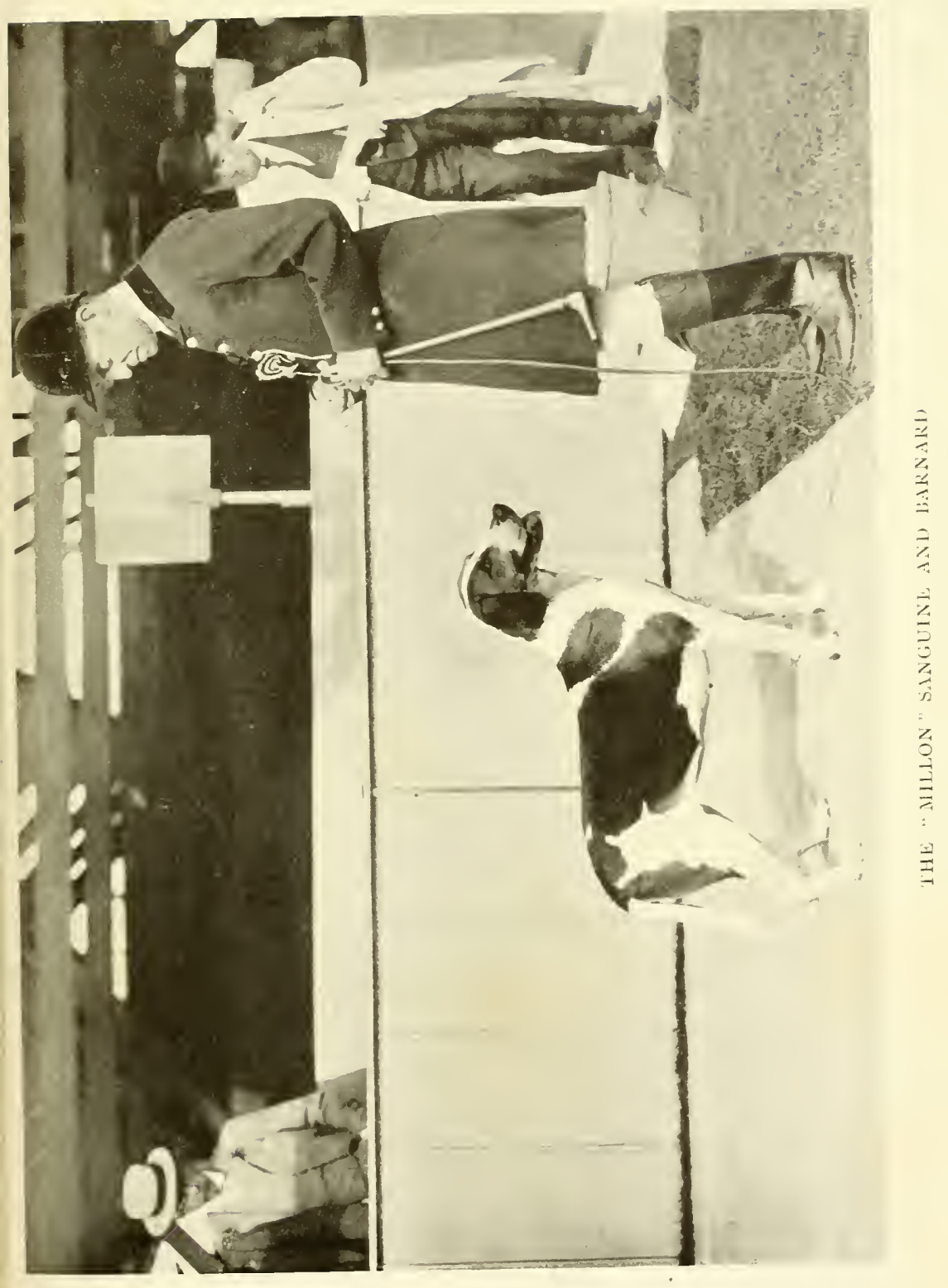



an elephant, and that was Mr. George Nurse. Truth compels us to say that the hounds were hardly as good as the horses. This, however, may be accounted for by the fact that Mr. Maughan had had bad luck with his hounds, and had to depend to a great extent on drafts. They were not particularly level, while some were deficient in bone and other qualities. Still, there were some nice hounds among them, as the Bramham, Badminton, Lord Yarborough's, Milton, Quorn, Belvoir, Warwickshire, and Eggesford blood was represented. For these twenty-one couples there was but one bid-I 5 gs. - by Mr. Nurse, and for that sum he became possessor of the pack-a bargain, when we call to mind that ere now five couples have brought $720 \mathrm{gs} . "$

On April 25, 1885, owing to Mr. Arthur Longman giving up, the Old Berkeley East were brought to the hammer and seventy-eight hounds with puppies fetched $£$ II61, or an average of $£_{15}$ I2s. 6d., Sir R. Sutton giving $220 \mathrm{gs}$. for two couples of unentered bitches, while it should be added that a few seasons before Mr. Mackenzie had bought the dog hounds to hunt the western portion of the country with. In March, I886, Mr. Deacon sold twenty-eight couples of foxhounds from the kennels of Mr. C. A. R. Hoare at the V.W.H. Repository, Swindon, when Mr. Van Notten Pole, of Watermor, Cirencester, bought the five lots for $£ 15$ ros. At the following Rugby Hound Sale nineteen and a half couples of the East Sussex were sold for 293 gs., $5^{2}$ gs. being given for three couples, while a draft from the South Dorset, consisting of three and a half couples, realised 47 gs., the best price of the day.

The sale of the year, however, was recorded when the Cattistock, which the Earl of Guildford had purchased a few years previously from Mr. Froude Bellew, were 
brought to the hammer, the total amount realised being I $400 \mathrm{gs}$., I $30 \mathrm{gs}$. being given for two and a half couples of entered hounds.

In the May of 1887 the Blankney, Cranbourne, and Chiddingfold tried their luck at Rugby, but high prices were not in the ascendant, though the first-named pack fetched IOI4 gs. for twenty-five couples, an average of a little over 40 gs. a couple, 125 gs. being paid by Mr. Austin Mackenzie for one and a half couples. In July, I889, on the retirement of $\mathrm{Mr}$. Harding Cox, the Old Berkeley were put up for sale, the pack having been got together at great trouble and expense almost entirely from the Blankney and Curraghmore. They consequently inherited the Old Burton blood, secured when Mr. Chaplin became possessed of Lord Henry Bentinck's famous pack. At the sale thirty-six couples were sold, the lots averaging one and a half couples each, and the total sum realised was 1003 gs. Mr. Chandos Pole gave Ioo gs. for two couples, and Mr. Selby took two couples more at the same price.

In the April of 1890 it was said that Lord Portsmouth had sold his hounds privately through the medium of Messrs. Tattersall to the then Marquis of Worcester and Sir Watkin Wynn, the big pack going to Badminton and the small one to Wynnstay in equal portions, for the sum, it was said, of $3000 \mathrm{gs}$.

By this time the Rugby Hound Sales had become firmly established, and in May, I893, Mr. Lort Phillips sold his entire dog pack there, and other hounds as well, in consequence of the Pembrokeshire country being divided. The total amount realised was $3 \mathrm{I} 6 \mathrm{gs}$. for twenty-three and a half couples of working hounds, or an average of about 13 gs. per couple, the top price being $38 \mathrm{gs}$. for one couple. At the same time Lord 
Radnor, who was reducing the number of his hunting days, sold twenty-three and a half couples at an average of 6 gs. per couple, one lot of two and a half couples realising 60 gs. In 1898 the Suffolk sold at an average of no more than 3 gs. a couple, while Mr. Gerald Hardy, who at that time was master of the Atherstone, received 23 I gs. for seventeen and a half couples of entered hounds.

In the following July no little interest was aroused over the sale of the Quorn horses, the property of Lord Lonsdale, when her ladyship's Odipus, a chestnut gelding, by Oedipus, was bought by Mr. P. Whitaker, of the Oakley, for $760 \mathrm{gs} .$, Bay Prince realising 660 gs. and Eggshell 630 gs., the average of fifty-four hunters being $£ 290$ and the average of nineteen of Lord Lonsdale's stud being $£_{3} 80$. This, of course, brought up a number of reminiscences, and it was remembered that when Mr. Drake gave up the Bicester country in 1862 he received $300 \mathrm{gs}$. for a hunter (a very ordinary price in these days), while Lord Lonsdale in the same year experienced what may be termed the frowns of Fortune, in that out of the Old Berkeley stud only about half a dozen were sold, the prices ranging from $35 \mathrm{gs}$. to $80 \mathrm{gs}$., and when Mr. Baker gave up the North Warwickshire the majority of his stud ran to no more than $20 \mathrm{gs}$. or 30 gs., while only two exceeded Ioo gs. Prices ruled better, however, in I863, when Lord Stamford sold seventy-nine of the Quorn horses for the sum of $£$ I5,060, or an average of about $£$ rgo each, individual bids being 520 gs., 510 gs., and $460 \mathrm{gs}$. Again, when Sir G. Heathcote's hunting stud was sold at Tattersall's, one horse brought $360 \mathrm{gs}$. , while three others realised $310 \mathrm{gs.}$ (2) and $300 \mathrm{gs}$, and three more sums ranging from $200 \mathrm{gs}$. to $300 \mathrm{gs}$. Lord 
Plymouth would give $700 \mathrm{gs}$. for a hunter, and in the sixties Mr. Chaplin's hunters brought such long prices as 400 gs., $35^{\circ}$ gs., and 300 gs., while fourteen others realised over 100 gs. each. When Lord Henry Bentinck gave up the Burton in 1862 his hunters brought $£$ I $2,46 \mathrm{I}$, the sale taking place on the same day as that appointed for the first horse show held at the Agricultural Hall, at Islington, under the late Mr. Sidney's management, and in the course of the a f rnoon that gentleman entered the arena to announce that the first three horses sold by Lord Henry had passed into the hands of Mr. Chaplin for $£ 1000$, and he urged his hearers to note the fact by way of bearing in mind what could be made out of hunter breeding. It may be added that at $\mathrm{Mr}$. James Hall's Holderness sale the sum of $400 \mathrm{gs}$. was given for a hunter.

At the beginning of the year 1899, to return to the hound sale proper, no little excitement was roused at the news that Mr. Austin Mackenzie, who was then giving up the Woodland Pytchley, had sold his pack of about fifty couples for $£ 5000$, the Marquis of Worcester taking the dog hounds at $£ 2000$, and $\mathrm{Mr}$. Wroughton the bitches at $£_{3000}$. In the November of 1900, when the North Cornwall hounds were sold at Aldridge's, sixteen couples realised from $8 \mathrm{gs}$. to $2 \frac{1}{2}$ gs. a couple, while in the June of the following year Mr. Bathurst on giving up the Eggesford country parted with thirty-one and a half couples of entered hounds for 660 gs., twelve brood bitches and puppies for 370 gs., and eleven and a half couples of unentered hounds for 155 gs., making a total of II $85 \mathrm{gs} ., \mathrm{Mr}$. Dun Waters giving 150 gs. for one and a half couples and bitches. 


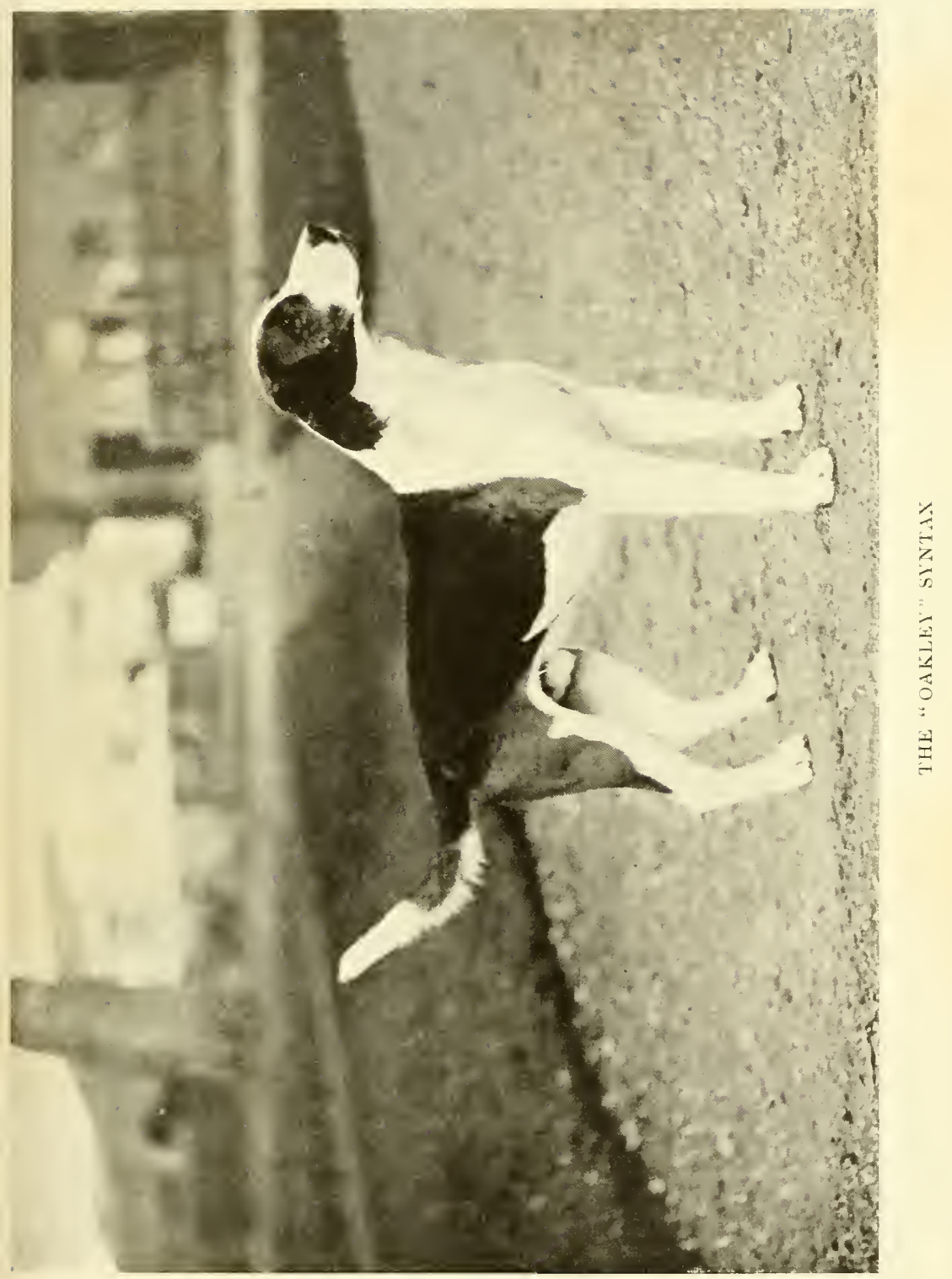



At the Rugby Hound Sale of May 19, I902, Mr. R. Carnaby Forster sold the Ledbury dog pack at the kennels owing to his hunting fewer days a week, and so confining himself to hunting with the bitch pack. He, however, did not have a very good sale at Rugby, as only nineteen couples out of thirty-six entered and unentered hounds were disposed of, fifteen couples of entered hounds realising $\mathbf{I} 74 \mathrm{gs}$., or an average of II $\frac{1}{2}$ gs., Mr. Compton, of the New Forest, giving 5I gs. for two and a half couples. In the December of this same year Mr. Poole sold the Teme Valley foxhounds at Knighton to Mr. Peter Ormrod, the price being. I Io gs.

In the following February, when Mr. J. C. Munro resigned the mastership of the Atherstone, certain gentlemen connected with the country purchased the pack for 3500 gs. through Messrs. Tattersall, and at Rugby, during the annual sales, twenty-seven and a half couples of the Percy sold for $5^{\text {I } 5}$ gs., or an average of about $£$ I 8 a couple, Mr. Bell giving 96 gs. for two couples, and ninety-eight lots, including nearly two hundred couples, amounting to a grand total for the whole sale of $2178 \mathrm{gs}$, this including ten couples of entered hounds and a stallion hound of the North Herefordshire, which changed hands for $376 \mathrm{gs}$. At the first Rugby Hound Sale for 1904, presided over by Mr. Rawlence, so well known on these occasions to hunting men, seventy-one lots, made up of one hundred and sixty-six and a half couples, realised $£_{521}$ I7s., the Pytchley-fourteen couples of entered and twenty-five and a half couples of unentered hounds-realising 105 gs., while in the May sale seventy-two lots realised £gr5 I2s. The Galtee were sold for 322 gs., 25 gs. being given for two couples of unentered bitches, but it should 
be remembered that in the ranks of the lots offered all through the catalogue were some four or six season hunters, hounds who would probably never have secured a bid had it not been for, say, a couple of youngsters judiciously thrown in. All things considered, therefore, the total amount realised, as mentioned above, shows that even in cast-offs, and second and third choices, there is a certain amount of business to be done in hounds.

In 1905 the Dulverton, including twenty-three couples of entered hounds, five couples of unentered hounds, and some odd lots, made $247 \frac{1}{2}$ gs., the proceeds being divided between the Hunt Servants' Benefit Society and the Royal Agricultural Benevolent Society, Lord De Clifford paying $3^{\mathrm{I}}$ gs. for two couples. The Hundred of Hoo pack, consisting of nineteen and a half couples, made $5^{8} \mathrm{gs} .$, and in 1906 Lady Craven's hounds realised 1004 gs., the Duke of Beaufort giving 70 gs. for a couple of dog hounds.

In the Field of September I, 1906, the following letter appeared, which brings the story of the hound sales down to that year :-

In Igor Mr. Charles McNeill purchased a mixed pack (dogs and bitches) from Captain Stacey, who had been hunting the North Cotswold country up to that period and for five years previously. Mr. C. McNeill sold the dog hounds, about sixteen couples, to Lord Portman, and, on giving up the country in May last, sold his bitches (forty-six couples), practically, therefore, two packs, for $£ 3000$, to Sir John Hume Campbell, who also bought some fifteen or sixteen couples of unentered hounds. Almost every hound, old and young, were got by Belvoir sires. The price seems high, but on looking into the hound list and noticing that every hound is a bitch, and these of exceptional lineage, besides their being two packs, capable of hunting four days a week, then one realises 
that it is nothing like the price given by Mr. W. M. Wroughton for Mr. Austin Mackenzie's pack. Mr. McNeill's bitches had also earned a great reputation for tongue and also for catching their foxes. Hunting ninety-two days last season they killed ninety-seven foxes, a grand record in so difficult a country.

A private sale of importance took place in connection with the Morpeth hounds, when Mr. Clayton Swan gave up the country in 1902. The elected master, Mr. A. B. Cresswell, who had been in command of the adjoining Percy country for six seasons, gave 3000 gs. for the pack. As it happened, Mr. Cresswell never took up his mastership, but the pack was transferred to Mr. F. B. Atkinson, the present master, at, it was said, a discount of $£_{300}$. In 1907 the South Cheshire bitch pack were sold at Rugby for $£$ I 700 , and in June of the present year (IgoS) Mr. Wroughton's Woodland Pytchley pack were disposed of at the same place, for a total of $432 \mathrm{I}$ gs. To go a little into detail, seven and a half couples of unentered $\operatorname{dog}$ hounds made 227 gs., seven couples of entered dogs $57^{2}$ gs., four stallion hounds 360 gs., eight couples of unentered bitches $75^{\mathrm{I}} \mathrm{gs}$., twelve and a half couples of entered bitches 2035 gs., and brood bitches and whelps 376 gs. And just as this volume goes to press another very big private sale has taken place, Lord Leconfield buying fifteen couples of the Atherstone for $2000 \mathrm{gs}$. Of these ten couples were entered and five couples unentered hounds, and the average works out at a little over $132 \mathrm{gs}$. a couple. In the case of unentered hounds, truly a very high price, but Lord Leconfield had the right to choose from the whole pack, including several recent Peterborough winners. 


\section{CHAPTER IX \\ HORSES AND STABLES}

T $\mathrm{N}$ connection with hunting there is no more important question than that of horses. To be well 1 carried during a run with hounds enhances the enjoyment one hundred fold, and to be badly carried means converting what in a natural way should be a pleasure into a most uncomfortable task. There is a period of one's life when ability to gallop and jump is the only thing looked for in a hunter, when bad manners are lightly thought of, and even vice is looked upon with a lenient eye. There are, too, some men, and not a few women, who can make themselves at home and be thoroughly happy on what the average hunting man would call a rotten bad horse, and there is another and a smaller group of individuals who can succeed in getting to the front on horses which, in ordinary hands, would be hopelessly tailed off before hounds had been running ten minutes.

But to the majority of men and women it is essential that their hunters should be, at least, useful animals ; that they should have a fair amount of endurance, be able to gallop at a steady pace, and to jump smoothly without rushing their fences, while-most important of all-they should be free from vice, and have manners which are reasonably good. It is well enough for those whose business it is to make hunters to come out on raw, half-broken horses, who have all their educa- 
tion before them, but such horses only suit men who are professional or semi-professional horse makers or breakers. For a beginner a horse which is absolutely quiet is almost a necessity, but for the rank and file of hunting people first-rate condition is the great desideratum, for all who have secured a certain amount of experience will surely ride the horses which suit them, and will discard those horses which have confirmed bad habits, or any real vice.

In this connection it is a somewhat curious fact that many people-especially, perhaps, the owners of small studs-will, after they have once bought a horse, struggle on with him for months when he does not suit them rather than dispose of him at once. It is, of course, most annoying to buy a horse which appeared to be temperate when tried and then to find that he rushes his fences, or that he pulls all day long ; but this is a thing which constantly happens, and it is better, supposing the horse cannot be returned, to cut one's loss at once rather than keep a brute which does not give satisfaction.

Quite lately we noticed a quiet-riding, middle-aged man begin a season with two new horses, which were taking the place of two veterans which had carried their owner some ten seasons apiece. The new horses were young, good-looking, and apparently well behaved, and during the month of October their owner was much pleased with them. But as the season advanced one began to pull very hard, while the other was found to be a confirmed rusher, who would go blindly at any place forty miles an hour, and who, though a big jumper, was terribly rash. Their owner was advised to hand both horses over to a rough-rider for a while, but though a quiet, most unassuming man, 
he was also gifted with great determination, and had been in his younger days a bold horseman. He did not like to be beaten either, so he struggled on with the pair, and it became quite a usual thing for him to be seen galloping round and round a big enclosure when hounds were going away, because he could not hold his horse. By Christmas-time he had brought both horses to a slightly better frame of mind, but hunting was stopped by frost, and after two or three weeks of inactivity the horses were worse than ever.

The puller, having been continually ridden by a man who could not hold him, had become a confirmed runaway, and the rusher not only rushed more, but now chanced his fences, and had also taken to pulling hard between the jumps. The owner tried all sorts of bits, gave his horses double exercise, and put them on a short allowance of corn. He also had their rough edge taken off by a strong, early gallop on hunting mornings, but it was all of little use, and although he continued to hunt them to the end of the seasons, the horses always had the best of it, and their rider's season was completely spoilt.

A really good horseman can of course succeed with ninety-nine awkward horses out of a hundred, but the average rider should always get rid of any horse which has a bad fault; and perhaps the greatest fault which a hunter can have is to be a runaway. Kicking is bad enough, but people will avoid a kicker when he carries the danger signal in the shape of a red ribbon in his tail, whereas a horse which bolts will often, when he has taken complete charge of his rider, make straight for the thick of the crowd, and set half a dozen other horses off their balance.

And apropos of kicking and the red ribbon, we have 
a strong opinion that in these days no one is justified in taking any incorrigible kicker out hunting. Many years ago, when fields were much smaller than they are now, when the dangers of unmarked wire were unknown, and when in the average hunting field every one not only knew every one else, but knew all about their horses as well, it was often customary for the man who rode a kicker to wear on the back buttons of his coat a bit of white cardboard, with the single word "Kicks" inscribed thereon in big black letters. On a scarlet or on a black coat this notice was most conspicuous, and the kicker was duly avoided, but in an unfortunate moment some one hit upon the idea of a red ribbon in a horse's tail, and that was quickly taken up, and now a dozen or more red ribbons can be seen in any hunting field of fair dimensions, and two or three even where the numbers are quite small.

But the wearing of the red ribbon is not always legitimate, for certain people have taken advantage of the custom, and have adopted it, not because their horses are kickers, but in order that they may not be crowded, and may find more elbow-room at gaps, gates, and in narrow places, such as the rides of a covert. This is one way in which the wearing of the danger signal is abused, but there is another and more important side to the question, this being the hard fact that many people who ride confirmed kickers think that when they have once announced the fact to all and sundry by placing a ribbon in their horse's tail they have done all that is required of them, and that afterwards they are not to blame if anything happens. And having once sported the signal, these irresponsible men and women will push and shove into the crowd where it is thickest, will hustle for their turn at an 
awkward hunting wicket, and will, in point of fact, act exactly as if they were riding a horse which has not a kick in it.

Our experience is that certain horses will always kick at other horses which come too close to them, and during the last few weeks of the season many mares, which are steady enough at other times, are not to be trusted. But it is unquestionably the duty of the rider of a kicker to keep him wide of the crowd, so wide indeed that he can do no harm. The man who is on a confirmed kicker has no right to take his place at a crowded gate; he is bound in all fairness to find another road for himself, and if he loses a run, he must accept the loss as the penalty entailed by hunting a kicker. How much damage is done by these kickers there are no statistics to show, but we have twice seen a man's leg broken by another horse in the hunting field, and scores of hounds are killed or badly hurt every season.

Curiously enough there are horses which do not kick at other horses but will invariably kick a hound, and when this vice is discovered the greatest care should be taken to keep such horses well away from the pack. As for the horses which cannot be cured of the habit of kicking at other horses, they are not fit to be hunted, and should at once be relegated to some of the lower walks of horse enterprise. In these days "fields" are too large for kickers, and owing to the presence of so much wire in the country there is more danger than there used to be, because it is so often necessary for every one to rush to some particular unwired place-possibly an invitation jump-or to a gate. Crowding, then, must be of very frequent occurrence, and the kicker much more out of place than he was a generation ago, and this fact cannot be too generally recognised. There 


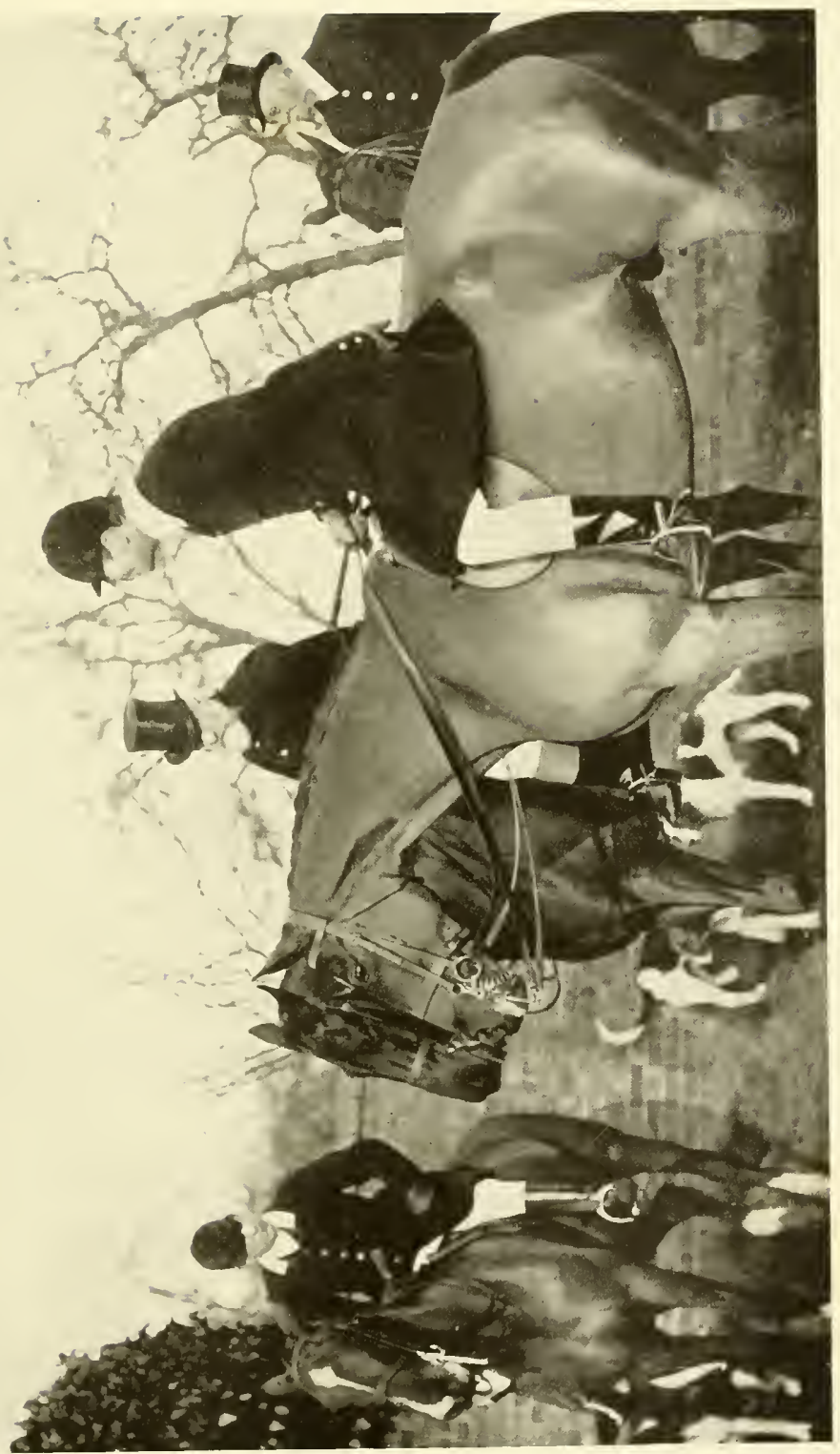

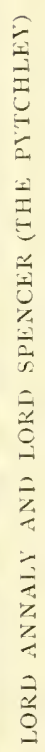



is an odd man, of course, who, being aware that he is on a horse which is not to be trusted, will give every one a wide berth all day long, but the rank and file are not only too fond of the red ribbon, but when anything happens will loudly urge that they cannot possibly be to blame because of their having worn the danger signal. Such a defence is, however, grossly unfair, most unsportsmanlike, and unsound as an argument, for in the excitement of a run people cannot be continually looking for red ribbons, especially when they know that scores of horses so adorned have never been known to kick.

There are very many, perhaps indeed a majority, of hunting folk who are able to gauge their own riding capacity. Some of these know that they can show a bold front if only they are well mounted; others are fully aware that they can get along comfortably in a fair place, but feel that they are not exactly fitted to cut out the work; while a third section are perfectly content to follow on to the best of their ability, seldom near the front, except by accident, but enjoying themselves quite as much as those who are leading the van a field or two ahead.

But on the other hand there are individuals who seem to be of opinion that what one man can do another can also achieve, and thus " A," an ordinary hunting man, but not exactly accustomed to go in the first flight, sees “ B," an exceptional horseman, doing great things on a young horse which he wishes to sell. "A" is much taken with the performance, and a deal is quickly effected. But to "A's" surprise he finds that the horse when he is riding it is quite a different animal, and as he will not realise that " $\mathrm{B}$ " is ten times as good a horseman as he is, he is in a quandary. $\mathrm{He}$ 
cannot exactly blame the horse, because he has seen it do big things for another man; he will not blame himself, because that would be admitting that his horsemanship was inferior to that of " B." So he makes excuses for the nag, and parts with him as quickly as possible.

It is an undoubted fact that there are a few men in every large hunt, and an odd one in every small hunt, who can go in front on any and every sort of horse, and can keep them there as long as condition of their horses will allow of it. Not only are such men fine horsemen, but they are gifted with some indescribable knack of getting along. They have falls, of course, but no more than their neighbours when their style of riding is taken into consideration, and what they really excel in is that they are able to make horses gallop and jump in a way which is an impossibility to other men. It is not the honest, willing horse that they are seen to so much advantage on, but the raw, ignorant horse, or very often the animal which is in ordinary hands a shocking bad hunter.

A rather heavy man once bought a big, fairly goodlooking horse which had been working in a road coach, the horse having a previous character to the effect that he was a good hunter. His new owner could not make him jump, and found that he could not gallop fast enough to keep up with what Miss Somerville calls " the flotsam and jetsam of the field." He was on the point of being sent up for sale by auction, when some one suggested that the crack rider of the hunt should have a day on him. As it happened Lord - 's hounds were in their best country on the following day; the coach horse was sent on, his owner went to see what occurred, and to his surprise the horse which 
would not go a yard for him was in the van all day, and fairly "brought down the house" by a marvellous exhibition of gate jumping.

The average hunting man or woman must be content, then, to take his or her proper place in the field, and to buy horses which are suited to his or her capacity. It is hardly within our province to inflict a horse-dealing lecture on our readers, nor have we the space for anything like a full review of this absorbing question, but a few general hints may not be out of place, and, firstly, it cannot be too strongly impressed upon those who hunt that breeding is the greatest essential in a hunter. The better bred a horse is the better hunter he is likely to be, and any horse which is very short of breeding should be avoided at all costs. And when we write of breeding we refer solely and entirely to the blood (more or less of which is to be found in almost every light horse) which comes from the thoroughbred. The thoroughbred is the original source of the modern hunter, and though horses which are of absolutely pure blood-entered in the General Stud Book-are few and far between in the hunting field, a huge majority of the present-day hunters, including all the best of them, have a considerable amount of pure blood in their veins. A common-bred horse may, on the other hand, be both good-looking and clever, and yet by no means a good hunter. His good looks may find him a purchaser at a fair price, and in some hands he may get through his work with credit. But this is dependent upon two things, either that his owner has found out all his weak points, or that he is bought by some one who does not care to go fast, but who just potters on well behind the crowd when hounds are running. 
If the owner of one of these common but yet goodlooking horses is clever enough to arrive at a true estimate of his nag's capabilities, he will take good care that the weak points are not allowed to show themselves. He will be prominent enough when hounds are creeping after a fox, feeling for the line all the way, and if he be a bold man he will occasionally indulge in a gallery jump. But under no circumstances will he let his underbred horse gallop itself to a standstill, and if he (the owner) has to be content with a bad place when hounds run hard, he will very likely make up for this by passing the horse on at a profit to some one who has been struck by the good looks and jumping capacity.

In the other case, that is to say, when the owner is a man who cares little for galloping, a common horse may do well enough, and may work in satisfactory fashion through half a dozen seasons. It is fast galloping which finds out the weak spot in an underbred horse, and if such a one is urged beyond his speed, or has to unduly exert himself, he quickly collapses. When this happens he falls all in a heap when he attempts to jump, or not infrequently crosses his legs and comes down in the centre of a field. The horse which is short of breeding will not stand being pushed as will the well-bred horse, and has not the same power of recovery; in fact, when a common horse gets into the hands of a man or woman whose pluck is in advance of his or her knowledge of horses and riding, collapse and perhaps a heavy fall are sure to come sooner or later.

Breeding is the first thing to be looked for in a hunter, and as a matter of fact this is far more necessary than good looks. It has at times been said that 
a very good-looking, hunter-like horse must be well bred, merely because he is good-looking, but this is not always the case, for many so-called weight carriers of grand appearance have been bred from a cart mare and a thoroughbred sire, and have entirely favoured the sire in appearance. On the other hand the union of a thoroughbred with a pony or cob-mare has often resulted in the breeding of a good hunter, of fair size and up to a deal of weight, but there is no golden rule in the matter, and it is impossible to get at the real capabilities of any horse until he is fairly tried. The underbred horse may give great satisfaction when hacked and cub-hunted, and he may be the most comfortable hunter on days of quiet sport, but if hounds run hard, and the going is heavy, he will soon be spun out, and he will, in addition, take much longer to recover than the well-bred nag.

Still, common horses are to be found in every hunting field, and many of them give great satisfaction to their riders. This is accounted for by the fact that a considerable section of the hunting community either do not know how to, or do not care to gallop. When hounds go fast they are content with an unassuming position in the rear of the hunt, having at the start allowed all the pushing ones to pass them. They go along so quietly that they are practically saving their mounts all day long, and when men hunt after this fashion a lack of breeding in their horses is of little consequence. There are hunting folk, too, who will seldom hesitate to jump a big place, and yet who never gallop at top speed. Some of them do not like it, others seem to be without the knack, or are not bold enough to let their horses stretch out at their best pace, and thus one occasionally has seen a man who on an 
ordinary day may appear to be an almost brilliant performer, but who is never by any chance in the van if the pace is really fast.

Again, the horse which lacks breeding has very often a heavy and straight shoulder and, as a natural consequence of this formation, rough, uneasy action. Possibly he lifts his legs too high in trotting and strikes the ground too hard in his gallop. He will, moreover, very often pull hard in the early part of a run, and want kicking along after the first ten minutes. $\mathrm{He}$ is, in fact, quite out of place in the hunting field, but for all that he is very much in evidence, because in these days, when so many people hunt, a fair number of them must be without much knowledge of horses, and therefore likely to be imposed upon.

A hunter with a very big head should always be avoided, as should a horse with a straight shoulder. A long back generally indicates weakness in a gelding, but not always in a mare, and a curly tail or curly hair about the fetlocks shows that plebeian blood is not far removed. Then a horse who shows the white of his eye is often dangerous, and nearly always sulky tempered, while a horse which is low in the withers and short in the neck is generally uncomfortable to ride. Obvious defects need hardly be pointed out, but a horse which is back at his knees will seldom stand much work, while a horse which is a little over at the knees may go on for several seasons. A horse to avoid is the animal which carries his hocks too far behind him or has them too close together or too far apart, and horses which are very light of bone cannot carry weight, and seldom last long.

On the other hand, the perfect hunter as regards work is to be found in many shapes and forms, and is 


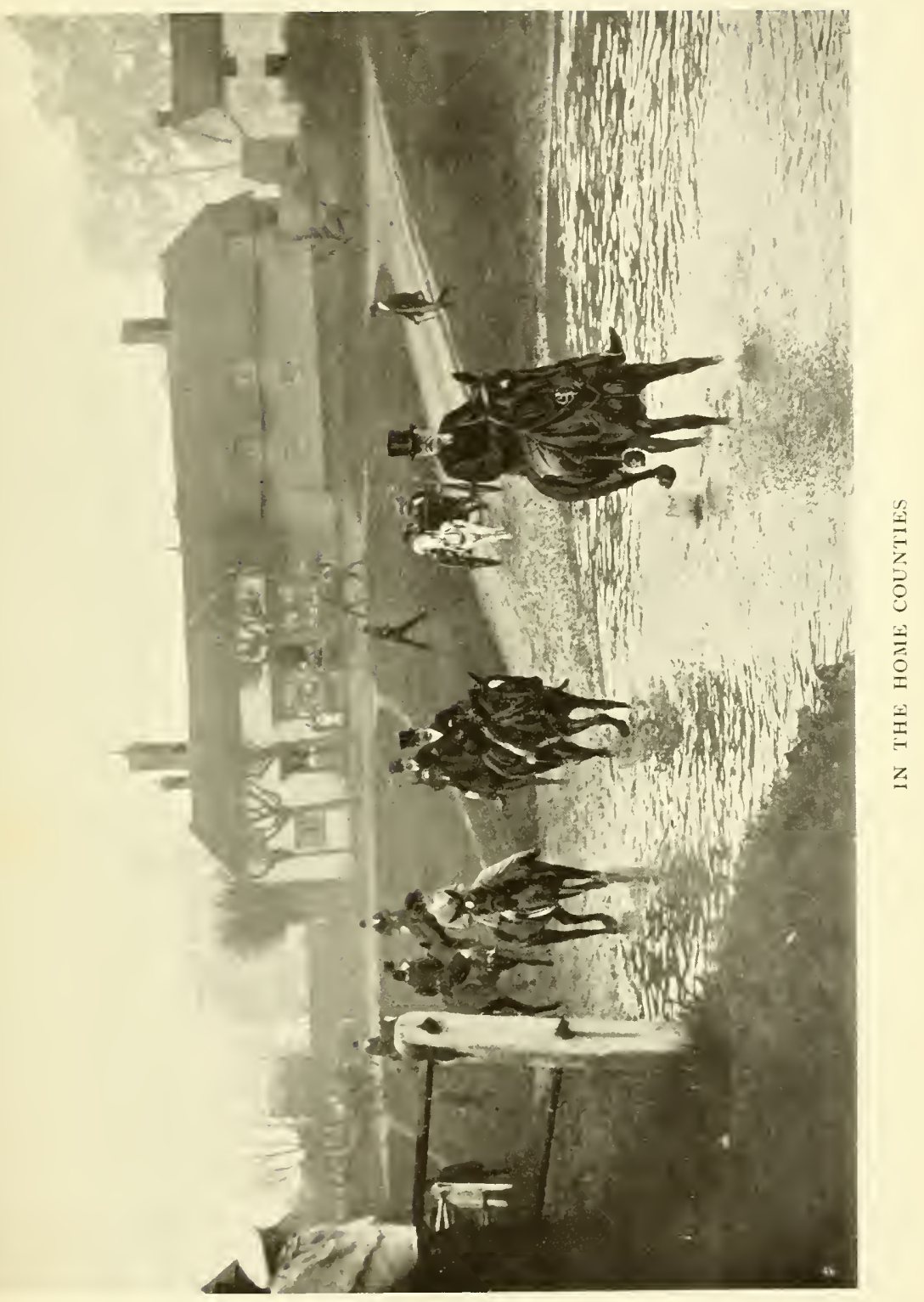



by no means of the accepted show-ring type. It is true that hundreds, probably thousands, of really high-class hunters have received notice at the shows, but a great deal more than make and shape, manners, and an aptitude for galloping round a show-ring are wanted in the outfit of a perfect hunter, and some of the necessary qualifications cannot be discovered by looking at a horse or trying his paces. Constitution, for example, must be forthcoming in every horse which is required to come out once a week or oftener, and though a good guess at what a horse's constitution is likely to be can be made when he is carefully examined, this cannot be really determined until the horse is doing hard and regular work.

Horse shows no doubt suggest the type which breeders of hunters should aim at, but the horse who wins in a show-yard is not necessarily a good hunter; and this reminds one of a certain master of hounds who was asked to support the hunter classes at a local show. He was by no means keen on exhibiting, but so much pressure was brought to bear on him that he sent two or three entries. In an open heavy-weight class he showed his best horse-a magnificent hunter of great constitution, a horse who could gallop fast all day long, who could jump five feet of timber from a trot, who could fly a big brook or creep through a tangled fence-a perfect hunter, in fact, who was used by his owner when hunting hounds in his best country. He also, on the suggestion of his stud groom, showed a six-year-old gelding which he had bred himself, but which was at the moment one of the bad tickets of the stable. This horse had good looks, but nothing would induce him to jump, though he had been fairly forced through fences by a rough rider. Neither could he 
gallop more than a field or two, and he was always ailing. But he took first prize, while his stable companion was never looked at; and the judges were right enough from their point of view, because the bad horse was handsome of outline and a pretty mover in the ring, while the really valuable, tried hunter was slightly hog-backed and not by any means a handsome horse.

It is not necessary to offer much advice as regards buying horses, because so much depends on the knowledge and judgment of the buyer, and so much more on the length of his purse. The man to whom the price is of little account almost invariably puts himself in the hands of a big dealer, and the dealer soon gets to know the sort of horse his customer requires, and probably four out of five which he may send will give satisfaction. But the hunting man of less ambition, who hunts two or three days a week in a provincial country, and who does not care to give more than $£ 70$ or $£ 80$, is not so easily suited. He of course must be very careful that he does not buy a misfit, for he probably cannot afford to keep a horse which does not serve his turn, or to lose money by buying a "wrong un." If he has the knack of picking out a good horse, the buying of a new one is sometimes a source of pleasure, but if he knows little about horses his task is a hard one, and he is very likely to be done. One man who hunts regularly can gauge all the young horses bred by the farmers in his district to a nicety, while his neighbour, hunting just as often, will be "stuck" by all the gay deceivers of the country-side. Some men are so conceited that they do not realise their own ignorance or gullibility in the matter of horseflesh, but trust to their own judgment, and are generally badly 
mounted. One can think of men who are fair horsemen, plucky riders, and most anxious to go in the front rank, but who are invariably handicapped because their steeds are quite unable to rise to their masters' ambition. One can also think of the man who is over-horsed, the light-weight who comes out on an eighteen-stone horse, and looks like a tomtit on a round of beef, who is too small and weak to hold his nag together, and not strong enough to pull him up in a few strides.

During the famous joint mastership of the Old Berks by the late Earl of Craven and the late Mr. Thomas Duffield there was a wealthy undergraduate located at Oxford who rode about eight stone and a half all told. He commissioned a big dealer to send him half a dozen horses, and as nothing was said about price he received a consignment of great weightcarrying nags, all over sixteen hands high, big boned, heavily built, and strong enough to carry a Daniel Lambert. Their owner was not wanting in pluckindeed, he charged an iron gate in Middleton Park when hunting with the Bicester, and got over with a rattle-but he was weak of wrist, and these big horses almost invariably took charge, and under such circumstances it was perhaps injudicious of him to tempt Providence by going to the "Old Berks"; but he liked the country, and did not seem to mind the abuse he came in for, and for several weeks caused great amusement. Then there came a day when one of the big horses ran away with him, as he was coming on to join hounds. They had just found a fox but had not got away with it when the big horse arrived in the field. He had been pulling hard before, but now he took the bit in his teeth, charged down on the crowd, 
got through it somehow, but fell in trying to jump a gate immediately afterwards, and so injured his little owner that all hunting was out of the question for months to come.

But the under-horsed man is more frequently seen than the man who rides horses a good deal above his weight, and, as a rule, the rider lias been persuaded that he and his horse are a fit, whereas they are quite the reverse. "What you want is breeding, not size," we once heard a dealer exclaim, who was trying to palm off a lightly-made, fifteen-hands weed on a fourteen-stone man, and the would-be buyer must have been taken in by the remark, as he appeared at the covert-side a day or two later on the same horse, but he knocked it up in a month.

There is no golden rule as to what weight horses will carry, and often a horse which is light in appearance will go through many seasons carrying a man who, at a glance, is far too heavy for him. A shortbacked horse who is well ribbed up and well bred to boot will often look a thirteen-stone horse, and yet can carry fifteen stone with ease, and a big, loosely made horse who looks up to a lot of weight will not be equal to within two or three stone of what his appearance suggests. In a really provincial country a strong cob or a weight-carrying polo pony will give far more satisfaction than a low-priced "hunter," and ought probably to be much cheaper to buy. Many powerful polo ponies are a little too short of pace to be valuable for the game, and scores of these are in the market at the end of the polo season, many of which make capital light or medium weight hunters for an ordinary country.

If a man intends to hunt in the Shires or in the best 


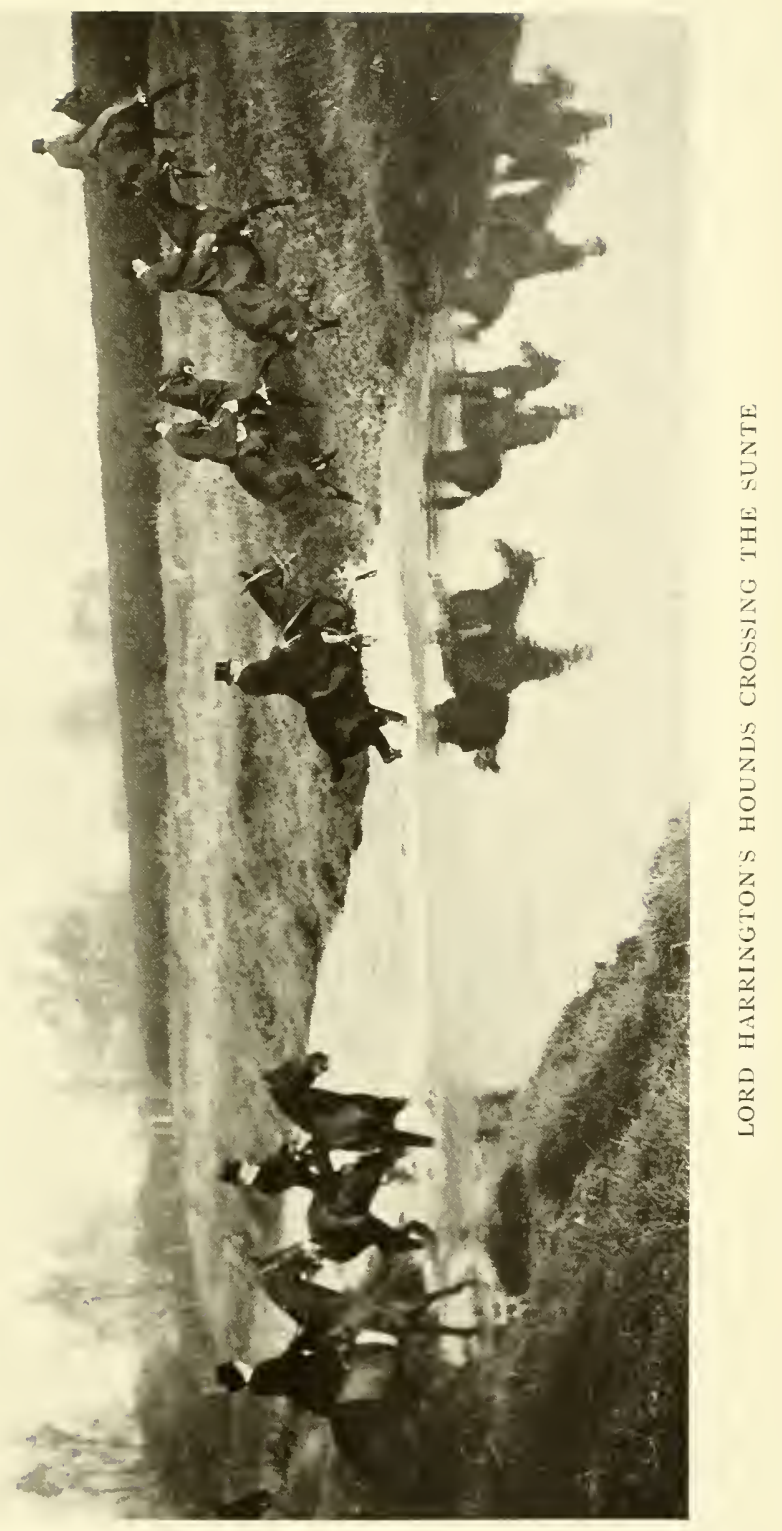



of the provincials, he must, of course, have breeding and pace, but where the country is hilly, where there is more arable land than grass, and where there is a good deal of scrambling about in rough and deep woodlands, then a clever, big pony is, as a rule, a capital conveyance, and it is perhaps within the mark to suggest that many of this class of animal carry far more weight, in proportion, than big horses. Look at the ponies one sees really heavy men riding at polo, and look at some of the ponies which come into the ring in the saddle classes at Islington every March. Some of these classes are full of weight carriers, and hunting men who are content to ride a pony should bear in mind that at the expense of a little trouble many really good ones are to be picked up late in the year.

What perhaps is most against hunting a pony is that many of the species do not spread themselves when they jump, but go up and down, rising to a considerable height, but not covering a distance of ground. Such ponies are of little use in a flying country, where there is a ditch on one or both sides of the fence and several feet in length to be covered at nearly every jump, but in a stone-wall country or where there is a good deal of timber they do wonderfully well, and of course some of them can extend themselves as well as go high. This high jumping, too, is often a feature of the common-bred horse, and one such we knew took a host of jumping prizes at the summer shows, but was never sent to compete where there was a water jump. At high jumping, at an in-and-out, even at a bank he was an extraordinary performer, but in vain his owner tried to get him to land clear over the water. He would go at it and jump as far as he could, but 
could never achieve within two or three feet of the proper distance, and doubtless it was his want of quality which was accountable for his failure.

So much has been written elsewhere concerning stables, so many plans have been published in various books, and so much advice has been given that the subject is rather worn. Wealthy hunting folk can have stables on a most elaborate scale, and can spend big sums of money on outward adornment, but it is greatly open to doubt whether their horses are any better for it, while one feels quite certain that in many cases some horses suffer from too much artificial heating, and coddling generally.

Still one likes to see a stable that is pretty without, and clean, tidy, and roomy within, and as in nearly every other question of life the happy medium is what should be aimed at. On the whole boxes are more suitable for hunters than stalls, for a horse can move about in a box, whereas in a stall he must stand all day with his head tied up. But about half a dozen boxes inside a big stable are best, for horses like to live in company. The size of the stable must of course depend upon the strength of the stud, and yet the plan of having a very great number of boxes or stalls under one roof is not altogether satisfactory, because of the chance of fire breaking out. We have no statistics on the subject from the fire offices, but we incline to the opinion that fires in stables are fairly common, and certainly many such have been known in the training stables. The fact is that straw is about the most inflammable material that there is, and if it becomes ignited the blaze follows so quickly that there is often the greatest difficulty in rescuing the inmates-and horses go almost mad with fear when fire is in their immediate 
vicinity. Fires, too, have occurred in stables where there was artificial heating, and this, we think, should never be used under any circumstances. It is often stated with some show of authority that the temperature of a stable should be about sixty-two degrees, but in a hot summer it is difficult to keep either a stable or a box as cool as this, even with all the windows and the door open, while in winter the temperature must at times be very much lower, unless indeed the stable is small, close, and stuffy.

Roof room should be made a strong point, for it is only when there is plenty of open space at the top of the box or stall that the proper degree of coolness can be obtained. If horses are kept in too hot an atmosphere they become delicate, susceptible to cold, and at times bad feeders. Too much heat does far more harm to hunters than cold air about them, provided that there are no draughts. In a state of nature the horse can stand the hardest winter out of doors, as is proved by the fact that the half-wild ponies on Exmoor, in the New Forest, and further north, as in the Shetland Isles and Norway, flourish out of doors all the year round, no matter what the weather may be. Horses which have been regularly worked, too, are constantly turned out for the winter, and such horses, when once their winter coat has grown, seem to be none the worse for living in the open air. The horse which is kept stabled, groomed, fed on specially-chosen food, and worked regularly, may not be so hardy when he is living under these conditions of confinement, but he is protected by rugs in the stable, and where stables are kept really cool, an extra rug in times of frost and snow will meet the case far better than any artificial heating. 
To go to personal experience for proof that a very cool atmosphere will suit hunters well, we once had some old farm-house stabling for two seasons which was in a shocking state of repair. The stable was a long one, and at one end of it there were holes in the roof of two or three feet in circumference. There was no ceiling, the stable being open up to the rafters, and this allowed of plenty of air circulating. We placed three horses at the dry end of the stable in early autumn, and there they remained throughout the winter, and during that time not one of the three was sick or sorry, all keeping as hard as nails, and retaining their condition right up to the end of the season.

Yet the stable was always cold, and there was more than one vigorous visitation of frost and snow. When this occurred each horse had a third rug, and some few of the holes were stopped up with straw, but no attempt to repair the defective roof was ever made, and as far as the comfort of the horses was concerned there seemed to be no reason why the roof should be mended. In another case we knew of a hunter who was famous in his own neighbourhood. He carried a huntsmanmaster for ten seasons, and lived throughout that period in an old wooden box of the most tumbledown description. At times he was changed into a brandnew box, built on the most modern principles, but he was inclined to fret when stabled anywhere but in his regular quarters, and, most extraordinary of all, he used constantly to kick out certain boards near the bottom of his box. Times out of number these boards were replaced, but he always kicked them down again, as if he knew that he must have air at any price. This horse always carried a lot of flesh, and great condition 
in the hunting season, and when sixteen years old, and still as sound as a foal, he reached the end of an honourable career in the hunting field.

A master of hounds with a stud of about twenty hunters tried all sorts of experiments in the matter of stabling. He built stone boxes, stalls, wooden boxes, and brick boxes, and after considerable experience he came to the conclusion that his horses thrived best in the wooden boxes. These were about fifteen feet by twelve, some eighteen feet in height, had flat, cemented floors and a tiled roof, with enough ventilation holes placed low down and rather high up to allow of the fresh air coming in and the stale air going out at the top. Either in a stable or a box the floor should be nearly level, for if it slopes considerably downwards to allow of drainage, the horse has constantly to stand on an uneven surface, and this should be avoided at all costs. A fall of not more than four inches will allow the water to run off when the box is washed out, and will not hurt the horse. But, as every one who has experience with horses will gradually find out, much depends on the constitution of each particular horse. One horse will thrive in a tumbledown hovel, so low that he can hardly stretch his head to its full height, while another must have light and air, and be well looked after and attended to.

We are not going to write a treatise on stables, and shall only repeat that light and air must be considered essentials, and that a hot stable is apt to make hunters delicate. We can think of a hunting stable which at one time contained some eighteen or twenty hunters all through the season. The stud groom was a coddler in every sense of the word, and the upshot was as soon as the hunting season was fairly under 
way an epidemic of coughing invariably set in, and this would go right through the stable.

"Coughing," which in horses seems to be very like influenza in human beings, of course varies a great deal in its severity, but with some grooms horses may be coughing badly one day, and will be hunting again in less than three weeks. On the other hand, where there is a groom who coddles, six weeks will elapse before the horse is at work again, and if the cough happens to come in the middle of the season there must be a great deal of inconvenience.

It stands to reason that a horse which has to face all sorts of severe winter weather, clipped and unsheeted; who has to be taken slowly to covert when the thermometer is close to freezing point; who may be from eight to ten hours in pouring rain ; and who is in the habit of travelling long distances home at a slow pace, when it is cold, dark, and often wet, must be hardy if he has to retain his health. It is on account of what he has to go through that a horse of delicate constitution often fails as a hunter. As long as the sun is on his back, and the work is not too severe, such a horse will get along all right; but when autumn has given way to winter and the temperature is low, the delicate horse very easily takes cold.

A horse which is rather delicate in his younger days can often be gradually hardened, and we have known hunters which were always ailing in their first season, and which afterwards became quite normal in this respect. Irish horses are often very hardy in their young days, but many young horses, between the time they leave the breeder and the time they pass into the possession of the hunting man, go through an interregnum which is spent in a dealer's stable. It goes without 


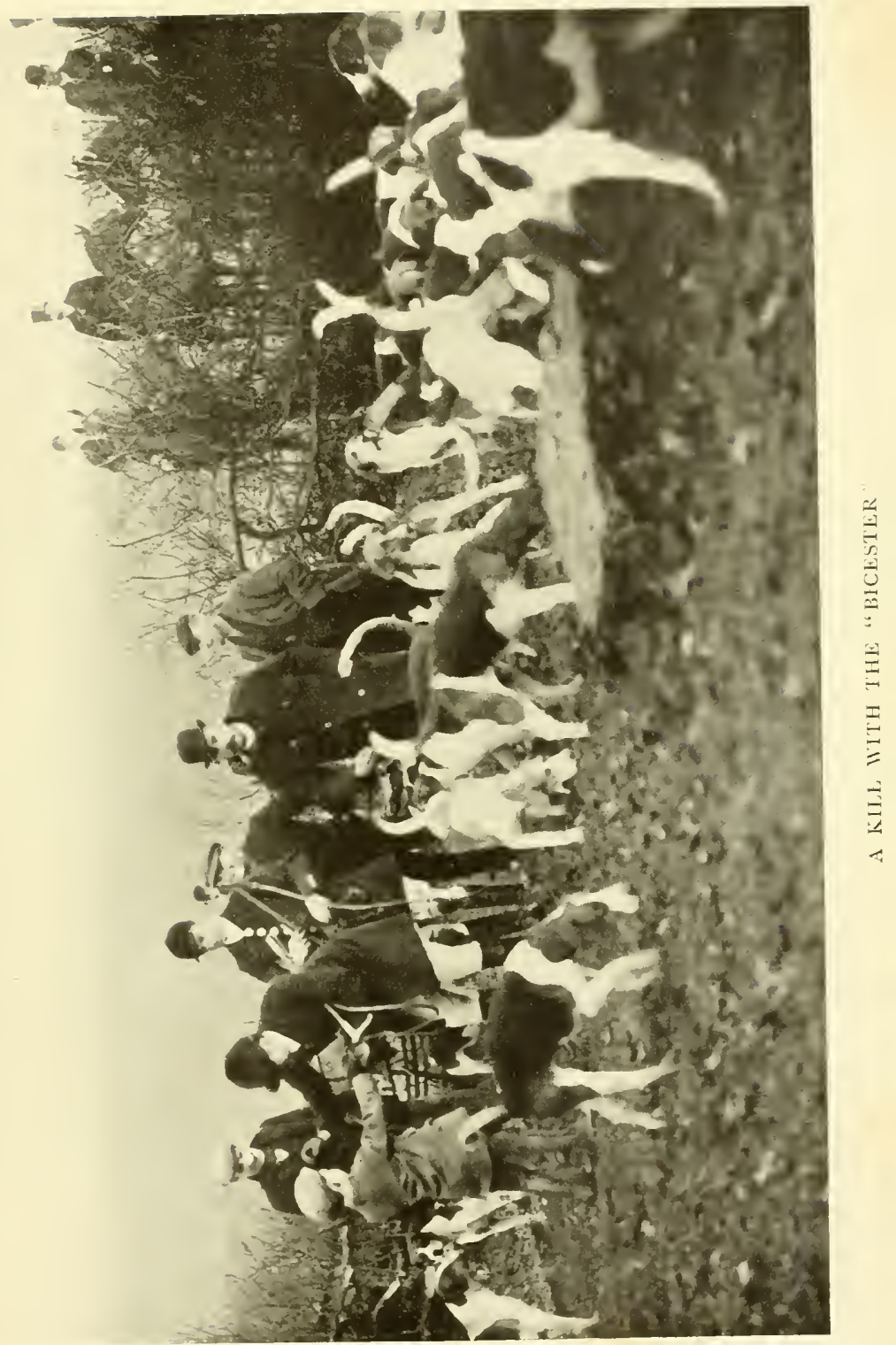



saying that in the best dealers' stables the horses are not unduly coddled, and are as well cared for as they are likely to be in after life. But there are dealers and dealers, and undoubtedly some horses when in the dealer's hands are fattened up on soft food, and are in consequence very difficult to manage for a timeunless, indeed, they are of the hardy sort to which nothing comes amiss. And if horses which have-like prize cattle-been fattened for the market happen to fall into the hands of a coddling groom, it is fair odds that they do no good afterwards. The change of food probably puts them wrong to begin with, and then if they seem at all dull and listless, the coddling begins, and they are kept in far too hot a stable and treated as if they were really delicate, whereas they would probably come right if left more alone.

"If a horse goes wrong put him in a box, give orders that he has to have plenty of hay and water and very little corn, and forget him for a month," was the advice once given by a man who was famous for his good hunters, and there is a fair substratum of truth in the dictum. All our experience is to the effect that horses which are kept in hot stables are far more likely to take cold than nags which can always breathe pure air, and we can add to this that hundreds and hundreds of hunters suffer because they do not get enough work. The average matured horse in hard condition is equal to a full day's hunting about every fifth day. Young horses should not be out more than once a week, and at first half-days or short days are enough for them, but the hunter of nine or ten years old who is hardy and healthy is all the better for more work, and this the owners of small studs prove day after day.

Then, again, the horse who is doing a lot of work is 
a more reasonable animal to ride than the horse which comes out one half-day a week. The former has his back down and is not stupid, whereas the latter is often a mad horse for a couple of hours in the forenoon, and quickly dead beat if he gets a gallop which is longer than usual.

The question of summering hunters is one for which there are various solutions, and our experience is that horses of quiet temperament are all the better for being turned out in May and June, but three things they must have, or else they are better indoors. These are shade, water, and a certain amount of corn. There should be a stream or a trough in every pasture field in which valuable hunters are run out, and there should be the shade of big trees, so that they may escape the rays of the sun during the hottest part of the day. If the horse-owner has a field which is without shade and water, but which is suitable in other ways, he must keep his horses in during the day-time and turn them out at night after the sun has gone down. A good pasture is nearly always damp at night-time in May and June, and there will be plenty of moisture, but even then it is well to place a stone trough in the field (if there is no other supply) and see that it is always filled with water. Horses drink a great deal when they are running out.

That hunters should not be kept in the fields too late in the summer is another matter of importance, but in the north of England the grass is always two or three weeks later than it is in the south, and therefore the bringing them in again can be delayed. Much in this connection depends on the weather. If it is abnormally hot, and the hunters are being much troubled by flies, they (the hunters) should be brought in during the day. 
Again, if the pasture becomes baked and hard and the grass dried up, horses should be taken elsewhere, for they will not thrive unless they have plenty of food. Late-summer pasturing of hunters is a great mistake ; firstly, because all, or nearly all, the good has gone out of the grasses; and secondly, because horses which are to be used at the beginning of the season should be put into work not later than towards the end of July.

Some horses become very fat during six or eight weeks of grass food, but although they acquire fat, they do not lose their muscle in so short a period of time, and the fat gradually disappears when the horse is put into regular work. As a rule, however, nine hunters out of ten do very little work until they are. taken out cub-hunting, for it is not every groom who is conscientious enough to give his charges long spells of trotting and walking under an August sun. This question of work is one which is very difficult to manage, because so many hunting men are from home in August and September, and so much must therefore be left to grooms. Where it is possible the hunting man who looks after everything himself should have a horse out every morning at this time of year, and should indeed be in the saddle not later than seven o'clock. An early-morning ride in late summer or early autumn is only to be tried to be appreciated, and the man who has a horse or two fairly fit to go by the beginning of October has a great pull over the man whose horses have been a month later in beginning their work.

Horses which are of excitable temperament should not be turned out at all, for they are quite likely to injure themselves. Veterans are always better for a 
run in the fields, and as a rule the veteran can stand a longer run than the young horse without taking hurt. Horses which are given to jumping fences when out of doors should be kept in the stable also, for one of these in a field has been known to infect all his companions with the jumping fault. We have known two such horses, and one of them was at times found miles away from his own home; the other never went further than the nearest clover-for which he had a wonderful nose. 


\section{CHAPTER $\mathrm{X}$}

\section{HARRIERS AND BEAGLES}

HAT harehunting is far older than foxhunting need hardly be said, nor that very many of

1 the existing packs of foxhounds began life as harrier packs; and although foxhounds have during the last hundred years been the most numerous, and far the most important of all the various breeds of hounds in the United Kingdom, harriers and beagles have fully maintained their popularity, and are still followed by a host of enthusiasts in all parts of the country. As a rule neither harriers nor beagles have what is known as a "country" of their own, a big majority of the packs being located where there are foxhounds as well, but this does not hold good everywhere, as many harrier packs hunt where there are no foxhounds, on land which is often unsuitable for foxhunting, or in a district which has been given up by the nearest foxhound pack, on account of excessive building, too much wire, or even because of its inaccessibility. To give an example or two, in Lancashire and in parts of the West Riding of Yorkshire there are at least a dozen old-established harrier packs whose operations are confined to wild, hilly districts which have known no foxhounds for many a long year, and in many places where there never was any established pack of the latter. The Penistone Hunt in South-Western Yorkshire may be quoted as one of those packs which 
have a country of their own : this particular hunt dates back to 1260 , and quite lately its history has been published in book form. Another West Yorkshire pack hunting where no foxhounds are is the Craven, and in Lancashire such ancient establishments as the Bury, the Holcombe, the Vale of Lune, the Rossendale, and the Pendle Forest may be quoted. Some of these packs hunt over moorland country, and others-the Bury to wit-over high-lying agricultural land, which though still suited for harehunting is far too thickly populated and too devoid of coverts for foxes. Another famous pack with a rough but rideable country is the High Peak in Derbyshire. Here there is some vale land and a good deal of stony moorland, but it is fine harehunting ground, and at the moment the pack is undoubtedly the finest in the kingdom, proof of which is afforded by the numerous successes which it has achieved at recent Peterborough shows. Then, again, the Wirral Harriers in Cheshire have a country of their own, the Cheshire hounds having long since ceased to draw any coverts in the Wirral peninsula. This particular district embraces all the country which lies between Chester and Birkenhead, and is for the most part a grass country of dairy farms. It has, however, been greatly built over in recent years, and parts of it are full of wire. Still, it is fair harehunting ground, and the hunt a very popular one with the local people. Then in Somerset there are at least two packs of harriers hunting where there are no foxhounds, viz. the Wells Subscription and the Weston. The firstnamed have their country on the Mendip Hills, and the Weston nearer the sea coast, and both districts are outside the area of any foxhound pack. Another hunt of whose district the greater part is free from foxhounds 
is the pack once again known as the Thanet and Herne, whose country lies between Herne and Whitstable in Kent, and which was previously known as the Thanet. Thanet and Herne is, however, the original name, and the pack has had an uninterrupted existence of almost a hundred and forty years.

Perhaps Devonshire can claim more packs of harriers than any other county, no fewer than thirteen of the packs tabulated in the last hound list issued by the Field being entirely located in or doing a considerable portion of their hunting in that country. The packs in question were the Ashburton, the Axe Vale (who hunt in Dorsetshire as well), Sir John Amory's, the Cotley (also hunting in Somerset and Dorsetshire), the Dart Vale, the Furlong, the Haldon, the Modbury, the Quarme, the Silverton, the South Molton, the South Pool, and Mr. Sherling's. This is a goodly list for a single county, especially when it is noted that beagle packs are not included; but Devonshire is one of the greatest sporting counties of the kingdom, and staghounds, foxhounds, harriers, and beagles hunt every corner of its area.

Whereas foxhunting has changed little in fifty years or more as to the manner in which it is carried on in the field, harehunting has witnessed one most radical change, viz. the discontinuance of the practice of dragging up to the hare on her seat or form. Two generations ago, or perhaps a little earlier, it was everywhere the custom for harriers to meet at an early hour, and to try for the morning drag. This would be found in any and every field where hares were plentiful, but hounds were as a rule taken to where the hares were known to feed, and of course it often happened that the drag was worked heelway at first. Hounds, 
however, would as a rule quickly discover their mistake, and would puzzle out all the daybreak turns and twists made by an animal that had been feeding, and was not being pursued. Sooner or later puss would be located, and then, as often as not, she was pushed from her form by some one who carried a pole, there being always a danger that she might be chopped if hounds were allowed to work right up to her form. Hounds almost invariably got a view as the result of this procedure, and then began a hunt, which lasted minutes or hours (more frequently the latter) according to the quality of the scent and the speed of the pack. All this sort of thing has long been voted slow, and now hounds meet at any hour of the forenoon, and in the case of foot beagles even later, and draw for their hares, amongst root crops and over fallows if it is an arable country, and in rough grass if it is a country of pasture. Whether the old plan or the modern one is the best is of little consequence, but this is an age of hurry, and many of the crack packs of the present day run and kill four, five, and even half a dozen hares in a shorter time than the old packs would have taken in bringing a single hare to hand.

But the greatest change of all has taken place with regard to hounds. Not more than a generation ago harriers were of all shapes and sizes, and of a whole host of colours which are rarely seen now. Some few packs-generally very old establishments-have stuck to their guns both as regards make, shape, and colour, but many more have become of the dwarf foxhound sort, and broadly speaking, the modern harrier may be said to be of this type. Moreover, new packs of harriers are constantly being formed, while scores of packs have only a brief existence. And every new 
pack goes for the foxhound-harrier, not only because they are more easily procured, but because of their greater speed. When the field is mounted a quick gallop with a good deal of jumping is thought to be better fun than a long, slow hunt, which includes a great deal of hound work, and thus it happens that twothirds, or perhaps even more, of the harrier packs are now purely of foxhound blood.

\section{"A PERSonal NARrative"}

Perhaps we can give some idea of the change which has occurred by drawing upon our memory for harehunting reminiscences, and we can claim over forty years' experience in this direction. Beginning then in the early sixties, the first pack we saw were the beagles which were then kept by the members of Durham University. These were what would now be called a very scratch lot, as they varied in height from fourteen to eighteen inches or more. They were mostly followed on foot, and the huntsman generally ran with them, though he was occasionally mounted, as were, at times, some of the field. As a boy at Durham School we had the chance of seeing these little hounds twice a week-on the two half-holidays in fact-and rarely missed an opportunity of hunting, though at times meets were too far away. On Sundays we often visited the kennels, which were within a mile of the school, and thus early in life became conversant with hounds on the flags. The feeder, "old Peter" we used to call him, was an enthusiast, who would discourse for hours on the merits of his favourites. And in the winter vacation, when members of the University 
were "down," we used to borrow the pack, and locate them at Broadwood or Woodlands, a dozen miles west of Durham, and have them out sometimes on three consecutive days. Old Peter used to come with them, and between us we managed to kill a hare or two, but there was no Ground Game Act in those days, and hares were far too numerous for sport.

A year or two later, in the winter of ' $67-8$, owing to an accident at school, we spent the best part of a year at Woodlands mentioned above, and with a couple of ponies succeeded in securing an average of four days a week with foxhounds or harriers. And of the latter the now defunct Wolsingham pack were most frequently in our neighbourhood. These were harriers of a very old-fashioned type, high on the leg-probably twenty-two inches-very light of bone, slack-loined, flat-sided, and light in colour, but they could hunt a hare, having wonderful nose and a great deal of pace. The pack only numbered seven or eight couples, and their huntsman, one Vasey, was a regular Jonathan Jobling, being probably twenty stone in weight. $\mathrm{He}$ rode a strongly built "Dales" pony, and his language -unshackled Doric with a Northern twang-would have been quite urintelligible to a Southern. He would take his hounds off the road into a moor edge allotment, and begin in stentorian accents, "How shift her! How shift her, Comely woman! How shift her off the ling!" and he would in this fashion talk on to himself all day long, but he seldom addressed a word to any of his small field, and in all our life we have never seen a man who was more thoroughly engrossed in his occupation, or apparently more sullen over his hunting. But he was an enthusiast from the button of his hunting cap to the soles of his hob-nailed 
boots, and in a quiet, unpretentious fashion he showed wonderful sport. He never spoke to us except when he wanted "leave" which he thought we might get for him, but when we were stranded with a lame pony one night near his house, he sent us home in his trap, after having done the honours of his house amid almost perfect silence.

The other harrier pack which came our way were the Newcastle and Gateshead Harriers, of which the late Colonel Hawks and the late Mr. F. H. Lamb were then joint masters. Their kennels were twenty miles away, but hounds were brought to a farm named High Woodside two or three times in the season, at that period, and used to attract all the riff-raff, mounted and on foot, of the country-side. This pack was also rather of the scratch order. There was no uniformity as in the Wolsingham, the masters being open to receive gifts of undersized foxhounds. The consequence was that there was a difference of six or seven inches between the biggest and the smallest hounds, and when they were running a hare the tail would be half a mile long. The huntsman was one Siddle Dixonfather of the better-known Siddle Dixon so long huntsman of the late Colonel Cowen's foxhounds-and like Vasey he was a welter-weight, but he knew all about harehunting, and if his pack had been a little more even he would doubtless have shown better sport. As it was he helped to make the pack very popular, and his name was for long enough a household word in the north of England.

After leaving school we were with an easy-going tutor at Malvern, and when not hunting with the Ledbury, Lord Coventry's (now the Croome), or the Worcestershire, used to put in a considerable I8 
amount of time with harriers. These were a small pack kept by a Mr. Clarke (we think), and their operations were chiefly confined to the Ledbury side of the country, the foxhounds of that name only hunting twice a week in those days. Mr. Clarke's pack were big in size and small as regards numbers, but their owner knew how a hare should be hunted, and was very successful. Of the hounds we can remember little, except that they had all the faults to look at which are possible in a hound.

A year or two later, about 1875 or 1876 , the late $\mathrm{Mr}$. John Greenwell, of Broomshields, in the county of Durham, got a pack together, and soon began to show excellent sport. A born huntsman was Mr. Greenwell, and to his natural gifts in that direction was added an extraordinary amount of knowledge as to everything connected with the hare. Like ourselves lie had served a boy apprenticeship to hunting, and before he had harriers of his own he had been in the habit of inviting every pack which was within reach of the place to Broomshields. And he had, too, a wonderful harehunting country at hand, wide-spreading pastures of rough grass, separated with stone walls, with few woodlands, and practically no population. The meets were not advertised, cards being merely sent to those who would appreciate the sport. Drafts formed the pack at first, but some of these were not big enough for the higher walls, and were quickly passed on. About eleven to thirteen or fourteen couples were the working pack, and uniformity in height was aimed at, but large-or what was then thought large-hounds were preferred, as Mr. Greenwell used at times to go long distances from home, and the bigger hounds travelled home better than 
small ones. Writing from memory, we would say that about twenty inches was the average, and very quickly the pack became wonderfully even.

Their owner would draft a hound that went too fast for the others, and would not keep one which lagged behind on a good scenting day, and in point of fact he drafted everything which was not up to the mark. Just at first he was obliged to put on hounds he did not like on account of making up his number, but it happened that just then the market was flooded with harriers, and as Mr. Greenwell made several tours of inspection to other countries he was not long in finding what he wanted. The result of all this was that after a few months he was showing the very best sport we ever saw with harriers, though he killed nothing like so great a number of hares as some packs we have since seen. Why he did not kill four, five, or six hares a day, as do some of the presentday packs, is easily explained. In the first place, hares were scarce in much of his country; in the second place, nine out of ten of those he hunted were mooredge hares of extraordinary stoutness; and in the third place, he never lifted his hounds to a holloa whilst they had a vestige of the line. When one adds to this that he had a strong objection to killing more than two hares a day, that he would stop his hounds if he knew they were running a leveret, or what he took to be a doe in the spring of the year, it will be readily understood that his number of kills was insignificant compared with the scores of some other packs. On no account would he allow a hare to be mobbed either, but in his home country there was no chance of such a thing occurring, as the field was always small, there was no local force of pedestrians, and his sup- 
porters knew the master far too well to interfere in any way.

But we recollect one experience of mobbing, and of fighting as well with this pack. By request of the late Mr. Anthony Maynard, then master of the North Durham foxhounds, Mr. Greenwell had taken his hounds to Newton Hall, near Durham, and as Mr. Maynard then had six hundred acres of land in hand it was thought that there would be little chance of getting on to the ground of a neighbour who was known to be unfriendly. The first hare, however, took hounds straight to the forbidden ground, and the first that we, who were comparative strangers, knew of the ill-feeling was finding ourselves confronted by half a dozen labourers armed with pitchforks. Hounds were running hard, and it was not difficult to dodge the opposing forces by jumping a fence, but almost immediately the hare began to circle back, and was seen to lie up in the hedge near which the labourers, headed by their master, were standing. Hounds checked at the fence, and one or two were knocked about before Mr. Greenwell could get them away, while, to make matters worse, a lot of ladies who were following the hunt on foot had now reached the scene of action and were being soundly abused by the farmer.

For a moment matters looked very awkward, but the situation was saved by the arrival of a well-known wine merchant who was also a hunting man. He, it appeared, was the wrathful farmer's purveyor of whiskey, and coming on the scene when the dispute was most violent, he shouted out at the top of his voice, "Mr. — , if you don't beg these ladies' pardon at once, I shall physic the whiskey you ordered yesterday." Now the speaker and the farmer were firm friends, and 
the laugh which the remark raised caused a cessation of the threats, and in two minutes the wine merchant had restored peace. The hare was then pushed out of the hedge and the hunt resumed, but shortly afterwards she or another hare took hounds through a small plantation, beyond which was a colliery. Scores of men and boys were on the "pit heap," and all left their work and threw themselves in the hunt. The hare, of course, sought the shelter of the little covert again, but they were all round the place in a moment, and as hounds caught the hare a dozen of them were to be seen struggling for her carcase, while the hounds slunk away, frightened at the shouting and noise.

For three seasons or three and a half Mr. Greenwell's hounds showed wonderful sport, and then their owner, who was now in poor health, parted with them to the late Lord Lonsdale, who placed them at Penrith for the use of his tenants. But after his own pack had gone there was no falling off in the number of harrier packs which came to Broomshields. Harriers owned by the late Mr. Nicholas Bowser, of Bishop Auckland, were there frequently, and so too were the Durham Beagles, of which Mr. Crichton Forster was then master. But the pack which came oftenest in the early eighties were the Darlington Foot Harriers, a seventeen-inch pack of which Mr. Thomas Watson was master and huntsman. This pack was established in 1874 , and as far as work was concerned it was almost impossible to find fault with it. Mr. Greenwell had decided that hounds less than twenty inches were not big enough for the tallest of the stone walls, but Mr. Watson thought otherwise, and it is a fact that his hounds could climb a wall which was too high for them to jump on to the top of in foxhound fashion. Mr. Watson hunted his 
hounds on foot, whereas Mr. Greenwell rode, and this doubtless made it of less consequence whether hounds were delayed a minute or two. The Darlington, even then, before the days of the Harrier Stud Book, were an even and a smart pack, and one hound named Crowner was the best road hunter we ever saw. Many of them were somewhat light in colour, but they had wonderful nose, great drive, and were very free with their tongues when running a hare. On more than one occasion they killed five hares in a day on the Broomshields estate, but they began early and left off late, and there were more hares on the ground than there had been in Mr. Greenwell's time.

And whilst the Darlington were still coming to Broomshields, something like once a month, Mr. J. E. Rogerson, who has been master of the North Durham foxhounds since I888, took over the Durham Beagles, and paid frequent visits to the place. About this time, too, the Shotley Bridge Beagles came into existence, and for three or four seasons were monthly visitors to the Broomshields estate. These were the smallest pack (in height) which we ever saw in a bigstone-wall country, but they got along somehow, though at times there was some delay. The Shotley Bridge pack, of which Mr. J. A. K. Falconer was master, were pure beagles of from fifteen to sixteen inches, and the field was on foot. The hounds were immensely popular with the farmers, and whereas Mr. Greenwell's harriers ten or twelve years before used to attract half a dozen mounted men, the whole country-side, including scores of ladies, would be present on foot when the Shotley Beagles were hunting over the same ground. This we attribute very largely to the fact that in the late eighties beagling was 
quickly becoming a popular pastime, and also to the fact that the meets were well known all over the country at least a week before they took place. $\mathrm{Mr}$. Greenwell, on the other hand, only sent some halfdozen cards of his fixtures to those whom he thought likely to come, and in his time the country was full of foxhunters who had the chance of as much hunting as they could manage with foxhounds.

Now it can safely be said that not one of the packs we have mentioned, and which we hunted with constantly during a period of over twenty years, were really even, and what was most noticeable was not so much the difference in height as the great variety of type. In the Durham University pack, for example, there were sixteen-inch hounds as lightly built as a modern fox terrier, while others standing exactly the same height were of double the weight, being heavilybuilt, big-boned hounds, low for their size, and with a massive throat, a big head, and a bass voice almost as sonorous as that of a bloodhound. They were of all colours, and certainly were well off for nose, but they were slow and inclined to dwell on the line, and if the hare they hunted was a strong one, they could only wear her down by working up to where she had squatted every now and then. This irregularity had to a great extent disappeared when the Shotley Bridge Beagles came on the scene, and Mr. Falconer succeeded in breeding a very pretty pack, which will be found among the entries in the earliest volume of the Stud Book, but even the beagles of the late eighties would compare badly with what are now seen at Peterborough every year, and probably straightness is in a marked degree quite a modern thing in beagles, and to a great extent in harriers also. 
Before leaving this part of the subject, it may be mentioned that the Broomshields estate was an ideal harehunting ground. The estate consists of large enclosures of pasture land, which are never mown, and which, therefore, are covered with long grass. As scenting ground it takes very high rank, and there are no large coverts, merely a few larch plantations which have an undergrowth of grass, and which hounds can run through without slowing down. The only drawback is the height of some but not all of the walls, but these give the hare an advantage, which is all for the best. The stock of hares was, as a rule, just what was required for harriers, and the hares themselves as strong as any we ever saw. Then, too, the district is very thinly populated, and it was not until the period of the Shotley Bridge Beagles that there was any crowd. But these hounds, which were kennelled ten miles away, used to be brought over on the preceding day, and their regular field arrived on wheels, or from the nearest railway station on the morning of hunting.

Some twenty years ago, or rather more, a very smart pack was owned by a Colonel Anderson, who lived at Ryton Woodside, not many miles distant from Newcastle-on-Tyne. With these hounds at times we witnessed capital sport, especially in the neighbourhood of Ponteland, where the country is well adapted to harehunting. It was when hunting with this pack that we saw a hare travel along a country lane for half a mile, whilst hounds ran her at top speed, but remained all the time on the other side of the fence, which was parallel to the lane. Scent was really breasthigh on this occasion, and as the ground sloped one could see both hare and hounds, and observe exactly 
what was taking place. It was not until the hare turned abruptly and went through the fence on the far side of the lane that hounds ever attempted to go through the first fence.

The trouble with these little hounds was that their owner, who suffered greatly from gout, used often to come out in a dog-cart, and at times he would attempt to hunt them from this position. He had a quick eye to a hare, and would bustle his cob along a by-road and often get in front of hounds. If he happened to view the hare over the road, out would come his horn -he dearly loved a blow-and hounds' heads would be taken from their noses. Hares were often lost when their enthusiastic owner cut off his pack, but it made no matter, as the field was seldom more than half a dozen strong, and the little hunt was quite private and unobtrusive. A tall, elderly, and angular Scotchman named Graham was kennel huntsman, and the queerest old hound-van ever seen was frequently used, and when it rained we have known hounds, huntsman, and the entire field to return inside this van-which at such times developed an extraordinary atmosphere.

Another quaint hunt, as regarded some of its customs, was that maintained for some years in the Isle of Anglesey by Henry, the fourth marquis of the line. Always a bit of a dandy, this particular Lord Anglesey was a keen sportsman, who hunted, raced, coursed, and last of all kept a pack of beagles. These were just as good as could be got in the eighties, and the sport they showed was first-rate, the country being open and well adapted for harehunting. But there was a comic side to the hunt, which was chiefly supplied by the noble owner. As far as costume was 
concerned he was the beagler to the life, wearing a smart green jacket with a scarlet collar, knickerbockers, and a black velvet cap, specially made, and less than half the weight of an ordinary hunting cap. That he wore white kid gloves, with two or three rings over them, will be no surprise to those who were acquainted with his lordship, but the comic element was forthcoming in a couple of scarlet-jacketed personal attendants, who each carried a neat and very light ladder of about four feet in height. The fact is that the country abounds in high stone walls, and Lord Anglesey was not very young. He therefore used these ladders whenever a big wall came in the line. One attendant would scramble over and place his ladder for the descent, while the other with his ladder helped Lord Anglesey on the near side. Still, as we have stated, the sport was good, and the arrangement for getting about a simple and sensible one, no matter how comic it appeared.

In more recent years we have had the opportunity of seeing many other packs of harriers and beagles, especially two very smart packs of beagles, viz. the Surbiton and the Worcester Park, and these little hounds, which are kept as nearly as possible to a uniform height of $15 \frac{1}{2}$ inches, are not only very good in their work, but hold their own on the show bench as well. Moreover, they kill a fair proportion of the hares they hunt, and each pack is followed by a most enthusiastic field. And as a matter of fact, packs of beagles are ousting harriers in what may be called the metropolitan districts. Previous to I 886 the Morden Harriers hunted a large district of Northern Surrey, but when Mr. Charles Blake had completed a twentyone years' mastership of the pack it was given up, and 
the Worcester Park Beagles took its place. The Surbiton had then been in existence for three or four seasons, and though the kennels of either pack are within a few miles of the other, there is no clashing, each having its own particular parts of the country. Another pack within reach of Town are the Stoke Place, whose kennels are not far from Slough, and these hounds are a little smaller than the Surbiton or Worcester Park, and are also well known at the shows. This pack has been some fifteen or sixteen years in existence, but a much newer pack which has achieved great celebrity, both on the show bench and in the field, is the Halstead Place, whose operations are confined to a district of North Kent, and of which $\mathrm{Mr}$. James Russel is the master. There are, too, a pack at Buckland Court, near Betchworth, but this pack, the Stoke Place (of which Mr. H. H. Howard Vyse is master), and the Halstead Place are all private packs, whereas the Surbiton and the Worcester Park are subscription packs.

It has been stated that harriers of the dwarf foxhound type have in recent years become more fashionable than the old sorts, and this is to some extent an outcome of the establishing of the Harrier and Beagle Stud Book. Previously there had been a growing tendency towards foxhound blood, and in some countries nothing had been used for many years except undersized foxhounds. The Peterborough Show has also had much to do with setting the fashion, for in these days no harrier has a chance of recognition from the judges unless he is a foxhound in miniature. He must not only have the make and shape of a foxhound, and the bone, but he must be perfectly straight, and clean about his neck and shoulder. Now it is quite certain 
that the harriers of an early period were light of bone, anything but straight, and, as a rule, exceedingly throaty. Then comes the question of whether harehunting is better, or not so good as it was, and this is a question about which the older generation of harrier men will argue for ever and a day. Personally we incline very strongly to the present fashion, deeming it to be in every way more satisfactory to hunt with a pack of hounds which are level, all of one type, and as good-looking as possible. It is generally admitted amongst connoisseurs of dogs generally that a perfect foxhound is the most perfect dog in the world, the most symmetrical and the freest from fault. The remark in these days applies equally to the best harriers, which are, in point of fact, foxhounds in miniature. There are hound men present at Peterborough every summer who are heard to say that, judged as individuals, the pick of the winners in the larger harrier classes are superior to the pick of the winners in the foxhound classes. Into this we need not enter, but it can be stated with confidence that the harriers from some of the crack packs are just about as near perfection as they well can be. Indeed, one is sometimes inclined to think that to breed a perfect hound of twenty-one inches is not quite such a difficult task as to breed one of three inches higher, though it may be stated that it is no easy matter to secure the exact height which is aimed at.

As regards the merits of the older sorts and the modern hound few will dispute the fact that the oldfashioned pure harrier, who had no foxhound blood in him, had a better nose than the average so-called harrier of the present day. He could own a stale line or hunt a hare which had been gone half an hour or 
more in a patient fashion which is seldom seen in these days, but he dwelt terribly on a cold scent, and would at times quarter his ground in setter-like fashion, speaking occasionally, but getting forward so slowly that no real progress was made. There was, in fact, a total absence of drive about many of the old harriers, and we can remember one pack which hunt in the West of England, and where an old-fashioned type of hound is still used, in which this want of drive was very pronounced. We shall not mention the name of the pack, but may say that we saw them hunting less than a dozen years ago, and this is what happened.

A hare was put up in a big pasture, hounds caught a view and started at their best pace, but the hare was soon half a mile ahead, going gradually towards the summit of a hill, which was studded for several acres with gorse bushes and bracken. Hounds soon slowed down, and from a gallop one dropped to a gentle canter and then to a trot. Still scent appeared to be fair, and in about a quarter of an hour the hill was reached, the pack still working the line with considerable bustle. The field walked or led their horses to the top of the hill, then dismounted and lit their pipes, and when we asked one of them to explain what the apparent slackness meant he replied that it generally took hounds half an hour to drive a hare from that particular gorse, as no one ever interfered with them, and no hare ever went straight through. The noninterference one could appreciate, but with such persistent line hunters a thick growth of cover must always mean a long delay, and this would hardly occur with a pack which had even a small amount of drive.

It struck us, then, that old-fashioned harriers should do best in a very open country, where hares can be 
found which will never go near a covert, and where there is bad scenting ground, which would bring powers of nose into play. On the other hand, nine hares out of ten are overmatched on a day of good scent when hunted by pure foxhounds, or by very big harriers which are so well bred that they can go as fast as foxhounds. And much depends upon the country and the hares. In some of the corn countries the hares are big, fat, and incapable of standing up before hounds as do the hares on the moorlands, the marshes, or the down countries. It is greatly a question of training. It is said that unless it is hunted, or frightened off its usual ground, a hare will spend its life within half a mile of the place of its birth, provided, of course, that there is a sufficient supply of food within the area. But in a very open country where little or no corn is grown, where, in fact, there is practically no tillage land, a hare must travel for its food, and when hares have to do this they are in far better condition to be hunted than those who feed night after night in the same field, and perhaps have their form in the adjacent hedgerow while they are resting. Some years ago, when the country was undergoing a long snowstorm, there were no stubbles, and only one "seed" field in the parish where we were living. After a few days one noticed that the hares were feeding regularly on these seeds, and after a fresh fall of snow the experiment was made of tracking some of these hares to their forms, when it was found that some had come two or three miles to the seeds.

As to how greatly the strength and stamina of English hares varies the harrier man would probably learn something from the coursing man, who goes the round of the more important coursing meetings, and 
who, if he exercises his powers of observation, must know where hares are very strong, and where they are the reverse. Many harrier men spend much of their hunting lives in one country, and possibly do not see many distinct packs of hounds at work. When this happens the stoutness of hares will be gauged locally, and a man who is accustomed to hunt hares on highlying ground at no great distance from the moors will, in all probability, have a higher opinion as to the stoutness of the average hare found than the man who hunts in an ordinary enclosed country where there is plenty of food everywhere. Coursing men set great store by the hares found on the cultivated marshy land of East Lancashire, those coursed on the Clifton estate, near Lytham, being especially famous. The hares found on the Wiltshire Downs, in such districts as Amesbury and Everleigh, have also a big reputation; but no matter where one goes the quality of hares varies in some degree, and thus from one beat at a coursing meeting all the hares will run like stags, while from the next beat half a dozen weak hares will come forward in succession. It is the case, too, that hares are greatly affected by weather, many of them being weak and feeble when the land is very wet.

Those who hunt with harriers will have noticed that one hare stands up for an hour or more, and covers a great deal of country during that time, while perhaps the next one hunted seems incapable of a big effort, and is quickly accounted for. This variation in power is most frequently found amongst the hares of a flat enclosed country, and least frequently amongst mooredge hares, and possibly it is accounted for by the fact that a hare which has its home on a hillside can always find dry lying. On the whole we are inclined to think 
that the strongest hares, which took most killing of all we have seen hunted, were found at from seven hundred to one thousand feet above sea level, and where the supply was very small. Moor-edge hares we have called them, because their ground was near to but at a lower level than the moors. As every one knows, the fringe of a moorland district is almost invariably rough pasture land, and it is the hares which this sort of ground produces that we have most respect for. They are seldom numerous, no matter how well preserved the land may be, because they live well outside any grain-bearing country, but their stamina is extraordinary, and the percentage of good to bad ones most remarkable. Such hares are to be found all along the backbone of England, and are hunted chiefly by the Lancashire, West Yorkshire, and Derbyshire packs, while several packs whose operations are usually confined to an enclosed country are occasional visitors to some of the hilly countries where these strong hares exist. 


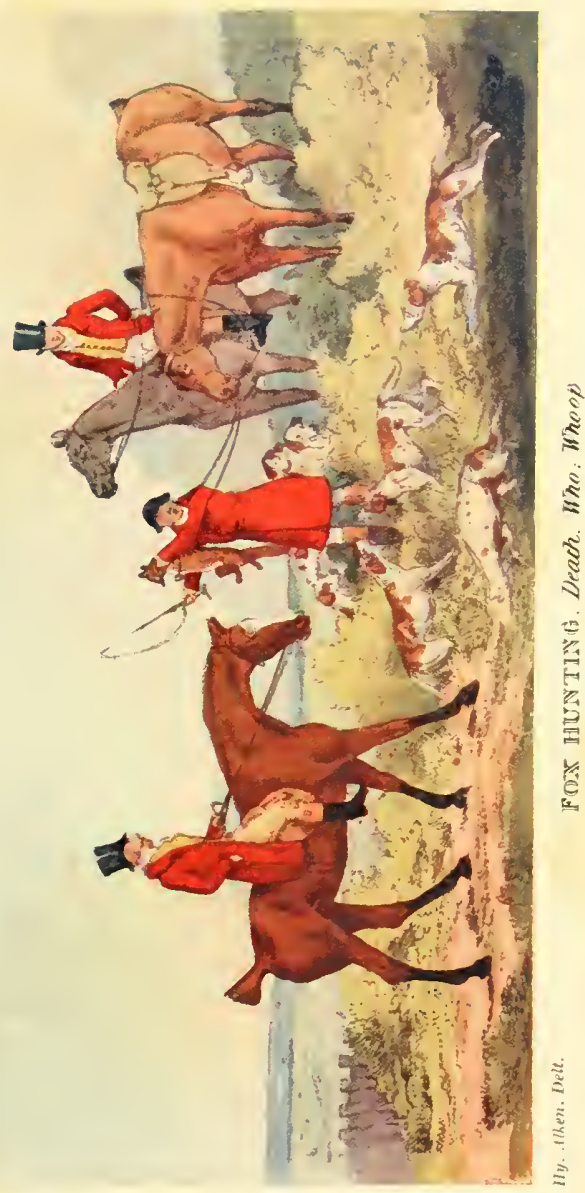





\section{INDEX}

Abbott's Hall, Braintree, 228

Abingdon, 222

Agricultural Hall, Islington, 238

Albrighton hunt, 23, 200

Aldershot, 175

Aldridge's, 238

Allen, Mr., 225

Alnmouth, 197

Alnwick, 197

Althorp, Lord, 221

Amersham, I 72

Amesbury, 287

Amory, Sir John, harrier pack, 269

Anderson, Colonel, 280-1

Anglesey, Henry, $4^{\text {th }}$ Marquis of, $28 \mathrm{I}-2$

Annaly, Lord, I 5

Annan, I98

Arkwright, Mr. J. H., 232

Arrian, I

Ascot, 175

Ashburton harriers, 269

Ashdown Forest, 182

Askew, Mr., 23I

Assheton-Smith, Mr., 24

Atherstone hunt, the, I6, 162,166 , I67, I68, 237; subscription, 107 ; pack sales, 229, 230, 239, 24 I

Atkinson, Mr. F. B., 24I

Axe Vale harriers, 269

Aylesbury, I7o

Aylesbury, Vale of, 172

Badminton hounds, I 2-14, I69, 204, $207,235,236$

Badminton Library, 201

Badminton Park, I69

Badsworth hunt, the, 2 I, I89

Baily's Hunting Directory, cited, $3,6,17,107,153$

Baird, Sir David, 226

Baker, Mr., 224, 226; stud sale, 237

Baker, T., publisher, of Southampton, 201

Barbed wire question, the, $5^{\mathrm{I}-7}$

Barlow, Major, 23 I
Barnard Castle, 195

Baronet, hound, 205, 206

Barrow-on-Soar, 163

Bath, I69

Bath road, the, 175

Bathurst, Earl (V. W. H.), I68

Bathurst, Mr., 238

Bay Prince, sale of, 237

Beagles, 199, 201, 267, 269, 270, 282-3

Beaufort, Duke of (1786), I 3 ; present Duke, 14, 240; $(1858)$ 222; Duke of Beaufort's hunt, I07, $169,204,227$

Beaufort Justice, hound, 204

Beckford, cited, 2OI-2

Bedale country, the, $2 \mathbf{I}-2$, 192-4, 196,228

Bedford, I 88

Beers, George, 226

Bell Hotel, Leicester, 162

Bell, Mr., 239

Bellagio estate, 183

Bellew, Mr. Froude, 235

Belvoir hunt, the, History, I2, I3, I4; the pack, 20, I52, 161, 204; subscription, I07; the country, 153, I88; the blood, 207,227 , 235,240

Benedict, hound, 205

Bentinck, Lord Henry, 224; his pack, 227,236 ; stud sale, 238

Berkeley Castle, 18

Berkeley, Colonel (afterwards Lord Segrave), I 7, 224

Berkeley, Earl of, 17

Berkeley, Grantley, Reminiscences of a Huntsman, quoted, I 7-18

Berkeley hunt, the, $17-18,23,168$

Berks (South) hunt, the, 175,176

Berwickshire pack, the, I98

Betchworth, 177, 283

Bethel, Mr. IVilliam, 2 I

Beverley, I91

Bicester hunt, the, I6, I07, I70, 255 ; hound sales, 226, 230 .

Billingsgate, hound, 206 
Bilsdale hunt, the, 5, 8-9, 2I, 192

Birmingham, 168

Bishop's Stortford, 173

Black Country, the, 200

Blackmore Vale hunt, the, 5, 10, $23,107,154,185,232$

Blake, Mr. Charles, 282

Bland, Major, 23

Blankney hunt, the, $1_{3}, 1_{5}, 20,188$, I 89, 236

Bletchley, izo

Boileau, Mr., 179

Boothby, Thomas, 7-8

Border hunt, the, 23

Borough Bridge, 2 I

Boughey, Mr., 233

Bowser, Mr. Nicholas, 277

Bracken as a covert, 70-I

Bradwell Grove country, I 70

Braes of Derwent hunt, the, 22, 196

Braintree, 228

Bramham Moor pack, the, 2I, I89, 190, 228, 235

Bridge House, Catterick, 193

Bridgnorth, 200

Bridles, remarks concerning, I 24

Bright, Mr., of Badsworth, 2 I

Brighton, 184

Bristol, I8

Broadway, 170

Broadwood, 272

Brockenhurst, I 85

Brocklesby pack, the 12-I3, 20-I, I 89, 204, 207

Brocklesby and Southwold, the, 189

Bromyard, 168

Brooksby, cited, ${ }^{5} 5^{2}, 165^{-6}$

Broomhead Hall, 3

Broomshields, $274-80$

Browne, Major, 230, 233

Broxbourne, 172

Brunskill, Mr., 232

Buccleugh, Duke of, his pack, 197-8

Buckingham, 170

Buckingham, Duke of, 8-9

Buckingham Stone, 9

Buckland Court, 283

Buckley, Mr., 227

Buller, Colonel, 229

Burford country, i 70

Burstow hunt, the, 19, 107, 177, I 79, 180, I81, 182, I83

Burton hunt, the, 13, 20-1, 189, 228, 238

Burton, Mr., 23I

Bury pack, the, 268
Caging of foxes, 40-4

Calcraft, Mr., 204

Calne, 169

Cambridge, 188

Cambridgeshire hunt, the, 20, 1734,188

Campbell, Sir John Hume, 240

Capper, Mr. Harcourt, 233

Capping system, the, $104-7$

Cardigan, Lord, 224

Carlisle, 198

Catterick, 192, 193

Catterick Bridge, 192

Catterick racecourse, the, 193

Cattistock hunt, the, $5,23,24,154$, I 85, 235

Causton, Mr., 224

Cecll, cited, 221

Chalon, H. B., painter, 205, 206

Chaplin, Mr., 236; his hunters, 238

Charles I, 9, 10

Charlton hunt, the. See Goodwood hunt

Charlton, village of, 7

Chelmsford, 173

Cheltenliam, 168

Cheltenham Horse Repository, 232

Chertsey, I75, 176

Cheshire, 198

Cheshire hounds, the, $23,198-200$, 227,268

Cheshire (South) hunt, the, I5

Cheshunt, 20

Chester, 199

Chesterfield, Lord, 224

Chichester, 7,184

Chiddingfold kennels, I 76 ; sales, $23^{6}$

Chippenham, 169

Chipping Sodbury, 169

Chobham Ridges, I75

Chopwell Wood, 7 I

Christmas and New Year meets, I $16-18$

Church Stretton, 200

Cirencester, 169

Cirencester hunt, the, 17

Cirencester kennels, 223

Clarke, Mr., 274

Cleasby, 195

Cleveland, Duke of, 224

Cleveland hunt, the, 22

Clifford, Lord de, 240

Clifton, hares of, 287

Clonmel, Ireland, 207

Clowes, Mr., 227

Cobham, 177

Cockermouth, 198 
Combe, Mr., I7-18

Compton, Mr., 239

Comus, the Belvoir, 229

Coniscliffe, 195

Cooke, Sir IVilliam, 9, 21; his country, 8,191

Cookson, Mr., 233

Coombe, Mr. Harvey, 22.4-5

Cope, Sir John, 19

Coquetdale, 197

Coquetdalc hunt, the, 23

Corbet, Mr., 15

Cornwall (North) pack, the, $23^{8}$

Cornwall, packs of, 24

Cotley harriers, 269

Cotswold hunt, the, 23, 168

Cotswold (North) hunt, the, 23, I $68,170,213,240$

Cottesmore hunt, the, $14,15,152$, I 53, 161-2, 164-6, 188 ; subscription, 107

"Countries," formation of, 12 ; subscriptions, 14 ; grass countries, 153-5; plough countries, I 73-4

Coventry, 168

Coventry, Lord, 23 ; pack, 232, 273

Coverts, good and bad places, 6879 ; riverside, 74 ; Tynedale, 111 ; rents, $112-13$

Cowarne Gorse, 76

Cowden, 183

Cowen, Colonel, 273

Cox, Mr. Harding, 236

Craftsman, hound, 205

Cranborne Chase hunt, the, 5, 1011, 23-4; sales, 236

Cranford kennel, 18

Craven, $4^{\text {th }}$ Lord (1739), I8; Earl of, 255

Craven harriers, the, 268

Craven hunt, the, 18, 176, 221, 229, 233

Craven, Lady, pack, 240

Crawley, 180 , I 83

Crawley hunt, the, $6,184,228$

Cresswell, Mr. A. B., 241

Crewe, 199, 200

Cricklade country hunt, the, 17

Croft Spa, 193-5

Croome hunt, the, 23, 168-9, 273

Croome, Mr. IV. Fielder, 223

Crops, hunting, remarks concerning, $134-6$

Crowner, hound, 278

Croxton Park country, the, 161

Croydon, 179

Croydon Hill, 187
Cub-hunting, 40-2, 70, 132

Cubs, mange among, $5^{\circ}$

Cuddington, 199

Cumberland hunt, the, 23,198

Cumberland (WVest) liunt, the, 198

Curraghmore sale, the, $23^{6}$

Curzon, Lord, 224, 226, 229, 230

Cutandly Wood, I82

Dacre, Lord, 224

Damage and poultry expenses, $110-13$

Darlington, 193-5

Darlington, Earl of, 2I-2, 192 ; the "Earl of Darlington and his Foxhounds," by Marshall, 205-6

Darlington foot harriers, the, 2778

Dart Vale harriers, 269

Davenport, Mr. IVilliam, 229

Day, Tom, 228

Deacon, Mr. 235

Dee river, 198

Delamere Forest, 199

Dent, Mr. Edward, 197

Derwent. See Braes of Derwent

Derwent river, Yorkshire, I9I

Devon and Somerset staghounds, 108, 186

Devon, Mid and East, the, 186

Devon (South) and Dartmoor, the, I 86

Devonshire country, the, $185^{-6}$

Devonshire, foxhound packs of, 24 ; harrier packs of, 269

Dixon, Siddle, huntsman, 273

Dixon, W. Scarth, Foxhounds of Great Britain and Ireland, cited, 9-10

Doncaster, 189

Doneraile, Lord, 224, 227

Dorchester, I 85,229

Dorking, 177,178

Dorset (South) hunt, the, 5, 24, 235

Drake, Mr. W. Tyrwhitt, present master of Old Berkshire, 16; sale of the Drake pack in 1862 , 225-6, 237

Draper, Mr. William, master, $\mathbf{1 7 2 6}$, 2 I

Driffield district, 191

Drove House, 6

Ducie, Lord, 222

Duffield, Mr. Thomas, 255

Dulverton, 186, 187

Dulverton pack, sale of, 240

Dumfries, 198 
Dumfriesshire pack, the, 198

Duncombe, Hon. E. See Feversliam, Lord

Dunster, I 86

Durham, 196

Durham beagles, the, 277,278

Durham (North) foxhounds, the, $22,45,196,276,278$

Durham School, 271

Durham (South) hounds, 194, 196

Durham University liariers, the, $271-2,279$

Eastbourne, 184

Eastbourne hunt, the, 19

Eaton Hall, Chester, 199

Edenbridge, 179

Edward III, royal buckhounds of, 3-4

Eggesford pack, the, 229, 235, 238

Eggshell, sale of, 237

Eglinton, Lord, 226; hunt, 198

Egremont, Lord, hunt, 6

Encyclopedia of Sport, cited, IO-I I

Epsom, 178

Eridge hunt, the, 19

Esher, I77

Eskdale pack, the, 198

Essex and Suffolk pack, the, 173, I 74

Essex (East) hunt, the, 19, 173, 228

Essex liunt, the, 19, 107, 171-4

Essex Union hunt, the, I9, I7 I, 173

Euston, Lord, 226

Everleigh, 287

Evesham, 170

Exeter, 186

Exford, 186

Exmoor pack, the, I86, 187

Exmoor ponies, 259

Falconer, Mr. J. A. K., $278-9$

Faringdon, 170

Farnliam, I 75

Farquharson, Mr., 24

Fell hounds, the, 202

Fernie, Mr., Mr. Fermie's pack, I4, $107,152,153,161-2,164-6$

Feversham, Lord (Hon. E. Duncombe), 228

Field master, question of a, 83-90

Field, the, cited, $7,95^{-6}, 234$, 240-I, 269
Field, the - Christmas and New Year meets, 116-18. Equipment -saddlery, 123-7; the horse, $127-8$; toilet of the rider, $128-$ 34 ; crops, 134-6. General expenses, 108-16. Horsemanship, necessity for good, 118-23; Rider, the, his conduct in the field, 136-46. Subscriptions, amount of, 98-101 ; paynent by lady members, 101-3; when hunting with more than one pack, 103-4; the short-time subscription, I04; the capping system, $104-7$; average rate of, $107-8$

Fife hunt, the, 198

Filey, 9

Findon kennels, 6

Fires in stables, $25^{8-60}$

Fitzhardinge, Lord, 17, 23, 168; sale of hounds, 232

Fitzwilliam country, the $(\mathrm{Mr}$. George Fitzwilliam's), I66, Is8

Fitzwilliam, Lord, Fitzwilliam packs, 20, $189,203,204,229$, 233

Fletcher, Major, 224

Foley, Lady Emily, 76

Foljambe family, the, 20

Foljambe, Mr., 221, 227, 229

Forester, Lord (1830-57), I3

Forfarshire, country, the (Lord Panmure's), 228

Forster, Mr. Crichton, 277

Forster, Mr. R. Carnaby, 238

Fownes, Mr. Thomas, 10-1 I, 24

Fox, Lane, family, 21

Foxes-Bagged, 26-3o. Degeneration of, $216-18$. Importation of, 48-51. Mange among, 44-51

Foxhound Kennel Stud Book, cited, 203, 204

Foxhound Stud Book, Vol. I, 207

Foxhounds - Origin of the foxhound, $201-5$; question of " bone," 205-6, 208-9; pedigree, 206-7; hound shows, see also Peterborough, 207-8; straightness, 209-10; quality, 210; types, 210-12; breeding, 21 2-14; after the kill, 214-15; question of scenting, $215^{-19}$; over-riding of, 218-19; important sales of, $220-41$

Foxhounds of Great Britain and Ireland, cited, $15^{1-2}$ 
Foxhunting-Earliest, I-4. Modern conditions-use of the bagman, 25-30; tampering with wild foxes, 30-I; the shooting tenant, 32-7; common tricks of gamekeepers, 37-44; the mange scourge, 44-5I ; necessity for restocking, $48-5^{\mathrm{I}}$; barbed wire question, $5 \mathrm{I}-7$

Funds, poultry and damage, I Io13

Furlong harriers, the, 269

Galtee pack, sale, 239

Galway country, the, I 54

Galway (East) country, the, I54

Galway, Lord, master is76-1907, 20

Gamekeepers, common tricks of, $37-44$

Game preservation, evils of excessive, $26-41,46,48,50$

Garth hunt, the, 19, 107, 175-6

Garth, Mr., 19

Gatwick racecourse, ${ }_{1} \delta_{3}$

Gerard's Cross kennel, is

Germany, foxes imported from, 49-50

Giles, Mr., 224

Gillingham pack, the, 21

Glamorganshire hounds, the, 233

Glendale country, the, 23,197

Goathland hunt, the, 8-9

Gonalston kennels, 23I

Goodwood pack, the, $5^{-8}, 18_{3}$

Goodwood racecourse, 7

Governess, hound, 205

Grafton, Dukes of, 16, 230

Grafton hunt, the, 16, 170, 213

Graham, huntsman, 28 I

Graham, Sir Bellingham, 15

Grantham, 188, 189

Graphic, the, 160

Grass countries, the, ${ }^{5} 53-5$

Great Central Railway, 172

Greaves, Mr. Henley, 224; his pack, 228

Greenall, Sir Gilbert, I3

Greene, Mr., 222

Greenwell, Mr. John, of Broomshields, harriers, $274-80$

Grey, Earl (1609), 5

Grinstead (East), I81, 182, I84

Grove hunt, the (Lord Fitzwilliam's and Lord Galway's), 20, I89

Grove Park, Kingsbury, 234

Guildford, 177, 178

Guildford, Earl of, 235
Haldon harriers, the, 269

Hale, South, 182

Hall, Mr. A. IV., 227, 229

Hall, Mr. James, stud sale, 238

Halstead Place beagles, $2 \mathrm{~S}_{3}$

Hambledon hunt, the, $6,19,18_{5}$

Hammerwood, $18_{3}$

Hanimond, Mr., 227

Hampshire hunt, the, I8-19, I 75, 176, 185

Hamsterley Hall, 71

Hanbury, Mr. Sampson, 20

Handley Cross, 7 I

Hankey, Captain, 224

Hankey, Mr. J. Barnard, 178

Hardy, Mr. Gerald, 237

Hare hunting, 4, 267, 269-70; reminiscences, 271-88; habits of the hare, 286-8

Harrier and Beagle Stud Book, 283

Harrier Stud Book, cited, 278, 279

Harriers, packs, 198-9, 267-9 ; types, 270-I, 284-5

Harrington, Lord, I 88

Harrogate, 190-I

Hartford Bridge district, I 75

Hassocks, 184

Hastings, 184

Hastings, Marquis of, 227, 228; sale of horses and hounds, 23 I

Hatfield hounds, the, 20

Hawkcombe Head, 187

Hawks, Colonel, 273

Hawthorn Hill, 175

Haydon hounds, the, 22; pack sale, 234

Heathcote, Sir G., stud sale, 237

Hedge-cutting competitions, 55

Henley-on-Thames, $18,175,176$

Hereford (North) country, the, 76 , เ68; pack sales, 232, 233, 239

Hereford (South) country, the, 76

Hereford (West) country, the, 200

Herefordshire hunts, the, 23

Herne, 269

Heron, Mr., 203

Hertford, 172

Hertfordshire hunt, the, 19-20, I 7 1-3

Heythrop House, I6

Heythrop hunt, the, I6, 141, 170, 232

Heythrop (Southern) country, the, 170

High Peak pack, the, 268

High Woodside Farm, 273

Hoare, Mr. C. A. R., 235 
Hoare, Mr. Gerard, 182, 183,184

Hodgson, Mr., 221

Holcombe pack, the, 268

Holderness hunt, the, 21, 190, I9I, 228

Holme Lacey, 76

Home counties, hunting localities in, $171-87$

Hopeful, hound, 204

Horley, I8o, 182

Horlock, Mr., 22 I

Horncastle, I89

Horne, 182

Horse shows, 253

Horsemanship, advice concerning, I1 8-23

Horsham, 177

Horsham hunt, the, $6,18_{3}, 184$

Hounds-Antiquity of packs, 3-1 I ; family packs, 12-15, 16, 18, 99 ; subscription packs, 14, 16, 18, 99; foot packs, 23; "Shire" packs, ${ }^{152-3}$; the southern hound, 201 ; Welsh hounds, 202, 209; hound shows, 207-8, see also Peterborough

Humble, Mr., 22

Humphreys, Mr., 232

Hundred of Hoo pack, the, 240

Hunt Servants' Benefit Society, 160,240

Hunters-Importation of foreign breeds, 2 ; appearance in the field, I 27-8 ; pullers and rushers, 242-4; kickers, 244-7; knack of horsemanship, 247-9; breeding essential, 249-54; advice as to buying, $254-5$; question of weight, 255-7; jumping, 257-8; coddling of, $260-4$; summering of, $264-6$

Hunting-Authorities on, I-2, 15 I2, 20I-2. Localities: Midland, 147-70; Home and Southern, 171-87; Northern, I88-200. Modern conditions, $25-57$

Huntingdon, i 88

Hunts, principal, dates of, $12-24$

Huntsman, the, as deputy for the master, 79-83

Hursley hunt, the, 19, I 85

Hurworth hunt, the, 22, I90, I92, 194

Hyde Park Corner, sale of hounds, 226

Ilfracombe, 186

Ingram, Mr. Meynell, pack, 229

Invitation jumps, 53-4
Ipswich, 230

Ireland, countries in, 154

Jarrett, Captain, 227

Jasper, hound, 205

Jed Forest pack, the, 198

Jones, Mr. Morgan, 225-6

Jorrocks, 71, 164, 188, 202

Kelso, 198

Kennet Valley, I 76

Kensington Gardens, I8

Kent (East) hunt, the, 19

Kent (West) hunt, the, I9, I $\delta_{3}$

Kerrison, Sir Edward, 231, 232

Kildare country, the, I 54

Knatchbull, Sir Edward, 19

Knee-rolls, 125

Knighton, 239

Lady riders, subscriptions of, IOI-3 Lake district, foot packs of the, 23 ; hill packs of the, 198

Lamb, Mr. F. H., 273

Lambton, Mr. Ralph, 22, 206, 221

Lanarkshire hunt, the, 198

Lancashire, harrier packs of, 268

Lancashire hunt, the, 23

Langston, master, 17

Lea river, 171

"Leadenhallers," 27-30

Leamington, 167 , 168

Leatherhead, 177,178

Leconfield, Lord, Lord Leconfield's hunt, 6-7, I84-5, $24 \mathrm{I}$

Ledbury House, 233

Ledbury hunt, the, 23, 75, 132, I68-9, 238, 273

Legard, Mr. Cecil, 207

Leicester as a hunting centre, I 62-3

Leicestershire country, the, ${ }_{15} \delta$, $22 \mathrm{I}-2$

Leigh, 177

Leighton, I 70

Leighton Buzzard, I 70

Lewes, I 84

Lillie Bridge, 232

Lincoln, 188-9

Lincolnshire packs, the, 20-1

Lingfield, 182

Liverpool, 199

Localities, hunting. See under Hunting

Lockerbie, 198

London, hunting centres close to, I 71 et seq. 
Longman, Mr. Arthur, 235

Lonsdale, Lord, 15 ; the Lonsctale pack, 204, 226, 231-2, 277; stud sale, 237

Lonsdale - Shrewsbury driving match, iso

Loughborough, 163-4

Louth, IS9

Lowndes, Mr. Sclby, 226, 227, 229

Lowther, Sir William ( 788 ), I5; (afterward Lord Lonsdale), 204

Ludlow hunt, the, 23, 200

Lumley family, the, zo

Luxton, Mr., 229

Lyndhurst, $18_{5}$

Lynmouth, 186

Lynmouth pack, the, 186

Lynton, 186

Lywood, Mr., 229

Mackenzie, Mr., 235

Mackenzie, Mr. Austin, 236; pack, 238,240

McNeill, Mr. Charles, 213, 240

Mahomet, hound, 205

Maiden Newton, 185

Maidenhead, 175

Maidenhead Thicket, $\mathbf{1 7 5}$

Malpas, 200

Malton, I9I

Malvern, 168-9

Mange among foxes, $44^{-5^{1}}$

March, Lord. See Richmond, Duke of

Market Harborough, 164

Market Rasen, iso

Marriott, Mr. Richard, 228

Marshall, painter, picture by, 205-6

Mason, Mr., 76

Master of hounds, the-dignity of his position, $5^{8-60}$; qualities required in him, $60-6$; discipline in the hunting field, $63-6,68$; classes of masters, $66-9$; distribution of the hunt, 69-77; formation of a plan of campaign, 77-80; delegation of duties, 80-3; joint mastership, 82-3; question of a field master, $83-90$; his relations with the over-rider, $9 \mathrm{I}-7$

Maughan, Mr. Nicholas, sale of hounds, 234-5

Maughan, Mr. Nicholas, senior, 22
Maynard, hound, 205

Maynard, Mr. Anthony, 276

Meath country, the, 154

Melton Mowbray, 161-2, 167

Melville, Whyte, cited, ${ }_{15}^{8}$

Mendip Hills, 268

Merrick, Mr., 234

Merryman, hound, 205

Mersey river, 198

Meynell hunt, the, 16, 107

Meynell, Mr. Hugo Charles, 8, I6

Middleham training stables, 193

Middlesborough, 195

Middleton, Lord, 21, 224, 226 ; his pack, 190, 191, 192, 195, 207

Middleton Park, 255

Midhope, Sir Elias de, 3

Midhurst, 7

Midlands, the, hunting localities in, 147-70, 188 et seq.

"Milton Blood," the, 20

Milton pack, 207, 235

Milton Park kennels, 20

Minehead, 186

Minehead harriers, the, 187

Modbury harriers, the, 269

Modish, hound, 205

Molton (South) harriers, the, 269

Monmouth, Duke of, 5

Monmouthshire Hunt Club, the, 23

Monson, Lord, 3rd Lord (1774), 20 ; pack, 204, 224

Montague, Mr., 224

Morden harriers, the, 282

Moreton-in-the-Marsh, 170

Morpeth hunt, the, 22, 154, 196-7, 241

Morrell, Mr. Charles, 75, 132, 222

Mortimer, Mr., master, $\mathbf{r} 78$

Mostyn, Sir Thomas, 204

Much Wenlock, 200

Mufti, hunting, 13 $3^{[-2}$

Munro, Mr. J. C., 239

Muskerry country, the, 154

Musters, Mr., 15, 221 , 226

Nantwich, 200

Nettlebed, 176

Nettlebed kennel, I 8

Neville, Mr., 75

New Chapel Green, 183

New Forest, 185

New Forest foxhounds, 24 
New Forest Hunt Club, 24

New Forest Justice, hound, 204

New Forest ponies, 259

Newark, i 88

Newbury, 176

Newcastle and Gateshead harriers, the, 273

Newcastle-on-Tyne, 195, 196

Newmarket and Thurlow pack, 173,174

Newton Hall, Durham, 276

Nicholl, Mr., master, 178

Nidd river, 190

Noel family, the, $14^{-1} 5$

Noel, Mr., pack, 204

Noel, Thomas, Book of Hounds, cited, I4

Norfolk (West) pack, 227

Northallerton, 192

Northumberland, 196-7

Northumberland (North) hunt, the, 22-3, 197

Northumberland pack, the, 233

Northwich, 200

Norway, ponies of, 259

Notts, the South, Lord Harrington's, I 88

Nurse, Mr. George, 234-5

\section{Oadby, 162}

Oakham, 166, 167

Oakley hunt, the, 17, I 88

Odiham, 175

Odipus, sale of, 237

Old Berkeley (East), the, 171, 172, 235

Old Berkeley pack, the, see also Berkeley, 16, 17, 18 ; pack sale, 226, 236; stud sale, 237

Old Berkeley (IVest), the, I 7o, I 7 I, 172

Old Berkshire hunt, the, 16, I7o, 222, 255

Old Burton blood, 236

Old Surrey hounds, the, 19, 176, i 78 - So ; Surtees' references, 178

Oldaker, Tom, i 8

Ormrod, Mr. Peter, 239

Osbaldeston, Mr. George, I5, I74; pack, 204, 224-5

Otter hounds, 209

Oundle, I 88

Over-riders, troubles caused by, 9I-7

Oxenden, Sir H., 19

Oxford, 18, I 70
Oxfordshire (South) hunt, the, I7, I8, 170,176

Packs. See under Hounds

Pain, Mr., 227, 234

Panmure, Lord, 228

Payne, Mr. G., 224

Payne, Mr. J., 224

Peirson, Mr., 9

Pelham, Mr., master, I2

Pembrokeshire country, 236

Pendle Forest pack, the, 268

Penistone harriers, the, 3

Penistone hunt, the, 267

Percy country, the, 22, 197, 221, 241 ; pack sale, 239

Peterborough hound shows, 207-8, $210-11,213,241,268,28_{3}, 28_{4}$

Petre, Mr., 224

Petworth kennels, 7

Peyton, Captain, 226

Peyton, Sir Algernon, 226, 230

Pheasants, preservation of, $26-7$

Phillips, Mr. Lort, 236

Pickering, I9I

Pickering, forest of, 8-9, 10

Pigg, James, 7 I

"Pinch me Near Forest," 7 r

Platt, Mr., 233-4

Plough countries, I73-4

Plummer, Mr. Scott, pack, 198

Plymouth, Lord, 237

Pole, Mr. Chandos, 236

Pole, Mr. Van Notten, 235

Poltimore, Lord, pack, 227 ; sale, 229

Ponies, 257, 259

Ponteland, 280

Pool (South) harriers, 269

Poole, Mr., 239

Porlock, I 86

Porlock Weir, 186, I 87

Portcullis Hotel, Badminton Park, I69

Portman, Lord, 24, 240 ; Lord Portman's hunt, 5

Portsmouth, 177,185

Portsmouth, Lord, pack, 227, 229, 236

Poultry and damage expenses, IIO-13

Prudhoe pack, the, 22

Puckeridge hunt, the, 19-20, 1 7 1-4, 227

Punch pictures, 9I

Puppy shows, II

Pytchley hunt, the-Masterships, 15-16; amount of subscription, 
107 ; the Pytchley country, 152, I53, 164, 165, I66, 174; pack sales, 234,239

Quarme harriers, the, 269

Quorn hunt, the-History, 5, 7-8; masterships, I5-I6, 60-I; amount of subscription, IO7; "Shire" pack, I $52-3$; the Quorn country, I6r, rSS; pack sales, 22I, 222, 227, 228, 235 ; stud sales, 237

Raby pack, the, 2I-2, 205, 206 ; sales, 224

Radclyffe, Mr., 229

Radnor, Lord, 24, $236-7$

Radnorshire hunt, the, 200

Rasher, Major, 75

Rawlence, Mr., 239

Rawnsley, Mr. Preston, Southwold pack, I89

Reading, 1 75, 176

Redesdale, Lord, I7

Redhill, I 79, ISo

Reigate, ISo-S1, I 82, 207

Rendlesham, Lord, 228 ; sale, $230-1$

Renfrewshire hunt, the, I98

Retford, I 89

Richardson, Mr., 226

Richmond, Duke of, 5-6

Richmond, York, I95, 196

Rickmansworth, I 72

Ridley, Sir Matthew White, 22

Rigden, Mr., 224, 232

Ripley, 176

Ripon, 192

Roper, master, 5

Robertson, Mr., 22 I

Robsons of Byrness, 23

Roche, Sir D., 232

Rogerson, Mr. J. E., 278

Rolle, Hon. Mark, 230 ; sale of hounds, 232

Roote, Mr., 232

Rossendale pack, the, 268

Rothschild, Lord, his staghounds, 170

Roxby and Cleveland hunt, the, 22

Royal Agricultural Benevolent Institute, 55, I 60,240

Royal buckhounds, the, 3, 207

Rufford pack, the, I88, IS9, 22 I ; sale, 23 I

Rufforth, 189

Rugby, I 5, 166

Rugby hound sales, $234,235,236$, $238-9$
Russel, Mr. James, $28_{3}$

Rutland, Duke of, 22t; pack, I3, $203,204,227,229$

Ryton Woodside, 2So

Saddles, remarks concerning, I247, $158-60$

Saffron IValden, I74

St. Boswell's, rg8

Salisbury family, the, 20

Salisbury, Marchioness of, 20

Sandiway kennels, the, 199

Scarborough, 191-2

Scotch packs, $197-8$

Scott, Mr. Francis, I 78

Scratch Wood, I 8

Segrave, Lord, I7

Selby-Lowndes family, the, I 6

Selby, Mr., 236

Serlby, 20

Serrell, Miss, With Hound and Terricr in the Field, quoted, 10

Sherborne, IS $_{5}$

Sherling, Mr., harriers, 269

Shetland ponies, 259

Sheward, Dr., 76

Shire countries - The "Shire" packs, 152-3; description of country, I5 $5^{2-7}$; expenses, $15^{8-}$ 6 I

Shooting tenants, 30-1, 33-7

Shotley Bridge beagles, the, 27880

Shrewsbury, 200

Shropshire, Igs

Shropshire hunt, the, 23

Shropshire (North) pack, the, 200

Shropshire (South) pack, the, 200

Sidney, Mr., $23^{S}$

Sileby, $6_{3}$

Silk and Scarlet, "The Druid" quoted, 4

Silverton harriers, the, 269

Simnington hunt, the, 5, 8-9, 21, I 90-2

Skeffington Hall, 23 I

Sladeland kennels, the, 6

Smith, Mr. Assheton, 221, 229

Smith, Mr. "Tom," I5

Somerset, harrier packs in, 268

Somerville, Miss, quoted, 248

Sondes, Lord, I9

Sore backs, causes, I59-60

Southampton, I 85

Southampton, Lord, 226

Southdown hunt, the, 19, I 84

Southern counties, hunting localities in, $17 \mathbf{r}-87$ 
Southwold pack, the, 20-1, I89

Spencer, Lord (1750), I5

Squerries, 19

Stables, remarks concerning, $25^{8-}$ 66

Stacey, Captain, 240

Stafford, 200

Staffordshire (North) hunt, the, 23, 200 ; sale, 229

Staffordshire (South) hunt, the, 23, 200

Staghunting, 24, 186-7

Staines, 175

Staint on Dale hunt, the, 8, 9, 10, 192

Stamford, 166

Stamford, Lord, 163,224 ; stud sale, 237

Stamfordham, 196

Stanford, Mr., 228

Stephen, King, 8

Steyning, 184

Stirrup leathers and stirrups, remarks concerning, $120-2,127$

Stockton, 195

Stockton Forest, 190

Stoke Edith, 76

Stoke Place beagles, $28_{3}$

Stratton Audley, 225, 226

Stud sales, 237-8

Subscriptions. See under Field

Suffield, Lord, 22 I

Suffolk hunt, the, 19, 20, I73, 237

Sumner, Captain A. H., 232

Sunderland, 195

Sunderland Bridge, 22

Surbiton, 177

Surbiton beagles, the, 282-3

Surrey Union hunt, the, $19,176-80$

Surtees' works cited, 7 I, 75, 1 1 10-I I, I51, 178-9, 204

Sussex Archaological Collections cited, 5

Sussex (East) hunt, the, 19, 184; pack sale, 234, 235

Sussex (IVest) hunt, the, 6

Sutton, Sir Richard, 222, 235

Swan, Mr. Clayton, 24I

Swinley Forest, 175

Sykes family, the, 2 I

Symphony, hound, 205

Syston, 163

\section{Tadworth, 177}

Tailby, Mr., 226, 231-2

Takeley Forest, I73

Talbot, Mr., 233

Tar Wood, I4I
Tarporley, 199

Tattersall sales, 221, 222, 224, 225, $227-9,234,236,237-8,239$

Tedworth country, the, 24

Tees river, the, 193

Teme Valley pack, the, 200, 239

Tenbury, 200

Tetbury, 169

Thanet and Herne pack, the, 269

Thirsk, 192

Thomson, Colonel Anstruther, I5, 165 ; Reminiscences cited, 150

Thrapston, I 88

Thurlow country, the, I74

Tickham country, the, I9

Tipperary country, the, I 54

Tiverton, 24, I 86, I 87

Tiverton pack, the, 186

Tooley Park, Leicester, 7

Torquay, i 86

Totnes, I86, 232

Treadcroft, Mr., 224

Trentham, 229

Tubney kennels, the, 222

Twici, Guillaume, I-2

Tynedale Hunt Club, the, III, I 3

Tynedale hunt, the, 22, I54, 196-7

Tyrwhitt, master, I 2

United hounds, the, 200

Uppingham, 166

Uxbridge, 17 I

Vale land, I 77

Vale of Lune pack, the, 268

Vale of White Horse hunt, theOrigin, I 7; Earl Bathurst's, 168, 169 ; Cricklade, I69, 170 ; mastership, 222, 223

Vale of White Horse Repository, Swindon, 235

Vane family, the, 192

Vasey, huntsman, 272

Vaughan, Sir Robert IVilliams, 222-3, 228

Vernon, Lord, pack, 204

Villebois, Mr., 224, 227

Vine hunt, the, $18,176,229$

Virginia IVater, I75

Vyner, Mr. Robert, master, I2, 16; quoted, 5, 203, 204, 207, 216-17

Vyse, Mr. H. H. Howard, 283

Walton and Lee, Messrs., 234

Walton-on-the-Heath, I 77 
Walworth, 197

Warde, Mr. John, 15, I6, 19, 22 I

Warkworth, 197

Warwick, 167

Warwickshire hunt, the, 16, Io7, I66-7, I 70, 235

Warwickshire (Nortli) hunt, the, 16, 107, 166, 168; pack sale, 226 ; stud sale, 237

Warwickshire Vale, I zo

"Waterloo" run of the Pytchley, I 65

Waters, Mr. Dun, 238

Watson, Mr. Thomas, harriers, 277-8

Weatherby road, the, 189

Webb, Mr., master, 17

Weldon Bridge, 197

Wells subscription pack, the, 268

Welsh hounds, the, 202, 209

Wemyss, Lord, 22-3; country, $22 \mathrm{I}$; pack sale, 23I

Wentworth, 20

Wentworth Woodhouse, 20

Westerham country, the, I9

Westminster, Duke of, 199

Westmorland, 198

Weston pack, 268

Weybridge, 177

Weymouth, 185

Whaddon Chase hunt, the, I6, I 70

Whalton, 196-7

Wheatland hunt, the, 23,200

Whieldon, Mr., 224

Whitaker, Mr. P., 237

Whitby, 9

Whitchurch, 200

White Cross kennels, the, 232

White, huntsman, $18_{3}$

White, Mr., 224

Whitstable, 269

Wickets, hunting, 54

Williams, Captain, 22I

Willoughby family, the, $2 \mathrm{I}$

Willow Bridge, 195

Wilson, Mr., 3

Wilton hunt, the, 24

IVilts (South-IVest) hounds, the, $24,169,227$

Winchester, 185
Windernere, 195

IVindlesham, 176

Winclsor, 175

IVinslow, 170

IVirral harriers, the, Cheshire, 268

Wirral Peninsula, the, 198, 268

Woking, 177

Wokingham, 175

Wolsingham pack, the, 272, 273

Woodland Pytchley hunt, theHistory, 15 ; a mount of subscription, I07; the Pytchley country, I53, 164, 166, I85; pack sales, $23^{8}$

Woodlands, 272

Worcester, Marquis of, 233,236 , 238

Worcester Park, 176

Worcester Park beagles, the, 282-3

IVorcestershire hunt, the, I68-69, 232, 273

Worksop, I89

Wormwood Scrubs, is

Wrexham, 200

Wroughton, Mr. W. M., I5, $23 \mathrm{~S}$, 240

Wyke, Hayburn, Io

Wyndham, Coloncl George. See Leconfield, Lord

Wyndham, Sir Henry, 6

Wynn, Sir Watkin, 23, 200, 236

Wynnstay pack, the, $23^{6}$

Yarborough, Lord, 13 ; hounds, $203,204,227,229,235$

Yeovil, IS5

York, I89-92, 195

York and Ainsty hunt, the, 21, 22, I 89-90, 192, 228, 229

York (East) and Ainsty Hunt, the, 190

Yorkshire-Hunts of North-East, $S$; foxhound packs, $2 \mathrm{I}-2$; harrier packs, 267

Yorkshire country, the, I90, 195

Zetland, Lord, 22 ; Lord Zetland's country, 190, 192, 193, 194, 195 
WILLIAM BRENDON AND SON, LTD.

PRINTERS, PLYMOUTH 


\section{A CATALOGUE OF BOOKS PUBLISHED BY METHUEN}

AND COMPANY: LONDON 36 ESSEX STREET

\section{W.C.}

\section{CONTENTS}

\begin{tabular}{|c|c|c|c|c|}
\hline & & $\begin{array}{r}\text { PAGE } \\
2.22\end{array}$ & & PAGE \\
\hline $\begin{array}{c}\text { General Literature, } \\
\text { Ancient Cities, }\end{array}$ & . & $2 \cdot 22$ & Little Galleries, & 28 \\
\hline $\begin{array}{l}\text { Ancient Cities, } \\
\text { Antiquary's Books, }\end{array}$ & . & 22 & Little Guides, . & 28 \\
\hline $\begin{array}{l}\text { Antiquary's Books, } \\
\text { Arden Shakespeare }\end{array}$ & · & 22 & Little Library, · · & \\
\hline $\begin{array}{l}\text { Arden Shakespeare } \\
\text { Beginner's Books }\end{array}$ & $\cdot$ & 23 & Little Quarto Shakespeare, & $3^{\circ}$ \\
\hline & . & 23 & Miniature Library, & 30 \\
\hline Business Books, . & - & 23 & Oxford Biographies, & 30 \\
\hline Byzantine Texts, . & . & 24 & School Examination Series, & $3^{\mathrm{I}}$ \\
\hline Churchman's Bible, & . & 24 & School Histories, . . & $3^{\mathrm{I}}$ \\
\hline Churchman's Library, & . & 24 & Simplified French Texts, & 3 I \\
\hline Classical Translations & & 24 & Standard Library, . & 3I \\
\hline Classics of Art, & . & 24 & Textbooks of Science, & $3^{2}$ \\
\hline Commercial Series, & . & 25 & Textbooks of Technology, & $3^{2}$ \\
\hline Connoisseur's Library, & & 25 & Handbooks of Theology, & $3^{2}$ \\
\hline Illustrated Pocket Libr & ary of & & Westminster Commentaries, & $3^{2}$ \\
\hline $\begin{array}{l}\text { loured } B \\
\text { 1ation S }\end{array}$ & $\begin{array}{l}\text { Books, } \\
\text { ieries, }\end{array}$ & $\begin{array}{l}25 \\
26\end{array}$ & & \\
\hline 10ol-Books, & . & 27 & Fiction, $\cdot$..$\quad$. & $33-39$ \\
\hline Leaders of Religion, & & 27 & Books for Boys and Girls, & 39 \\
\hline Library of Devotion, & & 27 & Novels of Alexandre Dumas, & 39 \\
\hline Little Books on Art, & & 28 & Methuen's Sixpenny Books, & 39 \\
\hline
\end{tabular}


a Preface by Canon Scotr Holland. Cr. 8vo. $3^{5.6}$.

Bartholomew (J. G.), F.R.S.E. See C. G. Robertson.

Bastable (C. F.), LL.D. THE COMMERCE OF NATIONS. Fourth Ed. Cr. 8vo. 2s. $6 d$.

Bastian (H. Charlton), M.A.,M.D., F.R.S. THE EVOLUTION OF LIFE. With Diagrams and many Photomicrographs. Demy 8vo. $7 s$. 6 d. net.

Batson (Mrs. Stephen), A CONCISF HANDBOOK OF GARDEN FLOWERS Fcap. 8vo. $3^{s}$. $6 d$.

THE SUMMER GARDEN OF PLEASURE. With 36 Illustrations in Colour by Osmund Pittman. Wide Demy 8vo. I 5s, net.

Batten (Loring W.), Ph.D., S.T.D. THF HEBREW PROPHET. Cr.8vo. $3 s .6$ d. net

Bayley (R. Child). THE COMPLETE PHOTOGRAPHER. With over too lllustrations. Third Edition. With Notc on Direct Colour Process. Demy 8vo. ros. $6 d$. net.

A Colonial Edition is also published.

Beard (W. S.). EASY EXERCISES IN ALGEBRA FOR BEGINNERS. Cr. 8vo is. 6d. With Answers. is. $9 d$.

See also Junior Examination Series and Beginner's Books.

Beckford (Peter). THOUGH T S ON HUNTING. Edited by J. OTho PAgeT and Illustrated by G. H. JALland. Second Edition. Demy 8vo. 6s.

Beckford (William). See Little Library.

Beeching (H. C.), M.A., Canon of Westminster. See Library of Devotion.

Beerbohm (Max). A BOOK OF CARI CATURES. Impcrial 4 to. $2 \mathrm{rs}$. net.

Begbie (Harold). MASTER WORKERS. Illustrated. Demy $8 v 0$. 7s. 6d. net.

Behmen (Jacob). DIALOGUES ON THF SUPERSENSUAL LIFE. Edited by Bernard Holland. Ficap. 8zo. 3s.6d.

Bell (Mrs. Arthur G.). IHE SKIRTS OF THE GREAT CITY. With I6 Illnstrations in Colour by ARThur G. Bell, I7 other Illustrations, and a Map. Secona Edition. Cr. 8\%o. 6s.

Belloc (Hilaire), M.P. PARIS. With 7 Maps and a Frontispiece in Photogravure. Second Edition, Rerised. Cr. 8zo. 6s.

HILLS AND THE SEA. Second Edition. Crozen 8vo. $6 s$.

ON NOTHING AND KINDRED SUB. JECTS. Fcap. 8vo. 55 .

A Colonial Edition is also published.

Bellot (H. H. L.), M.A. See Jones(L. A. A.)

Bennett (W. H.), M.A. A PRIMER OF THE BIBLE. With a concise Bibliography. Fourth Edition. Cr. 8vo. 2s. 6d.

Bennett (W. H.) and Adeney (W. F.). BIBLICAL INTRODUCTION. Fifth Edition. Cr. 8vo. 7s. 6d.

Benson (Archbishop) GOD'S BOARD Communion Addresses. Second Edition. Fcap. 8vo. 3s. 6d. net.
Benson (A. C.), M.A. See Oxford Bio. graphies,

Benson (R. M.). THE WAY OF HOLINESS: a Devotional Commentary on the irgth Psalm. Cr. 8vo. 5 s.

Bernard (E. R.), M.A., Canon of Salisbury. THE ENGLISH SUNDAY: 1TS ORIGINS AND ITS Claims. Fcap. 8vo. Is. $6 d$.

Bertouch (Baroness de). THE LIFE OF FATHER IGNATIUS. Illustrated. Demy 8vo, ros. $6 d$. net.

Beruete (A. de). See Classics of Art.

Betham-Edwards (Miss). HOME LIFE IN FRANCE. With 20 Illustrations. Fifth Edition. Crozun 8vo. $6 s$.

A Colonial Edition is also published.

Bethune-Baker (J. F.), M.A. See Handbooks of Theology.

Bidez (J.). See Byzantine Texts.

Biggs(C.R.D.), D. D. See Churchman's Bible.

Bindley (T. Herbert), B.D. THE OECU. MENICAL DOCUMENTS OF THE FAITH. With Introductions and Notes. Second Edition. Cr. 8vo. 6s, net.

Binns (H. B.). THE LIFE OF WALT WHITMA N. Illustrated. Demy $8 v o$. ros. $6 d$. net.

A Colonial Edition is also published

Binyon (Mrs. Laurence). NINETEENTH CENTURY PROSE. Selected and arranged by. Crown $8 v 0$. $6 s$.

Binyon (Laurence). THE DEATH OF ADAMI AND OTHER POEMS. $C r$. swo. 3s. 6 d. net.

See also Blake (William)

Birch (Walter de Gray), LL.D., F.S.A. See Connoisseur's Library.

BirnstingI (EtheI). See Little Books on Art.

Blackmantle (Bernard). See I.P.I.

Blair (Robert). See I.P.L.

Blake (William). THE LETTERS OF WILLIAM BLAKE, TOGETHER WITH A LiFE BY Frederick TATHAM. Edited from the Original Manuscripts, with an Introduction and Notes, by ARCHibaLD G. B. Russell. With i2 lllustrations. Demy 8vo. 7s. 6d. net.

ILLUSTRATIONS OF THE BOOK OF JOB. With General Introduction by Laurence Binyon. Quarto. zis, net.

See also Blair (Robert), I.P.L., and Little Library.

Bloom (J. Harvey), M.A. S H A K E SPEA RE'S GAR DEN. Illustrated. Fcap. 8vo. 3s. 6d.; leather, 4 s. 6.t. net.

See also Antiquary's Books

Blouet (Henri). See Beginner's Books.

Boardman (T. H.), M.A. See French (IV.)

Bodley (J.E. C.), Author of 'France." THE CORONATION OF EDWARD VII. Demy 8vo. 21s. net. By Command of the King.

Body (George), D.D. TH E SOU L'S PILGRIMAGE: Devotional Readings from the Published and Unpublished writ. ings of George Body, D.D. Selected and arranged by J. H. BURN, B.D., F.R.S.E. Demy 16mo. 2s. $6 d$. 


\section{General Literature}

Bona (Cardinal). See Library of Devotion. Boon (F. C.)., B.A. See Commercial Series. Borrow (George). See Little Library.

Bos (J. Ritzema). AGRICULTURAL ZOOLOGY. Translated by J. R. Ains. wORTH DAvis, M.A. With 155 Illustrations. Third Edition. Cr. 8vo. 3s. $6 d$.

Botting (C. G.), B.A. E A S Y G R E E K EXERCISES. Cr. 8vo. 2s.

See also Junior Examination Series.

Boulting (W.) TASSO AND HIS TIMES. With 24 Illustrations. Demy Svo. ros. $6 d$. net.

Boulton (E. S.), M.A. GEOMETRY ON MIODERN LINES. Cr. 8vo. 2s.

Boulton (William B.). T H O M A GAINSBOROUGH. His Life and Work, Friends and Sitters. With 40 Illustra. tions. Second Ed. Demy 8vo. 7s. 6d. net.

SIR JOSHUA REYNOLUS, P.R.A. With 49 Illustrations. Deny 8vo. 7s. 6d. net.

Bowden (E. M.), THE IMITATION OF BUDDHA : Being Quotations from Buddhist Literature for each Day in the Year. Fifth Edition. Cr. $x$. $m$ o. 2s. $6 d$.

Boyle (W.). CHRISTMAS AT THE ZOO. With Verses by W. Boyle and 24 Coloured Pictures by H. B. Neilson. Super Royal I6mo. 2s.

Brabant (F. G.), M.A. See Little Guides.

Bradley (A. G.). ROUND ABOUT WILT SHIRE. With I4 Iliustrations, in Colour by T. C. GoTCH, I 6 other Illustrations, and a Map. Second Edition. Cr. 8vo. 6s.

A Colonial Edition is also published.

THE ROMANCE OF NORTHUMBER LAND. With $x 6$ Illustrations in Colour by Frank Southgate, R.B.A., and 12 from Photographs. Second Edition. Demy' $8 z^{\prime}$. 7s. $6 d$ net.

A Colonial Edition is also published.

Bradley (John W.). See Little Books on Art.

Braid (James), Open Champion, Igor, Igos and rgo6. ADVANCED GOLF. With 88 Photographs and Diagrams. Fourth Edition. Demy 8vo. 10s. 6d. net.

A Colonial Edition is also published.

Braid (James) and others. GREAT GOLFERS IN THE MAKING. Edited by HENRY LEACH. With 24 Illustrations. Second Edition. Demy 8vo. 7s. 6d. net.

A Colonial Edition is also published.

Brailsford (H. N.). MACEDONIA ITS RACES AND THEIR FUTURF. With Photographs and Maps. Demy $8 v 0$. 12s, $6 d$. net.

Brodrick (Mary) and Morton (A. Ander son). A CONCISE DICTIONARY OF EGYPTIAN ARCHÆOLOGY. A Hand. Book for Students and Travellers. With 80 Illustrations and many Cartoucbes. $\mathrm{Cr}$. $8 z^{\prime} 0$. 3s. $6 d$.

Brooks (E. E.), B.Sc. (Lond), Leicester Municipal Technical School, and James (W. H.N.) A.R.C.S., A.M.I.E.E., Municipal School of Technology, Manchester. See Textbooks of Technology.

Brooks (E. W.). See Hamilton (F. J.)
Brown (P. H.), LL.D. SCOTLAND IN THE TIME OF QUEEN MARY. Demy 8vo. 7s. 6d. net.

Brown (S. E.), M.A., B.Sc., Senior Science Master at Uppingham. A PRACTICAL CHEMISTRY NOTE - BOOK FOR MATRICULATION AND ARMY CAN. DIDATES. Easy Experiments on the Commoner Substances. Cr. 4 to. xs. 6d. net.

Brown (J. Wood), M.A. THE BUILDERS OF FLORENCE. With 74 Illustrations by HERBERT RAILTON. Demy 4 to. I8s. net. Browne (Sir Thomas). See Standard Library.

Browneli (c. L.). THE HEART OF JAPAN. Illustrated. Third Edition. Cr. 8vo. 6s.; also Demy 8vo. 6d.

Browning (Robert). See Little Library.

Bryant (Walter W.), B.A., F.R.A.S., F.R. Met. Soc., of the Royal Observatory, Greenwich. A HISTORY OF ASTRONOMY. With 35 Illustrations. Demy 8vo. 7s. $6 d$. net.

Buckland (Francis T.).1 CURIOSITIES OF NATURAL HISTORY. Illustrated by H. B. Neilson. Cr. $8 v 0$. 3s. $6 d$.

Buckton (A. M.) THE BURDEN OF ENGELA. Second Edition. Cr. 8vo. $3 s$. 6d. net.

EAGER HEART : A Mystery Play. Seventh Edition. Cr. 8vo. Is. net.

KINGS IN BABYLON: A Drama. Cr. 8\%o. is. net.

SONGS OF JOY. Cr. 8vo. is. net.

Budge (E. A. Wallis). THE GODS OH THE EGYPTIANS. With over Ioo Coloured Plates and many Illustrations. Two Volumes. Royal8vo. $E_{3,3}$ s. net.

Bull (Paul), Army Chaplain. GOD AND OUR SOLDIERS. Second Edition. Cr. 8 vo. $6 s$.

A Colonial Edition is also published.

Bulley (Miss). See Dilke (Lady).

Bunyan (John). See Standard Library and Library of Devotion.

Burch (G. J.), M.A., F.R.S. A MIANUAL OF ELECTRICAL SCIENCE. Illustrated. $\mathrm{Cr}$.8vo. 35 .

Burgess (Gelett). GOOPS AND HOW TO BE. THEM. Illustrated. Small 4to. 6s.

Burke (Edmund). See Standard Library.

Burn (A. B.), D. D. Rector of Handsworth and Prebendary of Lichfield. See Hand. books of Theology.

Burn (J. H.), 1.D. D., F.R. S. E. THF CH U R CH A N'S TREASURY OF SONG: Gathered from the Christian poetry of all ages. Edited by. Fcap. 8vo. 3s. $6 d$. net. See also Library of Devotion.

Burnand (Sir F. C.). RECORDS AND REMINISCENCES. With a Portrait by H. v. Herkomer. Cr. 8zo. Fourth and Cheaper Edition. $6 s$

A Colonial Edition is also published.

Burns (Robert), THE POEMS. Edited by ANDREW LANG and W. A. CRAIGIE. With Portrait. Third Edition. Demy 8vo, gilt top. $6 s$. See also Standard Library. 
Burnside (W. F.), M.A. OLD TESTA. MENT HISTORY FOR USE IN SCHOOLS. Third Edition. Cr. 8vo, $3^{s} .6 \mathrm{~d}$.

Burton (Alfred). See I.P.L.

Bussell (F. W.), D.D. C H R I T I A N THEOLUGYAND SOCIAL PROGRESS (The Bampton Lectures of 1905). Denzy 8vo. Ios. 6d. net.

Butler (Joseph), D.D. See Standard Library.

Caldecott (Alfred), D.D. See Handbooks of Theology.

Calderwood (D. S.), Headmaster of the Normal School, Edinburgh. TEST CARDS IN EUCLID AND ALGEBRA. In three packets of 40 , with Answers. 1s. each. Or in three Books, price $2 d$., 2d., and $3 d$.

Canning(George). See Little Library.

Capey (E. F. H.). See Oxford Biographies. Careless (Jolın). See I.P.L.

Carlyle (Thomas). THE FRENCH REVOLUTION. Edited by C. R. L. FLETCHER, Fellow of Magdalen College, Oxford. Three Volumes. Cr. 8vo. I8s.

THE LIFE AND LETTERS OF OLIVER CROMWELL. With an Introdnction by C. H. Firth, M.A., and Notes and Appendices by Mrs. S. C. LomAs. Three Volumes. Demy 8vo. I 8 s. net.

Carlyle (R. M. and A. J.), M.A. See Leaders of Religion.

Carmichael (Philip). ALL ABOUT PHILIPPINE. With 8 Illustrations. Cr. 8vo. 2s. $6 d$.

Carpenter(Margaret Boyd). THECHILD IN ART. With 5o Illustrations. Second Edition. Large Cr. 8vo. 6s.

Cavanagh (Francis), M.D. (Edin.). THE CARE OF THE BODY. Second Edition. Demy 8vo. 7s. 6d. net.

Celano(Thomas of). THE LIVES OF ST. FRANCIS OF ASSISI. Translated into English by A. G. FERrERS Howell. With a Frontispiece. Cr. 8vo. 5s. net.

Channer (C. C.) and Roberts (M. E.). LACEMAKING IN THE MIDLANDS, PAST AND PRESENT. With 16 fullpage Illustrations. $\mathrm{Cr}, 8 \pi 0$. 2s. $6 d$.

Chapman (S. J.). See Books on Business.

Chatterton (Thomas). See Standard Library.

Chesterfield (Lord), THE LETTERS OF TO HIS SON. Edited, with an Introduction by C. Strachey, with Notes by A. Calthrop. Truo Volumes. Cr. 8vo. izs.

Chesterton(G.K.). CHARLES DICKENS. With two Portraits in Photogravure. Fift/h Edition. Cr. 8vo. $6 s$.

Childe (Charles P.), B.A., F.R.C.S. THE CONTRUL OF A SCOURGE : OR, How Cancer is Curable. Demy $8 v 0$. 7s. $6 d$. net.

Christian (F. W.). THE CAROLINE ISLANDS. With many Illustrations and Maps. Demy 8vo. i 2s. 6d. net.

Cicero. See Classical Translations.

Clapham (J. H.), Professor of Economics in the University of Leeds. THE WOOL.
LEN AND WORSTED INDUSTRIES. With 2I Illustrations and Diagrams. $\mathrm{Cr}$.

Clarke(F. A.), M.A. See Leaders of Religion. Clausen (George), A.R.A., R.W.S. SIX LECTURES UN PAINTING. With 19 lllustrations. Third Edition. Large Post 8vo. 3s. 6d. net.

AIMS AND IDEALS IN ART. Eight Lectures delivered to the Students of the Royal Academy of Arts. With 32 Illustrations. Second Edition. Large Post $8 v o$. 5s. net.

Cleather (A. L.). See Wagner (R).

Clinch (G.), F.G.S. See Antiquary's Books and Little Guides.

Clough (W. T.) and Dunstan (A. E.). See Junior School Books and Textbooks of

Science.
Clouston (T. S.), M.D., C.C.D., F.R.S.E. THE HYGIENE OF MIND. With no Illustrations. Fourth Edition. Demy $8 v 0$. 7s. 6 d. net.

Coast (W. G.), B.A. EXAMINATION PAPERS IN VERGIL. Cr. 8vo. $2 s$.

Cobb (W. F.), M.A. THE BOOK OF PSALNIS: with a Commentary. Demy $8 v 0$. ros. $6 d$. net.

Coleridge (S. T.). POEMS. Selected and Arranged by ARThur Symons. With a Photogravure Frontispiece. Fcap. 8vo. 2s. 6il. net.

Collingwood (W. G.), M.A. THE LIFE OF JOHN RUSKIN. With Portrait. Sixth Edition. Cr. 8vo. 2s. 6d. net.

Collins (W. E.), M.A. See Churchman's Library.

Combe(William), See I.P.L.

Conrad (Joseph). THE MIRROR OF THE SEA: Memories and Impressions. Third Edition. Cr. 8z'o. $6 s$.

Cook (A. M.), M.A., and Marchant (E. C.), M.A. PASSAGES FOR UNSEEN TRANSI.ATION. Selected from Latin and Greek Literature. Fourth Ed. Cr. 8vo. $3^{s .6 d}$. LATIN PASSAGES FOR UNSEEN TRANSLATION. Third Ed. Cr.8vo. is.6d. Cooke $=$ Taylor $(R$. W. $)$. THE FACTORY SVSTEM. Cr. 8vo. 2s. $6 d$.

Coolidge (W. A. B.), M.A. THE ALPS. With many Illustrations. Demy $8 v 0$. 7s. 6 d net.

A Colonial Edition is also published.

Corelli (Marie). THE PASSING OF THE GREAT QUEEN. Second Edition. Fcap. 4to. Is.

A CHRISTMAS GREETING. Cr. $4^{t o}$. $1 s$. Corkran (Alice). See Little Books on Art.

Cotes (Everard). SIGNS AND PORTENTS IN THE FAR EAST. With 35 Illustrations. Second Edition. Demy $8 v 0$. 7s. 6d. net.

A Colonial Edition is also published.

Cotes (Rosemary). DANTE'S GARDEN. With a Frontispiece. Second Edition. Fcap. 8vo. 2s. 6d.; leather, 3s. 6d. net.

BIBLE FLOWERS. With a Frontispiece and Plan. Fcap. 8vo. 2s. 6 d. net. 
Cowley (Abraham), See Little Library. Cowper (William). THE POEMS. Edited with an Introduction and Notes by J. C. BatLey, M.A. Illustrated, including two unpublished designs by WiLliam Blake. Demy 8vo. 1os. $6 d$. net.

Cox (J. Charles). See Ancient Cities, Antiquary's Books, and Little Guides.

Cox (Harold), B.A., M.P. NATIONAIZATION AND TAXATION. Second Edition revised. Cr. 8vo. 3s. 6d net.

Crabbe (George). See Little Library.

Craik (Mrs.). See Little Library.

Crane (C. P.), D.S.O. See Little Guides

Crane (Walter), R.W.S. AN ARTIST'S REMINISCENCES. With 123 Illustra. tions by the Author and otbers from Photographs. Second Edition. Demy 8vo. I8s. net.

A Colonial Edition is also published.

INDIA IMPRESSIONS. With 84 1llus trations from Sketches by the Autbor. Second Edition. Demy 8vo. 7s. 6d. net.

A Colonial Edition is also published.

Crashaw (Richard). See Little Library.

Crawford (F. G.). See Danson (Mary C.).

Crofts (T. R. N.), M. A., Modern Language Master at Merchant Taylors' School. See Simplified French Texts.

Cross (J. A.), M.A. THE F.AITH OF THE BIBLE. Fcap. 8vo. 2s. 6d. net.

Cruikshank(G.). THE LOVING BAL LAD OF LORD BATEMAN. With II Plates. Cr. 16 mo. Is. 6 d. net.

Crump (B.). See Wagner (R.).

Canllffe (Sir F. H. E.), Fellow of All Souls College, Oxford. THE HISTORY OF THE BOER WAR. With many Illus trations, Plans, and Portraits. In 2 vols. Quarto. I5s. each.

Cunynghame (H. H.), C.B. See Connois. seur's Library.

Cutts (E. L.), D.D. See Leaders of Religion.

Daniell (G. W.), M.A. See Leaders of Religion.

Dante (Alighieri). LA COMIEDIA DI DANTE. The Italian Text edited by Paget Toynbee, M.A., D. Litt. Cr.8vo. 6s.

THE DIVINE COMEDY. Translated by H. F. CARY. Edited with a Life of Dante and Introductory Notes by PAGET Toynbee, M.A. D. Litt. Demy 8vo. $6 d$.

THE PURGATORIO OF DA N T E Translated into Spenserian Prose by $C$. GORDON WRIGHT. With the Italian text. Fcap. 8zio. 2s. 6d. net.

See also Little Library, Toynbee (Paget), and Vernon (Hon. W. Warren).

Darley (George). See Little Library.

D'Arcy (R. F.), M.A. A NEW TRIGON. OMETRY FOR BEGINNERS. With numerous diagrams. $C r .8 v o$. 2s. $6 d$.

Davenport (Cyril). See Connoisseur's Library and Little Books on Art.

Davenport (James). THE WASH. BOURNE FAMILY. With is Illustra. tions and a Map. Royal 8vo. 2rs. net.
Davey (Richard). THE PAGEANT OF LONDON. With 40 Illustrations in Colour by John Fulleylove, R. I. InTzuo Volumes. Demy 8vo. 15s. net.

Davis (H. W. C.), M.A., Fellow and Tutor of Balliol College. ENGLAND UNDER THE NORMANS AND ANGEVINS: ro66-1272. With Maps and Illustrations. Demy 8vo. ios. 6d. net.

Dawson (Nelson). See Connoisseur's Library. Dawson (Mrs. Nelson). See Little Books or Art.

Deane (A. C.). See Little Library.

Deans (Storry R.). THE TRIALS OF FIV E O UEE N S: KATHARINE OF Aragon, Anne Boleyn, Mary Queen of Scots, Marie Antoinette and CaroL1NE OF BRUNSWICK. With I2 Illustrations. Demy 8vo. 1os. 6 d. net.

A Colonial Edition is also published.

Dearmer (Mabel). A CHILD'S LIFE OF CHRIST. With 8 Illustrations in Colour by E. Fortescue-Brickdale. Large $C r$. 8vo. $6 s$.

Delbos(Leon). THE METRIC SYSTEM. Cr. 8vo. 2s.

Demosthenes. AGAINST CONON AND CALLICLES. Edited by F. DARWIN SwiFt, M.A. Second Edition. Fcap. 8vo. 25 .

Dickens (Charles). See Little Library, I. P.L., and Chesterton (G. K.).

Dickinson (Emily). POEMS. Cr. $8 v 0$. 45. $6 d$. net.

Dickinson (G. L.), M.A., Fellow of King's College, Cambridge. THE GREEK VIEIV OF LIFE, Sixth Edition. $\mathrm{Cr}$. 8vo. 2s. $6 d$.

Dilke (Lady), Bulley (Miss), and Whitley (MIss). WOMEN'S WORK. Cr. 8vo. 2s. $6 d$.

Dillon (Edward), M.A. See Connoisseur's Library and Litıle Books on Art.

Ditchfield (P. M.), M.A., F.S.A. THE STORY OF OUR ENGLISH TOWNS. With an Introduction by Augustus Jessopr, D.D. Second Edition. Cr.8vo. 6s. OLD ENGLISH CUSTOMS: Extant at the Present Time. Cr. 8vo. $6 s$.

ENGLISH VILLAGES. With Ioo Illustra. tions. Second Edition. Cr. 8vo. 2s. 6d, net

THE PARISH CLERK. With 3I Illustrations. Third Edition. Demy8vo. $7 s, 6 d$. net.

Dixon (W. M.), M.A. A PRIMER OF TENNYSON. Second Edition. Cr. 8 vo. 2s. $6 d$.

ENGLISH POETRY FROM BLAKE TO BROWNING. Second Edition. Cr. $8 v 0$. 2s. $6 d$.

Dobbs (W. J.), M.A. See Textbooks of Science.

Doney (May). SONGS OF THE REAL. Cr. 82io. 35. 6d. net.

Douglas (Hugh A.). VENICE ON FOOT. With the ltinerary of the Grand Canal. With 75 Illustrations and II Maps. Fcap. 8vo. 5s. net. 
Douglas (James). THE MAN IN THE PULPIT. Cr. 8vo. 2s, 6d. net.

Dowden (J.) D.D., Lord Bishop of Edin. burgh. FURTHER STUDIES IN THE PRAYER BOOK. Cr. $8 v o$. $6 s$.

See also Churchman's Library.

Drage (G.). See Books on Business.

Draper (F. W. M.). See Simplified French Texts.

Driver (S. R.), D.D., D.C.L., Regius Professor of Hebrew in the University of Oxford. SERMONS ON SUBJECTS CONNECTED WITH THE OLD TESTAMENT. Cr. 8vo. 6s.

See also Westminster Commentaries.

Dry (Wakeling). See Iittle Guides.

Dryhurst (A. R.). See Little Books on Art.

Du Buisson (J. C. ), M.A. See Churchman's Bible.

Duguid (Charles). See Books on Business.

Dumas (Alexandre). THE CRIMES OF THE BORGIAS AND OTHERS. With an Introduction by R. S. GARNETT. With g Illustrations. Cr. 8vo. $6 s$.

THE CRIMES OF URPAIN GRAN DIER AND OTHERS. With 8 Illustrations. Cr. $8 \%$. $6 s$.

THE CRIMIES OF THE MAROUISE DE BRINVILLIERS AND OTHERS. With 8 Illustrations. Cr. 8vo. $6 s$.

THE CRIMES OF ALI PACHA AND OTHERS. With 8 Illustrations. Cr. 8vo. $6 s$.

Colonial Editions are also published.

MY MEMOIRS. Translated by E. M. WALLER. With an Introduction by ANDREW LANG. With Frontispieces in Photogravure. In six Volumes. Cr. 8vo. 6s. cach volume. A Colonial Edition is also published.

VOL. I. $1802-1821$. VOL. III. $1826-1830$. VOL. II. $1822-1825$. VOL. IV. $1830-183 x$.

Duncan(David), D.Sc., LL.D. THE LIFE AND LETTERS OF HERBERT SPENCER. With 5 Illustrations. Demy 8vo. $\mathrm{Y} 5 \mathrm{~s}$.

Dunn (J. T)., D.Sc., and Mundella (V. A.). GENERAL ELENENTARY SCIENCE. With II4 Illustrations. Second Edition. Cr. 8vo. 3s. 6 d.

Dunstan (A. E.), B.Sc. (Lond.), East Ham Technical College. See Textbooks of Science, and Junior School Books.

Durham (The Earl of ). A REPORT ON CANADA. With an Introductory Note. Demy 8vo. 4s. 6d. net.

Dutt(W. A.). THE NORFOLK BROADS. With coloured Illustrations by FRANk Southgate, R.B.A. Second Edition. Cr. 8vo. 6s.

WILD LIFE IN EAST ANGLIA. With I6 Illustrations in colour by FrANK SOUTH. Gate, R.B.A. Second Edition. Demy 8vo. 7s. $6 d$. net.

SOME LITERARY ASSOCIATIONS OF EAST ANGLIA. With 16 Illustrations in Colour by W. Dexter, R.B.A., and 16 other Illustrations. Demy 8vo. ros. 6 d. net. See also Little Guides.
Earle (John), Bishop of Salishury. MICRO. COSMOGRAPHIE, OR A PIECE OF THE WORLD DISCOVERED. Post I6mo. 2s. net.

Edmonds (Major J. E.), R.E.; D.A.Q.-M.G. See Wood (W. Birkbeck)

Edwards (Clement), M.P. RAILWAY NATIONALIZATION. Second Edition, Revised. Cronen 8vo. 2s. 6d. net.

Edwards (W. Douglas). See Commercial Series.

Edwardes (Tickner). THE LORE OF THE HONEV BEE. With many Illustra. tions. $\mathrm{Cr} .8 v 0.6 s$.

Egan (Pierce). See I.P.L.

Egerton (H. E.), M.A. A HISTORY OF BRITISH COLONIAL POLICY. A Cheaper Issue, with a supplementary chapter. Second Ed., Revised. Demy 8vo. 7s.6d. net. A Colonial Edition is also published.

Ellaby (C. G.). See Little Guides.

Ellerton (F. G.). See Stone (S. J.).

Epictetus. See Aurelius (Marcus).

Erasmus. A Book called in Latin EN. CHIRIDION MILITIS CHRISTIANI, and in English the Manual of the Christian Knight. Fcap. 8vo. $3^{5.6}$ d. net.

Ewald (Carl). TWO LEGS, AND OTHER STORIES. Translated from the Danish by Alexander Teixeira DE Mattos. Illustrated by Augusta Guest. Large $C r$. $8 v 0.6 s$.

Fairbrother (W. H.), M.A. THE PHILO. SOPHY OF T. H. GREEN. Second Edition. Cr. 8vo. 3s. $6 d$.

Fea (Allan). SOME BEAUTIES OF THE SEVENTEENTH CENTURY. With 82 Illustrations. Second Edition. Demy 8vo. 12s. 6d. net.

THE FLIGHT OF THE KING, With over 70 Sketches and Photographs by the Author. New and revised Edition. Demy 8vo, 7s. 6d. net.

A Colonial Edition is also published.

SECRET CHAMBERS AND HIDING PLACES. With 80 Illustrations. New and revised Edition. Demy $8 v 0$. 7s. 6d. net. A Colonial Edition is also published.

Ferrier (Susan). See Little Library.

Fidler (T. Claxton), M.Inst. C.E. See Books on Business.

Fielding (Henry). See Standard Library.

Finn (S.W.), M.A. See Junior Examination Series.

Firth (J. B.). See Little Guides.

Firth (C. H.), M.A., Regius Professor of Modern History at Oxford. CROM. WELL'S ARMY: A History of the English Soldier during the Civil Wars, the Commonwealth, and the Protectorate. Cr. $8 v o$. $6 s$.

Firth (Edith E.). See Beginner's Books.

FitzGerald (Edward). THE RUBÁlYÁT OF OMAR KHAYYÁM. Printed from the Fifth and last Edition. With a Commentary by Mrs. STEPhen BATson, and a Biography of Omar by E. D. Ross. Cr. 8vo. 6s. See also Miniature Library. 
FltzGerald (H. P.). A CONCISE HAND. BOOK OF CLIMBERS, TIVINERS, AND WALL SHRUBS. Illustrated. Fcap. 8vo. 3s. 6d. net.

Fitzpatrick (S. A. O.). See Ancient Cities.

Flecker (W. H.), M.A., D.C. L., Headmaster of the Dean Close School, Cheltenham. THE STUDENT'S PRAYER BOOK. The Text of Morning and Evening Prayer and Litany. With an Introduc. tion and Notes. Cr. 8vo. 2s. $6 d$.

Fletcher (J. S.). A BOOK OF YORK. SHIRE. With r6 Illustrations in Colour by Wal PAGet and Frank Southgate, R.B.A., and $x_{2}$ from Photographs. Demy 8vo. 7s. 6t. net.

A Colonial Edition is also published.

Flux (A. W.), M.A., William Dow Professor of Political Economy in M'Gill University, Montreal. ECONOMIC PRINCIPLES. Demy 8vo. $7 s .6 d_{\text {. net. }}$

Foat (F. W. G.), D.Litt., M.A., Assistant Master at the City of London School. LONDON : A READER FOR YOUNG CITIZENS. With Plans and Illustrations. $C r .8 v 0$. Is. $6 d$.

Ford (H. G.) iI. Assistant Master at Bristol Grammar School. See Junior Schoo! Books.

Forel (A.). THE SENSES OF INSECTS. Translated by MACLEOD YEARSLEY. With 2 Illustrations. Demy 8vo. ros. 6d. net.

Fortescue (Mrs. G.). See Little Books on Art.

Fraser (J. F.). ROUND THE WORLD ON A WHEEL. With roo Illustrations. Fifth Edition Cr. 8vo. $6 s$.

A Colonial Edition is also published.

French(W.), M.A. See Textbooks of Science.

Freudenreich (Ed. von). DAIRY BACTERIOLOGY. A Short Manual for Students. Translated by J. R. Alnsworth Davis, M.A. Second Edition, Revised. Cr. 8ro. $25.6 d$.

Fulford (H. W.), M.A. See Churchman's Bible.

Fuller(W. P.), M.A. See Simplified French Texts.

*Frvie (John). TRAGEDY OUEENS OF THEGEORGIAN ERA. With I6 Illustrations. Second Ed. Demy 8vo. r2s.6d.net.

Gallaher (D.) and Stead (W. J.). THE COMPLETE RUGBY FOOTBALLER, ON THE NEW ZEALAND SYSTEM. With 35 Illustrations. Second Ed. Demy 8vo. Ios. 6 d. net.

A Colonial Edition is also published.

Gallichan (W. M.). See Little Guides.

Gambado (Geoffrey, Esq.). See I.P.L.

Gaskell (Mrs.). See Little Library, Standard Library and Sixpenny Novels.

Gasquet, the Right Rev. Abbot, O.S.B. See Antiquary's Books.

George(H.B.), M.A., Fellow of New College, Oxford. BATTLES OF ENGLISH HISTORY. With numerous Plans. Fourth Edition. Cr. 8vo. 3s. 6 d.

A HISTORICAL GEOGRAPHY OF THE
BRITISH EMIPIRE. Third Edition. Cr. 8vo, 3s. 6d.

Gibbins (H. de B.), Litt.D., M.A. IN. DUSTRY IN ENGLAND : HISTORI. CAL OUTLINES. With 5 Maps. Fifth Edition. Demy 8vo. ros. 6d.

THE INDUSTRIAL HISTORY OF ENGLAND. With Maps and Plans. Fifteenth Edition, Revised. Cr. 87o. 3s.

ENGLISH SOCIAL REFORMERS. Second Edition. Cr. 87\%o. 2s. 6d.

See also Hadfield (R. A.)., and Commercial Series.

Gibbon (Edward). MEMOIRS OF MY LIFE AND WRITINGS. Edited by G. BIRKBECK HILL, LL.D Cr. 8vo, 6s.

THE DECLINE AND FALL OF THE ROMAN EMPIRE. Edited, with Notes, Appendices, and Maps, by J. B. Bury, M.A., Litt.D., Regius Professor of Greek at Cambridge. In Seven Volumes. Demy 8vo. Gilt top. 8s. 6d. each. Also, Crown 8vo. 6s, each.

See also Standard Library.

Gibbs (Philip). THE ROMANCE OF GEORGE VILLIERS : FIRST DUKE OF BUCKINGHAMI, AND SOME MEN AND WOMEN OF THE STUART COURT. With 20 Illustrations. Second Edition. Demy 8vo. r5s, nct.

A Colonial Edition is also published.

Gibson (E. C. S.), D.D., Lord Bishop of Gloucester. See Westminster Commentaries, Handbooks of Theology, and Oxford Biographies.

Gilbert (A. R.). See Little Books on Art.

Gloag (M. R.) and Wyatt (Kate M.). A BOOK OF ENGLISH GARDENS. With 24 Illustrations in Colour. Demy 8vo. ros. $6 d$. net.

Godfrey (Elizabeth). A BOOK OF RE. MEMBRA NCE. Being Lyrical Selections for every day in the Year. Arranged by. Fcap. 8vo. 2s. 6d. net.

ENGLISH CHILDREN IN THE OLDEN TIME. With 32 Illustrations. Second Edition. Demy 8vo. 7s. 6d. net.

Godley (A. D.), M.A., Fellow of Magdalen College, Oxford. LYRA FRIVOLA. Fourth Edition. Fcap. 8vo. 2s. 6d.

VERSES TO ORDER. Second Edition. Fcap. 8vo. 2s. 6d.

SECOND STRINGS. Fcat. 8vo, 2s, 6d. Goldsmith (Oliver). THE VICAR OF WAKEFIELD. With ro Plates in Photogravure by Tony Johannot. Leather, Fcap. $32 m o$. 2s. 6d. net.

See also I.P.L. and Standard Library.

Gomme (G. L.). See Antiquary's Bnoks.

Goodrich-Freer (A.). IN A SYRIAN SADDLE. Demy 8vo. 7s. 6d. nct.

A Colonial Edition is also published.

Gorst (Rt. Hon. Sir John). THE CHIL. DREN OF THE NATION, Secona? Edition. Demy 8vo. 7s. 6i. net.

Goudge (H. L.), M.A., Principal of Wells 'Theological College. See Westminster Commentaries. 
Graham (P. Anderson). THE RURAL EXODUS. The Problem of the Village and the Town. Cr. 8vo. 2s. 6d.

Granger (F. S.), M.A., Litt.D. PSYCHOLOGY. Third Edition. Cr. 8vo. 2s. $6 d$.

THE SOUL OF A CHRISTIAN. Cr. 8vo. 6s.

Gray (E. M'Queen). GERMAN PASSAGES FOR UNSEEN TRANSLATION. $C r$. 8vo. $2 s .6 d$.

Gray $(P$. L.) B.Sc. THE PRINCIPLES OH MAGNE'TISM AND ELECTRICITY. With I8I Diagrams. Cr. 8vo. 3s. $6 \mathrm{~d}$.

Green (G. Buckland), M.A., late Fellow of St. John's College, Oxon. NOTES ON GREEK AND LATIN SYNTAX. Second Ed. revised. Crown 8vo. $35.6 d$.

Greenidge (A.H.J.), M.A., D.Litt. A HISTORYOF ROME: From the Tribunate of Tiberius Graccbus to the end of the Jugurthine War, B.c. 133-104. Demy 8vo. ros. 6 d. net.

Greenwell (Dora). See Miniature Library.

Gregory (R. A.). THE VAULT OF HEAVEN. A Popular Introduction to Astronomy. Illustrated. $C r .8 v o$. 2s. $6 d$. Gregory (Miss E. C.). See Library of Devotion.

Grubb (H. C.). See Textbooks of Technology. Hadfield (R. A.) and Gibbins (H. de B). A SHORTER WORKING DAY. Cr. 8vo. 2s. 6 d.

Hall (Mary). A WOMAN'S TREK FROM THE CAPE TO CAIRO. With 64 Illustrations and 2 Maps. Second Edition. Deny 8 vo. 16 s. net.

Hall (R. N.) and Neal (W. G.). THE ANCIENT RUINS OF RHODESIA. Illustrated. Second Edition, revised. Demy 8vo. Ios. 6 d. net. A Colonial Edition is also published.

HaIl (R. N.). GREAT ZIMBABWE. With numerous Plans and Illustrations. Second Edition. Demy 8vo. Ios. 6d.net.

Hamel (Frank). FAMOUS FRENCH S A L O N S. With 20 Illustrations. Demy 8vo. 12s. 6d. net.

A Colonial Edition is also published.

Mamilton (F. J.), D.D. See Byzantine Texts.

Hannay (D.). A SHORT HISTORY OF THE ROYAL NAVY, 1200-1688. Illustrated. Demy 8zio. 7s. $6 d$.

Hannay (James O.), M.A. THE SPIRIT AND ORIGIN OF CHRISTIAN MONASTICISM. Cr.8vo. $6 s$.

THE WISDOM OF THEDESERT. Fcap. 8vo. 3s. 6 d. net.

Hardie (Martin). See Connoisseur's Library.

Hare (A. T.), M.A. THE CONSTRUCTION OF LARGEINDUCTION COILS. With numerous Diagrams. Demy 8vo. $6 s$.

Harvey (AIfred), M.B. See Ancient Cities and Antiquary's Books.

Hawthorne(Nathaniel). See Little Library.

Heath (Frank R.). See Little Guides.

Heath (Dudley). See Connoisseur's Library. Hello (Ernest). STUDIES IN SAINT. SHIP. Ficap 8vo. $3^{s, 6 d .}$
Henderson (B. W.), Fellow of Exeter College, Oxford. 'THE LIFE AND PRINCIPATE OF THE EMPEROR NERO. Illustrated. Neze and cheaper issue. Demy 8vo. 7s. 6R. net.

AT INTERVALS. Fcap 8vo. 2s. 6d. net.

Henderson (M. Sturge). GEORGE MEREDITH : NOVELIST, POET, REFORMER. With a Portrait in Photogravure. Second Edition. Crown 8vo. 6 s.

Henderson (T. F.). See Little Library and Oxford Biographies.

Henderson (T. F.), and Watt (Francis). SCOTLAND OF TO.DAY. With 20 Illustrations in colour and 24 other Illustrations. Second Edition. Cr. 8vo. 6s. A Colonial Edition is also published.

Henley (W. E.). ENGLISH LYRICS. CHAUCER TO POE, 1340-1849. Second Edition. Cr. 8vo. 2s. 6\%. net.

Henley (IV. E.) and Whibley 'C.) A BOOK OF ENGLISH PROSE, CHARACTER, AND INCIDENT, $1387 \cdot 1649$. Cr. 820. 2s. 6 d. net.

Henson (H.H.), B.D. Canon of Westminster. LIGHT AND LEAVEN : HISTORICAL and Social Sermons. Cr. 8vo. $6 s$.

Herbert (George). See Library of Devotion.

Herbert of Cherbury (Lord). See Miniature Library.

Hewins (W. A. S.), B.A. ENGLISH TRADE AND FINANCE IN THE SEVENTEENTH CENTURY. Cr.8vo. 2s. $6 d$.

Hewitt (Ethel M.) A GOLDEN DIAL. A Day Book of Prose and Verse. Fcap. 8vo. 2s. 6d. net.

Hey (H.), Inspector, Surrey Education Committee, and Rose (G. H.), City and Guilds Woodwork Teacher. THE MANUAL TRAINING CLASSROOM: WOODWORK. Book I. 4to. Is.

Heywood (W.). PALIO AND PONTE. A Book of Tuscan Games. Illustrated. Royal 8vo. 2is. net.

See also St. Francis of Assisi.

Hill (Clare). See Textbooks of Technology.

Hill (Henry), B.A., Headmaster of the Boy's High School, Worcester, Cape Colony. A SOUTH AFRICAN ARITHMETIC. Cr. 8vo. 3s. 6d.

Hind (C. Lewis). DAYS IN CORNWALL. IVith 16 Illustrations in Colour by WiLliam PAsCoE, and 20 other Illustrations and a Map. Second Edition. Cr. 8vo. 6s.

Hirst (F, IV.) See Books on Business.

Hoare (J. Douglas). A HISTORY OF ARCTIC EXPLORATION. With 20 Illustrations \& Maps. Demy8vo. 7s. 6d. net. Hobhouse (L. T.), late Fellow of C.C.C., Oxford. THE THEORY OF KNOW: LEDGE. Deny 8vo. ros. 6d. net.

Hobson(J. A.), M.A. INTERNATIONAL TRADE: A Study of Economic Principles. Cr. 8vo. 2s. 6 d. net.

PROBLEMS OF POVERTY. An Inquiry into the Industrial Condition of the Poor. Sixth Edition. Cr. 8vo. 2s. 6d. 


\section{General Literature}

THE PROBLEM OF THE UNEM. PLOYED. Third Edition. Cr.8vo. 25. Od.

Hodgetts (E. A. Brayley). THE COURT OF RUSSIA IN THE NINETEENTH CENTURY. With 20 Illustrations. Two Volumes. Demy 8vo. 24s. net. A Colonial Edition is also published.

Hodgkin (T.), D.C.L. See I.eaders of Religion.

Hodgson (Mrs. W.) HOW TO IDENTIFY OLD CHINESE PORCELAIN. With 40 Illustrations. Second Edition. Post8vo. 6s. Hogg (Thomas Jefferson). SHELLEY AT OXFORD. With an Introduction by R. A. Streatfeil. Foap. 8vo. 2s, net.

Holden-Stone (G. de). See Books on Business.

Holdich (Sir T. H.), K.C.I.E. THE INDIAN BORDERLAND: being a Personal Record of Twenty Years. Illustrated. Demy 8vo. Ios. 6d. nct.

A Colonial Edition is also published.

Holdsworth (IV. S.), M.A. A HISTORY OF ENGLISH LAW. Iı Two Volumes. Vol. I. Denzy 8vo. ios. 6d. net.

Holland (H. Scott), Canon of St. Paul's. See Newman (J. H.).

Hollway-Calthrop (H. C.), late of Balliol College, Oxford ; Bursar of Eton College. PETRARCH : HIS LIFE, WORK, AND TIMES. With 24 Illustrations. Demy 8vo. 12s. 6d. net.

A Colonial Edition is also published.

Holt (Emily). THE SECRET OF POPULARITY: How to Achieve Social Success. Cr. 8vo. 3s. 6d. net.

A Colonial Edition is also published.

Holyoake (G.J.). THE CO-OPERATIVE MOVEMENT OF TO-DAY. Fourth Ed. Cr. 8vo. 2s. 6 .

Hone (Nathaniel J.). See Antiquary's Books.

Hook (A.) H U M A I T Y AND ITS PROBLEMS. Cr. $8 v 0$. 5s. net.

Hoppner. See Little Galleries.

Horace. See Classical Translations.

Horsburgh (E. L. S.), M.A. WATERLOO With Plans. Second Edition. Cr. 8vo. $5^{s}$ See also Oxford Biographies.

Horth (A. C.). See Textbooks of Technology.

Horton(R. F.), D.D. See Leaders of Religion

Hosie (Alexander). MANCHURIA. With Illustrations and a Map. Sccond Edition. Demy 8vo. 7s. 6d. net.

A Colonial Edition is also published.

How (F. D.). SIX GREAT SCHOOL MASTERS. With Portraits and Illustrations. Second Edition. Denyy 8vo. 7s. 6d.

Howell (A. G. Ferrers). FRANCISCAN DAYS. Being Selections for every day in the year from ancient Franciscan writings. Cr. 8vo. 3s. 6d. net.

Howell (G.). TRADE UNIONISMI-NEW AND OLD, Fourth Edition. Cr. 8vo. 2s. $6 d$.

Huggins (Sir William), K.C.B., O.M., D.C.L. F.R.S. THE ROYAL SOC1ETY. With 25 Illustrations. Wide Royal $8 v 0$. 4s. 6 d. net.
Hughes (C. E.). THE PRAISE OF SHAKESPEARE. An English Antho. logy. With a Preface by Sidney Lez. Demy 8vo. 3s. 6it. net.

Huglies (Thomas). 'TOM BROIWN'S SCHOOLDAYS. With an Introduction and Notes by Vernon Rendall. Leather. Royal $32 m 0.2 s .6 d$. nct.

Hutchinson (Horace G.) THE NEI FOREST. Illustrated in colour with 50 Pictures by WALTER TYNDALE and 4 by LuCV KEMP.WELCH. Third Edition. Cr. 8vo. 6s.

Hutton (A. W.), M.A. See Leaders of Religion and Library of Devotion.

Hutton (Edward). THE CITIES OF UMBRIA. With 20 Illustrations in Colour by A. PISA, and 12 other Illustrations. Third Edition. Cr, 8vo. $6 s$.

A Colonial Edition is also published.

THE CITIES OF SPAIN. With 24 Illus. trations in Colour, by A. W. RIMINGTON, 20 other Illustrations and a Map. Second Edition. Cr. 8vo. 6s.

A Colonial Edition is also published.

FLORENCE AND THE CITIES OF NORTHERN T USCA NY, WITH GENOA. With 16 Illustrations in Colour by WILLIAM PARKINSON, and 16 other Illustrations. Second Edition. Cr. 8vo. 6s. A Colonial Edition is also published.

ENGLISH LOVE POEMS. Edited with an Introduction. Fcap. 8vo. 3s. 6d. net.

Hutton (R. H.). See Leaders of Religion.

Hutton (W. H.), M.A. THE LIFE OF SIR THOMAS MIORE. With Portraits after Drawings by HoLBEIN. Second Ed. Cr. 8vo. $5^{s}$.

See also Leaders of Religion.

Hyde (A. G.) GEORGE HERBERT AND HIS TIN1ES. With 32 Illustrations. Demy 8vo. Ios. 6d. net.

Hyett (F. A.). FLORENCE : HER HISTORY AND ART to THE FALL OF THE REPUBLIC. Demy 8vo. 7s. 6d. net.

Ibsen (Henrik). BRAND. A Drama. Translated by WILLIAM WILSON. Third Edition. Cr. 87io. $35.6 d$.

Inge (W. R.), M.A., Fellow and Tutor of Hertford College, Oxford. CHRISTIAN MYSTICISM. (The Banipton Lectures of 1899.) Deny 8vo. 12s. 6d. net.

See alsoLibrary of Devotion.

Ingham (B. P.). See Simplified French Texts.

Innes(A. D.), M.A. A HISTORY OF THE BRITISH IN INDIA. With Maps and Plans. Cr. 8ro. $6 s$.

ENGLAND UNDER THE TUDORS. With Maps, Second Edition. Demy $8 v 0$. Ios. 6 d. net.

Jackson (C.E.), B.A., Senior Physics Master, Bradford Grammar School. See Textbooks of Science.

Jackson (S.), M.A. See Commercial Series. Jackson (F., Hamilton). See Little Guides. Jacob (F.), M.A. See Junior Examination Series. 
James (W. H. N.). See Brooks (E. E.).

Jeans (J. Stephen). TRUSTS, POOLS, AND CORNERS AS AFFECTING COMMERCE AND INDUSTRY. $C r$. $8 v 0$. 2s. $6 d$.

See also Books on Business.

Jebb (Camilla). A STAR OF THE SALONS: JUL1E DE LESPINASSE. With zo Illustrations. Denzy $8 v 0$. Ios. $6 d$. net. A Colonial Edition is also published.

Jeffery (Reginald W.), M.A. THE THIRTEEN COLONIES OF NORTH AIIERICA. With 8 lllustrations and a Map. Demy 8vo. 7s. 6d. net.

A Colonial Edition is also published

Jeffreys (D. Gwyn). DOLLY'S THEATRI. CALS. Super Royal 16mo. 2s. 6d.

Jenks(E.) M.A. B.C.L. AN OUTLINE OFENGIISH LOCAL GOVERNMENT Second Ed. Revised by R. C. K. ENSOR, M.A. Cr. 8vo. 2s. $6 d$.

Jenner (Mrs. H.). See Little Books on Art.

Jennings (Oscar), M.D. EARLY WOOD CUT INITIALS. Demy 4 to. $2 \mathrm{r} s$. net.

Jessopp (Augustus), D.D. See Leaders of Religion.

Jevons (F. B.), M.A., Litt.D., Principal of Hatfield Hall. Durbam. RELIGION IN EVOIUTION, Cr. 8vo. 3s. 6d. net. See also Churcbman's Library and Handbooks of Theology.

Johnson(Mrs. Barham). WILLIAM BOD. HAM DONNE AND HIS FRIENDS. Illustrated. Demy 8vo. ros. 6d. net.

Johnston (Sir H. H.), K.C.B. BRITISH CENTRAL AFRICA. With nearly 200 Illustrations and Six Maps. Third Edition. Cr. 4 to. 18 s. net.

A Colonial Edition is also published.

Jones (H.). See Commercial Series.

Jones (H. F.). See Textbooks of Science.

Jones (L. A. Atherley), K.C., M.P., and Bellot (Hugh H. L.), M.A., D.C.L. THE MINER'S GUIDE TO THE COAL MINES REGULATION ACTS AND THE LAIV OF EMPLOYERS AND WORKMIEN, $C r .8 v o$. 2s. 6d. net.

COMIMERCE IN WAR. Royal 8ro. 2 Is. net.

Jones (R. Compton), M.A. POEMS Ol THE INNER LIFE. Selected by. Thir teenth Edition. Fcap. 8vo. 2s. 6d. net.

Jonson (Ben). See Standard Library.

Juliana (Lady) of Norwich. REVELATIONSOF DIVINE LOVE. Ed.by GRACE IVARRACK. Second Ed. Cr. 8vo. 3s.6d.

Juvenal. See Classical Translations.

'Kappa.' LET YOUTH BUT KNOW : A Plea for Reason in Education. Cr. 8vo. $3^{s .6} 6$. net.

Kaufmann (M.), M.A. SOCIALISM AND MODERN THOUGHT. Second Edition Revised and Enlarged. $C r .8 v 0.25 .6 d$. net.

Keating (J. F.), D.D. THE AGAPÉ AND THE EUCHARIST. $C r .8 v o .3^{s .} 6 d$.

Keats (John). THE POEMIS. Edited with Introduction and Notes by E. de SELINCOURT, M.A. With a Frontispiece in
Photogravure. Second Edition Revised. Demy 8vo. 7s. 6d. net.

REALMS OF GOLD. Selections from the Works of. Ficap. 8vo. 3s. 6d. net.

See also Little Library and Standard Library.

Keble (John). THE CHRISTIAN YEAR. With an Introduction and Notes by WV. Lock, D.D., Warden of Keble College. Illustrated by R. AnNing Bell. Third Edition. Ficap. $8 \% 0$. $3 s .6 d$.; padded moroceo, 5 s. See also Library of Devotion.

Kelynack (T. N.), M.D., M.R.C.P. THE DRINK PROBLEM IN ITS MEDICOSOCIOLOGICAL ASPECT. By four. teen Medical Authorities. Edited by. teen Memy 8vo. 7s.6d. net. Kempis (Thomas a). THE IMITATION OF CHRIST. With an Introduction by DEAN Farrar. Illustrated by C. M. GERE. Third Edition. Fcap.8vo. 3s.6d.; padded morocco. 5 s.

Also Translated by C. BigG, D.D. Cr. 8vo. $35.6 \%$.

See also Montmorency (J. E. G. de). Library of Devotion, and Standard Library. Kennedy (Bart.). THE GREEN SPHINX. Cr. 8vo. 3s. 6d. net.

Kennedy (James Houghton), D.D., Assist ant Lecturer in Divinity in the University of Dublin. ST. PAUL'S SECOND ANI THIRD EPISTLES TO THE CORIN. THIANS. With Introduction, Dissertations and Notes. $\mathrm{Cr}$. 8vo. $6 s$.

Klmmins (C. W.), M.A. THE CHEMISTRY OF LIFE AND HEALTH. Illustrated. $\mathrm{Cr}$. 8\%o. 2s. $6 \pi$.

Kinglake (A. W.). See Little Library.

Kipling (Rudyard). BARRACK-ROOM BALLADS. 83\% Thousand. Twentyfourth Edition. Cr. 8vo. 6s. Also Leather. Fip. 8vo. 5s.

A Colonial Edition is also published.

THE SEVEN SEAS. 70 th Thousernd. Thirteenth Edition. Cr.8vo. 6s. Also Leather. Ficap. 8vo. 5 s.

A Colonial Edition is also published.

'THE FIVE NATIONS. 6and Thousant. Foturth Edition. Cr. 8vo. 6s. Also Leather. Fcaf.8vo. 5 s.

A Colonial Edition is also published.

DEPARTMIENTAL DITTIES. Sixteenth Edition. Cr. 8vo. 6s. Also Leather. Feap. 8vo. 5.

A Colonial Edition is also published.

Knight (Albert E.). THE COMPLETE CRICKETER. With 5o Illustrations. Demy 8vo. 7s. 6d. net.

A Colonial Edition is also published.

Knight (H. J. C.), B.D. See Churchman's Bible.

Knowling (R. J.), M.A., Professor of New Testament Exegesis at King's College, London. See Westminster Commentaries.

Lamb (Charles and Mary), THE WORKS. Edited by E. V. LuCAS. Illustrated. In Seven Volumes. Demy 8vo. 7s. 6d. each. See also Little Library and Lucas (E. V.). 


\section{General Literature}

Lambert (F. A. H.). See Little Guides.

Lambros (Professor S. P.). See Byzantine Texts.

Lane $=$ Poole (Stanley). A HISTORY OF EGYPT IN THE MIDDLE AGES. Fully Illustrated. $\mathrm{Cr}$. 8vo. $6 s$.

Langbridge(F.), M.A. BALLADSOF THE BRAVE: Poems of Chivalry, Enterprise, Courage, and Constancy. Third Edition. Cr. 8vo. 2s. $6 d$.

Law (William). See Library of Devotion and Standard Library.

Leach (Henry). THE DUKE OF DEVONSHIRE. A Biography. With r Illustrations. Demy 8vo. 12s. 6d. net.

THE SPIRIT OF THE LINKS. Cr. 8vo.6s. A Colonial Edition is also published. See also Braid (James).

Le Braz (Anatole). THE LAND OF PARDONS. Translated by FrANCES M. Gostling. With 12 lllustrations in Colour by T. C. Goтch, and 40 other lllustrations. Second Edition. Crown 8vo. 6s.

Lee (Captain L. Melville). A HISTORY OF POLICE $1 \mathrm{~N}$ ENGIAND. Cr. 8vo. 3s. 6 d. net.

Lewes (V. B.), M.A. AIR AND WATER. Illustrated. Cr. 8vo. 2s. $6 d$.

Lewis (B. M. Gwyn). A CONCISE HANDBOOK OF GARDEN SHRUBS. With 20 Illustrations. Fcap. 8vo. $3 s .6 d$. net.

Lisle (Fortunfede). See Little Bookson Art.

Littlehales (H.). See Antiquary's Books.

Lock (Walter), D.D., Warden of Keble College. ST. PAUL, THE MASTER. BUILDER. Second Ed. Cr. 8vo. 3s. 6d.

THE BIBLE AND CHRISTIAN LIFE. Cr. 8vo. 6s.

See also Keble (J.) and Leaders of Religion.

Locker (F.). See Little Library.

Lodge (Sir oliver), F.R.S. THE SUB. SIANCE OF FAITH ALLIED WITH SCIENCE: A Catechism for Parents and Teachers. Ninth Ed. Cr.8vo. 2s. net.

Lofthouse (W. F.), M.A. ETHICS AND ATONEMENT. With a Frontispiece. Demy 8vo. 5s. net.

Longfellow (H. W.). See Little Library.

Lorimer (George Horace). LETTERS FROM A SELF-MADE MERCHANT TO HIS SON. Sixteenth Edition. Cr. 8ro. 3s. $6 d$.

A Colonial Edition is also published.

OLD GORGON GRAHAMI. Second Edition. Cr. 8vo. 6s.

A Colonial Edition is also published.

Lover (Samuel). See I.P.L.

E. V. L. and C. L. G. ENGLAND DAY PY DAY : Or, The Englishman's Handbook to Efficiency. 1llustrated by GRORGE MIORRow. Fourth Edition. Fcap. 4 to. Is. net.

Lucas (E. V.). THE LIFE OF CHARLES LAMB. With 28 Illustrations. Fourth and Revised Edition in One Volume. Demy 8vo. 7s. 6d. net.

A Colonial Edition is also published.
A WANDERER IN HOLLAND. With 20 Illustrations in Colour by HERBERT Marshall, 34 Illustrations after old Dutch Masters, and a Map. Eighth Edition. Cr. 8vo. 6s.

A Colonial Fdition is also published.

A WANDERER IN LONDON. With I6 Illustrations in Colour by NELson DAwson, $3^{6}$ other Illustrations and a Map. Sixth Edition. Cr. 8vo. $6 s$.

A Colonial Edition is also published.

THE OPEN ROAD : a Little Book for Wayfarers. Fourteenth Edition. Fcap. 8vo. 5s. ; India Paper, 7s. 6d.

THE'FRIFNDLY'TOWN : a Little Book for the Urbane. Fourth Edition. Fcap. 8vo. 5s.: India Paper, 7s. 6d.

FIRESIDE AND SUNSHINE. Third Edition. Ficas. 8vo. 5 s.

CHARACTER AND COMEDY. Third Edition. Fcap. 8vo. 5s.

THE GENTLEST ART. A Choice of Letters by Entertaining Hands. Fourth Edition. Fcap. 8vo. 5s.

A SWAN AND HER FRIENDS. With 24 Illustrations. Demy 8vo. 12s. 6d. net. A Colonial Edition is also published.

Lucian. See Classical Translations.

Lyde (L. W. ), M.A. See Commercial Series.

Lydon (Noel S.). See Junior School Books.

Lyttelton (Hon. Mrs. A.). WOMEN AND THEIR WORK. Cr. 8vo. 2s. $6 d$.

Macaulay (Lord). CRITICAL AND HIS. TORICAL ESSAYS. Edited by F. C. MON. TAGUE, M.A. Three Volumes. Cr. 8vo. 18 s.

M'Allen (J. E. B.), M.A. See Commercial Series.

MacCulloch (J. A.). See Churchman's Library.

MacCunn (Florence A.). MARY STUAR T. With 44 Illustrations, in cluding a Frontispiece in Photogravure. New and Cheaper Edition. Large Cr. $8 v o$. $6 s$.

See also Leaders of Religion.

McDermott (E. R.). See Books on Business. M'Dowall(A. S.). See Oxford Biographies.

Mackay (A. M.), B.A. See Churcbman's Library.

Mackenzie (W. Leslie), MI.A., M.D. D.P.H., etc. THE HEALTH OF THE SCHOÓL CHILD. Cr. 8vo. 2s. $6 d$.

Macklin (Herbert W.), M.A. See Anti. quary's Books.

M'Neile (A. H.), B.D. See Westminster Commentaries.

'MdIle Mori' (Author of). ST. CATHER. INE OF SIENA AND HER TIMES. With 28 Illustrations. Demy 8vo. 7s.6d. net.

Magnus (Laurie), MIA. A PRIMER OF WORDSWORTH. Cr. 8vo. 2s. $6 d$.

Mahaffy (J. P.), Litt.D. A HISTORY OF THE EGYPT OF THE PTOLEMIES. Fully Illustrated. Cr. 8vo. $6 s$.

Maitland (F. W.), M.A., LL.D. ROMAN CANON LAW IN THE CHURCH OF ENGLAND. Royal8io. 7s. $6 d$. 
Peel (Robert), and Minchin (H. C.), M.A. OXFORD. With 100 Illustrations in Colour. Cr. $8 v 0$. 6s.

A Colonial Edition is also published.

Peel (Sidney), late Fellow of Trinity College, Oxford, and Secretary to the Royal Commission on the Licensing Laws. PRACTICAL LICENSING REFORM. Second Edition. Cr, 8\%o. Is. 6 d.

Petrie(W.M. Flinders), D.C.L., LL.D., Pro fessor of Egyptology at University College. A HISTORY OF EGYPT. Fully Illus. trated. In sixvolumes. Cr. 8vo. 6s. each.

Vol. 1. From the EarLiest Kings to XVITH DyNaSTy. Sixth Edition.

VOL. II. THE XVIITH AND XVIIITH Dynasties. Fourth Edition.

Vol. III. XIXTH TO XXXTh Dynasties.

Vol. IV. The Egy of the Ptolemies. J. P. MAHAFFY, Litt. D.

Yol. y. Roman Egypt. J. G. Milne, M.A.

Vol. y. EGYPT IN THE MIDDLE Ages. Stanley Lane-Poole, M.A.

RELIGION AND CONSCIENCE IN ANCIENT EGYPT. Lectures delivered at University College, London. Illustrated. Cr. 8vo. 2s. $6 d$.

SYRIA AND EGYPT, FROM THE TELI EL AMARNA TABLETS. $C r .87,0.2 s, 6 d$.

EGYPTIAN TALES. Translated from the Papyri. First Series, Jvth to XIIth Dynasty. Edited by W. M. Flinders Petrie. Illustrated by Tristram Ellis. Second Edition. Cr. 8*0. 3s. 6 .

EGYPTIAN TALES. Translated from the Papyri. Second Series. xvirith to xixth Dynasty. Illustrated by Tristram Ellis. Crown 8vo. 3s. $6 \mathrm{~d}$.

EGYPTI IN DECORATIVE ART. A Course of Lectures delivered at the Roya Institution. Illustrated. Cr. 8vo. 3s. $6 d$.

Phlllips (W. A.). See Oxford Biographies.

Phillpotts (Eden). MY DEVON YEAR. With 38 Illustrations by J. LEY PEThy BRIDGE. Second and Cheaper Edition. Large Cr. 8vo. $6 s$.

UP ALONG AND DOWN ALONG. Illustrated by CLAUdE SHEPPERSON. Cr. 4 to. 5s. net.

Phythian (J. Ernest). TREES IN NA. TURE, MYTH, AND ART. With 24 Illustrations. Crown 8vo. 6s.

Plarr (Victor Q.). See School Histories.

Plato. See Standard Library.

plautus. THE CAPTIVI. Edited, with an Introduction. Textual Notes, and a Com. mentary, by W. M. LiNDSAy, Fellow of Jesus College, Oxford. Demy 8vo. Ios.6d.net.

Plowden $=$ Wardlaw (J. T.), B.A., King's College, Cambridge. See School Examina. tion Series.

Podmore (Frank). MODERN SPIRI. TUALISM. Trwo Volumes. Demy 8 vo. 21s. net.

Pollard (Alice). See Little Books on Art.

Pollard(Eliza F.). See Little Boolss on Art.

Pollock (David), M.1.N.A. See Books on Business.
Potter (M. C.), M.A., F.L.S. A N ELEMENTARY TEXT-BOOK OF AGRICULTURAL BOTANY. Illustrated. Second Edition. Cr. 8vo. 4s. $6 d$.

Power (J. O'Connor). THE MAKING OF AN ORATOR. Cr. 8vo. 6s.

Prance (G.). See Wyon (R.).

Prescott (O. L.). A BOUT MUSIC, AND WHAT IT IS MADE OF. Cr. 8vo. 3s. 6 d. net.

Price (Eleanor C.). A PRINCESS OF THE OLD WORLD. With $2 I$ Illus. trations, Demy 8vo. 12s. 6d. net.

Price (L. L.), M.A., Fellow of Oriel College, Oxon. A HISTORY OF ENGLISH POLITICAL ECONOMY FROM ADAM SMITH TO ARNOLD TOVNBEE. Fifth Edition. Cr. 8vo. 2s. 6 d.

Primrose (Deborah). A MODERN BOEOTIA. Cr. 8vo. 6s.

Protheroe (Ernest). THE DOMINION OF MAN. Geography in its Human Aspect. With 32 full-page lllustrations. Second Edition. Cr. 8vo. 2s.

Quevedo Villegas. See Miniature Library. 'Q' (A. T. Quiller Couch). THE GOLDEN POMP. A PROCESSION OF ENGlish Lyrics from SURREY to SHIR LEv. Second and Cheaper Edition. Cr. $8 v o$. 2s. 6 d. net.

G. R. and E. S. MR. WOODHOUSE'S CORRESPONDENCE. $\mathrm{Cr}, 8 v 0$. $6 s$.

A Colonial Edition is also published.

Rackham (R. B.), M.A. See Westminster Commentaries.

Ragg (Laura M.). THE WOMEN ART. ISTS OF BOLOGNA. With 20 Illustrations. Demy 8vo. 7s. 6 d. net.

Ragg (Lonsdale). B.D., Oxon. DANTE AND HIS ITALY. With 32 Illustrations. Demy $8 v 0$. I2s. 6 d. net.

Rahtz (F. J.), M.A., B.Sc., Lecturer in English at Merchant Venturers' Technical College, Bristol. HIGHER ENGLISH. Third Edition. Cr. 8vo. 3s. 6d.

Randolph (B. IV.), D.D. See Library of Devotion.

Rannie (D. W.), M.A. A STUDENT'S HISTORY OFSCOTLAND. Cr.8v0.3s. 6d

WORDSWORTH AND HIS CIRCLE With zo Illustrations. Demy 8vo. 12s. $6 d$. net.

Rashdall (Hastings), M.A., Fellow and Tutor of New College, Oxford. DOCTRINE AND DEVELOPMENT. $C r$. 8vo. $6 s$.

Raven (J. J.), D.D., F.S.A. See Antiquary's Books.

Raven-Hill (L.). See Llewellyn (Owen).

Rawstorne (Lawrence, Esq.). See I.P.L.

Raymond (Walter). See School Histories.

*Rea (Lilian). MADAME DE LA FA. YETTE. With many Illustrations. Demy 8ro. ros. 6d. net.

Real Paddy (A). See I.P.L.

Reason (W.), M.A. UNIVERSITY AND SOCIAL SETTLEMENTS. Edited by. Cr. 8vo. $2 s .6 d$. 
Redpath (H. A.), M.A., D. Litt, See Westminster Commentaries.

Rees (J. D.), C.I.E., M.P. THE REAL INDIA. Second Edition. Dcmy 8vo. ros. Gd. net.

A Colonial Edition is also published.

* Reich (Emil), Doctor Juris. IV O M A N THROUGH THE AGES. With 24 Illustrations. Two Volumes. Demy $8 v 0.21$ s, nct. A Colonial Edition is also published.

Reynolds (Sir Joshua). See little Galleries.

Rhoades (J.F.). See Simplified French Texts.

Rhodes (IV. E.). See Scbool Histories.

Rieu(H.), M.A. See Simplified French Texts.

Roberts (M. E.). See Cbanner (C. C.).

Robertson (A.), D.D., Lord Bishop of Exeter. REGNUM DEI. (The Bampton Lectures of 19or). A Ncw and Cheaper Edition. Demy 8zo. 7s.6 6 . net.

Robertson (C. Grant). M.A., Fellow of All Souls' College, Oxford. SELECT STATUTES, CASES, AND CONSTITUTIONAL DOCUMENTS, $r 660 \cdot 1832$. Denzy 8vo. ros, 6d. net.

Robertson (c. Grant) and Bartholomew (J. G.) F.R.S.E. F.R.G.S. A HIS. TORICAL AND MODERN ATLAS OF THE BRITISH EMIPIRE. Demy Quarto. 4s. 6 d. net.

Robertson(SirG.S.), K.C.S.I. CHITRAL: THE STORY OF A MiNor SIEGE. Third Edition. Illustrated. Cr.8vo. 2s.6d. net.

Robinson (A. W.), M.A. See Churchman's Bible.

Robinson (Cecilla). THE MINISTRY OF DEACONESSES. With an Introduction by the late Archbishop of Canterbury. Cr. 8vo. 3s. $6 d$.

Robinson (F. S.). See Connoisseur's Library.

Rochefoucauld (La). See Little Library.

Rodwell (G.), B.A. NEW TEST-IMENT GREEK. A Course for Beginners. With a Preface by WALter Lock, D.D., Warden of Keble College. Fcap. 8\%o. 3s, $6 \mathrm{~d}$.

Roe (Fred). OLD OAK FURNITURE. With many Illustrations by the Author, including a frontispiece in colour. Second Edition. Demy 8vo. 10s. fd. net.

Rogers (A. G. L.), M.A. See Books on Business.

Romney (George). See Little Galleries.

Roscoe (E. S.). See Little Guides.

Rose (Edward). THE ROSE READER. Illustrated. $C r$. 8vo. 2s. $6 d$. Also in 4 Parts. Parts 1. and II. 6d. each; Part III. 8d.; Part IV. rod.

Rose (G. H.). See Hey (H.)., and Baring Gould (S).

Rowntree (Joshua). THE IMPERIAL DRUG TRADE. A RE-STATEMENT OF THE OPIUM QUESTION. Third Edition Revised. Cr. 8vo. 2s. net.

Royde-Smith (N. G.). THE PILLOW BOOK: A GARNER OF MANY MOODS. Collected by. Second Edition. Cr. 8vo. 4s. 6d. net.

POETS OF OUR DAY. Selected, with an Introduction, by. Fcap. 8vo. 5s.
Rubie (A. E.), D.D. See Junior School Books.

Russell (Archlbald G. B.). See Blake (William).

Russell (w. Clark). THE LIFE OF ADMIRAI, LORD COLLINGIVOOD. With Illustrations by $F$. BRANGWYN. Fourth Edition. Cr. 8zo. 6s.

Ryley (M. Beresford). OUEENS OF THE RENAISSANCE. With 24 Illus trations. Demy 8vo. ros. 6 d. nct.

Sainsbury (Harrington), M.D., F.R.C.P. PRINCIPIA THERAPEUTICA. Denty 8vo. 7s. 6t. net.

St. Anselm. See Library of Devotion.

St. Augustine. See Library of Devotion.

St. Bernard. See Library of Devotion.

St. Cyres (Viscount). See Oxford Biographies.

St. Francis of Assisi. THE LITTLE FLOWERS OF THE GLORIOUS MESSER, AND OF HIS FRIARS. Done into English, with Notes by William HeYwood. With 40 Illustrations from Italian Painters. Demy $8 v o$. 5s. net.

See also Wheldon (F. W.), Library of Devotion and Standard Library.

St. Francis de Sales. See Library of Devotion.

'Saki' (H. Munro). REGINALD. Second Edition. Ficap. 8vo. 2s, 6d. net.

Salmon (A. L.). See Little Guides.

Sathas (C.). See Byzantine Texts.

Schmitt (John). See Byzantine Texts.

Schofield (A. T.), M.D., Hon. Phys. Freidenham Hospital. FUNCTIONAL NERVE DISEASES. Demny 8vo. 7s. 6d. net.

Scott (A. M.). WINSTON SPENCER CHURCHILL. With Portraits and lllustrations, $C r, 8 v o$. 3s. $6 \%$.

Scudamore (Cyril). See Little Guides.

Sélincourt (E. de.) See Keats (John).

Sells (V. P.), M.A. THE MECHANICS OF DAILY LIFE. Illustrated. Cr. 8vo. 2s. $6 d$.

Selous (Edmund). TOMMY SMITH'S ANIMIALS. Illustrated by G. W. ORD. Tenth Edition. Fcap. 8vo. 2s. 6 d. School Edition, xs. $6 d$.

TOMMY SMITH'S OTHER ANIMALS. Illustrated by Augusta Guest. Fourth Edition. Fcap. 8vo. 2s, 6 \%. School Edition, is. 6d.

Senter (George), B.Sc. (Lond.), Ph.D. See Textbooks of Science.

Shakespeare (William).

THE FOUR FOLIOS, $1623 ; 1632 ; 166_{4}$; r685. Each $£_{4}, 4$ s. $n e t$, or a complete set, ¿12, r2s, net.

Folios 3 and 4 are ready.

Folio 2 is nearly ready.

THE POEMS OF IVILILIAM SHAKE SPEARE. With an Introduction and Notes by Geokge IVyndham. Demy 8zo. Buckram, gilt top, ros. $6 d$.

See also Arden Shakespeare, Standard Library and Little Quarto Shakespeare. 
Sharp (A.). VICTORIAN POETS. Cr. 8vo. 2s. 62 .

Sharp (Cecil). See Baring-Gould (S.).

Sharp (Elizabeth). See Little Books on Art. Shedlock (J. S.) THE PIANOFORTE SONATA. Cr. 820.55 . 5

Shelley (Percy B.). See Standard Library.

Sheppard (H. F.), M.A. See BaringGould (S.).

Sherwell (Arthur), M.A. LIFE IN WEST LONDON. Third Edition. Cr. $8 v o$. 2s. $6 d$.

Shipley (Mary E.). AN ENGLISH CHURCH HISTORY FOR CHILD REN. With a Preface by the Bishop of Gibraltar. With Maps and Illustrations. Part I. Cr. 8vo. 2s. 6d. net.

Sichel (Walter). See Oxford Biographies.

Sidgwick (Mrs. Alfred). HOME LIFE IN GERMANY. With 16 Illustrations. Second Edition. Denty 8vo. ros. 6d. net.

A Colonial Edition is also published.

Sime (John). See Little Books on Art.

Simonson (G. A.). FRA N CESCO GUARDI. With $4 \mathrm{r}$ Plates. Imperial 4to. $\ell_{2}, 2 s$. net.

Sketchley (R. E. D.). See Little Books on Art.

Skjpton (H. P. K.). See Little Books on Art.

Sladen (Douglas). SICILY: The New Winter Resort. With over 200 Illustrations. Second Edition. Cr. 8vo. 55. net.

Small (Evan), M.A. THE EARTH. An Introduction to Physiography. Illustrated. Cr. 8vo. 2s. $6 d$.

Smallwood (M. G.). See Little Books on Art.

Smedley (F. E.). See I.P.L.

Smith (Adam). THE WEALTH OF NATIONS, Edited with an Introduction and numerous Notes by Edwin CanNan, M.A. Two volumes. Demy 8vo. 2is. met. Smith (H. Clifford). See Connoisseur's Library.

Smith (Horace and James). See Little Library.

Smith (H. Bompas), M.A. A N E W IUNIOR ARITHMETIC. Crozun 800. Without Answers, 2s. With Answers, 2s. 6d.

Smith (R. Mudie). THOUGHTS FOR THE DAY. Edited by. Fcap. 8vo. 35. 6 d. net.

Smith (Nowell C.). See Wordsworth (W).

Smith (John Thomas). A BOOK FOR A RAINY DAY : Or, Recollections of the Events of the Years 1766-1833. Edited by WILFRED WhiTten. Illustrated. Wide Demy 8vo. r2s. 6d. net.

Snell (F. J.). A BOOK OF EXMOOR. Illustrated. $\mathrm{Cr}$. 8vo. 6 s.

Snowden (C. E.). A HANDY DIGEST OF BRITISH HISTORY. Demy 8vo. 4s. $6 d$.

Sophocles. See Classical Translations.

Sornet (L. A.), and Acatos (M. J.) See Junior School Books.

South (E.Wllton), M.A. See Junior School
Southey (R.). ENGLISH SEAMEN Edited by David Hannay.

Vol. I. (Howard, Clifford, Hawkins, Drake, Cavendish). Second Edition. Cr. 8vo. 6s.

Vol. 11. (Richard Hawkins, Grenville, Essex, and Raleigh). Cr. 8vo. $6 s$.

See also Standard Library.

Spence (C. H.), M.A. See School Examination Series.

Spicer (A. Dykes), M.A. THE PAPER TRADE. A Descriptive and Historical Survey. With Diagrams and Plans. Demy 8vo. I2s. 6.t. net.

Spooner (W. A.), M.A. See Leaders of Religion.

Spragge (W. Horton), M.A. See Junior School Books.

Staley (Edgcumbe). THE GUILDS OF FLORENCE. Illustrated. Second Edition. Royal 8vo. I6s. net.

Stanbridge (J. W.), B.D. See Library of Devotion.

'Stancliffe.' GOLF DO'S AND DONT'S Second Edition. Fcap. 8vo. Is.

Stead (D. W.). See Gallaher (D.).

Stedman (A. M. M.), M.A.

INITIA LATINA : Easy Lessons on Elementary Accidence. Eleventh Edition. Fcap. 8vo. Is.

FIRST LATIN LESSONS. Eleventh Edition. Cr. 8vo. 2s.

FIRST LATIN READER. With Notes adapted to the Shorter Latin Primer and Vocabulary. Seventh Edition. I8mo. Is. $6 d$.

EASY SELECTIONS FROM CASAR. The Helvetian War, Third Edition. I 8 mo. Is.

EASY SELECTIONS FROM LIVY. The Kings of Rome. Second Edition. $18 \mathrm{mo}$ Is. 6 d.

EASY LATIN PASSAGES FOR UNSEEN TRANSLATION. Twelfth Ed. Ficap. 8vo. $15.6 d$

EXEMPLA LATINA. First Exercises in Latin Accidence. With Vocabulary. Fourth Edition. Cr. 8vo. is.

EASY LATIN EXERCISES ON THE SYNTAX OF THE SHORTER AND REVISED LATIN PRIMER. With Vocabulary. Twelfth and Cheaper Edition. Cr. 8vo. Is. 6d. KEX, 3s, net.

THE LATIN COMPOUND SENTENCE: Rules and Exercises. Second Eartion. Cr. 8vo. Is. 6\%. With Vocabulary. 2s.

NOTANDA QUAEDAM : Miscellaneous Latin Exercises on Common Rules and Idions. Fifth Edition. Fcap. 8vo. 1s.6d. With Vocabulary $2 s$, KEY, 2s, net.

LATIN VOCABULARIES FOR REPETITION: Arranged according to Subjects. Fiftecnth Edition. Fcap. 8\%o. Is. 6 d.

A VOCABULARY OF LATIN IDIOMS. 18mo. Fourth Edition. Is.

STEPS TO GREEK. Third Edition, re. visect. I 8 mo. Is. 


\section{General Literature}

A SHORTER GREEK PRIMER, Second Edition. Cr. 8vo. 1s. $6 d$.

EASY GREEK PASSAGES FOR UNSEEN TRANSLATION. Fourth Edition, re. vised. Fcap. 8vo. Is. 6d.

GREEK VOCABULARIES FOR REPETITION. Arranged according to Subjects. Fourth Edition. Fcap. 8vo. is $6 d$.

GREEK TESTAMENT SELECTIONS. For the use of Schools. With Introduction, Notes, and Vocabulary. Fourth Edition. Fcap. 8\%o. 2s. 6d.

STEPS TO FRENCH. Eighth Edition. $18 \mathrm{mo} .8 \mathrm{~d}$.

FIRST FRENCHLESSONS. Ninth Edi. tion. $\mathrm{Cr} .8 \%$. Is.

EASY FRENCH PASSAGES FOR UN. SEEN TRANSLATION. Sixth Edition. Fcap. 8\%o. rs. 6d.

EASY FRENCH EXERCISES ON ELE. MENTARY SYNTAX. With Vocabulary. Fourth Edition. Cr. 8z'o. 2s. 6d. KEY. 3s. net.

FRENCH VOCABULARIES FOR REPETITION : Arranged according to Subjects. Thirteenth Edition, Fcap. 8vo. Is, See also School Examination Series.

Steel (R. Elliott), M.A. F.C.S. THE WORLD OF SCIENCE. With I47 Illustrations, Second Edition. Cr. 8vo. 2s. 6d. See also School Examination Series.

Stephenson (C.), of the Technical College, Bradford, and Suddards (F.) of the Yorkshire College, Leeds. A TEXTBOOK DEALING WITH ORNAMENTAL DESIGN FOR WOVEN FABRICS. With 66 full-page Plates and numerous Diagrams in the Text. Third Edition. Demy 8vo. $7 s .6 d$.

Stephenson (J.), M.A. THE CHIEF TRUTHS OF THE CHRISTIAN FAITH. Cr. 8vo. $3 s .6 d$.

Sterne (Laurence). See Little Library.

Steuart (Katherine). BY A L LAN WATER. Second Edition. Cr. 8vo. 6s.

RICHARD KENNOWAY AND HIS FRIENDS. A Sequel to "By Allan Water.' Demy 8vo. 7 s. 6 d. net.

Stevenson (R.L.) THE LETTERS OF ROBERT LOUIS STEVENSON TO HIS FAMILY AND FRIENDS. Selected and Edited by Sidney Colyin. Third Edition. 2 vols. Cr. $8 v 0$. 12s.

Library Edition. 2 vols. Demy 8vo. 25s, net. A Colonial Edition is also published.

VAILIMA LETTERS. With an Etched Portrait by William Strang. Sixth Edition. Cr. 8vo. Buckram. 6s. A Colonial Edition is also published.

THE LIFE OF R. L. STEVENSON. See Balfour (G.).

Stevenson (iI. I.). FROM SARANAC TO THE MIAROUESAS. Being Letters written by Mrs. M. I. Sthvenson during 1887-8. Cr. 8vo. 6s. net.

A Colonial Edition is also published.

I.ETTERS FROM SAMOA, r891-95. Edited and arranged by M. C. BALFOUR With many Illustrations. Second Edition $\mathrm{Cr}$ 8vo. 6s. net.

A Colonial Edition is also published.

Stoddart (Anna M.). See Oxford Biographies.

Stokes (F. G.), B.A. HOURS WITH RABELAIS. From the translation of SiR T. URQuhart and P. A. Motteux. With

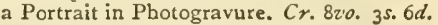
net.

Stone (S. J.). POEMIS AND HYMINS. With a Memoir by F. G. Ellerton, M.A. With Portrait. Cr. 8vo. $6 s$.

Storr (Vernon F.), M.A., Canon of Winchester. DEVELOPMENT A N D DIVINE PURPOSE Cr. 8vo. 5s. net.

Story (Alfred T.). A M E R I C A N SHRINES IN ENGLAND. With many Illustrations, including two in Colour by A. R. Quinton. Crown 8vo. 6s. See also Little Guides.

Straker (F.). See Books on Business.

Streane (A. W.), D.D. See Churchman's Bible.

Streatfeild (R. A.). MODERN MUSIC AND NUSICIANS. With 24 Illustrations. Second Edition. Demy 8vo. 7s. 6d. net.

Stroud (Henry), D.Sc., M.A. ELEMENTARY PRACTICAL PHYSICS. With II 5 Diagrams. Second Edit., revised. $4 s .6 \mathrm{~d}$.

Sturch (F.), Staff Instructor to the Surrey County Council. MANUAL TRAINING DRAWING (WOODWOR K). Wih Solutions to Examination Questions, Ortho. graphic, Isometric and Oblique Projection. With 50 Plates and 140 Figures. Foolscap. 5s. net.

Suddards (F.). See Stephenson (C.).

Surtees (R. S.). See I.P. L.

Sutherland (William). OLD AGE PEN. SIONS IN THEORY AND PRACTICE, WITH SOME FOREIGN EXAMPLES. Cr. 8zo. 3 s. 6 d. net.

Symes (J. E.), M.A. THE FRENCH REVOLUTION. Second Edition. Cr.8vo. 2s. 6 d.

Sympson (E. Mansel), M.A., M.D. See Ancient Cities.

Tabor (Margaret E.). THE SAINTS IN ART. With 20 Illustrations. Ficap. 8vo. 3s. 6 d net.

Tacitus. AGRICOLA. Edited by R. F. DAvis, M.A. Ficap. 8zo. $2 s$.

GERMIANIA. By the same Editor. Fcap. $8 v o$. $2 s$. See also Classical Translations.

Tallack (W.). HOWARD LET'TERS AND MEMORIES. Demy 8vo. Ios. 6d. net.

Tatham (Frederick). See Blake (William). Tauler (J.). See Library of Devotion.

Taylor (A. E.). THE ELEMENTS OF METAPHYSICS. Demy8ro. 10s. 6d. net.

Taylor (F. G.), M.A. See Commercial Series. Taylor (1. A.). See Oxford Biographies.

Taylor (John W.). THE COMING OF THE SAINTS. With 26 Illustrations. Demy, 8vo. 7s, 6d. net. 
Taylor (T. M.), M.A., Fellow of Gonville and Caius College. Cambridge. A CONSTITUTIONAL AND POLITICAL HISTORY OF ROME. To the Reign of Domitian. Cr. 8vo. $7 s .6 d$.

Teasdale-Buckell (G. T.). THE COM. PLETE SHOI. With 53 Illustrations. Third Edition. Demy 8v0. I2s. 6d. nct. A Colonial Edition is also published.

Tennyson (Alfred, Lord). EARLY POEMS. Edited, with Notes and an Introduction, by $\mathrm{J}$. ChuRTON Collins, M.A. Cr. 8ro. 6s.

IN MEMORIAM, MAUD, AND THE PRINCESS. Edited by J. CHURTON Collins, M.A. Cr. 8zo. $6 s$.

See also Little Library.

Terry (C.S.). See Oxford Biographies.

Thackeray (W. M.). See Little Library.

Theobald (F. V.), M.A. INSECT LIFE. Illustrated. Second Edition Revised. Cr. 8vo. 2s. $6 d$.

Thibaudeau (A. C.). BONAPARTE AND THE CONSULATE. Translated and Edited by G. K. Fortesque, LL.D. With I Illustrations. Demy $8 v 0$. Ios. $6 d$. net.

Thompson (A. H.). See Little Guides.

Thompson (A. P.). See Textbooks of Technology.

Tileston (Mary W.). DAILY STRENGTH FOR DAILY NEEDS. Fifteenth Edition. Medium 16 mo. 2s. 6d. net. Also an edition in superior binding, $6 s$.

Tompkins (H. W.), F.R.H.S. See Little Books on Art and Little Guides.

Townley (Lady Susan). MY CHINESE NOTE-BOOK With 16 Illustrations and 2 Maps. Third Ed. Demy $8 v 0$. 1os. 6 d. net A Colonial Edition is also published.

Toynbee (Paget), M.A., D. Litt. IN THE FOOTPRINTS OF DANTE. A Trea. sury of Verse and Prose from the works of Dante. Small Cr. $8 v 0$. 4s. 6 d. net. See also Oxford Biographies and Dante.

Trench (Herbert). DEIRDRE WEDDED AND OTHER POEMS. Second and Revised Edition. Large Post 8vo. 6s.

NEW POEMS. Second Edition. Large Post 8 vo. 6 s.

Trevelyan(G. M.), Fellow of Trinity College, Cambridge. ENGLAND UNDER THE STUARTS. With Maps and Plans. Third Edition. Demy 8vo. ros. 6d. net.

Troutbeck (G. E.). See Little Guides.

Tyler (E. A.), B.A., F.C.S. See Junior School Books.

Tyrrell-Gill (Frances), See Little Books on Art.

Vardon (Harry). THE COMPLETE GOLFER. With 63 Illustrations. Ninth Edition. Denzy 8vo. ros. 6 d. net. A Colonial Edition is also published.

Vaughan (Henry). See Little Library.

Vaughan (Herbert M.), B. A. (Oxon.). THE LAST OF THE ROYAL STUARTS, HENRY STUART, CARDINAL, DUKE OF YORK. With 20 Illustrations. Second Edition. Demy, 8vo. ros. 6d. net.
THE NAPLES RIVIERA. With 25 Illus. trations in Colour by MAURICE GREIFFEN. HAGEN. Second Edition. Cr. 8vo. $6 s$.

Vernon (Hon. W. Warren), M.A. READ. INGS ON THE INFER NO OF DAN'TE.

With an Introduction by the Rev. Dr. MOORE. In Two Volumes. Second Edition. Cr. 8vo. I5s. net.

READINGS ON THE PURGATORIO OF DANTE. With an Introduction by the late Dean Church, In Tzuo I olumes. Third Edition. Cr. 8vo. 15s. nct.

Vincent (J. E.). THROUGH EAST ANGLIA IN A MOTOR CAR. With I6 Illustrations in Colour by Frank South. GATE, R.B.A., and a Map. Cr. 8vo. 6s.

Voegelin (A.), M.A. See Junior Examination Series.

Waddell (Col. L. A.), LL.D., C.B. LHASA AND ITS MYSTERIES. With a Record of the Expedition of 1903-rgo4. With 155 llustrations and Maps. Third and CheaperEdition. Medium 8vo. 7s.6d, net.

Wade (G. WV.), D.D. OLD TESTAMENT HISTORY. With Maps. Fifth Edition. Cr. 8vo. 6s.

Wade (G. W.), D.D., and Wade (J. H.), M.A. See Little Guides.

Wagner (Richard), RICHARD WAGNER'S MUSIC DRAMAS : Interpreta. tions, embodying Wagner's own explanations. By Alice Leighton Ci.eather and BASIL CRUMP. In Three Volumes. Fcap 8vo. 2s. 6d. each.

Vol. 1.-The Ring of the Nibelung. Third Edition.

VOL. 11.-PARSIFAl, LOHENGRin, and The Holy Grail.

VOL. I11.-TRISTAN AND ISOLDE.

Walkley (A. B.). DRAMA AND LIFE. Cr. 8vo, 6s.

Wall (J. C.). See Antiquary's Books.

Wallace-Hadrill (F.), Second Master at Herne Bay College. REVISION NOTES ON ENGLISH HISTORY, Cr. 8vo. is.

Walters (H. B.). See Little Books on Art and Classics of Art.

Walton (F. W.). See School Histories.

Walton (Izaak) and Cotton (Charles). See I.P.L.

Walton(Izaak). See Little Library.

Waterlouse (Elizabeth). WITH THE SIMPLE-HEARTED : Little Homilies to Women in Country Places. Second Edition. Sinall Pott 8vo. 2s. net.

See also I ittle I ibrary.

Watt (Francis). See Henderson (T. F.).

Weatherhead (T. C.), M.A. EXAMINATION PAPERS IN HORACE. Cr. 8vo. $2 s$. See also Junior Examination Series.

Webber (F. C.). See Textbooks of Techno. logy.

Veir (Archibald), M.A. AN INTRODUCTION TO" THE HISTORY OF MODERN EUROPE. Cr. 8vo. 6 s.

Wells (Sldney H.) See Textbooks of Science. 


\section{General Literature}

Wells(J.), M.A., Fellow and Tutor of Wadham College. OXFORD AND OXFORD LIFE. Third Edition. $\mathrm{Cr} .8 \% 0.3 s .6 d$.

A SHORT HISTORY OF ROME. Eighth Edition. With 3 Maps. Cr. 8vo. 3s. $6 d$. See also Little Guides.

Wesley (John). See Library of Devotion.

Wheldon (F.W.). A LITTLE BROTHER TO THE BIRDS. The life-story of St. Francis retold for children. With I5 Illustrations, 7 of which are by A. H. BuckLAND. Large Cr. 8vo. $6 s$.

Whibley (C.). See Henley (W. E.).

Whibley (L.), MI.A., Fellow of Pembroke College, Cambridge. GREEK OLIGAR. CHIES: THEIR ORGANISATION AND CHARACTER. Cr. 8vo. $6 s$.

Whitaker (G. H.), M.A. See Churchman's Bible.

White (Gilbert). See Standard Library.

Whitfield (E. E.), M.A. See Commercial Series.

Whitehead (A. W.). GASPARD DE COL IGNY, ADMiRAL OF FRANCE. With Illustrations and Plans. Demy 8vo. I2s. 6d. net.

Whiteley (R. Lloyd), F.1.C., Principal of the MIunicipal Science School, West Bromwich. AN ELEMENTARY TEXT. BOOK OF INORGANIC CHEMISTRY. Cr. 8vo. 2s. 6d.

Whitley (Mlss). See Dilke (Lady).

Whitling (Miss L.), late Staff Teacher of the National Training School of Cookery. THE COMPLETE COOK. With 42 Illustrations. Demy 8vo. 7s. 6d. net. A Colonial edition is also published.

Whitten (W.). See Smith (John Thomas).

Whyte (A. G.), B.Sc. See Books on Business.

Wilberforce (Wilfrid). See Little Books on Art.

Wilde (Oscar). DE PROFUNDIS. Eleventh Edition. Cr. 8vo. 5s. net. A Colonial Edition is also published. THE WORKS.

A Uniform Edition. Demy $8 v 0$. I2s. 6d. net each volume.

THE DUCHESS OF PADUA: A Play.

POEMS.

INTENTIONS and THE SOUL OF MAN.

SA LO ME. A FLORENTINE TRAGEDY, and VERA; or, THE NIHILISTS.

LADY WINDERMERE'S FAN : A Play about a Good Woman.

A WOMAN OF NO IMPORTANCE : A Play.

AN IDEAL HUSBAND: A Play.

THE IMPORTANCE OF BEING EAR. NEST: A Trivial Comedy for Serious People.

A HOUSE OF POMEGRANATES, THE, HAPPY PRINCE, and OTHER TALES. LORD ARTHUR SAVILE'S CRIME and OTHER PROSE PIECES.

DE PROFUNDIS.

Wilkins (W, H.), P.A. THE ALIEN INVASION. Cr. 8vo. 2s. 6d.
Williams (A.). PETROL PETER: or Pretty Stories and Funny Pictures. Illus. trated in Colour by A. W. Mitls. Demy 4to. 3s. 6r. net.

Williamson (M. G.)., M.A. See Ancient Cities.

WVllliamson (W.), B.A. See Junior Ex. amination Series, Junior School Books, and Beginner's Books.

Wilmot-Buxton (E. M.). MAKERS OF EUROPE. Outlines of European History for the Middle Forms of Schools. With 12 Maps. Ninth Edition. $C \because 8 v 0$. 3s. $6 d$.

THE ANCIENT WORLD. With Maps and Illustrations. $\mathrm{Cr} .82 \%$. $35.6 \Omega$.

A BOOK OF NOBLE WOMEN. With 16 Illustrations. Cr. 8vo. 3s. $6 d$.

A HISTORY OF GREAT BRITAIN : FROM THE COMING OF THE ANGLES TO THE Year 1870. With 20 Maps. Cr. 8'o. $3^{5}$. $6 d$.

See also Beginner's Books.

Wilson(Bishop.). See Library of Devotion.

Wilson (A. J.). See Books on Business.

Wilson (H. A.). See Books on Business.

Wilson (J. A.). See Simplified French Texts.

Wilton (Richard), M.A. LYRA PASTORALIS : Songs of Nature, Church, and Home. Pott 8vo. 2s. 6d.

Winbolt (S. E.), M,A. EXERCISES IN LATIN ACCIDENCE. Cr. 8zo. Is. 6rt. LATIN HEXAMETER VERSE: An Aid to Composition. $\mathrm{Cr}$. 8vo. 3s. 6 d. $\mathrm{KEY}$, 5s. net.

Windle (B. C. A.), D.Sc., F.R.S., F.S.A. See Antiquary's Books, Little Guides, Ancient Cities, and School Histories.

Winterbotham (Canon), M.A., 13.Sc., LL.B. See Churchman's Library.

Wood (Sir Evelyn), F..M., V.C., G.C.B., G.C.G FROM MIDSHIPILAN TO FIELD-MARSHAL. With Illustrations, and 29 Maps. Fifth and Cheaper Edition. Demy 8vo. 7s. 6d. net.

A Colonial Edition is also published

Wood (J. A. E.). See Textbooks of Tecbnology.

Wood (J. hickory). DAN LENO. Illus. trated. Third Edition. Cr. 8vo. 6s.

A Colonial Edition is also published.

Wood (W. Birkbeck), M.A., late Scholar of Worcester College, Oxford, and Edmonds (Major J. E.), R.E., D.A.Q.-M.G. A HISTORY OF THE CIVIL WAR IN THE UNITED STATES. With an Introduction by H. SPENSER WILKINSON. With 24 Maps and Plans. Second Edition. Deny 8vo, I2s. 6r. net.

Wordsworth (Christopher), M.A. See Antiquary's Books.

Wordsworth (IV.). THE POEMS OF. With an Introduction and Notes by Nowell C. Smith, late Fellow of New College, Oxford. In Three Volumes. Demy 8zo. I 5s, net.

POEMS BY WILLIAM WORDSWORTH. Selected with an Introduction by STOPFOR! 
A. BROOKE. With 40 Illustrations by $\mathrm{E}$. H. NEw, including a Frontispiece in Photogravure. Cr. 8vo. 7s. 6d. net. See also Little Library.

Wordsworth (IV.) and Coleridge (S. T.). See Little Library.

Wright (Arthur), D.D., Fellow of Queen's College, Cambridge. See Churchman's Library.

Wright (C. Gordon). See Dante.

Wright (J. C.). TO-DAY. Thoughts on Life for every day. Deny i6mo. Is. 6d. net.

Wright (Sophie). GERMAN VOCABU. LARIES FOR REPETITION. Fcap. $8 v o$ is. $6 d$.

Wyatt (Kate M.). See Gloag (M. R.).

WyIde (A. B.). MODERN ABYSSINIA With a Map and a Portrait. Demy 8vo. I5s. net.

Wyllie (M. A.). NORWAY AND ITS FJORDS. With 16 Illustrations, in Colour by W. L. WYLLIE, R.A., and 17 other Illustrations, Crowen 8vo. $6 \mathrm{~s}$.

A Colonial Edition is also published.
Wyndham (George). See Shakespeare (William).

Wyon (R.) and Prance (G.). THE LAND OF THE BLACK MOUNTAIN. With 5 I Illustrations. Cr. 800 . 2s. 6 d. net.

Yeats (W. B.). A BOOK OF IRISH VERSE. Revised and Enlarged Edition. Cr. 8vo. 3s. $6 d$.

Young (Filson). T H E COM P LE T E MOTORIST. With 138 Illustrations. Neze Edition (Seventh), with many additions. Demny. 8vo. 12s.6d. net.

A Colonial Edition is also published.

THE JOY OF THE ROAD: An Appreciation of the Motor Car. With a Frontispiece in Photogravure. Small Demy 8vo. 5s. net.

Young (T. M.). TH E A M E R I C A N COTTON INDUSTRY: A Study of Work and Workers. Cr.8vo. Cloth, 2s.6d. ; paper boards, 1s. 6d.

Zimmern (Antonia). WHAT DO WVE KNOW CONCERNING ELECTRI CITY? Fcap. 8z'o. rs. 6 d. net.

\section{Ancient Cities}

General Editor, B. C. A. WINDLE, D.Sc., F.R.S.

$$
\text { Cr. 8vo. 45. 6d. net. }
$$

Chester. By B. C. A. WindIe, D.Sc. F.R.S. Lincoln. By E. Mansel Sympson, M.A., Illustrated by E. H. New.

Shrewsbury. By T. Auden, M.A., F.S.A. Illustrated by Katharine M. Roberts.

Canterbury. By J. C. Cox, LL.D., F.S.A. Illustrated by B. C. Boulter.

Edinburgh. By M. G. Williamson, M.A.

Illustrated by Herbert Railton. M.D. Illustrated by E. H. New.

Bristol. By Alfred Harvey, M.B. Illustrated by E. H. New.

Dublin. ByS.A. O. Fitzpatrick. Illustrated by W. C. Green.

\section{The Antiquary's Books}

\section{General Editor, J. CHARLES COX, LL.D., F.S.A.}

\section{Demy 8vo. 7 s. 6d. net.}

English Monastic Life. By the Right Rev. Abbot Gasquet, O.S.B. Illustrated. Third Edition.

Remains of the Prehistoric Age iN ENGland. By B. C. A. Windle, D.Sc. F.R.S. With numerous Illustrations and Plans.

Old SERVICE Books of THE ENGLish Church. By Christopher Wordsworth, M.A., and Henry Littlehales. With Coloured and other Illustrations.

Celtic Art in Pagan and Christian Times. By J. Romilly Allen, F.S.A. With numerous Illustrations and Plans.

Archeology AND False Antiquities. By R. Munro, LL.D. Illustrated.

Shrines of British Saints. By J.C. Wall. With numerous Illustrations and Plans.

The Royal, Forests of England, By J. C. Cox, LL.D., F.S.A. Illustrated.

The Manor and Manorial Records. By Nathaniel J. Hone. Illustrated.

English Seals. By J. Harvey Bloom. Illustrated.

The Bells of England. By Cation J. J. Raven, D.D., F.S.A. With Illustrations. Second Edition.

Parish Life in Medieval England. By the Right Rev. Abbott Gasquet, O.S.B. With many Illustrations. Second Edition.

The DomesDay Inouest. By Adolphus Ballard, B.A., LL.B. With 27 Illustrations.

The Brasses of England. By Herbert W. Macklin, M.A. With many Illustrations. Second Edition.

English Church Furniture. By J. C. Cox, LL.D., F.S.A., and A. Harvey, M.B. Second Edition.

Folk-Lore as an Historical Science. By G. L. Gomme. With many Illustrations.

* English Costume. By George Clinch, F. G.S. With many Illustrations. 


\section{The Arden Shakespeare}

Demy 8vo. 2s. 6d. net each volume.

An edition of Shakespeare in single Plays. Edited with a full Introduction, Textual Notes, and a Commentary at the foot of the page.

HAMLET. Edited by Edward Dowden.

ROMEO AND JULiet. Edited by Edward Dowden.

KING LEAR. Edited by W. J. Craig.

Julius Ca esar. Edited by M. Macmillan.

The Tempest. Edited by Moreton Luce.

Othello. Fdited by H. C. Hart.

Titus Andronicus. Edited by H. B. Baildon.

Cymbeline. Edited by Edward Dowden.

The Merry Wives of Windsor. Edited by H. C. Hart.

A Midsummer Night's Dream. Edited by H. Cuningham.

King HenRy V. Edited by H. A. Evans.

All's Well That EndS Well. Edited by IV. O. Brigstocke.

The Taming of the Shrew. Edited by R. Warwick Bond.

TrMoN of ATHENS. Edited by K. Deighton.
Measure for Measure. Edited by H. C. Hart.

TiWELF'TH Night. Edited by Moreton Luce. The Merchant of Venice. Edited by C. Knox Pooler.

Troilus and Cressida. Edited by $K$. Deighton.

The Two Gentlemen of Verona. Edited by $R$. Warwick Bond.

Antony and Cleopatra. Edited by R. H. Case.

Love's Labour's Lost. Edited by H. C. Hart.

Pericles. Edited by K. Deighton.

KING Richand 111. Edited by A. $H$. Thompson.

The Life AND Death of King John. Edited by Ivor B. John.

THE COMEDY OF ERRORs. Edited by Henry Cuningham.

\section{The Beginner's Books}

\section{Edited by W. WILLIAMSON, B.A.}

EAsy French Rhymes. By Henri Blonet. Easy Exercises in Arithmetic. Arranged Second Edition. Illustrated. Fcap.8vo. is. EAsy Stories from English History. By E. M. Wilmot-Buxton. Fourth Edition. Cr. 8vo. Is.

Stories from Roman History. By E. M. Wilmot-Buxton Cr. 8v0. Is. $6 d$.

A First History of GREece. By E. E. Firth. Cr. 8vo. Is. $6 d$. by W. S. Beard. Third Edition. Fcap. 8vo. Without Answers, Is. With Answers. Is. $3 d$.

Easy Dictation and Spelling. By W. Williamson, B.A. Seventh Ed. Fcap.8vo. Is.

An Easy Poetry Book. Selected and arranged by W. Williamson, B.A. Second Edition. Cr. 8vo. Is.

\section{Books on Business}

\section{Cr. 8vo. 2s. 6d. net.}

Ports And Docks. By Douglas Owen.

Railways. By E. R. McDermott.

The Stock Exchange. By Chas. Duguid. Second Edition.

The Business of Insurance. By A. J. Wilson.

THE Electrical INDUSTRY : Lighting, Traction, and Power. By A. G. Whyte, B. Sc.

THE SHIPBUILDING INDUSTRY: Its History, Practice, Science, and Finance. By David Pollock, M.I.N.A.

The Money Market. By F. Straker.

The Business Side of Agriculture. By A. G. L. Rogers, M.A.

LAw IN Business. By H. A. Wilson.

THE BREwing IndUStRy. By Julian $L$. Baker, F.I.C., F.C.S. Illustrated.

The Automobile Industry. By G. de Holden-Stone.

Mining AND Mining Investments. By 'A. Moil.'

The Business of Anvertising. By Clarence G. Moran, Barrister-at-Law, Illustrated.

Trade Unions. By G. Drage.

Civil EngineEring. By T. Claxton Fidler, M. Inst. C. E. Illustrated.

The Iron Trade of Great Brtain. By J. Stephen Jeans, Illustrated.

Monopolies, Trusts, and Kartells. By F. W. Hirst.

The Cotton Industry and Trade. Py Prof. S. J. Chapman, Dean of the Faculty of Commerce in the University of Man. chester. Illustrated. 


\section{Byzantine Texts}

Edited by J. B. BURY, M.A., Litt.D.

The SYriac Chronicle KNOWN AS THAT OF ZaCHARIAH OF MitYlene. Translated by F. J. Hamilton, D.D., and E. W. Brooks. Demy 8vo. I 2s. 6i. net.

Evagrius. Edited by L. Bidez and Léon Parmentier. Denty 8vo. 1os. 6d. net.

The History of Psellus. Edited by C. Sathas. Demy 8vo. I5s. net.

Ecthesis Chronica and Chronicon Athen. ARUM. Edited by Professor S. P. Lambros. Demy 8vo. 7s. 6d. net.

The Chronicle of Morea. Edited by John Schmitt. Demiy 8vo. 15s, net.

\section{The Churchman's Bible}

General Editor, J. H. BURN, B.D., F.R.S.E.

$$
\text { Fcap. 8vo. Is. 6d. net each. }
$$

The Epistle of St. Paul the Apostle to Isaiaf. Explained by W. E. Barnes, D.D. THE Galatians. Explained by A. W. Two Volumes. With Map. 2s. net each.

Robinson, M.A. Second Edition.

Ecclesiastes. Explained by A. W. Streane, D. D.

The Epistle of St. Paul the Apostle to THE Ephesians. Explained by G. H. Whitaker, MI.A.

The Epistle of St. Paul the Apostle to The Philjppians. Explained by C, R, D. Biggs, D.D. Second Edition.

The Epistle of St. James. Explained by H. W. Fulford M.A.

The Gospel, According to St. Mark. Explained by J. C. Du Buisson, M.A. 2s. 6 d. net.

The Epistle of Paul the Apostle to the Colossians and Philemon. Explained by H. J. C. Knight. 2s. net.

\section{The Churchman's Library}

General Editor, J. H. BURN, B.D., F.R.S.E.

Crown 8vo. 3s. 6d. each.

The Beginnings of English Christianity. | Evolution. By F. B. Jevons, M.A., Litt.D. By W. E. Collins, M.A. With Map.

THE KingDom DF HEAVEN HERE AND HERE. AFTER. By Canon Winterbotham, M.A., B. Sc., LL.P.

THE WORKMANSHIP OF THE PRAYER BOOK : Its Literary and Liturgical Aspects. By J. Dowden, D.D. Second Edition, Revised and Enlarged.

Some New Testament Problems, By Arthur Wright, D.D. $6 s$.

The Churchman's Introduction to The Old Testament. By A. M. Mackay, B.A. Third Edition.

Comparative Theology. By J. A. Mac. Culloch. $6 s$.

\section{Classical Translations}

\section{Crown svo.}

Escuylus - The Oresteian Trilogy (Agamem- Horace-The Odes and Epodes. Translated non, Choëpboroe, Eumenides). Translated by Lewis Campbell, LI.D. 5 s.

CiCERo-De Oratore I. Translated by E. N. P. Moor, M.A. Second Edition. 3s. $6 d$.

CiCEro-The Speeches against Cataline and Antony and for Murena and Milo. Trans. lated by H. E. D. Blakiston, M.A. 5 s.

C1CERO-De Natura Deorum. Translated by F. Brooks, M.A. 3s. $6 d$.

Cicero-De Officiis. Translated by G. B. Gardiner, M.A. $2 s .6 d$. by A. D. Godley, M.A. $2 s$.

LuCran-Six Dialogues Translated by S. T. Irwin, M.A. 3s. 6 .

SorHocles-Ajax and Electra. Translated by E. D. Morshead, M.A. $2 s .6 d$.

TAcitus-Agricola and Germania. Trans. lated by R. B. Townshend. 2s. $6 \mathrm{~d}$.

JUVENAL-Tbirteen Satires. Translated by S. G. Owen, M.A. $2 s .6 d$.

\section{Classics of Art}

Edited by Dr. J. H. W. LAING

The Art of the Greeks. By H. B. Walters. VelazQuez. By A. de Beruete. With 94 With II Plates and I Illustrations in the Plates. Wide Royal $8 v 0$. 10s. 6 d. net.

Text. Wide Royal 8zo. 12s. 6d. net. 


\section{GENERAL LiteraturE}

\section{Commercial Series}

\section{Crown Svo.}

British Commerce and Colonies from a Short Commercial Arithmetic. By F. Elizabeth to Victoria. By H. de B. G. Taylor, M.A. Fiourth Edition. is. 6d. Gibbins, Litt.D., M.A. Third Edition. 2s. French CoMmercial Correspondence. liy

Commercial Examination Papers. By H. de B. Gibbins, Litt.D., M.A. Is. 6 d.

The Economics of Commerce, By H. de B. Gibbins, Litt.D., M.A. Second Edition. Is. $6 d$.

A German Commercial Reader. By S. E. Bally. With Vocabulary. 2s.

A Commercial Geography of the British Empire. By L. W. Lyde, M.A. Sixth Edition. 2s.

a Commercial Geography of Foreign Nations. By F. C. Boon, B.A. $2 s$.

A Primer of Business. By S. Jackson, M.A. Fourth Edition. 1s. 6d.
S. E. Bally. With Vocabulary. Third Edition. 2s.

German Commercial Correspondence. By S. E. Bally. With Vocabulary. Second Edition. 2s, 6 .

A French Commercial Reader. By S. F. Bally. With Vocabulary. Second Edition. 2s.

Precis Writing and Office Correspond. ENCE. By E. E. Whitfield, M.A. Second Edition. 25 .

A Entrance Guide to Professions and Business. By H. Jones, $1 s .6 d$.

The Principles of Book-keeping by Douhi.r Entry. By J. F. B. M'Allen, M.A. $2 s$.

Commercial Law. By W. Douglas Edwards. Second Edition. $2 s$.

\section{The Connoisseur's Library}

\section{Wide Royal 8vo. 25 s. net.} Mezzotints. By Cyril Davenport. Witn 40
Plates in Photogravure.

Porcrlain. By Edward Dillon. With ig Plates in Colour, 20 in Collotype, and 5 in Photogravure.

Miniatures. By Dudley Heath. With 9 Plates in Colour, ${ }_{5}$ in Collotype, and ${ }_{5}$ in Photogravure.

Ivories. By A. Maskell. With 80 Plates in Collotype and Photogravure.

ENGlish Furniture. BY F. S. Robinson. With I60 Plates in Collotype and one in Photogravure. Second Edition.

ENGLISH Col.oured Books. By Martin Hardie. With 28 Illustrations in Colour and Collotype.

\section{The Illustrated Pocket Library of Plain and Coloured Books Fcap 8vo. 3s. 6d. net each volume. \\ COLOURED BOOKS}

Old Coloured Books. By George Paston. With 16 Coloured Plates. Fcap.8vo. 2s. net.

The Life and Death of John Mrtton, EsQ. By Nimrod. With I8 Coloured Plates by Henry Alken and T. J. Rawlins. Fourth Edition.

The Life of a Sportsman. By Nimrod. With 35 Coloured Plates by Henry Alken.

Handley Cross. By R. S. Surtees. With I7 Coloured Plates and roo Woodcuts in the Text by John Leech. Second Edition.

Mr. Sponge's Sporting Tour. By R. S. Surtees. With 13 Coloured Plates and 9o Woodcuts in the Text by John Leech.

JorRoCks' Jaunts AND Jollities. By R. S. Surtees. With I5 Coloured Plates by $\mathrm{H}$. Alken. Second Edition.

Ask Mamma. By R. S. Surtees. With I3 Coloured Plates and 70 Woodcuts in the Text by John Leech.
The Analysis of the Hunting Fizld. By R. S. Surtees. With 7 Coloured Plates by Henry Alken, and 43 Illustrations on Wood. THE TOUR OF DR. SyNTAX IN SEARCh OF the Picturesque By William Combe. With 30 Coloured Plates by T. Rowlandson. The Tour of Doctor Syntax in Search of Consolation. By Villiam Combe. With 24 Coloured Plates by T. Rowlandson. The THIRD TOuR OF Doctor Syntax in Search of a Wife. By William Combe. With 24 Coloured Plates by T. Rowlandson.

The History of Johnny Quae Genus: the Little Foundling of the late Dr. Syntax. By the Author of 'The Three Tours.' With 24 Coloured Plates by Rowlandson.

ThE ENGLISH DANCE OF DEATH, from the Designs of $\mathrm{T}$. Rowlandson, with Metrical Illustrations by the Author of 'Doctor Syntax.' Two Volumes.

This book contains 76 Coloured Plates. 
Illustrated Pocket Library of Plain and Coloured Books-continued.

Tie Dance of Life: A Poem. By the Author of 'Doctor Syntax.' Illustrated with 26 Coloured Engravings by T. Rowlandson.

LifE IN London: or, the Day and Night Scenes of Jerry Hawthorn, Esq., and his Elegant Friend, Corinthian Tom. By Pierce Egan. With 36 Coloured Plates by I. R. and G. Cruikshank. With numerous Designs on Wood.

Real Life in London: or, the Rambles and Adventures of Bob Tallyho, Esq., and his Cousin, The Hon. 'Tom Dashall. By an Amateur (Pierce Egan). With ${ }_{3}$ Coloured Plates by Alken and Rowlandson, etc. Two Volumes.

The Life of An Actor. By Pierce Egan. With 27 Coloured Plates by Theodore Lane, and several Designs on Wood.

The Vicar of Wakefield. By Oliver Goldsmith. With ${ }_{24}$ Coloured Plates by T. Row. landson.

The Military Adventures of Johnny Newcome. By an Officer. With ${ }_{5}$ Coloured Plates by $\mathrm{T}$. Rowlandson.

The National Sports of Great Britain. With Descriptions and 50 Coloured Plates by Henry Alken.

The Adventures of a Post Captain. By A Naval Officer. IVith 24 Coloured Plates by Mr. Williams.

Gamonia : or the Art of Preserving Game; and an Improved Method of making Plantations and Covers, explained and illustrated by Lawrence Rawstorne, Esq. With I5 $_{5}$ Coloured Plates by T. Rawlins.

An Academy for Grown Horsemen: Containing the completest Instructions for Walking, Trotting, Cantering, Galloping, Stumbling, and Tumbling. Illustrated with 27 Coloured Plates, and adorned with a Portrait of the Author. By Geoffrey Gambado, Esq.

Real LifF in IRELAND, or, the Day and Night Scenes of Brian Boru, Esq., and his Elegant Friend, Sir Shawn O'Dogherty. By a Real Paddy. With $x$ Coloured Plates by Heath, Marks, etc.

ThI Adventures of JoHnNy Newcome in THE Navy. By Alfred Burton. With $x 6$ Coloured Plates by T. Rowlandson.

The Old English Squire: A Poem. By John Careless, Esq. With 20 Coloured Plates after the style of T. Rowlandson.

ThE English Spy. By Bernard Blackmantle. An original Work, Characteristic, Satirical, Humorous, comprising scenes and sketches in every Rank of Society, being Portraits of the Illustrious, Eminent, Eccentric, and Notorious. With 72 Coloured Plates by R. Cruikshank, and many Illustrations on wood. Two Volumes. 7s. net.

\section{PLAIN BOOKS}

The Grave: A Poem. By Robert Blair. Illustrated by I2 Etchings executed by Louis Schiavonetti from the original Inventions of William Blake. With an Engraved Title Page and a Portrait of Blake by T. Phillips, R.A.

The illustrations are reproduced in photogravure.

ILlustrations of tTE BoOK OF Job. In. vented and engraved by Willianı Blake.

These famous Illustrations $-2 \mathrm{I}$ in number -are reproduced in photogravure.

Windsor Castle. By W. Harrison Ainsworth. With 22 Plates and 87 Woodcuts in the Text by George Cruikshank.

The Tower of London. By IV. Harrison Ainsworth. With 40 Plates and 58 Woodcuts in the Text by George Cruikshank.

Frank Fairlegh. By F. E. Smedley. With 3o Plates by George Cruikshank.

Handy ANDy. By Samuel Lover. With 24 Illustrations by the Author.

The Compleat Angler. By Izaak Walton and Charles Cotton. With $\mathrm{r}_{4}$ Plates and 77 Woodcuts in the Text.

The Pickwick Papers. By Charles Dickens. With the 43 Illustrations by Seymour and Phiz, the two Buss Plates, and the 32 Con. temporary Onwhyn Plates.

\section{Junior Examination Series}

\section{Edited by A. M. M. STEDMAN, M.A. Fcap. 8vo. Is.}

Junior French Examination Papers. By Junior latin Examination Papers. By C. F. Jacob, M.A. Second Edition.

Junior English Examination Papers. By W. Williamson, B.A.

Junior Arithmetic Examination Papers. By W. S. Beard. Fourth Edition.

Junior Algebra Examination Papers. By S. W Finn, M.A.

Junior Grerk Examination Papers. By T. C. Weatherhead, M.A. KEY, $3 s .6 d$. net. G. Botting, B.A. Fifth Edition. KEY, 35. 6 d. net.

Junior General. Information Examination PAPERs. By IV. S. Beard. KEY, 3s. 6 d. net.

Junior Geography Examination Papers. By W. G. Baker, M.A

Junior German Examination Papers. By A. Voegelin, M.A. 


\section{General Literature}

\section{Methuen's Junior School-Books}

Edited by O. D. INSKIP, LL.D., and W. WILLIAMSON, B.A.

A Class.Book of Dictation Passages. By W. Williamson, B.A. Fourteenth Edition. Cr. 8vo. Is. 6 d.

The Gospel According to St. Matthew. Edited by E. Wilton South, M.A. With Three Maps. Cr. 8vo. 1s. 6 $t$.

The Gospel According to St. Mark. Edited by A. E. Rubie, D.D. With Three Maps. Cr. 8vo. 1s. 6d.

A Junior English Grammar. By W. William. son, B.A. With numerous passages for parsing and analysis, and a chapter on Essay Writing. Fourth Edition. Cr. 8vo. 2s.

A Junior Chemistry. By E. A. Tyler, B.A., F.C.S. With 78 Illustrations. Fourth Edi. tion. Cr. 8vo. 2s. $6 d$.

THE ACTS OF THE APOSTLES. Edited by A. E. Rubie, D.D. Cr. 8vo. 25 .

A Junior French Grammar. By L. A. Sornet and M. J. Acatos. Second Edition. Cr. 8vo. 25 .

Elementary Experimental Science. Physics by W. T. Clough, A.R.C.S. Chemistky by A. E. Dunstan, B.Sc. With 2 Plates and
I54 Diagrams. Sixth Edition. Cr. 8vo. 2s. $6 d$.

A Junior Geometry. By Noel S. Lydon. With 276 Diagrams. Sixth Edition. Cr. $8 \approx 0.2 s$.

Elementary Expenimental Chemistry. By A. E. Dunstan, B.Sc. With 4 Plates and Iog Diagrams. Third Edition. C\%. 8\%०. $2 s$.

A Junior French Prose. By R. R. N. Baron, M.A. ThirdEdition. Cr.8vo, 2s.

The Gospel According To ST. LukE. With an Introduction and Notes by William Williamson, B.A. With Three Maps. Cr. 8vo. 2s.

The First Book of Kings. Edited by A. E. Rubie, D.D. With Maps. Cr. 8vo. 2s.

A Junior Greek History. By iV. H. Spragge, M.A. With 4 Illustrations and 5 Maps. Cr. 8vo. 2s. $6 d$.

a School latin Gramar. By H. G. Ford, M.A. Cr. 800 . 2s. $6 d$.

A Junior latin Prose. By H. N. Asman, M.A., B.D. Cr. 8vo. 2s. $6 d$.

\section{Leaders of Religion}

Edited by H. C. BEECHING, M.A., Canon of Westminster. With Portraits. Cr. 8vo. 2s, net.

Cardinal Newman, By R. H. Hutton. John Wesley. By J. H. Overton, M.A.

Bishop Wilberforce. By G. W. Daniell, M.A.

Cardinal Manning. By A. W. Hutton, M.A.

Charles Simeon. By H. C. G. Moule, D.D. JoHN KNox. By F. MacCunn. Second Edition. John Howe. By R. F. Horton, D.D.

Thomas Ken. By F. A. Clarke, M.A.

GEORGE Fox, THR QUAKER. By T. Hodgkin, D.C.L. Third Edition.

JoHN KEBLE. By Walter Lock, D.D.

Thomas Chalmers. By Mrs. Oliphant.

LANCELOT ANDREWES. By R. L. Ottley, D.D. Second Edition.

Augustine of Canterbury. By E. L. Cutts, D.D.

William Laud. By W. H. Hutton, M.A. Third Edition.

John Donne. By Augustus Jessopp, D.D.

Thomas Cranmer. By. A. J. Mason, D.D.

Bishop Latimer. By R. M. Carlyle and $A$. J. Carlyle, M.A.

Bishop Butler. By W. A. Spooner, M.A.

\section{The Library of Devotion}

With Introductions and (where necessary) Notes.

Small Pott 8vo, cloth, $2 s$.; leather, $2 s .6 d$. net.

The Confessions of St. Augustine. Edited by C. Bigg, D.D. Sixth Eutition.

THE IMITATION OF CHRIST : called also the Ecclesiastical Music. Edited by C. Bigg, D.D. Fifth Edition.

THE CHRISTIAN YEAR. Edited by Walter Lock, D.D. Fourth Edition.

LYRA INNOCENTIUM. Edited by Walter Lock, D.D. Second Edition.

THE TEMPLE. Edited by E. C. S. Gibson, D.D. Second Edition.

A Book of Devotions. Edited by J. W. Stanbridge. B.D. Second Edition.

a Serious Call to a Devout and Holy LIFE. Edited by C. Pigg, D.D. Fourth Ed.

A Guide to ETERnity. Edited by J. W. Stanbridge, B.D.
The Inner Way. By J. Tauler. Edited by A. W. Hutton, M.A.

ON THE LOVE OF GOD, By St. Francis de Sales, Edited by W. J. Knox-Little, M.A.

The Psalms of David. Edited by B. W. Randolph, D.D.

Lyra Apostolica. By Cardinal Newman and others. Edited by Canon Scott Holland, M.A., and Canon H. C. Beeching, M.A.

The Song of Songs. Edited by B. Blaxland, M.A.

The Thoughts of Pascal. Edited by $C$. S. Jerram, M.A.

A Manual of Consolation prom thp SaInts and Fathers. Edited by $J$. $H$. Burn, L.D. 
The Library of Devotron-continued.

The Devotions of St. Anselm. Edited by C. C. J. Webb, M.A.

Grace Abounding to the Chief of SinNERS. By John Bunyan. Edited by S. C. Freer, M.A.

Bishop Wilson's Sacra Privata. Edited by A. E. Burn, B.D.

LYRA SACra: A Book of Sacred Verse. Edited by Canon H. C. Beeching, M.A. Second Edition, revised.

A Day Book From the Saints and Fathers. Edited by J. H. Burn, B.D.

A LitTle Book of Heavenly Wisdom. A Selection from the English Mystics. Edited by E. C. Gregory.

LIGHT, LIFE, and Love. A Selection from the German Mystics. Edited by W. R.Inge, M.A.

An Introduction to The Devout Life. By St. Francis de Sales. Translated and Edited by T. Barns, M.A.

The LitTle Flowrrs of the Glorious Messer St. Francis and of his Friars. Done into English by W. Heywood. With an Introduction by A. G. Ferrers Howell.

Manchester al Mondo: a Contemplation of Death and Immortality. By Henry Montagu, Earl of Manchester. With an Introduction by Elizabeth Waterhouse, Fditor of "A Little Book of Life and Death.'

The Spiritual Guide, which Disentangles the Soul and brings it by the Inward Way to the Fruition of Perfect Contemplation, and the Rich Treasure of Internal Peace. Written by Dr. Michael de Molinos, Priest. Translated from the Italian copy, printed at Venice, 1685 . Edited with an Introduction by Kathleen Lyttelton. And a Note by Canon Scott Holland.

Devotions for Every DAy of THE WeEk and the Great Festivals. By John Wesley. Edited, with an Introduction by Canon C. Bodington.

Preces Private. By Lancelot Andrewes, Bishop of Winchester. Selections from the Translation by Canon F. E. Brightman. Edited, with an Introduction, by A. E. Burn, D.D.

\section{Little Books on Art}

With many Illustrations. Demy I6mo. 2s. 6d. net.

Each volume consists of about 200 pages, and contains from 30 to 40 Illustrations, including a Frontispiece in Photogravure.

Greek Art. H. B. Walters. Fourth Edition. Hoppner. H. P. K. Skipton.

BOOK PLATES. E. Almack.

REYNoLdS. J. Sime. Second Edition.

ROMNEY. George Paston.

WATTS. R. E. D. Sketchley.

Leighton. Alice Corkran. Gilbert.

Greuze And Boucher. Eliza F. Pollard.

VANDYCK. M. G. Smallwood.

TURNER. Frances Tyrrell-Gill.

DÜrER, Jessie Allen.

Holbein. Mrs. G. Fortescue.

Burne-Jones. Fortuné de Lisle. Third
Edition.

Rembrandt. Mrs. E. A. Sharp.

COROT. Alice Pollard and Ethel Birnstingl.

RAPHAEL. A. R. Dryhurst.

Millete. Netta Peacock.

ILLUMINATED MSS. J. W. Bradley.

JEWEllery. Cyril Davenport.

Claude. E. Dillon.

The Arts of Japan. E. Dillon.

ENamels. Mrs. Nelson Dawson.

Miniatures. C. Davenport.

\section{The Little Galleries}

Demy i6mo. 2s. 6 d. net.

Each volume contains 20 plates in Photogravure, together with a short outline of the life and work of the master to whom the book is devoted.
A Little Gallery of Reynolds.
A Little Gallery of Romney.
A Little Gallery of Millais.
A Little Gallery of Hoppner.
A Little Gallery of English Pokts.

\section{The Little Guides}

With many Illustrations by E. H. NEW and other artists, and from photographs. Small Polt 8vo, cloth, 2s. 6d. net.; leather, 3s. 6d. net.

The main features of these Guides are ( 1 ) a handy and charming form ; $(2)$ illustrationsfrom photographs and by well-known artists ; (3) good plans and maps; (4) an 
adequate but compact presentation of evcrything that is interesting in the natural features, history, archæology, and architecture of the town or district treated.

Cambridge and its Colleges. By A. Hertfordshire. by H. W. Tompkins, Hamilton Thompson. Second Edition.

OxFord AND its Colleges. By J. Wells, M.A. Eighth Edition.

St. Paul's Cathedral. By George Clinch. WestMinster Agbey. By G. E. Troutbeck. Second Edition.

The English Lakes. By F. G. Brabant, M.A. The Malyern Country. By B. C. A. Windle, D.Sc., F.R.S.

SHAKespeare's Country. By B. C. A. Windle, D.Sc., F.R.S. Third Edition.

NORTh WALES. By A. T. Story.

Buckinghamshire, By L. S. Roscoe.

Cheshire. By W. M. Gallichan.

Cornwal.t. By A. L. Salmon.

Derbyshire. By J. Cbarles Cox, LL.D., F.S.A.

Devon. By S. Baring-Gould.

Dorset. By Frank R. Heatb. Second Ed.

Hampsire. By J. C. Cox, LL.D., F.S.A. Sicily. By F. Hamilton Jackson.

\section{F.R.H.S.}

THE ISLE OF WIGHT. By G. Clinch.

Kent. By G. Clincb.

Kerry. By C. P. Crane.

Middeesex. By John B. Firth.

NORFOLK. By W. A. DutL.

NoRThAMPTONSHIRE. By Wakeling Dry.

OXFORDSHIRE. By F. G. Brabant, M.A.

Somerset. By G. W. and J. H. Wade.

SUFFOLK. By W. A. Dutt.

SURREY. By F. A. H. Lambert.

Sussex. By F. G. Brabant, M.A. Second Edition.

The EAst Riding of Yorkshire. By J. E. Morris.

TheNorth Riding of Yorkshire. By J. E. Morris.

Brittany. By S. Baring-Gould.

Normandy. By C. Scudamore.

Rome By C. G. Ellaby.

\section{The Little Library}

With Introductions, Notes, and Photogravure Frontispieces.

Small Pott 8vo. Each Volume, cloth, Is. 6d. net; leather, 2s. 6d. net.

Anon. A LITTLE BOOK OF ENGLISH | Craik (Mrs.). J O H N H A L I F A X, LYRICS.

Austen (Jane). PRIDE AND PREJUDICE. Edited by E. V. LuCAS. T wo Vols.

NORTHANGER ABBEY. Edited by E. V. LUCAS.

Bacon(Francis). THE ESSAYS OF LORD BACON. Edited by EDWARD WRIGHT.

Barham (R. H.). THE INGOLDSBY LEGENDS. Edited by J. B. AtLAy. Two Volumes.

Barnett (Mrs. P. A.). A LITTLE BOOK OF ENGLISH PROSE. Second Edition. Beckford (William). THE HISTORY OF THE CALIPH VATHEK. Edited by E. DENISON Ross.

Blake (WVilliam). SELECTIONS FROM W I L L I A II B L A K E. Edited by M. PERUGINI.

Borrow (George). LAVENGRO. Edited by F. HINDES GROOME. Two lolumes.

THE ROMANY RYE. Edited by JоHN SAMPSON.

Browning (Robert). S E L E C T I O N S FROM THE EARLY POEMS OF ROBERT BROWNING. Edited by W. HALL GRJFFIN, M.A.

Canning (George). SELECTIONS FROM THE ANTI-JACOBIN : with GEORGE CANNING's additional Poems. Edited by LLOVD SANDERS.

Cowley (Abraham). THE ESSAYS OF ABRAHAM COWLEY. Edited by H. C. Minchin.

Crabbe (George). SELECTIONS FRON GEORGE CRABBE. Edited by A. C. DEANE. GENTLEMAN. Edited by ANNiE MATHESON. Two Volumes.

Crashaw (Richard). THE ENGLISH POEMS OF RICHARD CRASHAW. Edited by Edyard Hutton.

Dante (Alighieri). THE INFERNO OF DAN'TE. 'Translated by H. F. CARY. Edited by Paget ToynbeE, M.A., D. Litt.

THE PURGATORIO OF DANTE. Translated by $\mathrm{H}$. F. CARY. Edited by PAGET TOYNBEE, M.A., D. Litt.

THE PARADISO OF DANTE. Trans lated by H. F. CARY. Edited by PAGET ToynbeE, M. A., D. Litt.

Darley (George). SELECTIONS FROM THE POEMS OF GEORGE DARLEY. Edited by R. A. Streatfeild.

Deane (A. C.). A LITTLE BOOK OF LIGHT VERSE.

Dickens (Charles). CHRISTMIAS BOOKS. Two Volumes.

Ferrier (Susan). MARRIAGE. Edited by A. GOODRICH - FREER and LORD IDDEsLeJGH. Two Volumes.

THE INHERITANCE. Tzuo Volumes.

Gaskell (Mrs.). CRANFORD. Edited by E. V. LuCAS. Second Edition.

Hawthorne (Nathaniel). THESCARLET LETTER. Ediled by PERCY DEARMER.

Henderson (T. F.). A LITTLE BOOK OF SCOTTISH VERSE.

Keats (John). POEMS. With an Introduction by L. BinYon, and Notes by J. MASEFIELD.

Kinglake (A. W.). EOTHEN. With an Introduction and Notes. Second Edition.

[Continued. 
The LitTLE LiBrary-continued.

Lamb (Charles). ELIA, AND THE LAST ESSAYS OF ELIA. Edited by E. V. LUCAS

Locker(F.). LONDON LYRICS Edited by A. D. Godlev, M.A. A reprint of the First Edition.

Longfellow (H. W.). SELECT I O N S FROM LONGFELLOW. Edited by L. M. FaithFulL.

Marvell (Andrew). THE POEMS OF ANDREW MARVELL. Edited by E. IVRIGHT.

Milton (John). THE MINOR POEMIS OF JOHN MILTON. Edited by H. C. BEECHING, M.A., Canon of Westminster.

Moir(D. M.). MANSIE WAUCH. Edited by T. F. HENDERSON.

Nichols (J. B. B.). A LITTLE BOOK OF ENGLISH SONNETS.

Rochefoucauld (La). THE MAXIMS OF LA ROCHEFOUCAULD. Translated by Dean Stanhope. Edited by G. H. POWELL.

Smith (Horace and James). REJECTED ADDRESSES. Edited by A. D. GoDLEY, M.A.

Sterne (Laurence). A SENTIMENTAL JOURNEY. Edited by H. W. PAUl.
Tennyson (Alfred, Lord). THE EARLY POEMS OF ALFRED, LORD TENNY. SON. Edited by J. Churton Collins, M. A. I N MEMORIAM. Edited by Canon H. C. BeEching, M.A.

THE PRINCESS. Edited by Elizabeth WORDSWORTH.

MAUD. Edited by ElizabeTH Wordsworth. Thackeray (W. M.). V A N I T Y FAIR. Edited by S. GWYNN. Three Volumes.

PENDE N N IS. Edited by S. GWYNN. Three Volumes.

ESMOND. Edited by S. GWYNN.

CHRISTMAS BOOKS. Edited byS. GWYNN.

Vaughan (Henry). THE POEMS OF HENRY VAUGHAN. Edited by EDWARD HutTon,

Walton (lzaak). THE COMPLEAT ANGLER. Edited by J. BUCHAN.

Waterhouse (Elizabeth). A LITTLE BOOK OF LIFE AND DEATH. Edited by. Eleventh Edition.

Wordsworth (W.). SELECTIONS FROM WORDSWORTH. Edited by NowELL C. Sмiтн.

Wordsworth (W.) and Coleridge (S. T.). LYRICAL BALLADS. Edited by GEORGE SAMPSON.

\section{The Little Quarto Shakespeare}

Edited by W. J. CRAIG. With Introductions and Notes

Pott I6mo. In 40 Volumes. Leather, price Is. net each volume. Mahogany Revolving Book Case. Ios. net.

\section{Miniature Library}

Reprints in miniature of a few interesting books which have qualities of humanity, devotıon, or literary genius.

Euphranor: A Dialogue on Youth. By/The Life of Edward, Lord Herbert of Edward FitzGerald. From the edition pub. lished by W. Pickering in 1851 . Demy $32 m o$. Leather, $2 s$. net.

Polonius: or Wise Saws and Modern Instances. By Edward FitzGerald. From the edition published by W. Pickering in 1852. Demy 32mo. Leather, 2s. net.

The RuBAivit of OMar KHAYyám. By Edward FitzGerald. From the 1st edition of 1859 , Fourth Edition. Leather, is. net.

\section{Oxford Biographies}

Fiap. 8vo. Each volume, cloth, 2s. 6d. net; leather, 3s. 6d. net.

Dante Alighieri. By Paget Toynbee, M.A., Robert Burns. By T. F. Henderson. D. Litt. With I Illustrations. Third Edition.

Girolamo Savonarola. By E. L. S. Horsburgh, M.A. With r2 Illustrations. Second Edition.

John Howard. By E. C. S. Gibson, D.D., Bishop of Gloucester. With I2 Illustrations.

Alfred Tennyson. By A. C. Penson, M.A. With 9 Illustrations. Second Edition.

Sir Walter Raleigh. By I. A. Taylor. With 12 Illustrations.

Erasmus. By E. F. H. Capey. With 12 Illustrations.

With 12 Illustrations.

Cinatham. By A. S. M'Dowall. With 12 Illustrations.

Francis of Assisi. By Anna M. Stoddart. With 6 Illustrations.

Canning. By W. Alison Phillips. With 12 Illustrations.

Beaconsfiel.d. By Walter Sichel. With 12 Illustrations.

Johann Wolfgang Goethe. By H. G. Atkins. With I6 Illustrations.

The Young Pretender. By C. S. Terry. Françors Fenelon. By Viscount St Cyres. With $x$ z Illustrations. With 12 lllustrations. 


\section{GENERAL Literature}

\section{School Examination Series}

Edited by A. M. M. STEDMAN, M.A. Cr. $8 v o$. 2s. $6 d$.

French Examination Papers. By A. M. History and Geography Examination M. Stedman, M.A. Fourtecuth Edition. $\quad$ PApers. By C. H. Spence, M.A. Third KEY. Sixth Edition. 6s. net.

Latin Examination Papers. By A. M. M. Stedman, M.A. Fourteenth Edition.

KEV. Sixth Edition. 6s. net.

Greek Examination Papers. By A. M. M. Stedman, M.A. Ninth Edition.

KEY. Fourth Edition. 6s. net.

German Examination Papers. By R. J. Morich. Seventh Edition.

KEY. Third Edition. 6s. net. Edition.

Physics Examination Papers. By R. E. Steel, M.A., F.C.S.

General Knowledge Examination PAPERS. By A. M. M. Stedman, M.A. Sixth Edition.

KEY. Fourth Edition. 7s. net.

Examination Papers in English History. By J. Tait Plowden. Wardlaw, B.A.

\section{School Histories}

Illustrated. Crown 8vo. Is. 6 d.

A School History of Warivickshire. By A School. History of Surrey. By H. E. B. C. A. Windle, D.Sc., F.R.S.

A SChool History of Somerset. By

Walter Kaymond. Second Edition.

A School History of Lancashire. By

W. E. Rhodes.

\section{Methuen's Simplified French Texts}

Edited by T. R. N. CROFTS, M.A.

\section{One Shilling each.}

L'Historre d'une Tulipe. Adapted by T. R. La Chanson de Roland. Adapted by H. N.Crofts, M.A. Second Edition.

ABDallah. Adapted by J. A. Wilson.

Le Docteur Matheus. Adapted by W. P. Fuller.

La Bouillie au Miel. Adapted by P. B. Ingham.

Jean Valjean. Adapted by F. W. M. Draper.

Rieu, M.A. Second Edition.

MÉMOIRES DE CADICHON. Adapted by J. F. Rhoades.

L'EQuipage DE LA BELLE-NIYERNAISE. Adapted by T. R. N. Crofts.

L'Histoire DE PierRe et Camille. Adapted by J. B. Patterson.

\section{Methuen's Standard Library}

Cloth, Is. net; doublevolumes, Is. 6d.net.

The Meditations of Marcus Aurelius. Translated by R. Graves.

Sense and Sensibility. Jane Austen.

Essays and Counsels and The New Atlantis. Francis Bacon, Lord Verulam.

Religio Medici and Urn Burial. Sit Thomas Browne. The text collated by A. R. Waller.

The Pilgrim's Progress. John Bunyan.

Reflections on the French Revolution. Edmund Burke.

The Poems and Songs of Robert Burns. Double Volume.

The ANalogy of Religion, Natural and REvealed. Joseph Butler.

Miscellaneous Poems. T. Chatterton.

Tom Jones. Henry Fielding. Treble Vol.

Cranford. Mrs. Gaskell.

The History of the Decline and Fall of THE ROMAN EMPIRE. F. Gibbon. Text and Notes revised by J. B. Bury. Seven double volumes.

The Case is Altered. Every Man in His Humour, Every Man Out of His Humour. Ben Jonson.
Paper, 6d. net; double volume, i s. net.

The Poemsan d Plays of Oliver Goldsmitu. Cynthia's Revels. Poetaster. Ben Jonson.

The Poems of John Keats. Double volume. The Text has been collated by $\mathrm{E}$. de Sélincourt.

ON the IMitation of Christ. By Thomas à Kempis. Translation by C. Bigg.

A Serious Call to a Devout and Holy LIFE. W. Law.

Paradise Lost. John Milton.

Eikonoklastes and THE TENURE of Kings and Magistrates. John Milton.

Utopia AND POems. Sir Thomas More.

The Republic or Plato. Translated by Sydenham and Taylor. Double Volume. Translation revised by W. H. D. Rouse.

The LitTle Flowers of St, Francis, Translated by W. Heywood.

The Works of William SHakespeare. In ro volumes.

Principal Pofms, 1815-1818. Percy Bysshe Shelley. With an Introduction by C. D. Locock.

The Life of Nelson. Robert Southey.

THE Natural Historyand ANTIQUities of SELBORNE. Gilbert White. 


\section{Textbooks of Science}

Edited by G. F. GOODCHILD, M.A., B.Sc., and G. R. MILLS, M.A. Fully Illustrated. Practical Mechanics. S. H. Wells.
Fourth Edition. Cr. 8 iro. 3s. 6d.

Practical Chemistiky. Part 1. W. French, M.A. Cr. 8vo. Fourth Edition. is. 6d.

Practical Chemistry. Part 11. W. French and T. H. Boardman. Cr. $8 v 0$. Is. $6 d$.

Examples in Physics. By C. E. Jackson, B.A. Cr. 8vo. $2 s, 6 d$.

Technical Arithmetic and Geometry. By C. T. Millis, M.I.M.E. Cr. $8 v 0$. 3s. $6 d$.

Plant Life, Studies in Garden and School. By Horace F. Jones, F.C.S. With 320 Diagrams. Cr. 8vo. 3 s. $6 d$.

The Complete School Chemistry. By F. M. Oldbam, B.A. With 126 Illustrations. Cr. 8 zo. 4 s. $6 d$.

Elementary Science for Pupil Teachers. Physics Section. By W. T. Clough,
A.R.C.S. (Lond.), F.C.S. Chemistry Section. By A. E. Dunstan, B.Sc. (Lond.), F.C.S. With 2 Plates and ro Diagrams. Cr. 8vo. 2s.

Examples in Elementary Mechanics, Practical, Graphical, and Theoretical. By W. J. Dobbs, MI.A. With 5 I Diagrams. Cr. 8vo. 5s.

Outlines of Physical Chemistry. By George Senter, B.Sc. (Lond.), Ph.D. With many Diagrams. Cr. $8 v 0$. 35. $6 d$.

AN Organic Chemistry for Schools and TEChNical Institutes. By A. E. Dunstan, B.Sc. (Lond.), F.C.S. With many Illustrations. $C r .8 v o$. 2s, $6 d$.

First Year Physics. By C. E. Jackson, M.A. With 5 I diagrams. Cr. 8vo. Is. 6 d.

\section{Textbooks of Technology}

Edited by G. F. GOODCHILD, M.A., B.Sc., and G. R. MILLS, M.A. Fully Illustrated.

How to Make a Dress. By J. A. E. Wood. Builders' Quantities. By H. C. Grubb. Fourth Edition. Cr. 8vo. Is. 6 .

Carpentry and Joinery. By F. C. Webber. Fifth Edition. Cr. 8z'0. $3^{s}$. $6 d$.

Millinery, Theoretical and Practical. By Clare Hill. Fourth Edition. Cr.8vo. 2s.

InSTRUCTION IN COOKERY. A. P. Thomson. 2s. $6 d$.

An Introduction to the Study of Textile Design. By Aldred F. Barker. Demy 8vo. 7 s. $6 d$. Cr. 8vo. 4s. 6d.

Répoussé Metal Work. By A. C. Horth. Cr. 8vo. 2s. 6 .

Electric Light and Power: An Intro. duction to the Study of Electrical Engineering. By E. E. Brooks, B.Sc. (Lond.). and W. H. N. James, A.R.C.S., A.I.E.E. Cr. 8vo. $4 s .6 d$.

Engineering Workshop Practice. By C. C. Allen. $\mathrm{Cr} 8 v 0$. 3s. $6 d$.

\section{Handbooks of Theology}

The XXXIX. Articles of The Church of ENGLAND. Edited by E. C. S. Gibson,
D.D. Sixth Edition. Demy 8vo. 12s. 6 .

AN INTRODUCTION TO THE History OF RELIGION. By F. B. Jevons. M.A., Litt.D. Fourth Edition. Demiy 8vo. 10s. $6 d$.

THE DOCTRINe OF THE InCARnation. By R. L. Ottley, D.D. Fourth Edition revised. Demy 8vo. I2s. 6d.

AN IntRoduction to THE History OF THE Creeds. By A. E. Burn, D.D. Demy 8vo. ros. $6 \pi$.

The Philosophy of Religion in England ANd America. By Alfred Caldecott, D.D. Demy 8vo. Ios. 6 d.

A History of Early Christian Doctrine. By J. F. Bethune-Baker, M.A. Demy 8vo. 105. $6 d$.

\section{The Westminster Commentaries}

General Editor, WALTER LOCK, D.D., Warden of Keble College, Dean Ireland's Professor of Exegesis in the University of Oxford.

The Book of Genesis. Edited with Intro- To the Corinthians. Edited by H. L. duction and Notes by S. R. Driver, D.D. Sixth Edition Deny 8vo. 10s. 6d.

THE BOOK OF JOR. Edited by E. C. S. Gibson, D.D. Second Edition. Demy8vo. 6s.

The ACTS OF the Apostles. Edited by R. B. Rackham, M.A. Deny 8vo. Third Edition. ros. 6 .

The First Epistle of Paul the Aposti Goudge, M.A. Demy 8vo. 6s.

The EPISTLE OF St. JAmes. Edited with Introduction and Notes by R. J. Knowling, D.D. Demy 8zo. $6 s$.

THE BOOK OF EzEKIEL. Edited H. A. Red. path, M.A., D. Litt. Demy 8vo. Ios. $6 d$.

A Commentary on Exonus. By A. $\mathrm{H}$. M'Neile, B.D. With a Map and 3 Plans. Demy 8vo. ros. $6 d$. 


\section{$\mathrm{P}_{\text {ART }}$ II._-Fiction}

Albanesi (E. Maria). SUSANNAH AND ONE OTHER. Fourth Edition. $C r$. 8\%0. $6 s$.

THE BLUNDER OF AN INNOCENT. Second Edition. Cr. 8vo. $6 s$.

CAPRICIOUS CAROLINE. Second Edi. tion. $\mathrm{Cr}$. 8vo. $6 \mathrm{~s}$.

LOVE AND LOUISA. Second Edition. Cr. 8vo. 6s. Also Medium 8vo. 6d.

PETER, A PARASITE. $\mathrm{Cr} .800 .6 s$.

THE BROWN EYES OF MARY. Third Edition. Cr. 8\%o. $6 \mathrm{~s}$.

I KNOW A MAIDEN. Third Edition. Cr. 8vo. 6s. Also Medium 8\%o. 6d.

Austen (Jane), PRIDE AND PREJUDICE. Medium 8vo. 6d.

Bagot (Richard). A ROMAN MYSTERY. Third Edition. Cr. 8vo. 6s. Also Medium 8vo. $6 \pi$.

THE PASSPORT. Fourth Edition. $\mathrm{Cr}$. $8 v 0.6 s$.

TEMPTATION. Fifth Edition. Cr. $8 v o$. $6 s$.

LOVE'S PROXY. A New Edition, Cr.8vo. $6 s$.

DONNA DIANA. Second Edition. Cr. $8 z^{\circ} 0.6 s$.

CASTING OF NETS. Twelfth Edition. Cr. 8vo. 6s. Also Medium 8vo. $6 d$.

Balfour (Andrew). BY STROKE OF SWORD. Medium $8 v 0.6 d$.

Baring=Gould (S.). ARMINELL. Fifth Edition. Cr. 8vo. $6 s$.

URITH. Fifth Edition. Cr. 8vo. 6s.

Also Medium 8vo. $6 d$.

IN THE ROAR OF THE SEA. Seventh Edition. Cr. 8vo. $6 \mathrm{~s}$. Also Medium 8vo. 6 d.

MARGERY OF QUETHER. Edition. $C r .8 v 0$. 6s.

THE QUEEN OF LOVE. Fifth Edition. Cr. 8vo. 6s. Also Medium 8vo. $6 d$.

JACOUETTA. Third Edition. Cr.8vo. $6 \mathrm{~s}$

KITTY ALONE. Fifth Eaition. Cr.8vo. 6s. Also Medium 8vo. $6 d$.

NOÉMI. Illustrated. Fourth Edition. $\mathrm{Cr}$. 8vo. 6s. Also Medium 8vo. 6d.

THE BROOM-SOUIRE. Illustrated. Fifih Editicn. Cr. 8vo. 6 s. Also Medium $8 v 0.6 d$.

DARTMOOR IDYLLS. $C r .8 v 0.6 s$.

THE PENNYCOMEQUICKS. Third Edition. Cr. 8vo. $6 s$.

GUAVAS THE TINNER. Illustrated. Second Edition. Cr. 8vo. 6s.

BLADYS OF THE STEWPONEY. Illus. trated. Second Edition. Cr. 8vo. 6s.

PABO THE PRIEST. Cr. 8vo. $6 s$.

WINEFRED. Illustrated. Second Edition. Cr. 8vo. 6s. Also Medium 8vo. 6d.

ROYAL GEORGIE. lllustrated. Cr. 8vo. 6 s.
CHRIS OF ALL, SORTS. Cr. 8vo. $6 s$. IN DEWISLAND. Second Ed. Cr. 8vo. 6s. THE FROBISHERS. Crown $8 v 0.6 s$. Also Medium 8vo. 6d.

DOMITIA. Illus. Second Ed. Cr. 8vo. 6s. MRS. CURGENVEN OF CURGENVEN. Crown 8vo. $6 s$

LITTLE TU'PENNY. A Neal Edition. Medium 8vo. $6 d$.

FURZE BLOOM. Medium 8vo. 6d.

Barnett (Edith A.). A WILDERNESS WIN NER. Second Edition. Cr. 8vo. $6 \mathrm{~s}$.

Barr (James). LAUGHING THROUGH A WILDERNESS. $C r .8 v 0,6 s$.

Barr (Robert). IN THE MIDST OF ALARMS. Third Edition. Cr. 8vo. 6s. Also Medium 8vo. 6d.

THE COUNTESS TEKLA. Fourth Edition. Cr. 8\%o. 6s. Also Medium 8vo. $6 d$.

THE MUTABLE MANY. Third Edition. Cr. 8vo. 6s. Also Medium 8vo. 6d.

THE TEMPESTUOUS PETTICOAT. Illustrated. Third Edition. Cr. 8\%o. $6 s$. THE STRONG ARM. Second Edition. Cr. 8vo. 6s.

JEN IE BAXTER JOURNALIST. Medium 8v0. 6d.

Begbie (Harold). THE CURIOUS AND DIVERTING ADVENTURES OF SIR JOHN SPARROW; or, ThE PROGRESS OF AN OPEN MIND. With a Frontispiece. Second Edition. Cr. 8vo. $6 s$.

Belloc(Hilaire), M.P. EMMANUEL BUR. DEN, MERCHANT. With 36 Illustrations by G. K. Chesterton. Second Ed. Cr. 8ro. 6s.

Benson (E. F.) DODO : A DETAlL OF THE DAY. Fifteenth Edition. Cr. 8zo. 6s. Also Medium 8vo. 6 d.

THE VINTAGE. Medium 8vo. $6 d$.

Benson (Margaret). SUBJECT TO VANITY, Cr. 8vo. 3s. 6d.

Birmingham (George A.). THE BAD TIMES. Second Edition. Crown 8vo. $6 s$.

Bowles (G. Stewart). A GUN-ROOM DITTY BOX. Second Ed. Cr.8vo. is. $6 d$. Bretherton (Ralph Harold). T H E MILL. Cr.8vo. 6s.

Brontë (Charlotte). SHIRLEX. Medzum $8 v 0$. $6 d$.

Burke (Barbara). BARBARA GOES TO OXFORD. With 6 Illustrations. Third Edition. Cr. 87.0. 6s.

Burton (J. Bloundelle). ACROSS THE SALT SEAS. MIedium 8vo. 6d.

Caffyn (Mrs.) ('lota'). ANNE MAULE. VERER. Medium 8vo. $6 d$.

Campbell (Mrs. Vere). F E R R I B Y. Second Edition. Cr. 8zo. 6s. 
Capes (Bernard). THE EXTRAORDINARY CONFESSIONS OF DIANA PLEASE. Third Edition. Cr. 8vo. 6s. A JAY OF ITALY. Fourth Ed. Cr. 8vo. 6s. LOAVES AND FiSHES. Second Edition. Cr. 8vo. 6s.

A ROGUE'S TRAGEDY. Second Edition. Cr. 8vo. 6s.

THE GREAT SKENE MYSTERY. Second Edition. Cr. 8vo. 6s.

THE LAKE OF WINE. Medium 8vo. $6 d$. Carey (Wymond). LOVE THE JUDGE. Second Edition. Cr. 8vo. 6s.

Castle (Agnes and Egerton). FLOWER $\mathrm{O}^{\prime}$ THE ORANGE, and Other Tales. With a Frontispiece in Colour by A. H. Buckland. Third Edition. Cr. 8vo. 6s.

Charlton (Randal). M A V E. Second Edition. Cr. 8vo. 6s.

THE VIRGIN WIDOW. Cr. 8vo. $6 s$.

Chesney (Weatherby). THE TRAGEDY OFTHEGREAT EMERALD Cr.8vo. $6 s$.

THE MYSTERY OF A BUNGALOW. Second Edition. Cr. 8vo. 6s.

Clifford (Mrs. W. K.) THE GETTING WELL OF DOROTHY. Illustrated by Gordon Browne. Second Edition. Cr. 8vo. 3s. 6 d.

A FLASH OF SUMMER. Medium 8vo. $6 \%$. MRS. KEITH'S CRIME. Medium 8vo. 6d. Conrad (Joseph). THE SECRE'T AGEN'T: A Simple Tale. Fourth Ed. Cr. 8vo. 6s. Corbett (Julian). A BUSINESS IN GREAT WATERS. Medium 8vo. $6 d$.

Corelli (Marie). A ROMANCE OF TWO WORLDS. Twenty-Ninth Ed. Cr.8vo. 6s. VENDETTA. Twenty-Sixth Ed. Cr.8vo. 6s. THELMA. Thirty-Eighth Ed. Cr. 8vo. 6s. ARDATH : THE STORY OF A DEAl SELF. Eighteenth Edition. Cr. 8vo, 6s.

THE SOUL OF LILITH. Fifteenth Edition. Cr.8vo. 6s.

WORMWOOD. Sixteenth Ed. Cr.8vo. 6s.

BARABBAS: A DREAM OF THE WORLD'S TRAGEDY. Forty.Third Edition. Cr. 8vo. 6s.

THE SORROWS OF SATAN. Fifty-Fourth Edition. Cr. 8vo. 6s.

THE MASTER CHRISTIAN. Eleventh Edition. r74th Thousand. Cr. 8vo. 6s.

TEMPORAL POWER: A STUDY IN SUPREMACY. 150th Thousand.Cr.8vo.6s GOD'S GOOD MAN : A SIMPLE LOVF STORY. Thirteenth Edition. I5oth Thou. sand. Cr. 8vo. 6s.

THE MIGHTY ATOM. Twenty-seventh Edition. Cr. 8vo. 6s.

BOY: a Sketch. Tenth Edition. Cr. 8vo. 6s. CAMEOS. Thirteenth Edition. Cr. 8vo 6s.

Cotes (Mrs. Everard). See Sara Jeannette Duncan.

Cotterell (Constance). THE VIRGIN AND THE SCALES. Illustrated. Second Edition. Cr. 8vo. $6 s$.

Crockett (S. R.), Author of "The Raiders," etc. LOCHINVAR. Illustrated. Third Edition. Cr. 8vo. 6s.

THE STANDARD BEARER, Cr.87o. 6s.
Croker (B. M.). THE OLD CANTON. MENT. Cr. 8vo. 6s.

JOHANNA. Second Edition. Cr. 8vo. 6s. Also Medium 8vo. $6 d$.

THE HAPPY VALLEY. Fourth Edition. Cr. 8vo. 6s.

A NINE DAYS' WONDER. Third Edition. Cr.8vo. $6 s$.

PEGGY OF THE BARTONS. Seventh Ed. Cr. 8vo. 6s. Also Mcdium 8vo. 6d. ANGEL. Fourth Edition. Cr. 8io. $6 s$. Also Medium 8vo. 6 .

A STATE SECRET. Third Edition. Cr. 8vo. 3s. 6d. Also Medium 8vo. 6d.

Crosbie (Mary). DISCIPLES. Second Ed. Cr. 8vo. 6s.

Cuthell (Edith E.). ONLY A GUARD. ROOM DOG. Illustrated by W. PARKINson, Crown 8vo. 3s. $6 d$.

Dawson (Warrington). THE SCAR. Second Edition. Cr. 8vo. 6s.

THE SCOURGE $\mathrm{Cr} .8 \%$. $6 s$.

Deakin (Dorothea). THE YOUNG COLUMBINE. With a Frontispiece by Lewis Paumer. Cr. 8vo. $6 s$.

Deane (Mary). THE OTHER PAWN. Cr. 8vo. 6s.

Doyle (A. Conan), ROUND THE RED LAMP. Tenth Edition. Cr. $8 v o$. $6 s$. Also Medium 8vo. $6 d$.

Dumas (Alexandre). See page 39

Duncan (Sara Jeannette) (Mrs. Everard Cotes). THOSE DELIGH T F U I AMERICANS. Medium 8vo. 6d.

A VOYAGE OF CONSOLATION. Illustrated. ThirdEdition. Cr. 8wo. 6s. Also Medizum 8vo. 6d.

Eliot (George). THE MILL ON THE FLOSS. Medium 8vo. $6 d$.

Erskine (Mrs. Steuart). THE MAGIC PLUMES. Cr. 8ro. $6 s$.

Fenn (G. Manville). SYD BELTON; or, The Boy who would not go to Sea. Illustrated by Gordon Browne. Second Ed. Cr. 8vo. 3s. $6 d$.

Findlater(J. H.). THE GREEN GRAVES OF BALGOWRIE. Fifth Edition. Cr. 8vo. 6s. Also Medium 8vo. 6d.

THE LADDER TO THE STARS. Second Edition. Cr. 8vo. 6s.

Findlater (Mary). A NARROW WAY. Third Edition. Cr. 8vo.. $6 s$.

OVER THE HILLS. Cr. 8\%o. $6 s$.

THE ROSE OF JOY. Third Edition. Cr. 8vo. 6s.

A BLIND BIRD'S NEST. With 8 Illus. trations. Second Edition. Cr. 8ro, 6s.

Fitzpatrick (K.) THE WEANS AT ROWALLAN. Illustrated. Second Edi. tion. Cr. 8vo. 6s.

Francis (M. E.). (Mrs. Francis Blundell). ST E P PING WESTWARD. Second Edition. Cr. 8vo. 6s.

MARGERY $\mathrm{O}^{\circ}$ THE MILL. Third Edition. Cr. 8vo. 6s.

Fraser (Mrs. Hugh). THE SLAKING OF THE SWORD. Second Edition. Cr. 8vo. 6s. 
IN THE SHADOW OF THE LORD. Third Edition. Crown 8vo. 6s.

Fry (B. and C.B.). A MOTHER'S SON. Fifth Edition. Cr. 8vo. $6 s$.

Fuller-Maitland (Ella). B L A N C H ESMEAD. Second Edition. Cr. 8vo. $6 s$.

Gallon (Tom). RICKERBY'S FOLLY. Medium 8vo. 6a.

Gaskell (Mrs.). CRANFORD. Medium 8 vo. $6 d$.

MARY BARTON. Medium 8zo. 6d.

NORTH AND SOUTH. Medium 8vo. 6d.

Gates(Eleanor). THE PLOW-WOMAN. Cr. 8vo. 6s.

Gerard (Dorothea). HOLY MATRI. MONY. Nedium 8vo. $6 d$.

MADE OF MONEY. Cr. 8vo. 6s. Also Medium 8vo. $6 d$.

THE IMPROBABLE IDYL. Third Edition. $\mathrm{Cr} .8 \mathrm{vo} 6 \mathrm{~s}$.

THE BRIDGE OF LIFE. $C r .8 v o .6 s$.

THE CONQUEST OF LONDON. Medium 8vo. $6 \pi$.

Gissing (George). THE TOWN TRA. VELLER. Second Edition. Cr, 8vo. $6 s$ Also Medium 8zo. $6 d$.

THE CROWN OF LIFE. Cr. $8 v o$. $6 s$. Also Medium 8vo $6 d$.

Glanville (Ernest). THE INCA'S TREASURE. Illustrated. $C r .820 .3 s .6 d$. Also Medium 8vo. 6d.

THE KLOOF BRIDE. Illustrated. Cr.8vo. 3s. 6d. Also Medium 87,0. 6d.

Gleig (Charles). BUNTER'S CRUISE. Illustrated. Cr. $8 v 0.35 .6 d$. Also Medium 8vo. $6 d$.

Grimm(The Brothers). GRIMM'S FAIRY TALES. Illustrated. Medium 8vo. $6 d$. Hamliton (M.). THE FIRST CLAIM. Second Edition. Cr. 8vo. 6s.

Harraden (Beatrice). I N VAR Y ING MOODS. Fourteenth Edition. Cr. 8vo. $6 s$.

THE SCHOLAR'S DAUGHTER. Fourth Edition. Cr. 8vo. 6 s.

HILDA STRAFFORD and THE REMIT TANCE MAN. Twelfth Ed. Cr. 8vo. $6 s$.

Harrod (F.) (Frances Forbes Robertson) THE TAMING OF THE BRUTE. C $r$. 8vo. $6 s$.

Herbertson (Agnes G.). PATIENCE DEAN. Cr. 8vo. 6s.

Hichens (Robert). THE PROPHET OF BERKELEY SOUARE. Second Edition. Cr. 8vo. 6s.

TONGUES OF CONSCIENCE. Third Edition. Cr. 8vo. 6 s.

FELIX. Sixth Edition. Cr. 8vo. 6s.

THE WOMAN WITH THE FAN, Sixth Edition. Cr. 8vo. $6 s$.

BYEWAYS. $C r .8 \% 0.6 s$

THE GARDEN OF ALLAH. Seventeent/h Edition. Cr. 8vo. 6s.

THE BLACK SPANIEL. Cr. 8vo. $6 s$.

THE CALL OF THE BLOOD. Seventh Edition. Cr. 8vo. 6s.

Hope (Anthony). THE GOD IN THE CAR. Tenth Edition. Cr. 8vo. $6 s$.
A CHANGE OF AIR. Sixth Ed. Cr.820. 6 s. Also Medium 8vo. $6 d$.

A MAN OF MARK. Fifth Ed, Cr, 8vo, 6s, Also Medium 8vo. 6d.

THE CHRONICLES OF COUNT AN. TONIO. Sixth Edition. Cr. 8vo. os.

Also Medium 8vo. 6 d.

PHROSO. Illustrated by H. R. MILlar. Seventh Edition. Cr. 8vo. 6s.

Also Medium 8vo. $6 d$.

SIMON DALE. Illustrated. Eighth Edition. Cr. $8 v o$. $6 s$.

'THE KING'S MIRROR. Fourth Edition. Cr. 8vo. 6s.

QUISANTE. Fourth Edition. Cr. 8vo. 6s. THE DOLLY DIALOGUES. $C r .8 v o$. $6 s$. Also Medium 8vo. $6 d$.

A SERVANT OF THE PUBLIC Illustrated. Fourth Edition. Cr. 8vo. 6s.

TALES OF TWO PEOPLE. With a Frontispiece by A. H. Buckland. Third Ed. Cr. 8vo. 6s.

Hope (Graham). THE LADY OF LYTE. Second Edition. Cr.8vo. 6s.

Hornung (E. W.). DEAD MEN TELL NO TALES. Nediz $m 8 v 0.6 \%$.

Housman (Clemence). THE LIFE OH SIR AGLOVALE DE GALIS. Cr. 8 $\% 0.6 s$

Hueffer (Ford Madox). AN ENGLISH GIRL: A Romance. Second Edition. Cr. 8vo. $6 s$.

Hutten (Baroness von). T H E H A LO. Fifth Edition. Cr. 8vo. $6 \mathrm{~s}$.

Hyne (C. J. Cutcliffe). MR. HOR ROCKS, PURSER. Fourth Edition. Cr. 8vo. 6s.

PRINCE RUPERT, THE BUCCANEER. Illustrated. 'Third Edition. Cr. 8vo. $6 s$

Ingraham (J. H.). THE THRONE OF DAVID. Medium 8vo. 6d.

Jacobs (W. W. ). MANY CARGOES Thirticth Edition. Cr. 8ro. 3s. 6 d.

SEA URCHINS. Fifteenth Edition. Cr. $820.35 .6 d$.

A MASTER OF CRAFT. Illustrated by WrLL OwEN. Eighth Edition. Cr. 8vo. 3s. 6al.

LIGHT FREIGHTS. Illustrated by WILI. OwEN and Others. Seventh Edition. Cr. 8vo. 35. $6 d$.

THE SKIPPER'S WOOING. Ninth Edition. Cr. 8ro. 3s. 6d.

AT SUNWICH PORT. lllustrated by Will OWEN. Ninth Edition. Cr.8vo. 3 s.6d.

DIALSTONE LANE. Illustrated by WiLL OWEN. Seventh Edition. Cr. 8vo. 35. 6d.

ODD CRAFT. Illustrated by WILL OWEN. Seventh Edition. Cr. 87io. 3s. 6d.

THE LADY OF THE BARGE. Eighth Edition. Cr. 8z'o. 35.6 .

James (Henry). THE SOFT SIDE. Second Edition. $C r .8 v 0.6 s$

THE BETTER SORT. Cr. 8vo. 6s.

THE AMBASSADORS. Second Edition. Cr. 8vo. 6s.

THE GOLDEN BOWL. Third Edition. Cr. 8vo. 6s.

Keays (H. A. Mitchell). HE THAT EATETH BREAD WITH ME. Cr.8vo.6s. 
Kester (Vaugban). THE FORTUNES OF THE LANDRAYS. Illustrated. $\mathrm{Cr} .8 v 0.6 \mathrm{~s}$. Lawless (Hon. Emily). WITH ESSEX IN IRELAND. Cr. 800 . $6 s$.

Le Queux (William). THE HUNCH BACK OF WESTMINSTER. Third Ed. Cr. 8vo. 6s. Also Medium 8vo. 6 d.

THE CROOKED WAY. Second Edition. Cr. 8 vo. 6 s.

THE CLOSED BOOK. Third Ed. Cr.8vo.6s.

THE VALLEY OF THE SHADOW. Illustrated. Third Edition. $C r .8 v o$. $6 s$.

BEHIND THE THRONE. Third Edition. Cr. 8vo. 6s.

Levett-Yeats (S. K.). ORRAIN, Second Edition. $\mathrm{Cr} .8 \% 0.6 \mathrm{~s}$.

THE TRAITOR'S WAY, Medium 8vo. $6 d$.

Linton (E. Lynn). THE TRUE HISTORY OF JOSHUA DAVIDSON. Medium $8 v 0.6 d$.

London (Jack). WHITE FANG. With a Frontispiece by CHARLES RivingSTON Boll. Sixth Edition. Cr. 8vo. 6s.

Lucas (E. V.). LISTENER'S LURE: An Oblique Narration. Fourth Edition. $C r$. $8 z o .6 s$.

Lyall (Edna). DERRICK VAUGHAN, NOVELIST. 42nd Thousand. Cr. 8vo. 3s. 6d. Also Medium 8vo. $6 d$.

Maartens (Maarten). THE NEW RELIGION: A Modern Novel. Third Edition. Cr. 8zo. $6 s$.

$M$ 'Carthy (Justin H.). THE LADY OF LOYALTY HOUSE. Illustrated. Third Edition. Cr. 8 vo. 6 s.

THE DRYAD. Second Edition. Cr.8vo. $6 s$.

THE DUKE'S MOTTO. Third Edition. Cr. 8vo. 6s.

Macdonald (Ronald). A HUMAN TRINITY. Second Edition. Cr. 8vo. $6 s$.

Macnaughtan (S.). THE FORTUNE OF CHRISTINA M'NAB. Fourth Edition. Cr. 8vo. $6 s$.

Malet (Lucas), COLONEL ENDERBY'S WIFE. Fourth Edition. Cr. 8vo. 6s.

A COUNSEL OF PERFECTION. Ner Edition. Cr. $8 v 0$. 6s.

Also Mcdinm 8vo. $6 d$.

THE WAGES OF SIN. Fifteenth Edition. Cr. 8vo. 6s.

THE CARISSIMA. Fifth Ed. Cr. 8vo. 6s. Also Medium 8vo. 6d.

THE GATELESS BARRIER. Fifth Edition. $C r .8 v o$. $6 s$.

THE HISTORY OF SIR RICHARD CALMADY. Seventh Edition. Cr.8vo. $6 s$. Mann (Mrs. M. E.). OLIVIA'S SUMMER. Second Edition. Cr. 8vo. $6 s$.

A LOST ESTATE. A NerU Ed. Cr.8vo. 6s. Also Medium 8vo. $6 d$.

THE PARISH OE HILBY. A Nerw Edition. Cr. 8vo. $6 s$

THE PARISH NURSE, Fourth Edition. Cr. 8zo. 6s.

GRAN'MA'S JANE. Cr. 8vo. $6 s$.

MRS, PETER HOWARD. Cr, 8vo, $6 s$. Also Medium 8vo. $6 a$.
A WINTER'S TALE. A Ner Edition. Cr. 8vo. 6s.

ONE ANOTHER'S BURDENS. A New Edition. Cr. 8vo. 6s. Also Medium 8vo. $6 d$.

ROSE AT HONEYPOT. Third Ed. Cr. 8vo. $6 s$.

THERE WAS ONCE A PRINCE. Illustrated by M. B. Mann. Cr. 8vo. 3s. 6d.

WHEN ARNOLD COMES HOME. IIIUS trated by M. B. Mann. Cr. 8vo. 3s. $6 d$.

THE EGLAMORE PORTRAITS. Third Edition. Cr. 8vo. $6 s$.

THE MEMORIES OF RONALD LOVE. Cr. 8vo. os.

THE SHEEP AND THE GOATS. Third Edition. Cr. 8zo. 6s.

A SHEAF OF CORN. Second Edition, Cr. 8vo. 6s.

THE CEDAR STAR. Medium 8vo. $6 d$.

Marchmont (A. W.). MISER HOADLEY'S SECRET. Medium 8\%o. 6d.

A MOMENT'S ERROR. Medium 8vo. 6d. Marriott (Charles). GENEVRA. Second Edition. Cr. 8vo. 6s.

Marryat (Captain). PETER SIMPLE Mledium $8 v 0$. $6 d$.

IACOB FAITHFUL. Medium 8vo, $6 d$.

Marsh (Richard). THE TWICKENHAM PEERAGE. Second Edition. Cr. $8 v 0$. $6 s$. Also Medium 8vo. $6 d$.

THE MARQUIS OF PUTNEY. Secord Edition. Cr.8zo. 6s.

IN THE SERVICE OF LOVE. Third. Edition. Cr. 8vo. $6 \mathrm{~s}$.

THE GIRL AND THE MIRACLE. Third Edition. Cr. 8vo. 6s.

THE COWARD BEHIND THE CURTAIN. Cr. 8vo. $6 s$.

A METAMIORPHOSIS. Medium 8vo. $6 d$. THE GODDESS. Medium 8vo. $6 d$.

THE JOSS. Medium 8vo. $6 d$.

Marshall (Archibald). MANY JUNES. Second Edition. Cr. 8vo. $6 s$.

Mason(A. E. W.). C L E I E N T I N A. Illustrated. Second Edition. Cr.8vo. $6 s$. Also Medium 8vo. $6 d$.

Mathers(Helen). HONEV. Fourth Ed Cr. 8vo. 6s. Also Mledium 8vo. 6d.

GRIFF OF GRIFFITHSCOURT, Cr. 8\%。 6s. Also Medium 8vo. 6d.

THE FERRYMAN Second Edition. $C r$ 8vo. $6 s$.

TALLY-HO! Fourth Edition. Cr. 8vo. $6 s$. SAM'S SWEETHEART. Medium 8vo. 6d. Maxwell(W. B.). VIVIEN, Ninth Edition. Cr.8vo. $6 s$.

THE RAGGED MESSENGER. Third Edition. $\mathrm{Cr} .8 \mathrm{w}^{\prime} \mathrm{O} .6 \mathrm{~s}$.

FABULOUS FANCIES. Cr. 8vo. $6 s$.

THE GUARDED FLAME. Seventh Edi. tion. Cr.8vo. 6s.

ODD LENGTHS. Second Ed. Cr. 8vo. 6s. THE COUNTESS OF MAYBURY: BETIVEEN YOU AND I. Being the Intimate Conversations of the Right Hon. the Countess of Maybury. Fourth Edition. Cr. 8rio. 6s. 
Meade (L. T.). DRIFT. Second Edition. Cr. 8vo. 6s. Also Medium 8vo. 6d.

RESURGAM. $C r$. 8vo. $6 s$.

VICTORY. Cr. 8vo. 6s.

A GIRL OF THE PEOPLE. Illustrated by R. BARNET. Second Ed. Cr. 8zo. 3s, 6d.

HEPSY GIPSY. Illustrated by E. HOPKINS. Crown 8vo. 2s, $6 d$.

THE HONOURABLE MISS: A STORY OF AN Old-FAshioned Town. Illustrated by E. Hopkins. Second Edition. Crown 8vo. 3s. $6 d$.

Melton (R.). CASAR'S WIFE. Second Edition. Cr. 8vo. 6s.

Meredith (EIIis). HEART OF MY HEART. Cr. 8vo. 6 s.

Miller (Esther). LIVING LIES. Third Edition. Cr. 8vo. 6s.

Mitford (Bertram). THE SIGN OF THE SPIDER. Illustrated. Sixth Edition Cr. 8vo. $35.6 d^{\prime}$. Also Medium 8vo. $6 d$.

IN THE WHIRL OF THE RISING. Third Edition. Cr. 8vo. $6 s$.

THE RED DERELICT. Second Edition. Cr. 8zo. 6s.

Molesworth (Mrs.). THE RED GRANGE. Illustrated by GORDON BROWNE. Second Edition. Cr. 8vo. $3^{3 .} 6$ \%

Montgomery (K. L.). COLONEL KATE. Third Edition. Cr. 8i'o. $6 s$.

Montresor (F. F.). THE ALIEN. Third Edition. Cr.8vo. 6s. Also Medium 8vo. $6 d$.

Morrison (Arthur). TALES OF MEAN STREETS. Seventh Edition. Cr. 8vo. 6s. A CHILD OF THE JAGO. Fifth Edition. Cr. 8vo. $6 s$.

CUNNING MURRELL. Cr. 8vo. 6s.

THE HOLE IN THE WALL. Fourth Edi. tion. Cr. 8vo. 6s. Also Medium 8vo. 6d.

DIVERS VANITIES. Cr. $8 v 0.6 s$.

Nesbit (E.). (Mrs. H. Bland). THE RED HOUSE. Illustrated. Fourth Edition. Cr. 8vo. 6s. Also Medium 8vo. $6 d$.

Norris (W. E.). HARRY AND URSULA: A STORY WITH TWO SIDES TO IT. Second Edition. Cr. 8\%o. $6 s$.

HIS GRACE. Medium 8vo. 6d.

GILES INGILBY. Medium $8 \approx 0.6 \pi$.

THE CREDIT OF THE COUNTY Medium 8vo. $6 d$.

LORD LEONARD THE LUCKLESS. Medium 8vo. 6d.

MATTHEW AUSTIN, Medium 8vo. 6d.

CLARISSA FURIOSA. Medium 8vo. $6 d$.

Oliphant (Mrs.). THE LADY'S WALK. Medium $8 v 0$. $6 d$.

SIR ROBERT'S FORTUNE. Medium 8vo. 6d.

THE PRODIGALS. Medium 8vo. $6 d$.

THE TWO MARYS. Medium 8vo. $6 d$.

Ollivant (Alfred). $O$ WD BOB, T H E GREY DOG OF KENMUIR. With a Frontispiece. Eleventh Edition, Cr. 8v0. $6 s$.

Oppenheim (E. Phlllips). MASTER OF MEN. Fourth Edition. Cr. 8vo. $6 s$. Also Medium 8vo. 6d.
Oxenham (John). A WEAVER OF WEBS With 8 Illustrations by MAURICE GREIF. FENHAGEN. Second Edition. Cr. 8vo. 6s.

THE GATE OF THE DESERT. With a Frontispiece in Photogravure by HAROLD Copping. Fifth Edition. Cr. $870.6 s$.

PROFIT AND LOSS. With a Frontispiece in photogravure by HAROLD COPPING. Fourth Edition. Cr. 8vo. 6s.

THE LONG ROAD. With a Frontispiece in Photogravure by HAROLD Copping. Fourth Edition. Cr. 8vo. 6s.

Pain (Barry). LINDLEY hAYS. Third Edition. Cr. 8vo. 6s.

Parker (Glibert). PIERRE AND HIS PEOPLE. Sixth Edition. Cr. 8vo. 6s.

MRS. FALCHION. Fifth Edition. Cr. 8vo. $6 s$.

THE TRANSLATION OF A SAVAGE. Third Edition. Cr. 8vo. 6s.

THE TRAIL OF THE SWORD. Illustrated. Ninth Edition. Cr. 8vo. 6s.

Also Medium 8vo. 6d.

WHEN VALMOND CAME TO PONTIAC : The Story of a Lost Napoleon. Sixth Edition. Cr. 8vo. 6s.

Also Medium 8vo. 6 d.

AN ADVENTURER OF THE NORTH. The Last Adventures of 'Pretty Pierre.' Fourth Edition. Cr. 8vo. 6s.

THE SEATS OF THE MIGHTY. Illustrated. Sixteenth Edition. Cr. 8vo. 6s.

THE BATTLE OF THE STRONG: a Romance of Two Kingdoms. Illustrated. Sixth Edition. Cr. 8vo. 6s.

THE POMP OF THE LAVILETTES. Third Edition. Cr. 8vo. 3s. 6 d.

Also Medium 8vo. $6 d$.

Pemberton (Max). THE FOOTSTEPS OF A THRONE. Illustrated. Third Edition. Cr. 8vo. 6s.

Also Medium 8vo. $6 d$.

I CROWN THEE KING. With Illustra. tions by Frank Dadd and $\mathrm{A}$. Forrestier. Cr. 8vo. 6s.

Also Medium 8vo. $6 d$.

Phillpotts (Eden). LYING PROPHETS. Third Edition. Cr. 8zio. 6s.

CHILDREN OF THE MIST. Fifth Edition. Cr. 8vo. $6 s$.

Also Medium 8vo. 6d.

THE HUMAN BOY. With a Frontispiece. Sixth Edition, Cr. 8vo. 6s.

Also Medium 8vo. $6 d$.

SONS OF THE MORNING. Second Edition. Cr. 8vo. 6s.

THE RIVER. Third Edition. Cr. 8vo. 6s. Also Medium 8vo. $6 d$.

THE AMERICAN PRISONER. Fourth Edition. $C r .8 v o$. $6 s$.

THE SECRET WOMAN. Fourth Edition. Cr. 8vo. 6s.

KNOCK AT A VENTURE. With a Frontispiece. Third Edition. Cr. 8\%o. $6 s$.

THE PORTREEVE. Fourth Ed. Cr.87'0. 6s.

THE POACHER'S WIFE. Second Edition Cr. 8vo. 6s.

Also Medium 8vo. $6 d$. 
THE STRIKING HOURS. Second Edition. Crowen 8vo. 65 .

THE FOLK AFIELD. Crown 8vo. 65.

Pickthall (Marmaduke). SATD THE

FISHERMAN. Seventh Ed. Cr. 8vo. 6s. BRENDLE. Second Edztion. Cr. 8vo. 6s. THE HOUSE OF ISLAM. Third Edition. Cr. 8\%o. 6s.

' $Q$ ' (A. T. Quiller Couch). THE WHITE WOLF. Second Edition. Cr. 8vo. $6 \mathrm{~s}$. Also Medium 8vo. $6 d$.

THE MAYOR OF TROY. Fourth Edition. Cr. 8vo. 6s.

MERRY-GARDEN AND OTHER STORIES. Cr. 8vo. $6 s$.

MAJOR VIGOUREUX. Third Edition. Cr. 8vo. 6s.

Rawson (Maud Stepney). THE EN. CHANTED GARDEN. Fourth Edition. Cr. 8vo. $6 s$.

Rhys (Grace). THE WOOING OF SHEILA. Second Edition. Cr. 8vo. $6 s$.

Ridge (W. Pett). LOST PROPERTY. Medium 8vo. $6 d$.

ERB. Second Edition. Cr. 8vo. 6s.

A SON OF THE STATE. Second Edition. Cr. 8vo. 3s. 6d. Also Medium 8vo. $6 d$.

A BREAKER OF LAWS. A Nerv Edition. Cr. 8vo. $35.6 d$.

MRS. GALER'S BUSINESS. Illustrated. Second Edition. Cr. 8vo. 6s.

THE WICKHAMSES. Fourti Edition. Cr. 8vo. $6 s$.

NAME OF GARLAND. Third Edition. Cr. 8vo. 6s.

GEORGE and THE GENERAL. Medium 8vo. $6 d$.

Ritchie (Mrs. David G.). MAN AND THE CAS SOCK. Second Edition. Crowen 8vo. 6s.

Roberts (C. G. D.). THE HEART OF THE ANCIENT WOOD. Cr. sio. 3s. $6 d$.

Robins (Elizabeth). THE CONVERT. Third Edition. Cr. 8vo. 65.

Rosenkrantz (Baron Palle). T H E MAGISTRATE'S OWN CASE. Cr. 8vo. $6 s$.

Russell (W. Clark). MY DANISH $\mathrm{S}$ WEETHEART. Illustrated. Fifth Edition. Cr. 8vo. 6s. Also Medium 8210. $6 d$.

HIS ISLAND PRINCESS. Illustrated. Second Edition. Cr. 8vo. $6 s$. Also Medium 8vo. $6 d$.

ABANDONED. Second Edition. Cr. Svo. 6s. Also Medium 8v'o. 6a.

MASTER ROCKAFELLAR'S VOYAGE. Illustrated by GORDON BROWNE. Third Edition. Cr. 8vo. 3s. 6d.

A MARRIAGE AT SEA. Medium 8vo. $6 d$.

Ryan (Marah Ellis). FOR THE SOUL OF RAFAEL. Cr. 8vo. $6 s$.

Sergeant (Adellne). THE MYSTERY OF THE MOAT. Second Edition. Cr. 8vio. $6 s$.
THE PASSION OF PAUL MARILLIER. Crown 8vo. 65.

THE QUEST OF GEOFFREY DARRELL. Cr. 8ro. $6 s$.

THE COMING OF THE RANDOLPHS. Cr. 8vo. 6s.

THE PROGRESS OF RACHAEL. $C r$. 8vo. $6 s$.

EARBARA'S MONEY. Cr. 8vo. $6 s$. Also Medium 8vo. $6 d$.

THE MASTER OF BEECH WOOD. Medium 8vo. 6d.

THE YELLOW DIAMOND. Second Ed. Cr. 8\%o. 6s. Also Medium 8vo. 6\%.

THE LOVE THAT OVERCAME. Medium $8 v 0.6 d$.

Shannon (W. F.). THE MESS DECK. Cr. 8vo. $35.6 d$.

Shelley(Bertha). ENDERBY. Third Ed. Cr. 8vo. 65 .

Sidgwick (Mrs. Alfred). THE KINS. MAN. With 8 Illustrations by C. E. Brock. Third Edition. Cr.8vo. 6s.

Smith (Dorothy V. Horace). MISS MONA. Cr. 8vo. $3 s .6 d$.

Sonnichsen (Albert). DEEP-SEA VAGA. BONDS. Cr. 8vo. 6s.

Sunbury (George). THE HA'PENNY MILLIONAIRE. Cr.8vo. 3s. 6d.

Surtees (R. S.). HANDLEY CROSS. Illustrated. Medium 8vo. 6d.

MR. SPONGE'S SPOR'TING TOUR. Illustrated. Medium $8 r^{\prime} 0$. $6 d$.

ASK MAMMA. Illus. Medium 8vo. $6 d$.

Urquhart (M.), A TRAGEDY IN COM. MONPLACE. Second Ed. Cr. 8vo. $6 s$.

Vorst (Marie Van), THE SENTIMEN. TAL ADVENTURES OF JIMMY BUL. STRODE. Cr.8vo. 6s.

Waineman (Paul). T H E B A Y O F L I L A C S: A Romance from Finland. Second Edition. Cr. 8vo. 6s.

THE SONG OF THE FOREST. $C r .8 v 0$. $6 s$.

Walford (Mrs. L. B.). M R, S M I T H. Medium 8vo. $6 d$.

THE BABY'S GRANDMOTHER. Medium 8vo. 6d.

COUSINS. Medium 8vo. $6 d$.

Wallace (General Lew). B EN-H UR. Medium 8vo. $6 d$.

THE FAIR GOD. Medium 8vo. 6d.

Watson (H. B. Marriott). CAPTAIN FORTUNE. Thurt Edition. Cr. 8vo. 6s.

TWISTED EGLANTINE. With 8 Illus. trations by Frank CraIg, Third Edition. Cr. 8vo. 6s.

THE HIGH TOBY : Being further Chapters in the Life and Fortunes of Dick Ryder, otherwise Galloping Dick, sometime Gentleman of the Road. With a Frontispiece by Claude Shepperson. Third Edition. Cr. 8vo. 6s.

A MIDSUMMER DAY'S DREAM. Third Edition. Crown 8vo. 6s. 


\section{FICTION}

THE PRIVATEERS. With 8 Illustrations by Cyrus Cuneo. Sccond Edition. Cr. 8vo. $6 s$.

A POPPY SHOV : BeING Divers AND Diverse Tales. Cr.8vo. $6 \mathrm{~s}$.

THE ADVENTURERS. Mcdium 8vo. 62.

Weekes (A. B.). THE PRISONERS OF WAR, Medium 8vo. 6d. 8vo. 6s. Also Medium 8vo. 6d.

Weyman (Stanley). UNDER THE RED ROBE. With Illustrations by R. C. WooDVILLE. Twenty-First Edition, Cr. 8vo. 6s.

White (Percy). THE SVSTEM. Third Edition. Cr. 8vo. 6s.

A PASSIONATE PILGRIM. Medium 8vo. $6 d$.

Williams (Margery). TiE BAR. Cr. 8vo. $6 s$.

Williamson (Mrs. C. N.). THE A D. VENTURE OF PRINCESS SYLVIA. Second Edition. Cr. 8vo. 6s.

THE WOMAN WHO DARED. Cr. 8vo. $6 s$.

THE SEA COULD TELL. Second Edition. Cr. 8vo. 6s.

THE CASTLE OF THE SHADOWS Third Edition. Cr. 8vo. $6 s$.
Wells (H. G.). THE SEA LADY. $C r$.

PAPA. Cr. 8\%o. 6s.

Williamson (C. N. and A. M.). THE LIGHTNING CONDUCTOR: The Strange Adventures of a Motor Car. With 16 Illustrations. Seventeenth Edition. $C r$. 8vo. $6 s$.

THE PRINCESS PASSES: A Romance of a Notor. With 16 Illustrations. Ninth Edition. Cr. 8vo. 6 s.

MY FRIEND THE CHAUFFEUR. With I6 Illustrations. Ninth Edit. Cr.8vo. $6 s$. LADY BETTY ACROSS THE IVATER. Tenth Edition. Cr. 8vo. $6 s$.

THE CAR OF DESTINY AND ITS ERRAND IN SPAIN. With 17 Illus trations. Fourth Edition. Cr. 8vo. 6s.

THE BOTOR CHAPERON. With a Frontispiece in Colour by A. H. BuckLAND, 16 other Illustrations, and a Map. Fifth Edition. Cr. 8vo. 6s.

SCARLET RUNNER. With a Frontispiece in Colour by A. H. BUCKLAND, and 8 other Illustrations. Third Ed. Cr. 8vo. 6s.

Wyllarde (Dolf). THE PATHWAY OF THE PIONEER (Nous Autres). Fourth Edition. Cr. 8vo. 6s.

Yeldham (c. C.). DURHAM'S FARII. Cr. 8vo. 6s.

\section{Books for Boys and Girls}

Illustrated. Crowen 8vo. 3s. $6 d$.

The Geting Well of Dorothy. By Mrs. The Red Grange. By Mrs. Molesworth. W. K. Clifford. Second Edition.

ONLY a GUARD-Room Dog. By Edith E. Cuthell.

Master Rockafellar's Voyage. By W. Clark Russell. Third Edition.

Syd Belton: Or, the Boy who would not go to Sea. By G. MIanville Fenn. Second Ed.
A Girl of the People. By L. T. Meade. Second Edition.

Hepsy Gipsy. By L. T. Meade. 2s. $6 d$. The Honourable Miss. By L. T. Meade. Second Edition.

There was once a Prince. By Mrs. M. E. Mann.

When Arnold comes Home. By Mrs. M. E. Mann.

\section{The Novels of Alexandre Dumas \\ MTedium 8vo. Price 6d. Double Volumes, is. \\ COMPLETE LIST ON APPLICATION.}

\section{Methuen's Sixpenny Books}

Medium Svo.

Albanesi (E. Maria). L O V E A N D LITTLE TU'PENNY. LOUISA.

I KNOW A MAIDEN.

Austen (J.). PRIDE AND PREJUDICE.

Bagot (Richard). A ROMAN MYSTERY.

CASTING OF NETS.

Balfour (Andrew). BY STROKE OF SWORD.

Baring=Gould (S.). FURZE BLOOM.

CHEAP JACK ZITA.

KITTY ALONE.

URITH.

THE BROOM SQUIRE.

IN THE ROAR OF THE SEA.

NOEMI.

WINEFRED

THE FROBISHERS.

THE OUEEN OF LOVE.

Barr (Robert). JENNIE BAXTER.

IN THE MIDST OF ALARMS.

THE COUNTESS TEKLA.

THE MUTABLE MANY.

Benson (E. F.). DODO.

THE VINTAGE.

Brontë (Charlotte), SHIRLEY.

Brownell (C. L.). THE HEART OF JAPAN.

Burton (J. Bloundelle). ACROSS THE SALT SEAS.

A BOOK OF FAIRY TALES. Illustrated. Caffyn (Mrs.). ANNE MAULEVERER. 
Capes (Bernard). THE LAKE OF WINE.

Clifford (Mrs. W. K.). A FLASH OF SUMMER.

MRS. KEITH'S CRIME.

Corbett (Julian). A BUSINESS IN GREAT WATERS.

Croker (Mrs. B. M.). ANGEL.

A STATE SECRET.

PEFGY OF THE BARTONS.

JOHANNA.

Dante (Alighleri). THE D I V I N E COMEDY (Cary).

Doyle (A. Conan). ROUND THE RED LAMP.

Duncan (Sara Jeannette). A VOYAGE OF CONSOLATION.

THOSE DELIGHTFUL AMERICANS. FLOSS.

Findlater (Jane H.). THE GREEN GRAVES OF BALGOWRIE.

Gallon (Tom). RICKERBY'S FOLLY.

Gaskell (Mrs.). CRANFORD.

MARY BARTON.

NORTH AND SOUTH. Gerard (Dorothea). HOLY MATRI.
MONY.

THE CONQUEST OF LONDON.

MADE OF MONEY.

Gissing (G). THE TOWN TRAVELLER.

THE CROWN OF LIFE.

Glanville (Ernest). TH E I N CA'S TREASURE.

THE KLOOF BRIDE.

Gleig (Charles). BUNTER'S CRUISE.

Grimm (The Brothers). GRIMM'S FAIRY TALES.

Hope (Anthony). A MAN OF MARK.

A CHANGE OF AIR.

THE CHRONICLES OF COUNT ANTONIO.

PHROSO.

THE DOLLY DIALOGUES.

Hornung (E. W.). DEAD MEN TELL NO TALES.

Ingraham (J. H.). THE THRONE OF DAVID.

Le Queux (W.). THE HUNCHBACK OF WESTMINSTER.

Levett=Yeats (S. K.). THE TRAITOR'S WAY.

Linton (E. Lynn). THE TRUE HIS. TORY OF JOSHUA DAVIDSON.

Lyall (Edna), DERRICK VAUGHAN.

Malet (Lucas). THE CARISSIMA.

A COUNSEL OF PERFECTION.

Mann (Mrs.). MRS. PETER HOWARD.

A LOST ESTATE.

THE CEDAR STAR.

ONE ANOTHER'S BURDENS.

Marchmont (A. W.). MISER HOAD. LEY'S SECRET.

A MOMENT'S ERROR.

Marryat (Captain). PETER SIMPLE. JACOB FAITHFUL.

Marsh (Richard). A METAMORPHOSIS. THE TWICKENHAM PEERAGE.

THE GODDESS.

THE JOSS.

Mason (A.E. W.). CLEMENTINA.

Mathers (Helen). HONEY.

GRIFF OF GRIFFITHSCOURT

SAM'S SWEETHEART.

Meade (Mrs. L. T.). DRIFT.

Mitford (Bertram). THE SIGN OF THE SPIDER.

Montresor (F. F.). THE ALIEN.

Morrison (Arthur). THE HOLE IN THE WALL.

Nesbit (E.) THE RED HOUSE.

Norris (W. E.). HIS GRACE.

GILES INGILBY.

THE CREDIT OF THE COUNTY.

LORD LEONARD THE LUCKLESS.

MATTHEW AUSTIN.

CLARISSA FURIOSA.

Oliphant (Mrs.). THE LADY'S WALK.

SIR ROBERT'S FORTUNE.

THE PRODIGALS.

THE TWO MARYS.

Oppenheim (E. P.). MASTER OF MEN.

Parker(Gllbert). THE POMP OF THE LAVILETTES,

WHEN YALMOND CAME TO PONTIAC THE TRAIL OF THE SWORD.

Pemberton (Max). THE FOOTSTEPS OF A THRONE.

I CROWN THEE KING.

Phillpotts (Eden). THE HUMAN BOY. CHILDREN OF THE MIST.

THE POACHER'S WIFE.

THE RIVER.

' $Q$ ' (A. T. Quiller Couch). T H E WHITE WOLF.

Ridge(W.Pett). A SON OF THE STATE. LOST PROPERTY.

GEORGE and THE GENERAL.

Russell (W. Clark). ABANDONED.

A MARRIAGE AT SEA.

MY DANISH SWEETHEART.

HIS ISLAND PRINCESS.

Sergeant (Adeline), THE MASTER OF BEHCHWOOD.

BARBARA'S MONEY.

THE YELLOW DIAMOND.

THE LOVE THAT OVERCAME.

Surtees (R. S.). HANDLEY CROSS. MR. SPONGE'S SPORTING TOUR. ASK MAMMA.

Walford (Mrs. L. B.). MR. SMITH. COUSINS.

THE BABY'S GRANDMOTHER.

Wallace (General Lew). BEN-HUR.

THE FAIR GOD.

Watson (H. B. Marriott), THE ADVEN. TURERS.

Weekes (A. B.). PRISONERS OF WAR.

Wells (H. G.). THE SEA LADY.

White (Percy). A PASSIONATE PILGRIM. 

Webster Family Library of Veterinary Medicine Cummings School of Veterinary Medicine at Tufts University $200 \mathrm{j}$ Westboro Road North Grafton, MA 01536 

